San Jose State University

SJSU ScholarWorks

Master's Theses

Master's Theses and Graduate Research

1993

\title{
Precipitation-runoff modeling system for the Blackwood Creek drainage basin, Placer County, California
}

James Charles Kirschner

San Jose State University

Follow this and additional works at: https://scholarworks.sjsu.edu/etd_theses

\section{Recommended Citation}

Kirschner, James Charles, "Precipitation-runoff modeling system for the Blackwood Creek drainage basin, Placer County, California" (1993). Master's Theses. 688.

DOI: https://doi.org/10.31979/etd.2bfk-m3gk

https://scholarworks.sjsu.edu/etd_theses/688

This Thesis is brought to you for free and open access by the Master's Theses and Graduate Research at SJSU ScholarWorks. It has been accepted for inclusion in Master's Theses by an authorized administrator of SJSU ScholarWorks. For more information, please contact scholarworks@sjsu.edu. 


\section{INFORMATION TO USERS}

This manuscript has been reproduced from the microfilm master. UMI films the text directly from the original or copy submitted. Thus, some thesis and dissertation copies are in typewriter face, while others may be from any type of computer printer.

The quality of this reproduction is dependent upon the quality of the copy submitted. Broken or indistinct print, colored or poor quality illustrations and photographs, print bleedthrough, substandard margins, and improper alignment can adversely affect reproduction.

In the unlikely event that the author did not send UMI a complete manuscript and there are missing pages, these will be noted. Also, if unauthorized copyright material had to be removed, a note will indicate the deletion.

Oversize materials (e.g., maps, drawings, charts) are reproduced by sectioning the original, beginning at the upper left-hand corner and continuing from left to right in equal sections with small overlaps. Each original is also photographed in one exposure and is included in reduced form at the back of the book.

Photographs included in the original manuscript have been reproduced xerographically in this copy. Higher quality $6 "$ x 9 " black and white photographic prints are available for any photographs or illustrations appearing in this copy for an additional charge. Contact UMI directly to order.

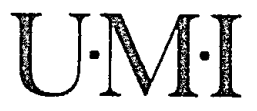

University Microfilms International

A Bell \& Howell Information Company 

Order Number 1356471

Precipitation-runoff modeling system for the Blackwood Creek drainage basin, Placer County, California

Kirschner, James Charles, M.S.

San Jose State University, 1993

Copyright (C1993 by Kirschner, James Charles. All rights reserved.

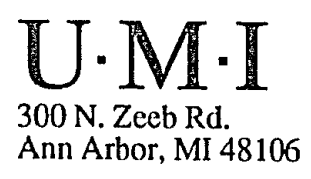





\title{
PRECIPITATION-RUNOFF MODEUNG SYSTEM FOR THE BLACKWOOD CREEK DRAINAGE \\ BASIN, PLACER COUNTY, CALIFORNIA
}

\author{
A Thesis \\ Presented to \\ The Faculty of the Department of Geology \\ San Jose State University \\ In Partial Fulfillment \\ of the Requirements for the Degree \\ Master of Science
}

By

James Charles Kirschner

December, 1993 
(C) 1993

James Charles Kirschner

AURIGHTS RESERVED 


\section{APPROVED FOR THE DEPARTMENT OF GEOLOGY}

Delizeral R. liälele -

Dr. Deborah R. Harden

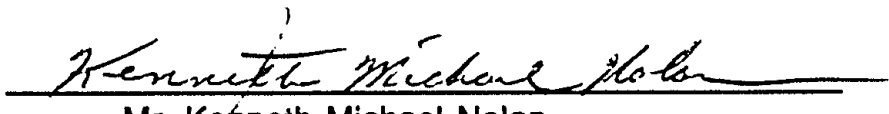

Mr. Kofineth Michael Nolan

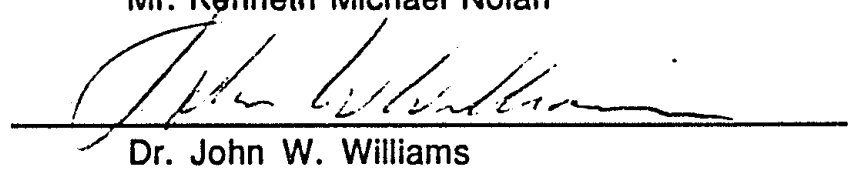

APPROVED FOR THE UNIVERSITY

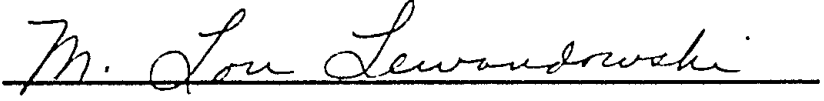




\title{
ABSTRACT \\ PRECIPITATION-RUNOFF MODELNG \\ SYSTEM FOR THE BLACKWOOD CREEK DRAINAGE \\ BASIN, PLACER COUNTY, CALIFORNIA \\ by James Charles Kirschner
}

\begin{abstract}
Movement of water through the Blackwood Creek drainage basin, California, was determined using the U.S. Geological Survey's precipitation-runoff modeling system (PRMS). Calculated basin characteristics, measured climatological data, and measured streamflow data were input into PRMS to simulate movement of water through the basin. The PRMS simulated discharge data are compared to the observed streamflow measurements to allow the model to be calibrated. The PRMS revealed that the majority of water moves through the Blackwood Creek drainage basin by subsurface flow, with little water traveling as surface flow. A small scale infiltration study was conducted to complement the PRMS study. Infiltration rates of the forest soil ranged from $30-440$ $\mathrm{cm} / \mathrm{hr}$, which exceeded the anticipated infiltration rates. Results of the infiltration study supported the PRMS results, which revealed that water infiltrates into the forest soil so rapidly that little water is available to flow as surface flow.
\end{abstract}


TABLE OF CONTENTS

Page

ABSTRACT . . . . . . . . . . . . . . . iv

INTRODUCTION AND PREVIOUS STUDIES . . . . . . . . . 1

LOCATION AND BASIN CHARACTERISTICS . . . . . . . . 7

GEOOGY . . . . . . . . . . . . . . 13

HYDROLOGY . . . . . . . . . . . . . . 18

PRMS DESCRIPTION AND OPERATION . . . . . . . . . 20

PRMSCOMPONENTS . . . . . . . . . . . . . . . 23

Watershed Partitioning . . . . . . . . . . . 23

Parameter Estimation . . . . . . . . . . . 25

Input Parameters . . . . . . . . . . . . 26

Card Group Number 1 (CG1) . . . . . . 27

Cards 1,2. . . . . . . . . . . 28

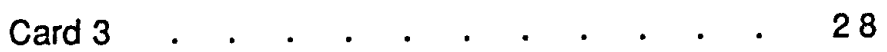

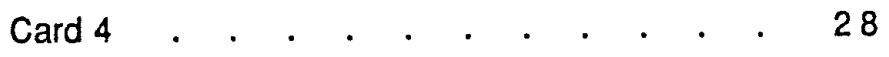

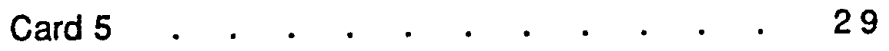

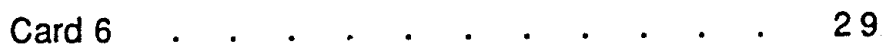

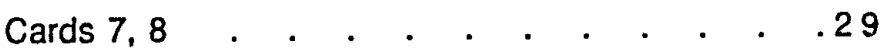

Card $9 . \quad . \quad . \quad . \quad . \quad . \quad . \quad . \quad 30$

Card $10 . \quad . \quad . \quad . \quad . \quad . \quad . \quad . \quad 30$

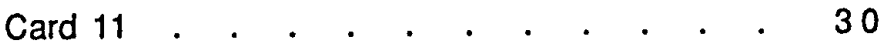

Card 12 .

Card 13 .

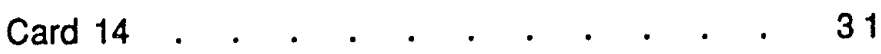




\begin{tabular}{|c|c|c|c|c|c|c|c|c|c|c|c|c|}
\hline Card 15 & . & . & . & . & • & . & . & . & . & . & . & 3 \\
\hline Card 16 & . & . & . & - & . & . & . & . & . & . & . & 33 \\
\hline Card 17 & . & - & . & . & $\cdot$ & . & . & . & . & . & . & 34 \\
\hline Card 18 & . & . & . & . & . & . & . & . & . & . & . & 34 \\
\hline Card 19 & . & . & $\cdot$ & . & . & · & . & · & . & . & . & 35 \\
\hline Card 20 & . & . & $\cdot$ & . & . & . & · & - & . & . & . & 36 \\
\hline Card 21 & . & . & $\cdot$ & . & $\cdot$ & $\cdot$ & $\cdot$ & $\cdot$ & · & $\cdot$ & . & 36 \\
\hline Card 22 & . & . & . & $\cdot$ & · & . & $\cdot$ & . & . & . & . & 36 \\
\hline Card 23 & . & . & . & . & $\cdot$ & $\cdot$ & . & - & . & . & . & 37 \\
\hline Card 24 & . & . & . & . & - & . & · & . & . & . & . & 37 \\
\hline Card 25 & . & . & . & . & . & . & · & $\cdot$ & . & . & - & 38 \\
\hline Card 26 & . & . & . & . & . & . & . & . & . & . & . & 39 \\
\hline Card 27 & . & . & . & . & $\cdot$ & . & · & . & . & . & . & 39 \\
\hline Card 28 & · & . & $\cdot$ & . & $\cdot$ & . & . & . & . & . & . & 40 \\
\hline Card 29 & . & . & . & . & $\cdot$ & . & . & . & . & . & . & 40 \\
\hline Card 30 & . & . & . & $\cdot$ & $\cdot$ & . & . & . & $\cdot$ & . & . & 40 \\
\hline Card 31 & . & . & . & . & $\cdot$ & . & . & . & . & . & . & 40 \\
\hline Card 32 & . & . & . & $\cdot$ & $\cdot$ & . & . & $\cdot$ & . & . & · & 41 \\
\hline Card 33 & . & . & . & . & $\cdot$ & . & . & . & . & . & . & 41 \\
\hline Card 34 & $\cdot$ & . & . & $\cdot$ & $\cdot$ & · & . & . & . & . & . & 42 \\
\hline Card 35 & . & . & . & . & $\cdot$ & . & . & . & . & . & . & 42 \\
\hline Card 36 & $\cdot$ & · & . & $\cdot$ & $\cdot$ & . & . & $\cdot$ & $\cdot$ & . & $\cdot$ & 43 \\
\hline Card 37 & . & . & . & . & . & . & . & . & • & . & . & 47 \\
\hline
\end{tabular}


Card 38 .

Card Group Number 5 (CG5) • . . . . . 54

MODELTESTRUNS . . . . . . . . . . . . . . 56

Manual Optimization and Sensitivity Analyses . . . . 57

PRMS Optimization and Sensitivity Analyses . . . . 61

Model Optimization Results . . . . . . . 62

Model Sensitivity Results . . . . . . . 67

MODELRESULTS . . . . . . . . . . . . . . . . 69

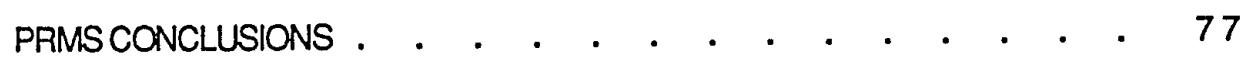

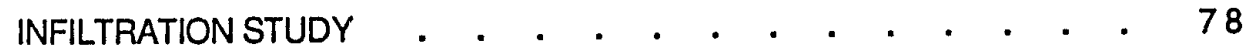

SITESELECTION • . . • . . . . . . . . . . . . 81

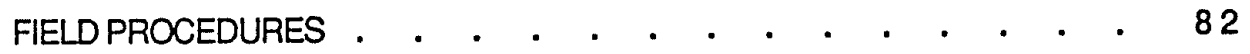

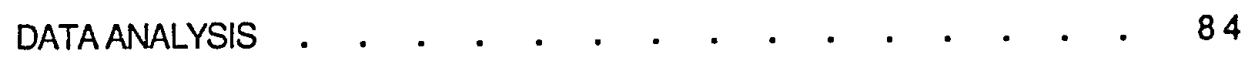

RESULTS AND INTERPRETATIONS $\quad . \quad \cdot \quad \cdot \quad \cdot \quad \cdot \quad \cdot \quad \cdot \quad \cdot \quad 87$

INFILTRATION CONCLUSIONS ..$\quad \cdot \quad \cdot \quad \cdot \quad \cdot \quad \cdot \quad \cdot \quad \cdot \quad \cdot \quad \cdot \quad 88$

THESISCONCLUSIONS

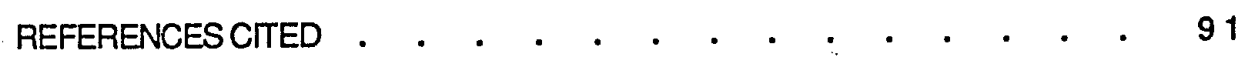

APPENDIX

A, Definitions of Card Gioup1 Parameters . . . . . 93

B, Input of PRMS Run 1 . . . . . . . . . . 103

C. Input of PRMS Run 2 . . . . . . . . . 106

D, Input of PRMS Run 3 .

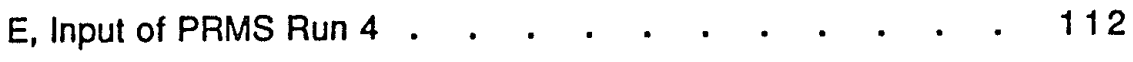

F, Input of PRMS Run 5 . 


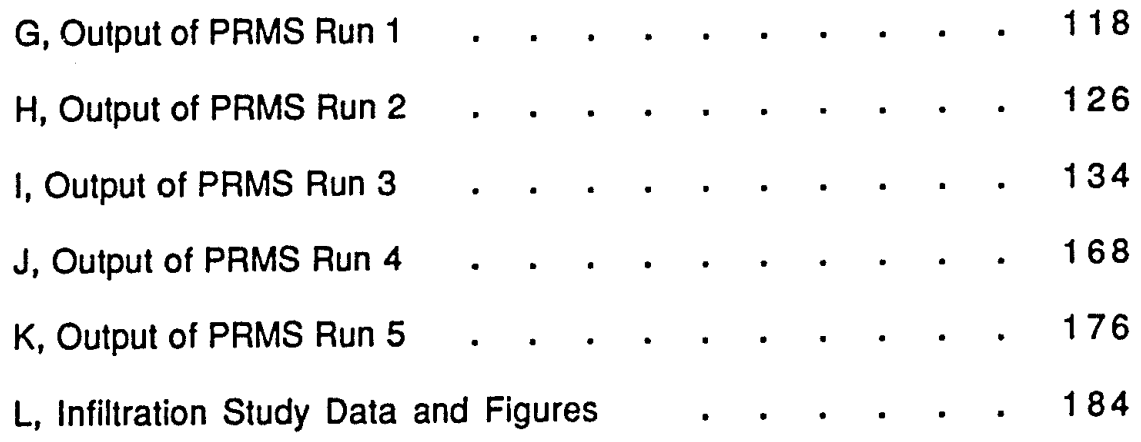




\section{UST OF TABLES}

Table

Page

1 Input for CG5 . . . . . . . . . . . . . . .

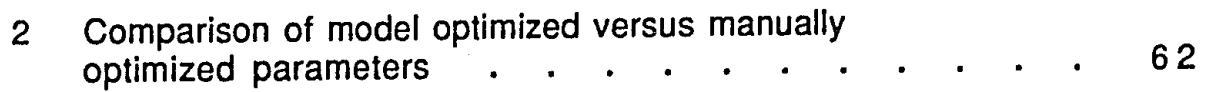

3 Magnitude of error for model optimized parameters . . . 67 


\section{LIST OF FIGURES}

Figure Page

1 Schematic Diagram of Hydrologic Cycle . . . . . . . 5

2 Location Map of Blackwood Creek Drainage Basin . $\quad$ - . $\quad 8$

Northeastern View of the Blackwood Creek Drainage
Basin, Showing Vegetation Types . . . . . . 10

Eastern View of the Blackwood Creek Drainage Basin,
Showing Vegetation Types. . . . . . . 10

5 Schematic of Conceptional PRMS Water Movement . . . . 21

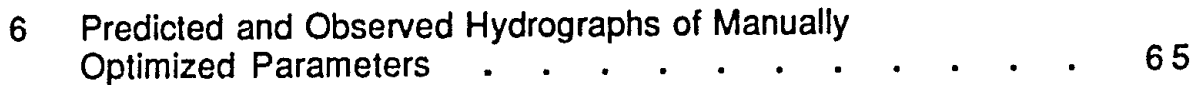

$7 \begin{aligned} & \text { Predicted and Observed Hydrographs of Model } \\ & \text { Optimized Parameters . . . . . . . . . . . } 66\end{aligned}$

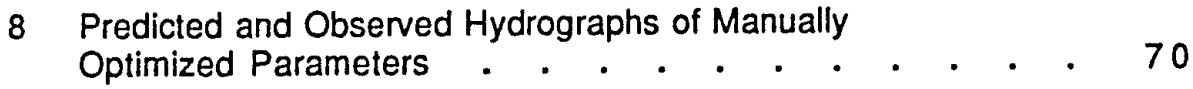

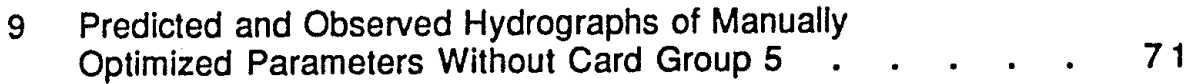

10 Predicted and Observed Hydrographs of Model
Optimized Parameters Without Card Group 5 . . . . . . 72

11 Predicted and Observed Hydrographs of Model
Optimized Parameters With Card Group 5 . . . . . . . 73

12 Predicled and Observed Hydrographs of Model Optimized Parameters Without Card Group 5 . . . . 74

13 Schematic of a Double Ring Infiltrometer . . . . . . 79

14 Summary of Infiltration Data . . . . . . . . . 85

15 Infiltration Graph of Site 1-1987 . . . . . . . 86 


\section{UST OF PLATES}

\section{Plate}

1 Simplified Geologic Map . . . . . . . . . in pocket

2 Hydrologic Response Units (HRUs) . . . . . . . in pocket

3 Soil Survey . . . . . . . . . . . . . in pocket 


\section{INTRODUCTION AND PREVOUS STUDIES}

The purpose of this project was to define the movement of water through the Blackwood Creek drainage basin, located near the town of Homewood, Placer County, California. The study of water movement through the basin was conducted in conjunction with a study by K. Michael Nolan of the U.S. Geological Survey.

K. Michael Nolan of the U.S. Geological Survey's Water Resource Division directed a study of sediment transport in the Blackwood Creek basin. Data for Nolan's study, which included preparation of a sediment budget, were collected from 1983 to 1987. Two publications resulted from the information obtained during this study. The first publication, entitled "Sediment-Source Data for Four Basins Tributary to Lake Tahoe, California And Nevada, August 1983-June 1988," (Hill and others, 1990) contained the necessary data to calculate the sediment budgets. The second publication, entitled "Suspended-Sediment Budgets For Four Drainage Basins Tributary to Lake Tahoe, California and Nevada, 1984-87," (Nolan and others, 1991) included sediment budgets based on information provided by Hill and others (1990).

Determination of sediment sources was necessary to establish the sediment budget of the basin (Hill and others, 1990). Data collected to evaluate the source of sediment include changes in bank and bed positions at channel cross sections, results of stream-channel inventories, analyses of bank and bed material samples, tabulations of bed-material pebble counts, measured rates of hillslope erosion, dimensions of gullies, suspended-sediment data collected during synoptic snowmelt sampling, and physiographic data for the study basin.

Sediment source data were used to develop a suspended-sediment budget (Nolan and others, 1991) for the Blackwood Creek drainage basin. The sediment budget study 
was conducted by the U.S. Geological Survey, in cooperation with the Tahoe Regional Planning Agency, to obtain data on sources, characteristics, volume, and rates of production and transport of eroded material in the Lake Tahoe basin in order to improve the understanding of the processes of erosion and deposition in the basin. Erosional processes were monitored during 1984-87, and a sediment budget was formulated to identify processes that supply sediment to Blackwood Creek and ultimately to Lake Tahoe.

The sediment budget study evaluated the data collected to assess rates of hillslope erosion, streambank erosion, streambed scour and fill, and amount of sediment storage in stream channels of the Blackwood Creek basin. Three requirements were necessary to complete the sediment budget: (1) recognition and quantification of transport processes (streambank erosion, streambed erosion, and hillslope erosion), (2) recognition and quantification of storage elements (streambed storage and colluvial storage), and (3) identification of linkages among transport processes and storage elements.

Nolan and others (1991) indicated that most previous sediment budgets had been conducted on basins where the primary source of sediment was landsliding. Initial inspection of the Blackwood Creek drainage basin indicated that landsliding was not a particularly active erosional process. Therefore, erosional processes such as channel erosion, rainsplash, and sheetwash on the hillslopes must be the dominant erosional processes in the basin. Lack of bare ground and the presence of highly permeable soils indicate that channel erosion probably dominates over erosional processes operating on the hillslopes.

Nolan and others (1991) produced two types of sediment budgets for the Blackwood Creek drainage basin. The first type was an estimated "gross" sediment budget which represents the amount of sediment eroded by all processes, minus the amount of sediment deposited along main-channel streambeds. Data used for the 
estimated gross sediment budget were used to produce the second type of sediment budget known as a "routed" sediment budget. The routed sediment budget was determined by defining sections of the main channels and estimating sediment mobilization, storage, and discharge within each section. The routed sediment budget provided a check for gross sediment budget calculations, and also provided information on the locations where most sediment was eroded and deposited within the basin.

Results of the study conducted by Nolan and others (1991) revealed that the gross sediment budget predicted an average annual suspended-sediment output of 2,420 megagrams $(\mathrm{Mg})$ and the routed sediment budget predicted an average annual suspendedsediment output of $2,100 \mathrm{Mg}$. These predictions compare closely with the average annual measured suspended-sediment discharge of 2,030 Mg between 1984 and 1987. The study also revealed that of the 2,420 megagrams (Mg/a) of annual output estimated by the gross sediment budget, $106 \mathrm{Mg} / \mathrm{a}$ (4 percent) came from hillslopes, $968 \mathrm{Mg} / \mathrm{a}$ (40 percent) from first-and second-order tributaries, $1,190 \mathrm{Mg} / \mathrm{a}$ (49 percent) from eroding banks along the main channel, and $163 \mathrm{Mg} / \mathrm{a}$ (7 percent) from the bed of the main channel. Based on the information produced by Nolan and others (1991), it is apparent that the stream channels are by far the dominant source of sediment in Blackwood Creek drainage basin.

To completely study sediment transport through Blackwood Creek drainage basin, the knowledge and understanding of water movement through the basin is necessary. The study by Nolan and others (1991) revealed that the majority of sediment transported to Lake Tahoe via Blackwood Creek originated from stream channels. Because it is apparent that the sediment is transported by water, the question arises, how does the water move through the basin? 
In order to define the movement of water through the basin, the hydrologic cycle of the basin was studied. The hydrologic cycle is the endless circulation of water between the ocean, atmosphere, and land (Freeze and Cherry, 1979). For the purpose of this study, the oceanic and atmospheric portions of the hydrologic cycle were neglected to focus on the land-based portion (fig. 1).

Inflow to the system originates as precipitation, which takes the form of either rain or snow (fig. 1). The water can then move in two directions, as it is either intercepted or delivered to the land-based portion of the cycle as throughfall. Precipitation that is intercepted becomes oufflow from the system in the form of evapotranspiration. Precipitation delivered to the land as throughfall has the possibility of three basic routes: (1) it can move to interception storage where it will be lost in the evapotranspiration process; (2) it can move as overland flow directly into the channel and become runoff; or (3) it can infiltrate into the soil. Water that infiltrates into the soil can then move in three directions: (1) it can be consumed in the evapotranspiration process; (2) it can move as interflow directly into the channel and become runoff; or (3) it can slowly percolate into the groundwater recharge zone and become groundwater storage.

Once in the groundwater, the water can move in two directions: (1) it can be lost as evapotranspiration; or (2) it can flow into the channel as baseflow and becoine runoff. In summary, the water arrives in the basin as precipitation and is discharged as evapotranspiration and streamflow, which is the sum of overland flow, interflow, and baseflow.

The tool that was used to predict overland flow, interflow, and baseflow was the standard United States Geological Survey (USGS) Precipitation Runoff Modeling System (PRMS). PRMS predicts the amount of runoff from the basin based on precipitation 


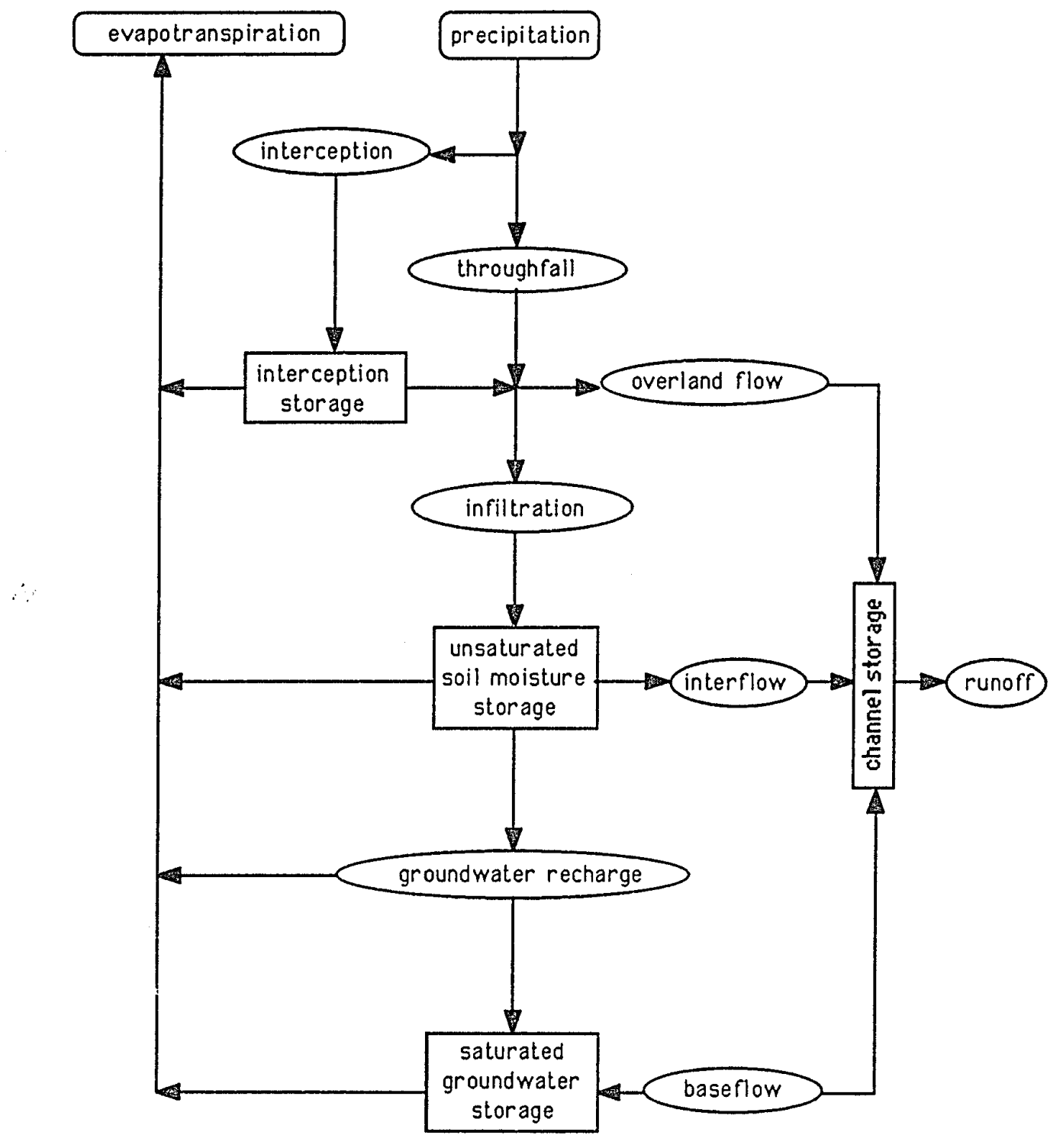

FIGURE 1.--Schematic diagram of Hydrologic Cycle, from Freeze and others (1979). 
and temperature data. Basin characteristics are determined and used with streamflow data to calibrate the model for the basin. Individual model parameters are adjusted, until the model predicts values similar to observed runoff values.

When the predicted values become close to the observed values, the model is calibrated, and the type of water movement through the basin can be studied. The objective of the PRMS is to determine which routes the water takes as it moves through the basin, and to determine which parameters of the model have the greatest impact on the model, and ultimately predict basin runoff.

Another basin characteristic related to PRMS and the sediment budget prepared by Nolan and others (1991) is the infiltration of water into the soil. An additional smaller scale study was conducted using a double ring infiltrometer to measure infiltration rates throughout the basin to determine whether abandoned logging roads are significant sediment sources. Infiltrometer data collected from this study were incorporated into the PRMS. 


\section{LOCATION AND BASIN CHARACTERISTICS}

The study area for this project is the Blackwood Creek drainage basin, located on the west side of Lake Tahoe near the town of Homewood in Placer County, California (fig. 2). Blackwood Creek drainage basin is one of sixty three drainage basins which make up the Lake Tahoe basin. The Lake Tahoe basin lies on the east side of the Sierra Nevada crest between the main range of the Sierra Nevada on the west and the Carson Range on the east (fig. 2). Blackwood Creek drainage basin is the fourth largest drainage basin tributary to Lake Tahoe (Evans and others, 1968).

Except for a small portion located on the 1:24,000-scale Wentworth Springs Quadrangle, the majority of the Blackwood Creek drainage basin is located on the 1:24,000 scale Homewood Quadrangle (Plate 1). The crest of the Sierra Nevada forms the western edge of the Blackwood Creek drainage basin (Tahoe Regional Planning Agency, 1971b). Total drainage area of the basin is 11.71 square miles (30.33 sq. $\mathrm{km})$, with a maximum elevation of 8,878 feet $(2706 \mathrm{~km})$ above mean sea level (msl) at Twin Peaks in the northwest section of the basin. The minimum elevation in the basin is lake level, which is 6,229 feet $(1898.6 \mathrm{~km})$ above msl. Four major tributaries drain into Blackwood Creek, the North Fork and the Middle Fork in the western portion of the basin and two unnamed streams in the central portion (Plate 1).

General basin orientation or basin aspect is toward the northeast at 45 degrees from true north (Hill and others, 1990). Slope steepness as determined by the line-

intersection method of Wentworth (1930), varies throughout the basin, from relatively flat $(11 \%$ grade) in the central section of the basin to the relatively steep ( $42 \%$ grade) slopes of the northern side of the basin. Hill and others (1990) report that the average land surface slope throughout the basin is 17.8 degrees from horizontal ( $32 \%$ grade). 


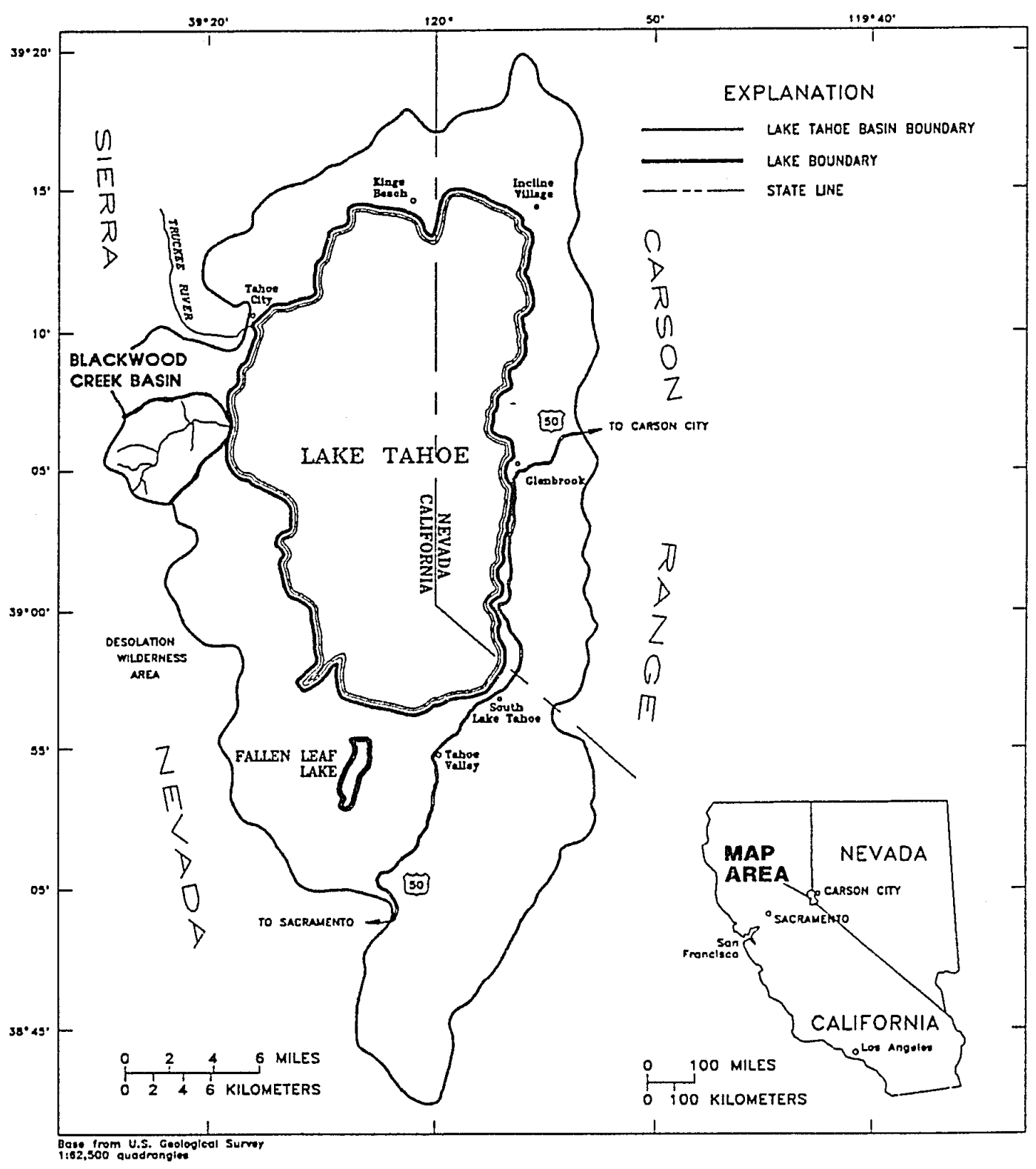

FIGURE 2.--Location of Blackwood Creek drainage basin, from Hill and others (1990). 
Specific slope steepness is discussed in more detail in the following sections which address specific basin characteristics as input data for the PRMS.

General forest vegetation in the basin consists primarily of white and red fir and lodgepole pine. Several south-facing slopes are devoid of vegetation except for shrub species such as ceanothus and manzanita (figs 3,4 ). Vegetation in the basin is characterized by moist soil conditions throughout the entire growing season (Nolan and others, 1991).

Historic land use in the basin consisted of sheep and cattle grazing from 1864 to 1962, logging in the late 1800's and again between 1953 and 1970, gravel mining from 1960 to 1967, and current off road recreational vehicle activity (Nolan and others, 1991). The basin is presently uninhabited from approximately 0.5 miles upstream from Lake Tahoe.

Grazing occurred primarily in the flat lying meadow area of the basin and on the less steep south facing slopes in the upper basin. Over-grazing was a primary concern in the basin as early as 1905 , when it was noted that overgrazing was causing an increase in gullying, channeling and overall erosion of the basin.

In addition to overgrazing, logging practices also affected historic erosion and water movement throughout the basin. Approximately two thirds of the basin was logged during the period of the late 1800's, and between 1953 to 1970 (Nolan and others, 1991). To assist the logging activity, a sawmill was constructed in the basin in 1956 to transform the timber into lumber. The sawmill was removed when lumbering activity was ceased in1970. Though the logging activity was ceased in 1970 , the roads constructed during this activity still exist. Several of the roads are open for off road vehicle use, while others have slowly become revegetated and are being transformed into the forest environment. 


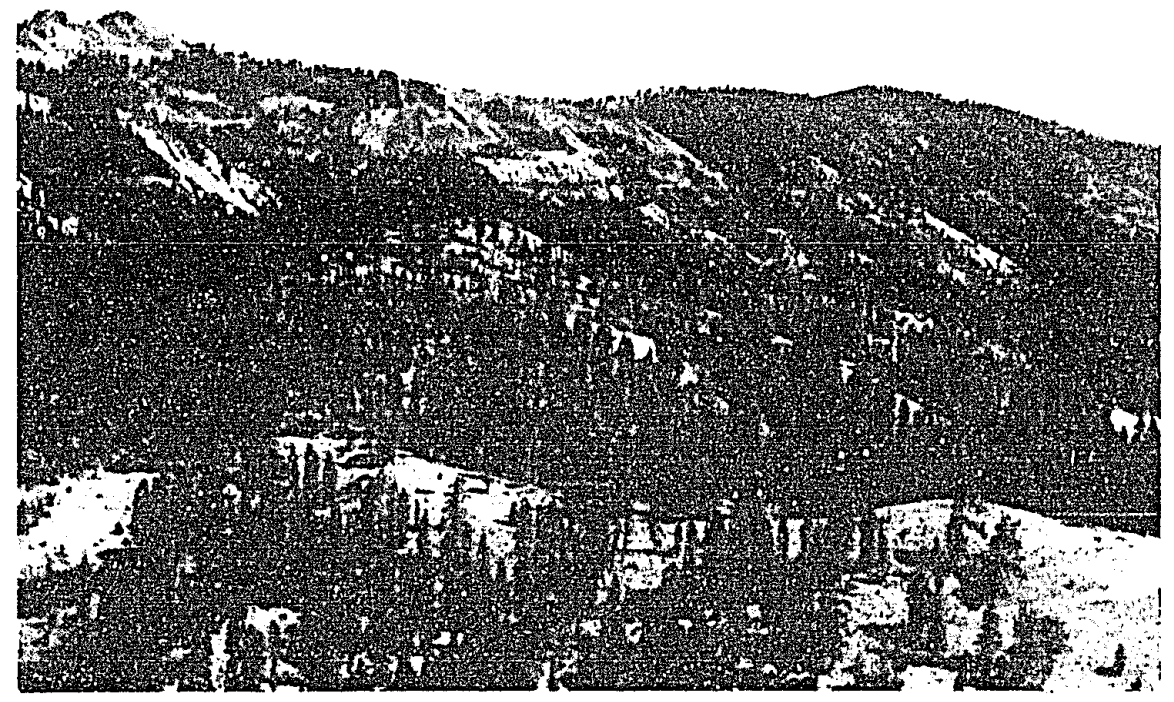

FIGURE 3.--Northeastern view of the Blackwood Creek drainage basin, showing vegetation types.



FIGURE 4.--Eastern view of the Blackwood Creek drainage basin, showing vegetation types. 
A gravel mining operation existed from 1960 to 1968 in the main channel of Blackwood Creek approximately $4 \mathrm{~km}$ from the mouth of the creek. Approximately $40,000 \mathrm{~m}^{3}$ of material was mined from the stream during this period (Nolan and others, 1991). To allow the mining of the stream channel, the stream was diverted into an artificial channel to the south of the original channel. The U.S. Forest Service constructed a dlvirsion channel in 1979 to redirect the stream into its original channel. In addition to the diversion channel, the U.S. Forest Service constructed several zones of rip rap beginning in 1986 to protect the fragile banks of the stream, reduce erosion of the streambank and ultimately reduce the amount of sediment transported to Lake Tahoe.

Temperature and precipitation measurements utilized for this study were obtained from Ward Bench monitoring station, located in the Ward Creek drainage basin directly north of the Blackwood Creek drainage basin (plate 1). The Ward Bench station is operated by Professor Earl Byron of the University of California at Davis. Three years of data (10/83 - 9/86) from the Ward Bench station were used as observed (measured) precipitation and temperature data for the Blackwood Creek drainage basin.

The Ward Bench station is located approximately 2 miles $(3 \mathrm{~km})$ due north of Twin Peaks, the northwest boundary of the Blackwood Creek drainage basin. The elevation of Ward Bench station is 7,218 feet $(2,200 \mathrm{~m})$ above $\mathrm{msl}$, and the mean elevation of the the Blackwood Creek drainage basin is 7,200 (2,195 m) above msl. Blackwood Creek drainage basin is oriented N45E, whereas Ward Creek basin is oriented approximately N85E. However, the monitoring station in the Ward Creek basin is located on a slope oriented approximately N50E. Because the Ward Bench station is located at a similar elevation to the mean elevation of Blackwood Creok, is similarly oriented to the northeast, and is the closest monitoring station to the Blackwood Creek drainage basin, 
the assumption was made that the measurements from the Ward Bench station would be similar to the observed data in the Blackwood Creek drainage basin.

Annual precipitation in the Ward Bench basin during the period of record (10/83 9/86) varied from a minimum of 40.53 inches $(103.9 \mathrm{~cm})(10 / 84-9 / 85)$ to a maximum of 82.12 inches $(210.6 \mathrm{~cm})(10 / 85$ - 9/86) with a mean of 63.7 inches $(163.3 \mathrm{~cm})$. Temperature also varies, with December through March being the coldest months with mean temperatures ranging from 24 degrees Fahrenheit $\left(-18.6^{\circ} \mathrm{C}\right)$ to 30 degrees Fahrenheit $\left(-15.3^{\circ} \mathrm{C}\right)$. During April through November, temperatures range from freezing $\left(0^{\circ} \mathrm{C}\right)$ to almost 90 degrees Fahrenheit $\left(18^{\circ} \mathrm{C}\right)$. 
The Blackwood Creek drainage basin is one of 63 drainage basins that make up the Lake Tahoe basin (Tahoe Regional Planning Agency, 1971). The geologic history of the Lake Tahoe basin is representative of the geologic history of the entire Sierra Nevada Range. A brief discussion of Lake Tahoe geology and physiography is included preceding a more detailed description of the geology and physiography of the Blackwood Creek drainage basin.

The Lake Tahoe basin is believed to have formed in a graben between the Sierra Nevada and the Carson Range approximately 3 million years ago (Hyne and others, 1972). It is believed that the crests were upfaulted and Lake Tahoe formed in the graben betricen the two :anges. The sirape of the lake is box-like with sides that dip steeply into the basin, indicative of normal faults. Minor faults have been located on both the east and west side of the basin, but, these faults are not continuous. Bounding faults are not well defined in this area, but it is believed that the basin was created by faulting and uplifting.

Four primary rock units characterize the Lake Tahoe area: (1) pre-Cretaceous metamorphic rocks; (2) Mesozoic plutonic rocks; (3) Cenozoic volcaric rocks, and (4) Quaternary glacio-fluvial deposits. The oldest rocks in the Lake Tahoe area are Jurassic sedimentary and volcanic rocks that have been metamorphosed. The original marine sediments consisted of sand, silt, and organic mud and are estimated to have been deposited in Early Jurassic time (Burnett, 1971). The oldest of these sediments are of marine origin and consisted of sand, silt, mud and organic material. Overlying the marine sediments are Late Jurassic volcanic rocks consisting of mudflows, volcanic ash (tuff), and bedded flows which are in excess of 15,000 feet $(4,473 \mathrm{~m})$ thick in some 
areas. Weathering of the metamorphic rocks takes place primarily along closely spaced joints, foliation and bedding planes.

The primary bedrock in the Lake Tahoe area is of intrusive origin. Granodiorite is the most common rock type identified, although quartz diorite, diorite and gabbro are present in small bodies adjacent to the metamorphic rocks. A sample of granodiorite dated by the K-Ar method yielded an age of $106 \pm 2$ million years old (Burnett, 1971).

Volcanism during the Cenozoic distributed various volcanic rocks over the entire Lake Tahoe area. The volcanic rocks consist mainly of mudflow breccias and flows of andesite, basalt, and latite (Burnett, 1971). Mudflows are massive and thickly bedded, whereas the lava flows are thinner and display prominent cross-jointing. Lava flows exhibit a much better resistance to weathering than do the massive mudflows, and soil horizons are more prominent on the mudflows than on the lava flows. The volcanic flows on the north side of Lake Tahoe have been age dated by K-Ar method, and revealed a relative age of 2.2 to 2.5 million years (Burnett, 1971).

Quaternary glacio-fluvial deposits correlate with several stages of glacial activity which substantially modified the Lake Tahoe basin during the Pleistocene Epoch. Pleistocene glaciation occurred only in the western, northern, and southern portion of the basin and was absent altogether from the eastern portion of the basin (Hyne and others, 1972). Glacial advances and withdrawals generated an extensive volume of glacial moraines which ultimately supplied the material for the glacio-fluvial deposits. The glacial deposits commonly referred to and most easily identified are: (1) glacial till, an unsorted and unstratified rock material deposited from the undersides of the glacier; (2) terminal moraines, mounds of unsorted and unstratified rock material deposited at the toe of the glacier; (3) lateral moraines, mounds of unsorted and 
unstratified rock material deposited at the flanks of the glacier; and (4) glacial outwash, sorted and stratified rock material transported and deposited by glacier meltwater.

Three primary glacial events (pre-Tahoe, Tahoe, Tioga) describe glacial activity of the Lake Tahoe basin. The pre-Tahoe glacial event is the oldest event and is characterized by deeply weathered boulders of granitic rock and to a lesser degree, weathered coarse grained volcanic rocks. Soil profiles vary on pre-Tahoe moraines, from poorly developed in the sandy granitic moraines to shallow and better developed in the volcanic moraines. Pre-Tahoe deposits are poorly preserved, and recognition is usually difficult (Birman, 1964). Pre-Tahoe glaciation is believed to have occurred approximately 750,000 years before present (Sharp and others, 1963). Complete deglaciation was encountered during the interval between the pre-Tahoe glaciation and the Tahoe glaciation.

The Tahoe glacial event is characterized by more developed moraines than the pre-Tahoe. Tahoe moraines are the most conspicuous in the area and can range from 50 - 100 feet (15.2 - $30.5 \mathrm{~m})$ high, with some reaching almost 400 feet (122 m) high. The typical Tahoe moraine does not complete closure in a terminal arc, as does the younger Tioga glacial moraines (Birman, 1964). The Tahoe glacial event was much less extensive in both space and time than the pre-Tahoe glacial event. Limited weathering has occurred on the rock material in the Tahoe moraines. The Tahoe glacial event is believed to have occurred approximately 130,000 years before present.

The Tioga glacial event is the youngest of the three primary glacial events, and is the most recognizable. Tioga moraines exhibit excellent closure of end-moraine arcs, although they are less extensive than both the Tahoe and the pre-Tahoe moraines. The Tioga glacial event is further characterized by moraines exhibiting sharp crests and an 
abundance of unweathered boulders and cobbles and an absence of a developed soil profile (Birman, 1964). The youngest Tioga moraines are approximately 20,000 years old.

The geology of the Blackwood Creek drainage basin is similar to that in the rest of the Lake Tahoe area. Plate 1 is a simplified version of an unpublished geologic map prepared by D. S. Harwood of the U. S. Geological Survey (personal communication, 1990). The geologic map is included to simplify the geological description of the Blackwood Creek drainage basin. The basin is underlain primarily by Mesozoic metamorphic rocks, Tertiary volcanic flows and blast deposits, and Quaternary glacial outwash and till with minor interbedded lake deposits. Igneous rocks are not exposed in the basin.

The oldest rocks in the basin are located in the south central section of the basin and are classified as metasediments of lower Jurassic age. The southeast portion of the basin is composed of upper Jurassic metamorphic rocks originally of volcanic origin. The steep northern and western slopes of the basin are composed primarily of dacitic blocks and pumice of blast origin (D.S. Harwood, U.S. Geological Survey, personal communication, 1990).

The central section of the drainage basin, which makes up the relatively flat lying areas, is composed mainly of glacial till, glacial outwash and lake deposits. The upstream portion of the central section is composed mainly of glacial moraines believed to have been deposited during the Tioga glaciation period (Evans and others, 1968). The lateral deposits located at the transition between the flat lying areas and the sleep side walls of the basin are believed to be Tioga till (D.S. Harwood, U.S. Geological Survey, personal communication, 1990). The cobbles and boulders in the moraines and the till are relatively resistant to weathering and supply cobbles and boulders to the lower channels. The central and lower portion of the stream channel are composed of Tioga 
outwash and Quaternary alluvium (D.S. Harwood, U.S. Geological Survey, personal communication, 1990). The lower areas near the mouth of the stream contain thick deposits of unconsolidated silt, sand, pebbles, cobbles and boulders derived from the glacially deposited material upstream, and deposited as lake sediments. 


\section{HYDAOLOGY}

The hydrologic cycle in the Blackwood Creek drainage basin initiates with precipitation in the form of either rain or snow, depending on the season. During the portion of the season that rain is the dominant form of precipitation, the hydrologic cycle consists of precipitation in the basin, infiltration into the limited soil zones, miner interception, evapotranspiration, and finally stream discharge. The hydrolngic cycle during the rainy season occurs very quickly due to the limited amount of water storage in the basin.

During the portion of the year when precipitation occurs in the form of snow, the hydrologic cycle progresses much differently. The snow accumulates throughout the basin and is intercepted by vegetation, soil and rock. Evapotranspiration is increased during this period because the precipitation (snow) stays in the basin for a longer period of time. Observation of the basin throughout the hydrologic cycle revealed that runoff from the snow occurs slightly during this part of the season; however, the majority of the runoff occurs at the end of the snow season or during the spring thaw.

The hydrology of the Blackwood Creek drainage basin initiates in the headwaters of Blackwood Creek, which contains of at least seven smaller tributaries (plate 1). Rainfall in the basin is transferred relatively quickly to the tributary system and delivered to Lake Tahoe. Rainfall interception occurs to a limited degree in the forested regions which are composed primarily of white and red fir and lodgepole pine, and is almost nonexistent in the southern areas, which are relatively devoid of vegetation.

During the winter months, precipitation occurs almost exclusively in the form of snow. In the forested areas, the fir and pine trees allow the snow pack to accumulate, without being subjected to the intense sunlight. This increase in accumulation of the 
snow creates an increase in potential evapotranspiration, which reduces the amount of water that can be transported through the basin. Streamflow is generally not an important factor of basin hydrology during the winter months, because the snow accumulates in the basin. During the spring thaw, the snow is transferred relatively quickly to Blackwood Creek as melt water, and transferred to Lake Tahoe. An understanding of the hydrology of the Blackwood Creek basin is imperative prior to evaluating how water moves through the basin. 


\section{PRMS DESCRIPTION AND OPERATION}

The major tool used during this project to predict how water moves through the Blackwood Creek drainage basin was the Precipitation-Runoff Modeling System (PRMS). The PRMS is a "modular-design, deterministic, distributed-parameter modeling system" developed to determine the impacts of various combinations of precipitation, climate and land use on stream flow, sediment yields and general basin hydrology (Leavesley and others, 1983). Basin response to variable rainfall and snowmelt are simulated in order to compare changes in water-balance relationships, flow regimes, flood peaks and volumes, soil-water relationships, and groundwater recharge. Figure 5 is a schematic diagram which identifies the different flow paths of the water as viewed by the PRMS. To reproduce the hydrologic system as closely as possible, each component of the hydrologic cycle is expressed in the form of known physical laws or empirical relationships that have some physical interpretation based on some measurable basin characteristics. For example, the amount of water that flows from the groundwater reservoir to the stream is calculated by the equation:

\section{$B A S=R C B * G W$}

BAS is the total daily flow from the groundwater reservoir (acre-in). $\mathrm{GW}$ is the amount storage available in the groundwater reservoir (acre-in). $R C B$ is the reservoir routing coefficient.

For this study input data for PRMS consisted of: (1) measurable basin characteristics obtained from aerial photographs or 1:24,000 U.S. Geological Survey topographic maps, (2) measured stream discharge (3) infiltration measurements, (4) temperature and precipitation measurements obtained from the Ward Bench climatological monitoring station, (5) parameters from previously published reports that utilized the PRMS, and (6) basin coefficients that are adjusted to calibrate the 


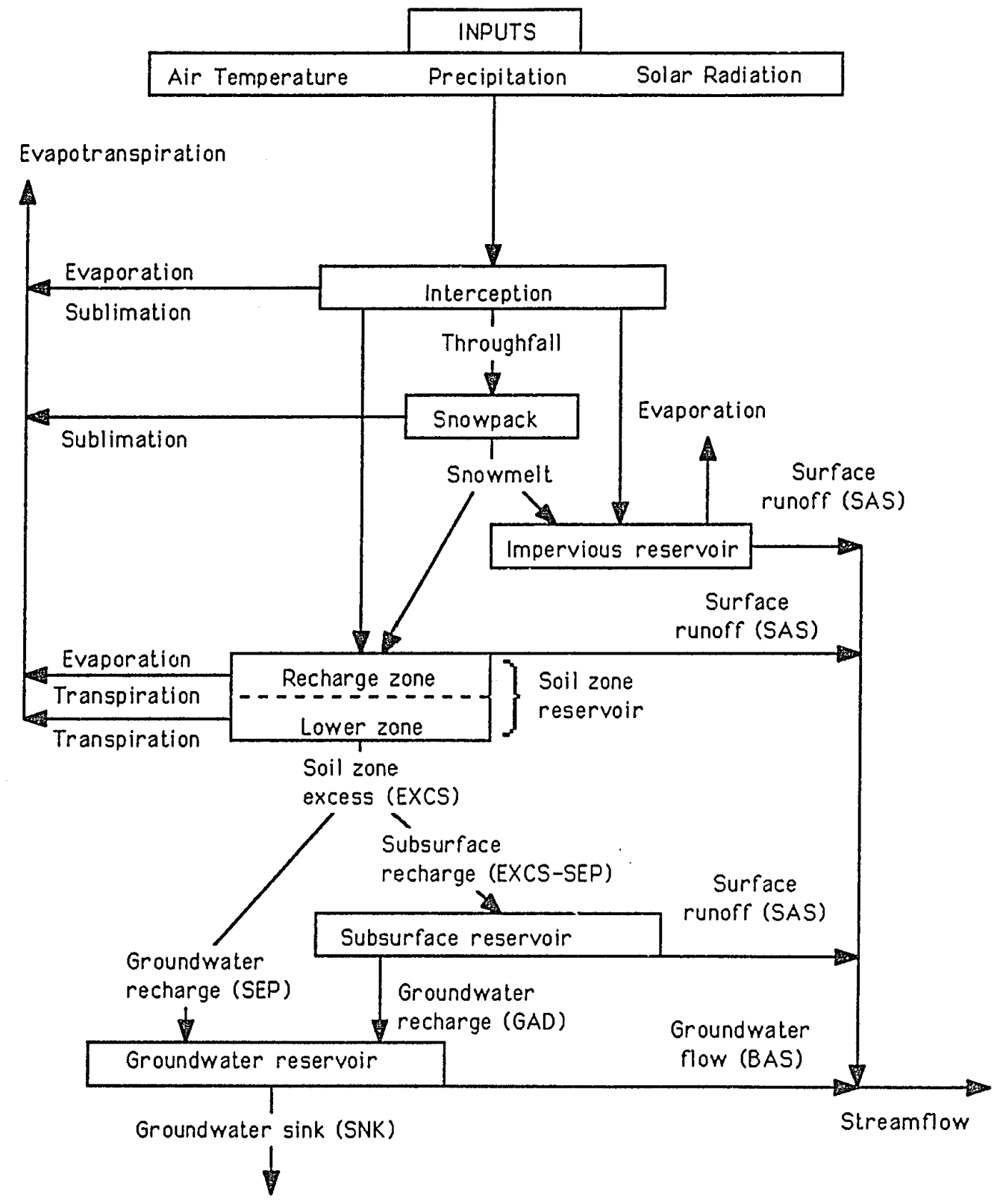

FIGURE 5.--Schematic of Conceptional PRMS Water Movement, from Leavesley and others (1983). 
PRMS with the observed or measured data. Input parameters for the PRMS use both english and metric units. To reduce confusion both units are listed when discussing basin parameters. 


\section{PRMS COMPONENTS}

PRMS is a modular design computer model coded in FORTRAN that uses subroutines to determine each section of the hydrologic cycle. These subroutines are automatically called by the main program and are designed to function independently from each other. The information that is used or created by each subroutine is transferred to the main program by COMMON statements. A COMMON statement or "COMMON block can be thought of as a sequence of data element storage units or memory locations" (Wagener, 1980). The COMMON statement enables the transfer of data between subroutines.

The subroutines fall under three basic categories: (1) the data management section, (2) the section related to the physical processes of the hydrologic cycle, and (3) the output section. The data management section is responsible for obtaining the daily basin characteristics which are stored in separate ASCII files. The basin characteristics obtained are: the maximum, minimum, and mean air temperature in degrees Fahrenheit $\left({ }^{\circ} \mathrm{F}\right)$; total precipitation in inches; mean discharge of the stream in

cubic feet per second $\left(\mathrm{ft}^{3} / \mathrm{s}\right)$, and other user defined basin characteristics. The section related to the hydrologic cycle is the core of the PRMS. It contains all of the subroutines needed to simulate the hydrologic cycle. The output section enables the user to display, analyze, and store the results.

Watershed Partitioning - Hydrolegic Respense Units

PRMS components are designed around the concept of partitioning a watershed into units with similar slope, slope aspect, vegetation type, soil type and precipitation distribution. Each unit is considered homogeneous with respect to its hydrologic 
response and is called a hydrologic response unit (HRU, plate 2). Partitioning provides the ability to impose land-use or climate changes on parts or all of the watershed and to evaluate resulting impacts on each HRU and on the total watershed. Input variables include descriptive data on physiography, vegetation, soils, rock type, hydrologic characteristics, and the variation of climate over the watershed.

The partitioning of the Blackwood Creek basin into HRU's was complicated by the presence of different lithologic units (plate 1), sixteen different mapped soil types (plate 3), and non-uniform vegetation. Partitioning based on soil type and vegetation was not possible because of the complex interfingering of many soil types and vegetation within the basin. Because of this difficulty, the decision was made to use only basin location, topography, and slope aspect as criteria to differentiate specific response units. After examination of the Blackwood Creek drainage basin, it was determined that seven HRU's would be sufficient to model the basin. The HRU's are designated HRU1 through HRU7 and the basic characteristics of each HRU are as follows:

HRU1

- Primarily south-facing slopes.

- Mean elevation of 7441 feet above sea level.

- Mean slope of 0.42 .

- Area of 3.9045 square miles.

HRU2

- Primarily north-facing slopes.

- Mean elevation of 7446 feet above sea level.

- Mean slope of 0.38 .

- Area of 0.4516 square miles.

HRU3

- Primarily east-facing slopes.

- Mean elevation of 7437 feet above sea level.

- $\quad$ Mean slope of 0.36 .

- Area of 0.7931 square miles.

HRU4

- Primarily north- and east-facing slopes.

- Mean elevation of 7569 feet above sea level.

- Mean slope of 0.34 . 
- $\quad$ Area of 1.9288 square miles.

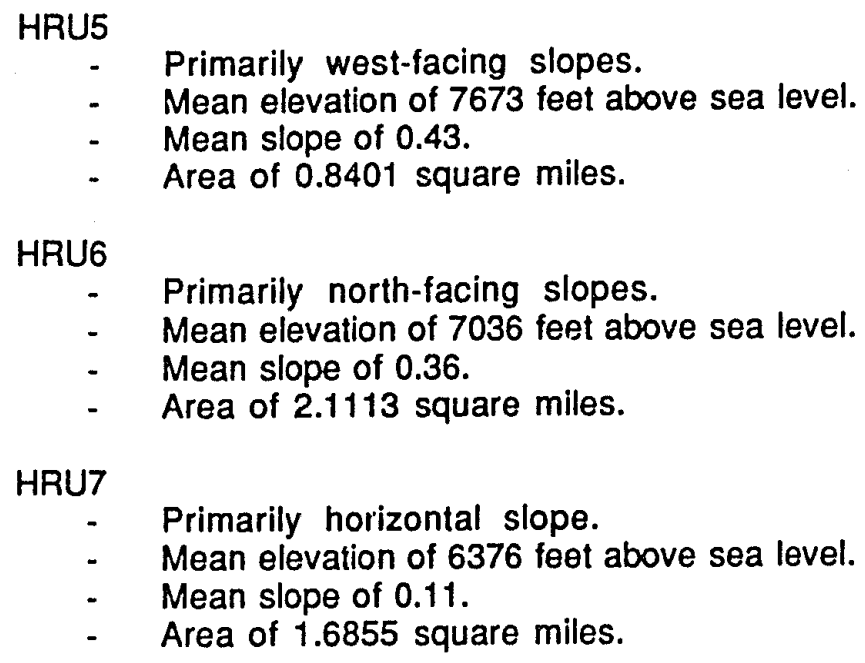

Subsurface partitions are also necessary for the operation of the precipitationrunoff model. The partitions are used to separate subsurface flow reservoirs and baseflow reservoirs. The purpose of a subsurface flow reservoir is to hold water in the soil when the infiltration rate of the water is greater than the seepage rate into groundwater, and a base-flow reservoir is a groundwater storage reservoir which holds water when the seepage rate to the groundwater reservoir is higher than the groundwater flow to the stream. The simplest case scenario uses one subsurface flow reservoir and one baseflow reservoir. Due to the lack of subsurface information and the conceptual idea of these reservoirs, only one subsurface flow reservoir and one base-flow reservoir were used. Detailed descriptions of the previous parameters are included in the following section.

\section{Parameter Estimation}

The partitioning of the basin into each individual HRU depends on the physical environment in that specific HRU. The perfect condition would be to base each HRU on 
completely unique parameters. Because the basin studied is composed of essentially similar vegetation, soil, topography, and climate, the perfect condition cannot be met. For this reason many of the parameters used are the same for all HRUs. The following sections will discuss the techniques used in determining the input parameters for the HRUs. Some of the parameters discussed have a strong physical basis and are easily determined from climatic data, soil and vegetation surveys, and topographic maps. Other parameters are based less on physical parameters and are difficult to estimate; many of these parameters are determined primarily during model calibration. Lack of physical data from the basin made it difficult to determine some of the parameters. Some of the parameters were obtained from the PRMS user's manual and other studies which used the PRMS model.

\section{Inout Parameters}

Parameter input into the PRMS is done through a system of input "cards." The PRMS was originally designed to accept input parameters through computer cards, before computer terminals and keyboards had evolved. Since the card format was already established, its use was continued.

PRMS accepts parameters from seven separate and distinct card groups. Card group number 1 (CG1) is the primary card group. All other card groups supplement the parameters input through CG1. The other six card groups are implemented by switches found in CG1. The model looks for the other six card groups when specified by CG1.

Card group number 2 (CG2) is used when storm mode parameters are used. A storm mode study was not conducted, so CG2 was not initialized. Card group number 3 (CG3) defines the infiltration and erosion characteristics of an HRU for storm mode computations and was not used. Card group number 4 (CG4) is used to define the type 
and flow characteristics of overland flow planes and channels. Flow planes were not determined or used, so CG4 was not used.

Card group number five (CG5) is designed to cause the model to override the algorithm which defines precipitation as either snow or rain, based on air temperature. CG5 was used to keep the snow pack from achieving an artificially induced melt stage. The calendar dates for which the override is conducted are user-defined in CG5. The use of CG5 was not initiated until all of the parameters in CG1 were determined.

Card group number six (CG6), which is used to adjust the snowpack water equivalents on each HRU, was not used. Card group number seven (CG7) is used to run optimization and sensitivity analyses on user defined parameters. CG7 was used following the initial runs of the model which were used to determine the original parameters. Inputs to Card Groups 1, 5, and 7 are discussed below.

Card Group Number 1 (CG1)

Thirty-eight input cards are allotted for the operation of the daily runoff mode which makes up CG1. The number of parameters on each card varies, depending on the number of HRU's, climate stations and various other basin characteristics. The input parameters for the cards consist of: operational switches which tell the main program to do specific calculations in a certain way, climatic parameters which are determined by data gathered in or around the subject basin, and landphase parameters which are determined by data which pertains to the specific environment in the basin or in each specific HRU.

CG1 contains 505 individual pieces of data that are grouped into four basic categories: operational switches; climatological data and basin characteristics; arbitrary coefficients from previous studies; and data modified by trial and error. 
Climatological data and basin characteristics account for 271 of the 505 pieces of data, or 53.66 percent of the total input parameters. Data and arbitrary coefficients obtained from previous studies account for 163 of the 505 pieces of data, or $32.28 \%$ of the total. Individual parameters obtained by trial and error consisted of only $8.12 \%(41)$ of the total, and operational switches consist of the final $5.94 \%$ of the input parameters. The parameters for cards 1 through 38 will be discussed below by card number, and definitions of each parameter can be found in Appendix A.

Cards 12. Parameters on cards 1 and 2 consist of switches for the operation of the model.

Card 3. Card 3 enables the user to put specific text on all output generated by the model.

Card 4. Basic watershed partitioning characteristics are input from card 4. The first parameter on this card is the number of rain gage data sets (NDS) used, which was set to one, because the Ward Bench climatological station in the Ward Creek basin was the only relatively close climate station to Blackwood Creek. The number of hydrologic response units (NRU) used was seven.

Each hydrologic response unit (HRU) is assigned a solar radiation plane, which is calculated by the slope and aspect of each particular HRU. HRU aspects were determined using the method described by Iwatsubo and others (1975), and the slope of each HRU was calculated using the line-intersection method of Wentworth (1930). The individual HRU aspects and slopes are input on card 14 and discussed in more detail in that section. 
The number of solar radiation planes (NRD) calculated for the seven HRUs were six, so NRD was set to 6 .

The number of subsurface flow routing reservoirs (NRES) and the number of groundwater flow routing reservoirs (NGW) were chosen to be 1 , because of the lack of subsurface information. The number of surface water detention storage reservoirs (NSTOR) was chosen to be 0 . Minor surface water detention reservoirs were identified on aerial photographs, but when the areas of these reservoirs were compared to the overall area of the basin, the reservoirs accounted for less than $0.5 \%$ of the entire basin. Since the reservoirs accounted for such a small portion of the basin, the decision was made to disregard the reservoirs, therefore setting NSTOR to 0 . The final parameter for this card is the total basin drainage area in acres (DAT). The basin area was determined using a digital planimeter to be 7497.54 acres.

Card 5. The parameters input on this card specify the beginning and ending dates of the data set. The model was run from information collected for the 1984 water year, from October 1, 1983 to September 30, 1984. Water year 1984 appeared to be an average water year compared with water years 1985 and 1986.

Card 6. Card 6 contains the beginning (MFS) and ending (MFN) months of objective computation. October and September were chosen for these parameters, which were the same as the beginning and ending months of the data set.

Cards 7.8. Cards 7 and 8 control the print functions for output generated by the model. The parameters for these cards were obtained from the PRMS manual (Leavesley and others, 1983). 
Card 2. The parameters input on this data card are switches that tell the main program that a particular data type will be input, and the model can access this data type for operation. The number of data types used in the simulation (NDTY) specifies how many separate data types will be called for input. The switches (IDUS(I)) are turned on (1) or off $(0)$ depending on the setting. The number of data types used in this study are: (1) daily mean discharge; (2) daily maximum air temperature; (3) daily minimum air temperature; and (4) daily precipitation.

Card 10. The parameters (PARMCA(I)) on this data card define the data sets specified on card nine. The options available are dependent on each data set. The parameter for daily mean discharge was set to 00060 which indicates that the input is in units of cubic feet per second (cfs). The input parameter for daily maximum and daily minimum air temperatures was set to 99998 which indicates that the input is in degrees Fahrenheit ( ${ }^{\circ} \mathrm{F}$ ). Daily precipitation is input in units of inches (in) and specified by 00045 .

Card 11. The parameters (STATCA(I)) on this data card define the statistical code for the parameters on card nine. The statistical code for daily mean discharge is 00003. The statistical code for daily maximum temperatures in degrees Fahrenheit $\left({ }^{\circ} \mathrm{F}\right)$ is denoted by 00001 and the statistical code for daily minimum temperatures in degrees Fahrenheit ( ${ }^{\circ} \mathrm{F}$ ) is denoted by 00002 . Daily precipitation is denoted by 00006. The statistical parameters mentioned are given in the PRMS operation manual (Leavesley and others, 1983). 
Card 12. This card enables the user to assign an identification number to the climatological station for which a specific data type was gathered. The data types referenced are those defined in card 9 and comprise the first eight data types. Since all of the climatological information gathered was obtained from one station (Ward Bench station), station identification numbers were not needed. Daily mean discharge was obtained from a separate stream gaging station, but this caused no confusion.

Card 13. The two parameters from this card are an extension of card 12. These are used to assign identification numbers to the climatological stations where daily and storm precipitation values were obtained. As stated before, only one station was used, so that identification numbers were not necessary.

Card 14. The parameters established on this card define the solar radiation planes needed to determine the rate of snowmelt for the individual HRU's. One card is required for each solar radiation plane defined in the basin. The number of cards used is six, equal to the parameter NRD specified on card no. 4. The first parameter is the index of each particular solar radiation plane (I). The second parameter is the slope and aspect $(\mathrm{SA}(\mathrm{I}))$ of the radiation (I). The aspect of the six radiation planes was calculated using the method described by Iwatsubo and others (1975). This method averages the aspect of several lines drawn perpindicular to countour intervals on the 1:24,000 U.S. Geological Survey topographic map. HRU average slopes were determined by the lineintersection method of Wentworth (1930). The six aspect and slope values that were 
input are as follows:

$\begin{array}{lll}\mathrm{SA}(1) & = & \mathrm{HOR} \\ \mathrm{SA}(2) & = & \mathrm{SE42} \\ \mathrm{SA}(3) & = & \mathrm{N} 38 \\ \mathrm{SA}(4) & = & \mathrm{E} 36 \\ \mathrm{SA}(5) & = & \text { NW40 } \\ \mathrm{SA}(6) & = & \mathrm{NE34}\end{array}$

The slope of each particular solar radiation plane, as calculated by the line-intersection method is specified in decimal form (ft/ft). The six calculated slopes are as follows:

$\begin{array}{lll}\text { SL(1) } & =0 \\ \text { SL(2) } & =0.42 \\ S L(3) & =0.38 \\ \text { SL(4) } & =0.36 \\ \text { SL(5) } & =0.40 \\ \text { SL(6) } & =0.34\end{array}$

The aspect of each particular solar radiation plane reported as true azimuths in degrees, where 0 and 360 degrees represent north are as follows:

$\begin{array}{lll}\operatorname{ASP}(1) & = & 0 \\ \operatorname{ASP}(2) & = & 110 \\ \operatorname{ASP}(3) & = & 0 \\ \mathrm{ASP}(4) & = & 90 \\ \mathrm{ASP}(5) & = & 300 \\ \operatorname{ASP}(6) & =\end{array}$

The final parameter on this card is the latitude of the basin, which is approximately 39 degrees north.

Gard 15. The data contained on this card are used by the subroutine which calculates the solar radiation striking the basin in any particular month. The parameter on this card is the slope of the line for the graph of the maximum daily air temperature $(x)$ versus the degree day coefficient $(y)$. To calculate the slope of the line, data for the first week of each month were used. Degree day coefficients were calculated for the same week of each month, by accumulating one degree for every degree that the daily mean temperature is above or below $65^{\circ}$ Fahrenheit. The slope of the best fit line of 
maximum daily air temperature versus degree day coefficients was calculated using a computer spreadsheet equipped with best fit line and slope functions. Graphical representation of the data was not necessary, therefore not prepared. The slopes of the data for each of the twelve months are listed below:

$\begin{array}{lll}\operatorname{RDM}(1) & = & -0.75 \\ \operatorname{RDM}(2) & = & -0.83 \\ \operatorname{RDM}(3) & = & -0.47 \\ \operatorname{RDM}(4) & = & -0.72 \\ \operatorname{RDM}(5) & = & -0.61 \\ \operatorname{RDM}(6) & = & -0.77 \\ \operatorname{RDM}(7) & = & -0.28 \\ \operatorname{RDM}(8) & = & -0.52 \\ \operatorname{RDM}(9) & = & -0.74 \\ \operatorname{RDM}(10) & = & -0.58 \\ \operatorname{RDM}(11) & = & -0.84 \\ \operatorname{RDM}(12) & = & -0.54\end{array}$

Card 16. The Y-intercepts (RDC(I)) of the data discussed for card 15 are input through this card. The $Y$-intercepts for each particular month were calculated using the same computer spreadsheet, so physical graphs were not prepared. The Y-intercepts for each specific month are as follows:

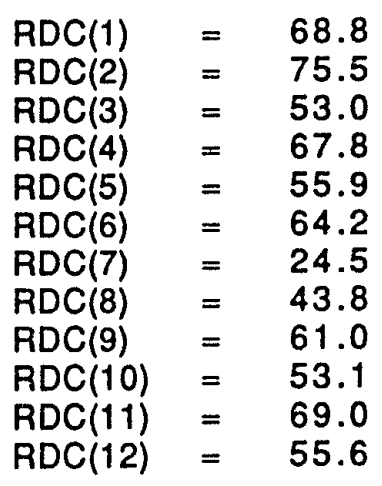


Card 17. The amount of solar radiation which hits the basin is very important for snow melt calculations, which in turn affect when snowmelt will occur. The parameters on this card are correction factors for solar radiation for specific situations. The amount of predicted solar radiation for a summer day with precipitation (PARS) was estimated to be roughly 50 percent $(.50)$ of normal (Leavesley and others, 1983). The correction factor for the amount of predicted solar radiation for a winter day with precipitation was estimated to be about 25 percent (.25) of normal (Leavesley and others, 1983). The final parameter of this card is the maximum percent of potential solar radiation available (RDMX). The setting chosen for RDMX was 80 percent (.80) and was based on previous work by Leavesley and others (1983).

Card 18. The elevation of the climaiological station (CSEL) is approximately 7,218 feet above mean sea level and is referred to as the Ward Bench station. The next two parameters (RMXA and RMXM) deal with the accumulation and melting stages in the snowpack during a mixed rain-snow event. In a mixed rain-snow event, the albedo of the snowpack is decreased, which can result in the snowpack going to the melt stage instead of the accumulation stage. RMXA is the proportion of rain in a rain-snow event above which snow albedo is not reset for the accumulation stage. RMXM is the proportion of rain in a rain-snow event above which snow albedo is not reset for the melt stage. RMXA was estimated to be approximately 80 percent $(.80)$ and RMXM was estimated to be approximately 60 percent (.60) (Leavesley and others, 1983).

For example, if the percentage of rain in a rain-snow event exceeds the RMXA (.80) value and the basin is in the accumulation time of the year, the model does not reset the clock which determines the time since the last snowfall. In other words, the model does not recognize the storm event as snowfall. In contrast, if the percentage of 
rain in a rain-snow event exceeds the RMXM $(.60)$ value and the basin is in the melt stage, the model does not reset the clock, and does not recognize the storm event as snowfall. The values assigned to RMXA and RMXM are strictly estimates and were derived from Leavesley and others (1983).

Card 19. The calculation of estimated daily potential evapotranspiration (PET) is computed in the subroutine PETS. The procedure selected computes PET as a function of daily air temperature and possible hours of sunshine (Leavesley and others, 1983). PET is computed by the equation:

$$
P E T=C T S(m o) * D Y L 2 * V D S A T
$$

where

CTS is an air temperature evapotranspiration coefficient for months 1-12, DYL is possible hours of sunshine, in units of 12 hour, VDSAT is the saturated water-vapor density (absolute humidity) at the daily mean air temperature in grams per cubic meter $\left(\mathrm{gm} / \mathrm{m}^{3}\right)$.

Of the three parameters used to estimate PET, CTS is the only user defined parameter. According to Leavesley and others (1983), a constant value of 0.0055 for CTS should be used for each month of the year. An initial value of 0.0055 was used, but appeared to produce too much evapotranspiration in the basin. After trial and error, a value of 0.001 was selected for months 1-12. It appears that the potential evapotranspiration in the basin is greatly reduced by the orientation and the vegetation in the basin.

Potential evapotranspiration is dependent on the amount of daily sunshine, and vegetation cover greatly reduces the amount of sunshine that is encountered. Also, the basin is oriented towards the northeast, which greatly reduces the amount of daily sunshine. The amount of potential evapotranspiration that is sublimated from a snow surface (CTW) is also input from this data card. A value of 0.1 was chosen for CTW, and was obtained from Leavesley and others (1983). 
Card 20. The maximum air temperature (PAT), which, when exceeded, forces all spring and summer precipitation to be rain regardless of the minimum air temperature, is input through this card. PAT was initially set to 39 degrees Fahrenheit, based on a study by the U.S. Army in the North Pacific Region of the United States (U.S. Army, 1956). Using 39 degrees Fahrenheit for PAT appeared to cause the model to simulate an unusual amount of rainfall. Comparison of the minimum and maximum temperatures revealed a broad range between the two temperatures. Snowfall in the Lake Tahoe area can occur during the night, even though daily maximum temperatures are relatively warm. Through trial and error, a value of 70 degrees Fahrenheit was chosen to allow the model to simulate actual snowfall. PAT is an adjustment parameter, actual snowfall is dependent primarily on minimum daily temperatures.

Card 21. The value input on this card is an adjustment for the proportion of rain in a rain-snow event for months 1-12 (AJMX(I)). AJMX(I) is a coefficient that is used to calculate the total precipitation occurring as rain. A value of 1.0 was used and was obtained from Leavesley and others (1983). A value of 1.0 was assigned to AJMX(I) which results in no effect on the amount of total precipitation occurring as rain. AJMX(I) has no measurable basis, and is primarily used as a coefficient to modify the calculated amount of precipitation occurring as rain. Because AJMX(I) is not used, precipitation will be either rain or snow, not a combination.

Card 22. The daily maximum air temperature input into PRMS is corrected for elevation by the variable TLX. Twelve values of TLX were determined, one for each month of the year. The values were determined by comparing the maximum daily temperatures for each month at the Ward bench station with the maximum daily 
temperatures from the National Weather Service station located at Tahoe City,

California. The elevation difference between the stations is approximately 1,000 feet.

The calculated lapse rates are in units of degrees Fahrenheit per 1,000 feet of elevation change. The calculated lapse rates for months 1-12 are as follows:

$\begin{array}{llr}\operatorname{TLX}(1) & = & -5.4 \\ \operatorname{TLX}(2) & = & -6.3 \\ \operatorname{TLX}(3) & = & -8.1 \\ \operatorname{TLX}(4) & = & -11.2 \\ \operatorname{TLX}(5) & = & -7.7 \\ \operatorname{TLX}(6) & = & 4.3 \\ \operatorname{TLX}(7) & = & 2.9 \\ \operatorname{TLX}(8) & = & 3.5 \\ \operatorname{TLX}(9) & = & 2.1 \\ \operatorname{TLX}(10) & = & 3.7 \\ \operatorname{TLX}(11) & = & 4.8 \\ \operatorname{TLX}(12) & = & 4.9\end{array}$

Card 23. The daily minimum air temperature is also corrected for elevation changes. The variable TLN represents the minimum daily temperature lapse rate for the months 1-12. The same procedure was used to determine TLN as was used to determine TLX on card 22. The values calculated for the 12 months are as followed:

$\begin{array}{llr}\operatorname{TLN}(1) & = & 5.3 \\ \operatorname{TLN}(2) & = & 4.0 \\ \operatorname{TLN}(3) & = & 5.2 \\ \operatorname{TLN}(4) & = & 3.8 \\ \operatorname{TLN}(5) & = & 1.9 \\ \operatorname{TLN}(6) & = & 1.2 \\ \operatorname{TLN}(7) & = & -0.2 \\ \operatorname{TLN}(8) & = & -0.1 \\ \operatorname{TLN}(9) & = & -0.8 \\ \operatorname{TLN}(10) & = & 1.1 \\ \operatorname{TLN}(11) & = & 2.2 \\ \operatorname{TLN}(12) & = & 4.6\end{array}$

Card 24. The evaporation pan coefficient (EVC) is used to calculate the evaporation from precipitation that is intercepted by the plant canopy. The use of this 
parameter is determined by the setting of the switch IPET on card 2. IPET has three potential settings: (0), calculates potential evapotranspiration from temperature and solar radiation data; (1), calculates potential evapotranspiration from temperature data only; and (2), calculates potential evapotranspiration from evaporation pan data only. The values for EVC are used in the evapotranspiration calculations when IPET is set to 2. Since the evapotranspiration calculations are based solely on temperature data and IPET was set to 1 , the values input on this card are not used by PRMS.

Card 25. The 8 parameters input on this card are used to determine snowpack accumulation and snowpack melting. The first parameter is the Julian calendar date at which the model begins to look for spring snowmelt (ISP1). The value chosen for ISP1 was 120 , which correlates to the first day of May. The second parameter is the Julian date at which the model forces the snowpack into the spring melt stage (ISP2). The Julian date chosen for this was also 120. These dates were based on information provided by Leavesley and others (1983). The emissivity of dry air (EAIR) over snowfields on days without precipitation has been estimated by the U.S. Army (1956) to be $75.7 \%(0.757)$. The value chosen for the free water holding capacity of snow (FWCAP) was $4.0 \%(0.04)$ and was based on the study by the U.S. Army (1956). The density of new fallen snow (DENI) is frequently estimated to be 0.1 grams per cubic centimeters $\left(\mathrm{gm} / \mathrm{cm}^{3}\right)$ (U.S. Army, 1956). This value is dependent on temperature and wind at the time of precipitation. Snowpack density measurements from the Central Sierra Snow Laboratory (U.S. Army, 1959) were reviewed, and an average value of $0.25 \mathrm{gm} / \mathrm{cm}^{3}$ was chosen for DENI. A value of $0.40 \mathrm{gm} / \mathrm{cm}^{3}$ was used for the average maximum snowpack density (DENMX) (U.S. Army, 1959). The snowpack settlement constant (SETCON) was obtained from Leavesley and others (1983) and was set to a 
value of 0.1 . The occurrence of rain or snow depends on the maximum and minimum temperatures and the base temperature (BST). BST is the temperature above which precipitation is all rain and below which is all snow. A value of 32 degrees Fahrenheit was chosen for BST.

Card 26. The parameter input on this card is the convection-condensation energy coefficient (CECN) in units of calories per degrees Celsius above zero (call ${ }^{\circ} \mathrm{C}$ above zero) for months 1-12. CECN is used in the equation:

$$
\text { CEN }=\text { CECN }(I) * \text { TAVC }
$$

where

CEN is the estimate of latent and sensible heat, and TAVC is the mean air temperature for a specific 12-hour period.

The values chosen for CECN were obtained from Leavesley and others (1983) and were as follows:

$\begin{array}{ll}\text { CECN (1) } & =5 \\ \text { CECN (2) } & =5 \\ \text { CECN (3) } & =6 \\ \text { CECN (4) } & =5 \\ \text { CECN (5) } & =6 \\ \text { CECN (6) } & =6 \\ \text { CECN (7) } & =6 \\ \text { CECN (8) } & =6 \\ \text { CECN (9) } & =6 \\ \text { CECN (10) } & =6 \\ \text { CECN (11) } & =5 \\ \text { CECN (12) } & =5\end{array}$

Card 27. Parameters on this card were not used by PRMS therefore the card is blank. 
Card 28. The amount of storage in inches in each subsurface reservoir (RES) is input through this card. Only one subsurface reservoir was utilized, so only one value is input on this card. Because of the lack of subsurface information in the basin, the final value assigned to RES was determined by model calibration. RES was modified during each run of the PRMS to help fit the calculated runoff hydrograph with the observed basin discharge hydrograph. A final value of 0.5 inches was chosen for RES.

Card 29. The amount of storage in inches in each groundwater reservoir (GW) is input through this card. Because of the lack of groundwater information in the basin, the final value assigned to GW was also determined by trial and error. GW was modified during specific runs of the PRMS to help fit the calculated runoff hydrograph with the observed basin discharge hydrograph. The final value chosen for GW was 0.5 inches.

Card 30. The index of the groundwater reservoir receiving recharge from the subsurface reservoir (KRSP) is specified by this card. Because only one groundwater reservoir and only one subsurface reservoir are utilized, the index number is 1 .

Card 31. The two variables (RESMX, REXP) input on this card are associated with the transfer of water from the subsurface reservoir to the groundwater reservoir. The movement of water from the subsurface reservoir to the groundwater reservoir is represented by the term GAD. GAD is calculated by the equation:

$$
\text { GAD }=\text { RSEP * }(\text { RES/RESMX })^{\text {REXP }}
$$

where

RSEP is a daily recharge coefficient, RES is the current storage in the subsurface reservoir (in), RESMX is a coefficient, and REXP is a coefficient. 
Of the 4 variables used to compute the seepage from the subsurface reservoir to the groundwater reservoir, 3 are user-defined coefficients which have no mathematical basis. Only RES, which is input on card 28 , is based on basin characteristics. RESMX and REXP are user defined coefficients which change the amount of movement of water from the two reservoirs. The setting of each of these parameters was determined by trial and error after many runs of the model. Setting the variables to 1 makes the routing of the water a linear function of the current storage in the subsurface reservoir (RES). The final settings of RESMX and REXP were chosen to be 0.8 and 0.01 , respectively.

Card 32. This card is used to input RSEP, which is one of the coefficients used to determine the movement of water from the subsurface reservoir to the groundwater reservoir. An explanation of the equation is defined under card no. 31. The setting that was chosen for this parameter was 0.04 , and was chosen by trial and error following numerous runs of the model.

Card 33. A groundwater sink can be established by the user to trap groundwater that does not flow into the stream. The water that enters the groundwater sink can not be used in the overall water budget. In theory the water is lost from the basin, and in this case the water actually goes directly to Lake Tahoe through subsurface channels. The amount of water accreted to the groundwater sink (SNK) is computed by the equation :

$$
\text { SNK }=\text { GSNK * GW }
$$

where 
The parameter that is input through this card, is the seepage constant (GSNK). This constant is user defined and is determined by trial and error. The user determines the amount of water available as groundwater, and how much water can be lost to the groundwater sink. The number determined for GSNK was 0.002 .

Card 34. The amount of groundwater that is discharged to the stream (BAS) is dependent on the amount of water in the groundwater reservoir (GW) and the groundwater routing coefficient (RCB). BAS is computed using the equation:

$$
B A S=R C B * G W
$$

where

BAS is the baseflow in acre-inches, $R C B$ is the groundwater routing coefficient, and GW is the water storage in inches in the groundwater reservoir.

$\mathrm{RCB}$ is determined by a comparison of the simulated hydrograph and the observed hydrograph. The parameter is changed to make the two hydrographs appear similar. The value determined for RCB was 0.05 .

Card 35 The parameters established on this card are the routing coefficients (RCF, RCP) used to determine the rate of outflow from the subsurface reservoir (RAS) to the stream. The rate of outflow from the subsurface reservoir is computed by the following equation:

$$
R A S=(R C F * R E S)+\left(R C P * R^{*} S^{2}\right)
$$

where

RES is the storage volume in the subsurface reservoir (in), RCF and RCP are routing coefficients.

The values chosen for these parameters were determined after many runs of the program. The simulated hydrograph was compared to the observed hydrograph and the 
coefficients were changed to adjust the simulated hydrograph. The values determined for RCF and RCP were 0.007 and 0.06 , respectively.

Card 36. This card is used to input the parameters for each specific HRU. The number of cards used is equal to the number of HRU's established. Each card contains 17 parameters. Each parameter will be discussed, and the calculated or chosen value will be listed. The first parameter on this card is the HRU identification number (IRU). Since seven HRU's were established, the identification numbers are 1 through 7.

The solar radiation plane index number (IRD) is input on this card and corresponds to the solar radiation planes defined on card no. 14. Six solar radiation planes were established which correlate to the seven HRUs. The input variables for IRD for each HRU are as follows:

$\operatorname{IRD}(1)=2$
$\operatorname{IRD}(2)=3$
$\operatorname{IRD}(3)=5$
$\operatorname{IRD}(4)=5$
$\operatorname{IRD}(5)=5$
$\operatorname{IRD}(6)=5$
$\operatorname{IRD}(7)=5$

The slope of each HRU is input through the variable SLP. The values for the slope in degrees relative to horizontal of each HRU were calculated by the line-intersection method of Wentworth (1930) and are as follows:

$\begin{array}{lll}\text { SLP(1) } & = & 0.42 \\ \text { SLP(2) } & = & 0.38 \\ \text { SLP(3) } & = & 0.36 \\ \text { SLP(4) } & = & 0.34 \\ \text { SLP(5) } & = & 0.40 \\ \text { SLP(6) } & =0.40 \\ \text { SLP(7) } & =0.11\end{array}$

The mean elevation (ELV) in feet above mean sea level was determined from 1:24,000 scale topographic maps for each HRU. Mean elevation was calculated as the 
difference between the highest and lowest altitudes within each HRU. ELV parameters for each HRU are listed below:

$\begin{array}{ll}\operatorname{ELV}(1) & =7441 \\ \operatorname{ELV}(2) & =7466 \\ \operatorname{ELV}(3) & =7437 \\ \operatorname{ELV}(4) & =7569 \\ \operatorname{ELV}(5) & =7673 \\ \operatorname{ELV}(6) & =7036 \\ \operatorname{ELV}(7) & =6376\end{array}$

The type of vegetation found in each HRU is specified by the parameter ICOV. This parameter is a switch with four settings; 0 =bare ground, 1=grass, 2=shrubs, and $3=$ trees. Field observations in conjunction with the dot grid method revealed that trees are the most abundant type of vegetation in the basin; however, a substantial amount (approximately 15 to 40 percent) of bare ground is located in each HRU. Because the majority of the vegetation in the basin is trees, the decision was made to set ICOV in each HRU to 3.

Another parameter related to the amount of vegetation, is the summer vegetation density (COVDNS). This number is expressed in decimal form and was calculated using a dot grid method. The method involved placing a transparent grid containing 0.25 inchspaced dots over the 1:80,000 scale aerial photograph and counting the number of dots that fall in the area of interest. The estimated values for COVDNS in percent are as follows:

$\begin{array}{lll}\text { COVDNS(1) } & = & 0.60 \\ \text { COVDNS(2) } & = & 0.70 \\ \text { COVDNS(3) } & = & 0.50 \\ \text { COVDNS(4) } & = & 0.60 \\ \text { COVDNS(5) } & = & 0.75 \\ \text { COVDNS(6) } & = & 0.75 \\ \text { COVDNS(7) } & = & 0.75\end{array}$

The PRMS differentiates between summer and winter vegetation. Winter vegetation cover density is input by the parameter COVDNW. This value was calculated 
using the information obtained in determining COVDNS. Since the majority of the vegetation in the basin is coniferous, the difference between winter and summer vegetation was considered to be minimal. The values of COVDNW were calculated by reducing the COVDNS values by approximately 10 percent. This reduction was estimated by observations in the basin. It was observed in several areas of the basin that approximately 10 percent of the vegetation would die out or be covered with snow in the winter months. Winter vegetation data were not available to support this assumption. The input values for COVDNW in percent are as followed:

\begin{tabular}{|c|c|}
\hline $\begin{array}{l}\text { COVDNW(1) } \\
\text { COVDNW(2) } \\
\text { COVDNW(3) } \\
\text { COVDNW(4) } \\
\text { COVDNW(5) } \\
\text { COVDNW(6) } \\
\text { COVDNW(7) }\end{array}$ & \\
\hline
\end{tabular}

The percent of short wave radiation that goes through the winter vegetation canopy (TRNCF) is input for each HRU. The values were obtained from figure 24 in the PRMS manual (Leavesley and others, 1983). The chart plots a functional relationship between winter forest cover density (COVDNW) and the transmission coefficient (TRNCF) of the forest canopy. To determine TRNCF, the values of COVDNW are plotted on the graph, and where these points intersect the previously established line represents the TRNCF coefficient for that particular HRU. The TRNCF values obtained for each HRU in percent are as follows:

$\begin{array}{lll}\operatorname{TRNCF}(1) & = & 0.26 \\ \operatorname{TRNCF}(2) & = & 0.19 \\ \operatorname{TRNCF}(3) & = & 0.34 \\ \operatorname{TRNCF}(4) & = & 0.22 \\ \operatorname{TRNCF}(5) & = & 0.19 \\ \operatorname{TRNCF}(6) & = & 0.19 \\ \operatorname{TRNCF}(7) & = & 0.19\end{array}$


The amount of snow, in inches, which the vegetation intercepts is input by the parameter SNST. This parameter is extremely variable and depends on temperature, wind speed, and density of the snow. The value chosen was 0.1 and was obtained from Leavesley and others (1983). Because of the lack of data in this area, the value was the same for all seven of the HRU's. The interception storage capacity of summer rain by the vegetation (RNSTS) was set to 0.1 and was obtained from Leavesley and others (1983). The interception storage capacity of winter rain by the vegetation (RNSTW) was set to 0.05 and was also obtained from Leavesley and others (1983).

The process of transpiration is dependent upon the surrounding environment. Transpiration is at a maximum during the warm summer months and at a minimum during the winter months. Taking this into consideration, the model allows the user to specify the month to start looking for transpiration (ITST), and the month for which transpiration ends (ITND). The values chosen for these parameters were obtained from Leavesley and others (1983). The value chosen for ITST was 4 which corresponds to the month of April, and the value chosen for ITND was 11 which corresponds to the month of November. These values are the same for each HRU.

Another parameter which deals with transpiration is the starting value for transpiration switch (ITSW). This switch is either set to 0 which specifies that the vegetation is dormant, or it is set to 1 which specifies that the vegetation is transpiring. For the purposes of this study, ITSW was set to 1 for all of the HRU's.

The air temperature for each HRU is corrected for aspect by the parameters TXAJ and TNAJ. TXAJ is the adjustment parameter for maximum air temperatures, and TNAJ is the adjustment parameter for minimum air temperatures. The daily temperatures were increased for southerly exposures and decreased for northerly exposures. The maximum increase and decrease in temperature was 1.4 degrees Fahrenheit for 
southerly exposures and -1.4 degrees Fahrenheit for northerly exposures. These corrections are based on the assumption that the climate station is on a horizontal surface. The TXAJ values for each HRU are as follows:

$\begin{array}{lll}\operatorname{TXAJ}(1) & = & 1.05 \\ \operatorname{TXAJ}(2) & = & -1.4 \\ \operatorname{TXAJ}(3) & = & 0.7 \\ \operatorname{TXAJ}(4) & = & -1.05 \\ \operatorname{TXAJ}(5) & = & -1.05 \\ \operatorname{TXAJ}(6) & = & -1.05 \\ \operatorname{TXAJ}(7) & = & 0.0\end{array}$

The TNAJ values for each HRU are as follows:

$\begin{array}{lll}\operatorname{TNAJ}(1) & = & 1.05 \\ \operatorname{TNAJ}(2) & = & -1.4 \\ \operatorname{TNAJ}(3) & = & 0.7 \\ \operatorname{TNAJ}(4) & = & -1.05 \\ \operatorname{TNAJ}(5) & = & -1.05 \\ \operatorname{TNAJ}(6) & = & -1.05 \\ \operatorname{TNAJ}(7) & = & 0.0\end{array}$

Card 37. This card is used to input additional parameters for each specific HRU. The number of cards used is equal to the number of HRU's established, which is seven. Each card contains 16 parameters. Like card 36, the first parameter on this card is the HRU identification number (IRU). Since $7 \mathrm{HRU}$ 's were established, the identification numbers are 1 through 7 .

The type of soil encountered in each HRU is specified by the parameter ISOIL. The model is fairly limited as to the possible types of soil that can be specified. The user has three choices of soil type: $1=$ sand, $2=l o a m$, and $3=$ clay. Seventeen inapable soil types were defined by Rogers (1974) for the Blackwood Creek drainage basin. Map 4 is a pictorial representation of the different soil types encountered in the basin that complicate the soil classifications for each HRU. The soil located in the central section of the basin near Blackwood Creek is classified as a sandy loam (plate 3). However, the 
majority of the north- and south-facing slopes of the basin are composed of rocky colluvium and rock outcrops, and do not fit into any of the three soil categories. Since ISOIL has little effect on the overall output generated by the PRMS, the decision was made to classify the soil in all HRUs as a loam and set ISOIL to 2. The soil zone is defined by the PRMS as the average rooting depth of the dominant vegetation in each specific soil type. The rooting depth for each soil type was obtained from Rogers (1974) and an average rooting depth was calculated for each HRU. The soil profile is divided into two sections: the recharge zone, which is the upper section; and the lower zone. The maximum available water holding capacity of the soil profile (SMAX) is determined by computing an area weighted average for each soil type within each HRU, and then multiplying this average by the average rooting depth. The calculated values for SMAX in inches are:

$\begin{array}{lll}\text { SMAX(1) } & =1.89 \\ \text { SMAX(2) } & = & 1.91 \\ \text { SMAX(3) } & = & 1.78 \\ \text { SMAX(4) } & =1.96 \\ \text { SMAX(5) } & =2.05 \\ \text { SMAX(6) } & =2.09 \\ \text { SAAX(7) } & =3.48\end{array}$

The current available water holding capacity (SMAV) in the soil profile was assumed to be zero, because of the lack of information available and because the infiltration rate observed during the infiltration study was so high that very little water is stored in the soil profile. The infiltration study was conducted during the summer months when the soil was predominantly void of moisture. Assuming that the available water holding capacity is zero for the entire year, may produce some error, and this value may increase when the soil moisture rises.

The maximum available water-holding capacity of the recharge zone (REMX) is calculated using the same procedure as SMAX, except that a soil depth of 12 inches is 
used instead of the rooting depth (Cary, 1984). A comparison of SMAV with REMX reveals that the soil profile has no current water-holding capacity, probably a result of the sandy texture, which allows the water to move through the soil without being held. When soil moisture increases, and the movement of water slows through the soil profile, the maximum holding capacities of the soil zones should be encountered. The calculated values for REMX in inches of water are as follows:

$\begin{array}{lll}\operatorname{REMX}(1) & = & 0.98 \\ \operatorname{REMX}(2) & = & 0.87 \\ \operatorname{REMX}(3) & = & 1.01 \\ \operatorname{REMX}(4) & = & 0.88 \\ \operatorname{REMX}(5) & = & 0.86 \\ \operatorname{REMX}(6) & = & 0.84 \\ \operatorname{REMX}(7) & = & 0.80\end{array}$

The current available water holding capacity of the recharge zone (RECHR) was calculated from the values specified as REMX. The current water holding capacity in the upper 12 inches of the soil profile is heavily dependent on the amount of soil moisture in the soil zone at the time of the measurement. From the infiltrometer data collected, it became apparent that the holding capacity was heavily dependent on soil moisture. RECHR is similar to SMAV, in that both parameters are time specific and are ever changing. Unlike SMAV, RECHR was not set to zero, but was calculated from the values computed for REMX. Because the upper 12 inches of the soil appeared so dry during field activities, the assumption was made that the current available water holding capacity was 90 percent of the maximum available water holding capacity. This assumption implies that the soil at the time of the observations contained 10 percent of the available water holding capacity. The values designated for RECHR are as follows:

$\begin{array}{lll}\operatorname{RECHR}(1) & = & 0.88 \\ \operatorname{RECHR}(2) & = & 0.78 \\ \operatorname{RECHR}(3) & = & 0.91 \\ \operatorname{RECHR}(4) & = & 0.80 \\ \operatorname{RECHR}(5) & = & 0.77 \\ \operatorname{RECHR}(6) & =0.76\end{array}$




\section{$\operatorname{RECHR}(7)=0.72$}

The infiltration of snowmelt into the soil, when the soil is at field capacity, is represented by the parameter SRX. The values that were chosen were based on the infiltration rates of the forest floor, which were obtained by the use of a double ring infiltrometer. The model limits the rate of infiltration which the user may specify. The maximum possible infiltration rate is 10 inches per ciay. This value is well below any of the values observed using the infiltrometer. The infiltrometer study was concentrated in the relatively flat lying portion of the basin. No infiltration data were collected on the surrounding mountain slopes. Since the infiltration data collected exceeded the model limits, the HRU located in the flat lying area was assigned an infiltration value of 10 inches per day. It was assumed that the infiltration rates would be reduced on the surrounding slope an unknown amount. A value of 5 inches per day, which was half of the value assigned to HRU7, was chosen for all of the remaining HRUs. The individual parameters with the corresponding values for each HRU are as follows:

$\begin{array}{llr}\operatorname{SRX}(1) & = & 5.0 \\ \operatorname{SRX}(2) & = & 5.0 \\ \operatorname{SRX}(3) & = & 5.0 \\ \operatorname{SRX}(4) & = & 5.0 \\ \operatorname{SRX}(5) & = & 5.0 \\ \operatorname{SRX}(6) & = & 5.0 \\ \operatorname{SRX}(7) & = & 10.0\end{array}$

Surface runoff depends on the rate of precipitation and the storage of the soil zone. If the precipitation rate or the snowmelt rate is greater than the soil storage, surface runoff occurs. The model calculates surface runoff (SRO) by the following equation:

$$
S R O=C A P * P T N
$$

where

CAP is the contributing area of the HRU, and PTN is the daily net precipitation. 
The contributing surface area (CAP) is computed by:

$$
C A P=S C N+[(S C X-S C N) *(R E C H R / R E M X)]
$$

where

$\mathrm{SCN}$ is the minimum possible contributing area (decimal fraction),

SCX is the maximum possible contributing area (decimal fraction),

RECHR is the current available water in the soil recharge zone (in), and

REMX is the maximum storage capacity of the recharge zone (in).

The values chosen for SCN and SCX originated from Leavesley and others (1983). These values were then modified and adjusted during preliminary model runs. The value chosen for SCN was 0.0001 for all of the HRU's. The value chosen for SCX was 0.0002 for all of the HRUs. The above computation for CAP expresses CAP as a linear relationship. If a nonlinear relationship is desired, another equation is used to determine CAP. This equation uses the parameter SC1, which is a coefficient to determine the relationship. Since a linear relationship was used, SC1 was set to zero.

Another parameter which contributes to the amount of surface runoff is the effective impervious area as a proportion of the total HRU (IMPERV). This number is expressed in decimal form and was calculated using a dot grid method. The method involved placing a transparent grid containing 0.25 inch-spaced dots over the 1:80,000 scale aerial photograph and counting the number of dots that fall in the area of interest. The number of counted dots are divided by the total number of dots, and the number is expressed in decimal form. By definition, impervious areas are portions of the HRU which do not allow infiltration, and deliver runoff directly to the stream. Both situations must be met in order for an area to be considered impervious. The difficulty arises in the classification of the impermeable zones. Originally, all rocky areas void of vegetation were point counted, and considered to be impermeable. After investigation of 
the rock types and the limited soil horizons associated with the rocky material, the decision was made that rock type material void of vegetation is not impervious, primarily because infiltration does occur through the rock. The water originating from this material is not transferred directly into the tributary system of the basin.

Roads in the basin are also potential impervious zones; however, the surface area of the roads is very small $(<0.5 \%)$ in comparison to the entire surface area of the basin. Various ages of roads are evident throughout the basin: some can be identified with aerial photographs and 1:24,000 U.S. Geological Survey topographic maps, but most of the older roads exhibit various stages of forest regrowth. Based on these observations, and because little of the water from the identifiable roads is transferred directly into the tributary system, the decision was made to disregard the roads as impervious zones. No impervious zones were clearly identified and therefore, IMPERV was set to zero for each HRU. Because of this assumption the maximum retention storage on impervious areas (RETIP) was not used.

The user specified parameter which determines the amount of water which moves from the soil zone to the groundwater resenoir is SEP. This user specified coefficient, which is unmeasurable and not based on any physical observation is modified to help calibrate the model. SEP is necessary to regulate the transfer of groundwater, and can be used to smooth out the predicted hydrograph so that unnecessary spikes are not encountered. SEP is modified by trial and error by comparing the predicted hydrograph with the observed hydrograph. The final SEP values expressed in inches per day for each HRU areas follows:

$\begin{array}{lll}\operatorname{SEP}(1) & = & 0.05 \\ \operatorname{SEP}(2) & = & 0.05 \\ \operatorname{SEP}(3) & = & 0.05 \\ \operatorname{SEP}(4) & = & 0.05 \\ \operatorname{SEP}(5) & = & 0.05 \\ \operatorname{SEP}(6) & = & 0.05\end{array}$




$$
\operatorname{SEP}(7) \quad=\quad 1.5
$$

The index of the subsurface reservoir which receives the water from the specific HRU is specified by the parameter KRES. Since only one subsurface reservoir was specified, all values for KRES are 1. KGW is the index of the groundwater reservoir which receives water from the subsurface reservoir. It also is set to 1 , because only one groundwater reservoir is used. The final parameter on this card is the index of the surface water detention storage reservoir (KSTOR) which receives water from the individual HRUs. This is set to 0 because no surface reservoirs were used.

Card 38. This is the final card in card group number 1 . There are seven parameters input on this card, one card per HRU. The first parameter is the HRU identification number (IRU). The rain gage index number (KDS) is next, which is set to 1 because only one rain gage was used. The drainage area of each HRU (DARU) in acres is specified next. Drainage areas were calculated using a digital planimeter which produced measurements in acres. The area for each HRU is:

$\begin{array}{llr}\operatorname{DARU}(1) & = & 2498.9 \\ \operatorname{DARU(2)} & = & 289.0 \\ \operatorname{DARU(3)} & = & 507.6 \\ \operatorname{DARU(4)} & = & 1234.1 \\ \operatorname{DARU(5)} & = & 537.7 \\ \operatorname{DARU(6)} & = & 1351.2 \\ \operatorname{DARU}(7) & = & 1178.7\end{array}$

The next three parameters (UPCOR, DRCOR, DSCOR) are correction factors for different types of precipitation. UPCOR is for rain correction for storm precipitation, DRCOR is for rain correction for daily precipitation, and DSCOR is for snow correction for daily precipitation. Because only one rain gage is used, correction factors are not necessary. The values chosen for the three parameters are 1.0 and were obtained from Leavesley and others (1983). 
The final parameter of this card is the temperature index, which determines the specific date to start transpiration (TST). Transpiration is assumed to begin when the sum of the maximum daily air temperatures for the specific month exceeds TST, beginning with the first day of the month specified by ITST on card 36. ITST was specified as 4 on card 36 which correlates to April. A value of 392 degrees Fahrenheit was chosen based on the study of Cary (1984). For April, 1984, the sum of the maximum daily air temperatures exceed 392 degrees Fahrenheit on April 7. This date corresponds reasonably well with the beginning of the typical observed snowmelt.

\section{Card Group Number 5 (CG5)}

Card group number 5 is designed to enable the user to adjust the form of precipitation for a specific day. Precipitation occurring on the Julian dates specified are considered to be all snow, which overrides the algorithm in the subroutine PRECIP which apportions snow on the basis of air temperature. The use of this card depends on the accuracy of the temperature data input into the model. After numerous runs of the model, it became evident that the temperature data were causing the model to make precipitation fall as rain and go into melt stage earlier than it actually did. The problem which arose was that the simulated runoff was increasing during the winter months, whereas the measured runoif was staying relatively constant.

In order to suppress the melt stage and make the precipitation fall as snow at various times of the year, card group number 5 was activated. Through careful analysis of the simulated runoff hydrograph, twenty four days were selected which would cause an override of the temperature data for that specific day. The days selected are referenced by the Julian date for which they represent (Table 1). 
TABLE 1.-- Input for CG5, illustrating calendar dates, Julian dates, and maximum and minimum temperatures.

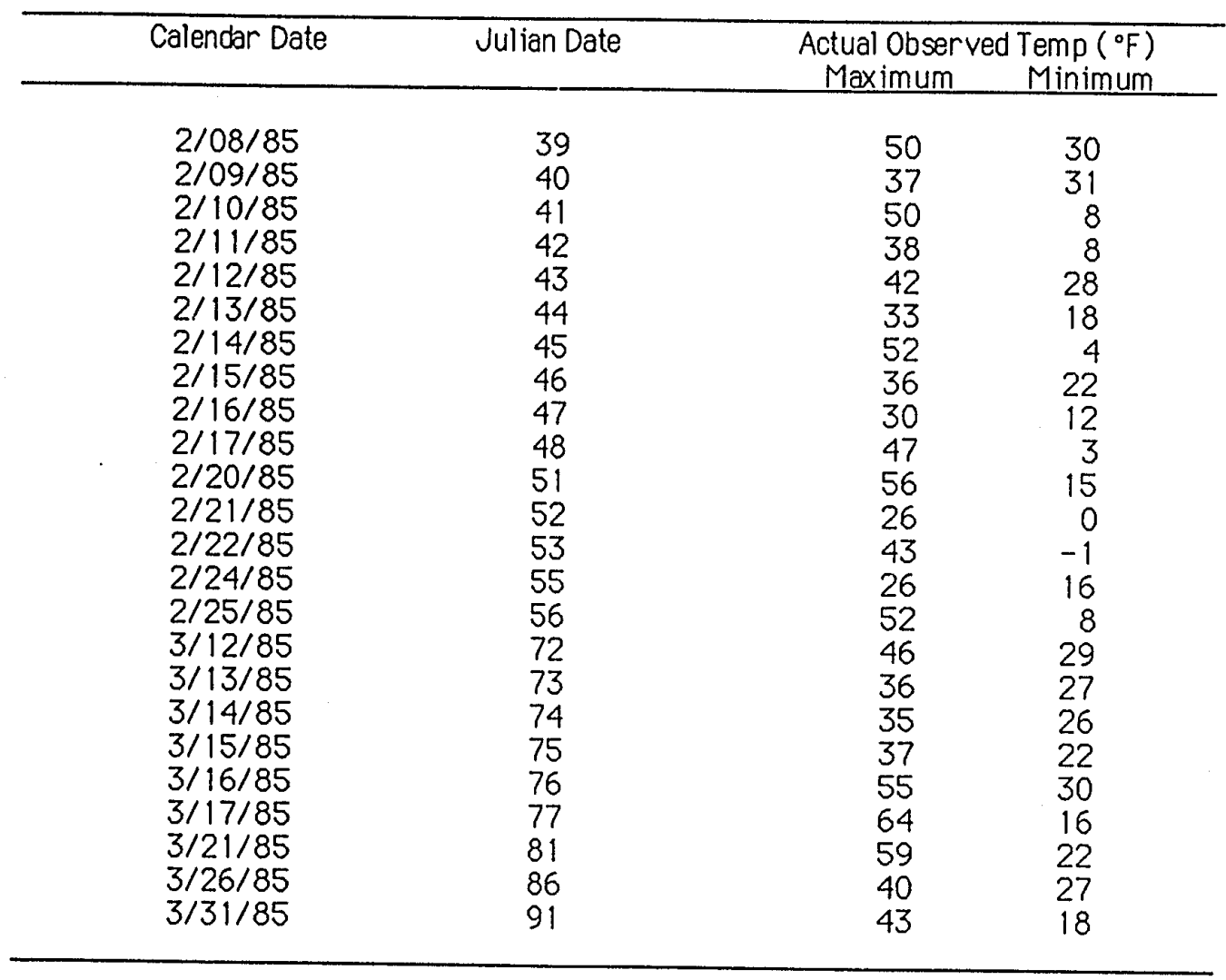




\section{MODEL TEST RUNS}

The daily simulation of the precipitation runoff modeling system was conducted using data from the water year of 1984 , which was an average year of precipitation and was considered represetativeof the basin. Precipitation and temperature data were obtained from the Ward bench monitoring station, and basin discharge measurements were obtained from the U.S. Geological Survey (Fogelman and others, 1985).

Many test runs of the model were conducted to determine which input parameters have the greatest impact on the simulated discharge. The initial parameters were obtained from Leavesley and others (1983), Cary (1984), and K. Michael Nolan. These parameters were input along with calculated basin characteristics for initial model runs. The initial runs of the model indicated that the input parameters were not adjusted properly because the predicted discharge hydrograph was very different from the observed discharge hydrograph. Through careful manipulation of each parameter and many runs of the model, the highly sensitive parameters that influenced the output the most were discovered. Once the sensitive parameters were determined, the parameters could be adjusted slightly to change the predicted output of the model to reflect the observed data.

The above process is a manual optimization analysis. The information obtained from the manual analysis was then used to set up a computer generated optimization and sensitivity analysis. The parameters which are determined to be the most sensitive are selected from the manual analysis and input by another card group. The results of the manual and computer sensitivity analyses are discussed in the next sections. 
Manual Optimization And Sensitivity Analyses

From the initial runs of the model it became evident that only a limited number of parameters or user-defined coefficients caused substantial changes on the predicted output of the model when changed. Initially, the amount of streamflow was believed to depend on surface runoff, subsurface flow, and groundwater flow equally. After execution of the model, and measurement of infiltration rates, it became apparent that very little water was contributed to the streamflow by surface runoff. The surface water parameters initially targeted for changes were:

SCN (minimum possible contributing area) SCX (maximum possible contributing area) RECHR (current available water in the soil recharge zone) REMX (maximum storage capacity of recharge zone)

These parameters are used to control the amount of water that is transferred into the soil and the amount of water that can be held in the soil. They are based on volumes of water, and they regulate how the water is transferred into and out of the soil zone, which determines how much water will be delivered to the stream system by surface flow. The controlling parameter of surface flow was the measured infiltration rate (SRX), and not the user-defined coefficients. Because of the high measured infiltration rates, the user defined coefficients originally targeted for modifications had virtually no effect on the output of the model. By making this observation, the parameters (user defined coefficients) which determine surface runoff were initialized and not changed for the duration of the modeling process.

By assuming that little water is contributed to the stream by surface runoff, the parameters which determine subsurface flow and groundwater flow bocome more important. The transfer of water from the soil zone to the subsurface reservoir and the groundwater reservoir is dependent on the following 3 parameters:

SMAX (maximum available holding capacity of the soil zone) 
SEP (recharge rate to the groundwater reservoir)

RES (storage volume in the subsurface reservoir)

which are all interdependent. The maximum holdirig capacity of the soil zone (SMAX) determines when and how much water will be discharged to the subsurface reservoir or the groundwater reservoir. The amount of water which moves from the soil zone to the two reservoirs is dependent on the amount of water which each reservoir is able to accept. SEP is the seepage rate of water into the groundwater reservoir and RES is the seepage rate of water into the subsurface reservoir. Based on the equations for the transfer of water through the soil zone, it was anticipated that the three parameters are interrelated, and in fact that was observed. A change to any one of the three parameters caused a change in the amount of water contributed to the stream by each reservoir. For this reason, SMAX, SEP, and RES were considered to be highly sensitive parameters. The classification of a sensitive parameter is for the purpose of model analyses that will be discussed in the following section.

Movement of water from the subsurface reservoir depends primarily on the following 5 parameters:

RCF (user defined routing coefficient, unitless)

RCP (user defined routing coefficient, unitless)

RESMX (user defined routing coefficient, unitless)

REXP (user defined routing coefficient, unitless)

RESP (daily recharge coefficient, unitless)

All five coefficients are user defined, and are not based on measured basin characteristics. These user defined coefficients are designed to allow the user the flexibility to modify the equations which calculate the amount of water to be transferred from one area or location to another area or location, without modifying the actual measured data. The five coefficients were initially established and modified following successive runs of the model. 
Water discharged directly into the stream from the subsurface reservoir as subsurface flow (RAS) is calculated by the equation:

$$
R A S=(R C F * R E S)+\left(R C P * R E S^{2}\right),
$$

where RCF and RCP are user defined coefficients and RES is the subsurface reservoir storage volume (in.). During successive runs of the model, values for RCF ranged from 0.005 to 0.10 and values for RCP ranged from 0.02 to 0.5498 . Because one equation determines the amount of water discharged as subsurface flow, RCF and RCP control the amount of flow, and therefore, these two parameters are classified as highly sensitive.

The amount of water which flows from the subsurface reservoir to the groundwater reservoir depends on the user defined coefficients RESMX, REXP, RSEP, RCF and RCP. The movement of water from the subsurface reservoir to the groundwater reservoir is dependent on the amount of water that is held in each reservoir at the time the calculations are completed. For example, water will be transferred to the groundwater reservoir from the subsurface reservoir if and only if there is water in the subsurface reservoir. If the amount of subsurface flow (RAS) is greater than subsurface recharge, no water will move to the groundwater reservoir. If water is available in the subsurface reservoir, the amount of water that can recharge the groundwater reservoir (GAD) is calculated by the equation:

$$
\text { GAD = RSEP * (RES/RESMX) REXP }
$$

where RESMX, REXP, and RSEP are user defined coefficients and RES is the subsurface reservoir storage volume (in). During successive runs of the model, values for RESMX ranged from 0.1 to 0.8 , values for REXP ranged from 0.01 to 1.5 , and values for RESP ranged from 0 to 1.0. Because the amount of water that moves from the subsurface reservoir depends on these two situations, the parameters which determine this movement are considered highly sensitive. 
The flow rate and total quantity of water which flows from the groundwater reservoir depends on the inflow rate and on the parameters which are used to determine the outflow rate. The amount of water delivered to the stream in the form of groundwater flow (BAS) is computed by the equation:

$$
B A S=R C B \text { * } G W \text {, }
$$

where RCB is a user defined routing coefficient, and GW is groundwater storage (in). During successive runs of the model values for $\mathrm{ACB}$ ranged from 0.005 to 0.1 . Because groundwater storage (GW) is a basin dependent parameter it was not changed from the initial input. Because RCB is a user defined coefficient and controls the amount of water transferred to the stream as groundwater flow the parameter RCB is considered highly sensitive.

Water transferred to the groundwater sink (SNK) is computed by the equation: $S N K=G S N K * G W$, where GSNK is a user specified seepage constant and GW is groundwater storage (in.). During successive runs of the model values for GSNK ranged from 0.004 to 0.1 . GSNK allows the user to dispose of extra water in the basin. In the situation of Blackwood Creek, the water budget is very tight (Appendix G), so the majority of the water must be routed into the stream. Because all of the water is needed in the budget, any change in SNK is critical, which indicates that GSNK is a highly sensitive parameter.

The findings discussed in this section were obtained from the numerical and visual comparison of the predicted and observed hydrographs. Parameter changes were made one at a time, and a log of the changes was kept, along with a note specifying how the change affected the output. After the most sensitive parameters were identified, the optimization and sensitivity analysis section of the model was initiated. The next section discusses the findings of these analyses. 
PRMS Optimization And Sensitivity Analyses

The purposes of the PRMS optimization section is to adjust the specified parameters automatically to reduce the subjectivity of the user. The user defines the parameters that are to be optimized and the model conducts the analyses. PRMS also allows the user to automatically conduct a sensitivity analysis on the defined parameters. The sensitivity analysis assesses the magnitude of parameter errors and parameter intercorrelations when an optimization is performed.

The optimization and sensitivity analyses of the PRMS are activated by two parameters on card 1 of card group number 1 and are designated IOPT and ISEN. These parameters are defined as switches, and can be specified as either on (1) or off (0). The model is set up in such a way that only one of the switches can be on at one time. This means that only one of the analyses can be performed at a specific time. To run the optimization and sensitivity analyses, card group number 8 was initialized and set up.

Initially, separate optimization and sensitivity analyses were to be conducted on the parameters identified during the manual operation of the model. This was changed when it was determined that neither the optimization nor sensitivity analyses could be run when card group number 5 was used. Because the use of card group number 5 is necessary to keep the model from creating an early mell stage, separate analyses were not run. For comparison, card group number 5 was disengaged and optimization and sensitivity analyses were conducted.

Upon disengaging card group number 5, card group number 8 was set up to contain information necessary to conduct both optimization and sensitivity analyses. Parameters input on card group number 8 were selected by the information obtained during the manual runs of the model. Six (RCF, RCP, RSEP, RESMX, REXP, RCB) parameters identified during the manual optimization were selected to be analyzed by 
model optimization and sensitivity analyses. The parameters chosen are all user defined coefficients not determined by basin characteristics.

\section{Model Optimization Results}

Model optimization is conducted using the mathematical Rosenbrock optimization technique which adjusts individual parameters in stages. The individual stages are compared with the results of the previous stages, until convergence is reached, which is determined by a comparison of the predicted and observed streamflow. The results of the Rosenbrock optimization analysis are illustrated in Table 2.

Table 2.--Comparison of model optimized versus manually optimized parameters

\begin{tabular}{lllc}
\hline Parameter & $\begin{array}{c}\text { Initial } \\
\text { Value }\end{array}$ & $\begin{array}{c}\text { Optimized } \\
\text { Value }\end{array}$ & $\begin{array}{c}\text { Change } \\
\text { (Percent) }\end{array}$ \\
\hline RCF (Subsurface flow) & 0.007 & 0.0066 & -5.71 \\
RCP (Subsurface flow) & 0.06 & 0.0324 & -46.00 \\
RSEP (Subsurface flow) & 0.04 & 0.0987 & 146.75 \\
RESMX (Subsurface flow) & 0.8 & 0.9613 & 20.16 \\
REXP (Subsurface flow) & 0.01 & 0.0002 & -98.00 \\
RCB (Groundwater flow) & 0.05 & 0.0449 & -10.20 \\
\hline
\end{tabular}

The changes in the five parameters ranged from an increase of $+146.75 \%$ to a decrease of $-98 \%$. It is difficult to determine why the parameters varied to such extremes in both directions, because card group number 5 was disengaged. Without card group number 5 , the basin exhibits an early melt stage which could probably be the reason that the modified parameters exhibit a large change. The following discussion trys to explain the changes observed during the model optimization process. 
The change in the values of RCF and RCP reflect how the two parameters are dependent upon each other when used to calculate subsurface flow (RAS). The model optimized values are within the ranges established during the manual optimization process, which indicates that the manual optimization process was conducted within the correct boundaries. The reduction of both parameters signals that less water is contributed to the stream from subsurface flow, which increases the amount of water transferred to the groundwater reservoir. The exact values obtained for both parameters is somewhat arbitrary, because the lowering of one and the raising of the other can yield the same result.

The same situation arises for RSEP, RESMX, and REXP. These three user defined parameters are used to calculate the amount of water recharging the groundwater reservoir. All are dependent upon each other. The large increase in RSEP is partially the result of the decrease of REXP. The slight increase For RESMX is also probably a result of the decrease of REXP. The three parameters determine the recharge of water to the groundwater reservoir. The model optimized values are fairly close to the ranges of the values investigated using the manual optimization technique. As previously discussed, the model optimization reduced the amount of subsurface flow, which increased the amount of groundwater recharge. This is reflected by the change of these three parameters. The exact numerical value for each parameter is not as important as is the final value of the equation which denotes the amount of water moving to the groundwater reservoir.

RCB was decreased only slightly during the optimization analysis. It was one of the least affected parameters. Decreasing RCB decreases the volume of water released into the stream from the groundwater reservoir. This allows more water to be held in storage to be released during times of the year when less water is available to the basin. 
Overall results of model optimized parameters, compared with the results of the manual optimized parameters indicate that the manually optimized parameters give a better representation of the drainage of the basin. A comparison of the graphs (figs. 6 and 7) generated from the manually optimized parameters and the model optimized parameters reveals that the manually optimized parameters predict a more similar hydrograph than do the model optimized parameters. The model optimized parameters produce more runoff between 120 days and 210 days. This is the period during Spring, when card group number 5 would be used to suppress the amount of early snowmelt. Because card group number 5 cannot be used during model optimization, the increase of runoff during early spring is expected. 


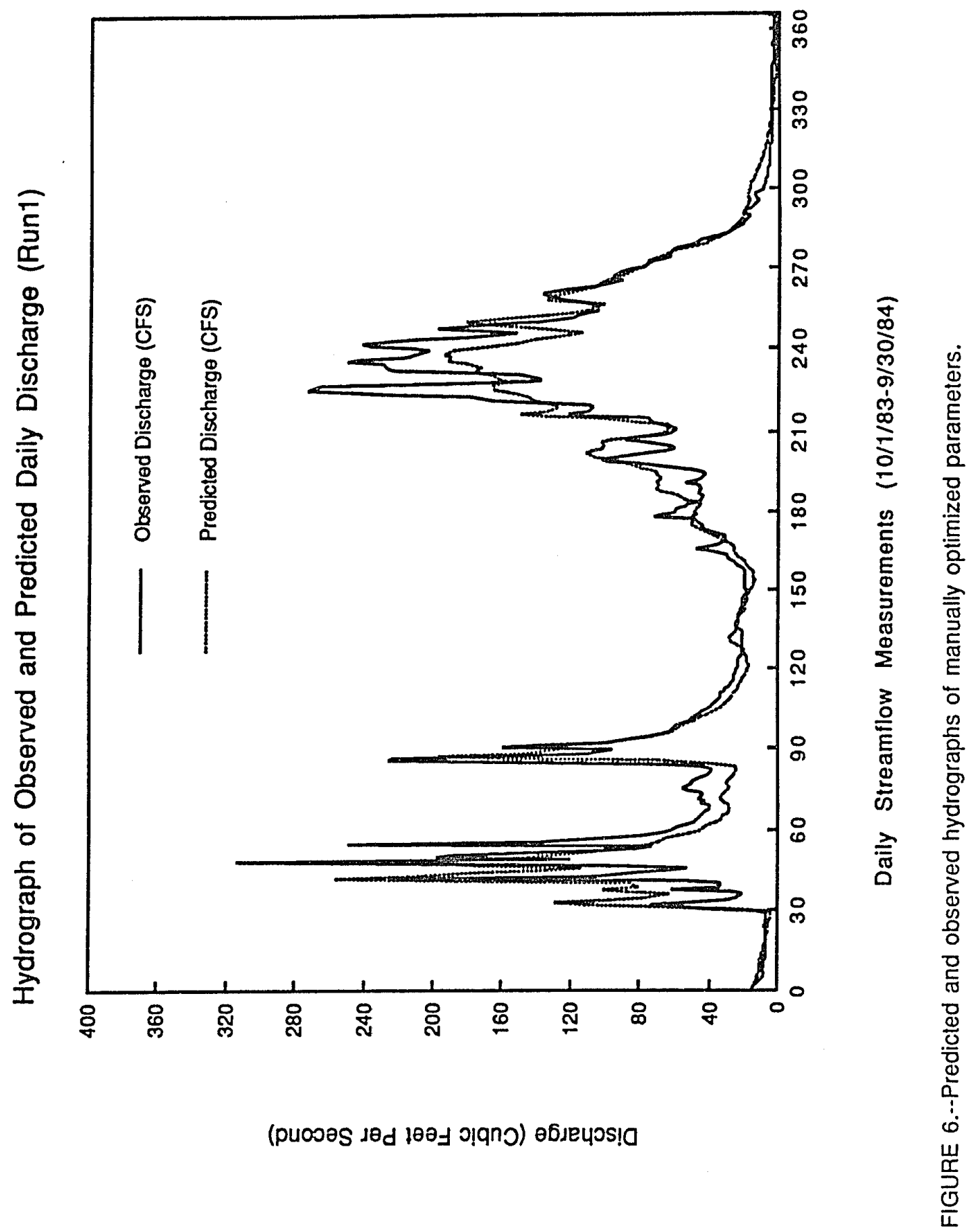







Model Sensitivity Analysis

The results of the model sensitivity analyses for the six optimized parameters are summarized in Table 3.

Table 3.--Magnitude of error for model optimized parameters

\begin{tabular}{lcccc}
\hline Parameter & \multicolumn{4}{c}{ Magnitude of Parameter Error (No Units) } \\
& $5 \%$ & $10 \%$ & $20 \%$ & $50 \%$ \\
\hline RCF & 0.00000 & 0.00000 & 0.00002 & 0.0066 \\
RCP & 0.00007 & 0.00270 & 0.00108 & 0.00675 \\
RSEP & 0.00005 & 0.00022 & 0.00086 & 0.00539 \\
RESMX & 0.00000 & 0.00000 & 0.00000 & 0.00000 \\
REXP & 0.00000 & 0.00000 & 0.00000 & 0.00000 \\
RCB & 0.00125 & 0.00501 & 0.02006 & 0.12535 \\
JOINT & 0.00138 & 0.00550 & 0.02202 & 0.13760
\end{tabular}

The data obtained from the model sensitivity analysis reveal the amount of error which is produced by making the individual parameter changes. For example, if an error of 5 percent is made to the parameter RCP, there would an increase of $0.00007(0.007$ percent) to the total predicted mean squared error for the output. If an error of $10 \%$ was made on RCP, there would be an increase of 0.00027 ( 0.027 percent) to the total predicted mean squared error. Table 3 represents the impact of errors on the error of the predicted output. The larger the magnitude of error, the more sensitive the parameter is to the output of the model.

Sensitivity results (Table 3 ) indicate that RCB, RCP, and RSEP are more sensitive to the output of the model than are RESMX, REXP, and RCF. The parameters which show the larger magnitude of error are the more sensitive parameters. RCB, the 
groundwater routing coefficient, exhibited the greatest magnitude of error, and therefore is the most sensitive parameter analyzed. A 50 percent error in RCB would result in an error of approximately 13 percent in the output of the model. All the other parameters analyzed are less sensitive than $\mathrm{RCB}$. With RCB being the most sensitive parameter analyzed, the assumption can be made that the transfer of water from the groundwater reservoir to the stream is probably the most critical stage of water transfer.

Based on the magnitude error results, RCP and RSEP are the next most sensitive parameters; a 50 percent error in these parameters would result in only a 0.7 percent error in the output of the model. This seems relatively minor compared to the error produced by RCB. RCF, RESMX, and REXP appear to have little impact on the output of the model, according to the the sensitivity analysis. Little or no increase in output error occurs when a 50 percent error is introduced to these parameters. 


\section{MODELRESULTS}

The results of the modeling process of the Blackwood Creek drainage basin are best depicted visually by stream hydrographs which represent the model predicted stream discharge versus the observed (measured) stream discharge. Five stream hydrographs were prepared to represent the results of the modeling process. The first computer run (Run1) represents the results of the manually optimized parameters with card group number 5 (fig. 8). The second computer run (RUN2) again uses the manually optimized parameters without the use of card group number 5 (fig. 9). The third computer run (RUN3) was begun with the manually optimized parameters, but incorporates the models optimization and sensitivity analyses to obtain new optimized parameters (fig. 10). Card group number 5 was not used for the analysis of RUN3. Following the optimization phase of PRMS, a computer run (RUN4) was conducted using card group number 5 and the newly generated optimized parameters from RUN3 (fig. 11). The fifth and final computer run (RUN5) used the model optimized parameters without card group number 5 (fig. 12). Input data for all computer runs are in included in Appendices B - F, and output data for all computer runs are included in Appendices $G$ $-K$.

The results generated from RUN1 are a good prediction of the actual observed data. Numerically, the predicted runoff (62.77 inches) was slightly lower than the observed (64.99 inches), but the comparison of the hydrographs of the predicted and observed runoff are fairly similar. The maximum and minimum values are not exact, but the overall trend of the predicted runoff versus the observed is quite similar.

Following the finalization of the input parameters, a review of the output was conducted. The output for RUN1 (Appendix G) indicated that the majority of the 


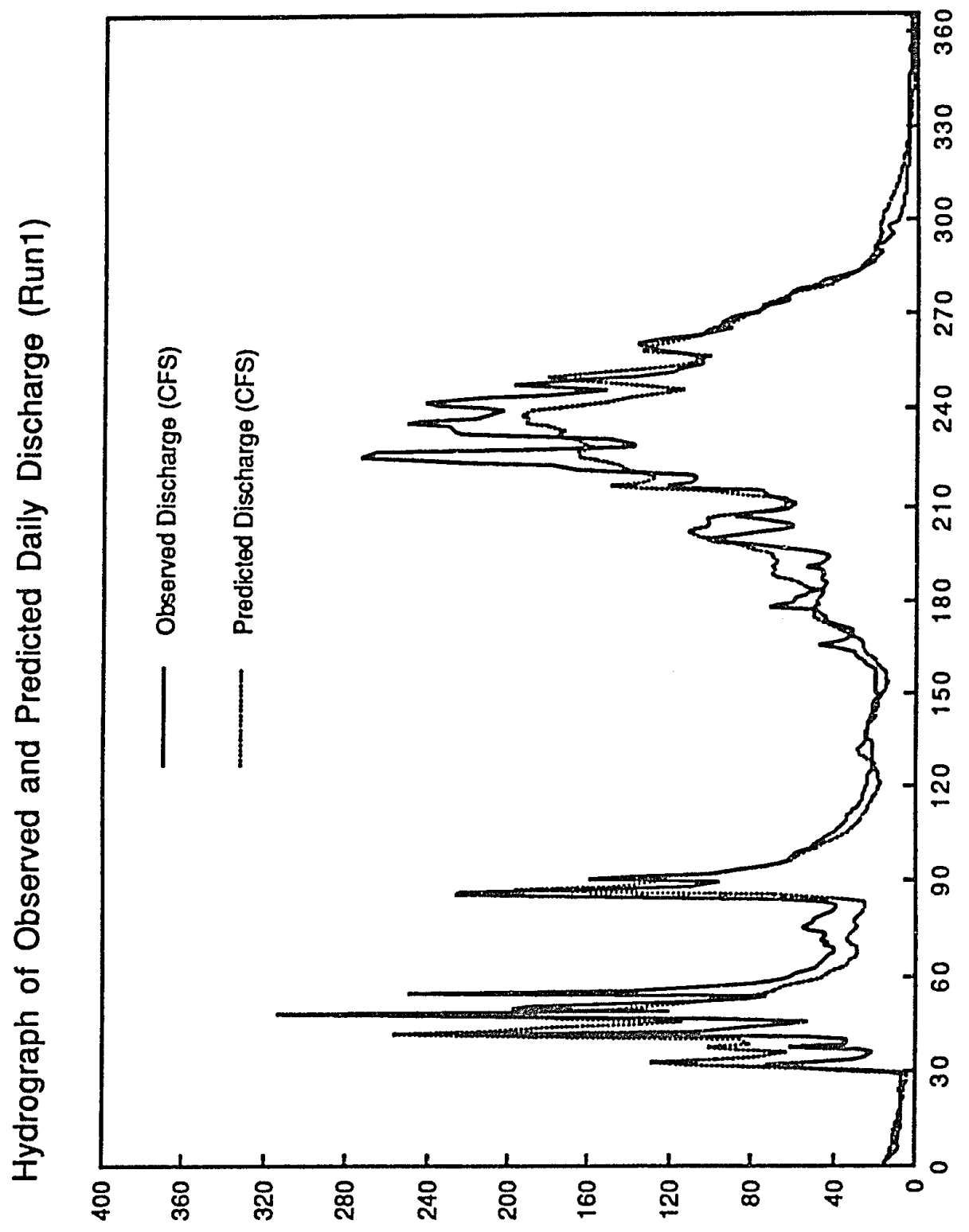

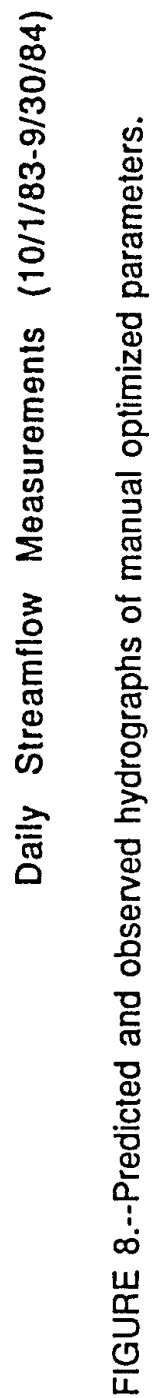




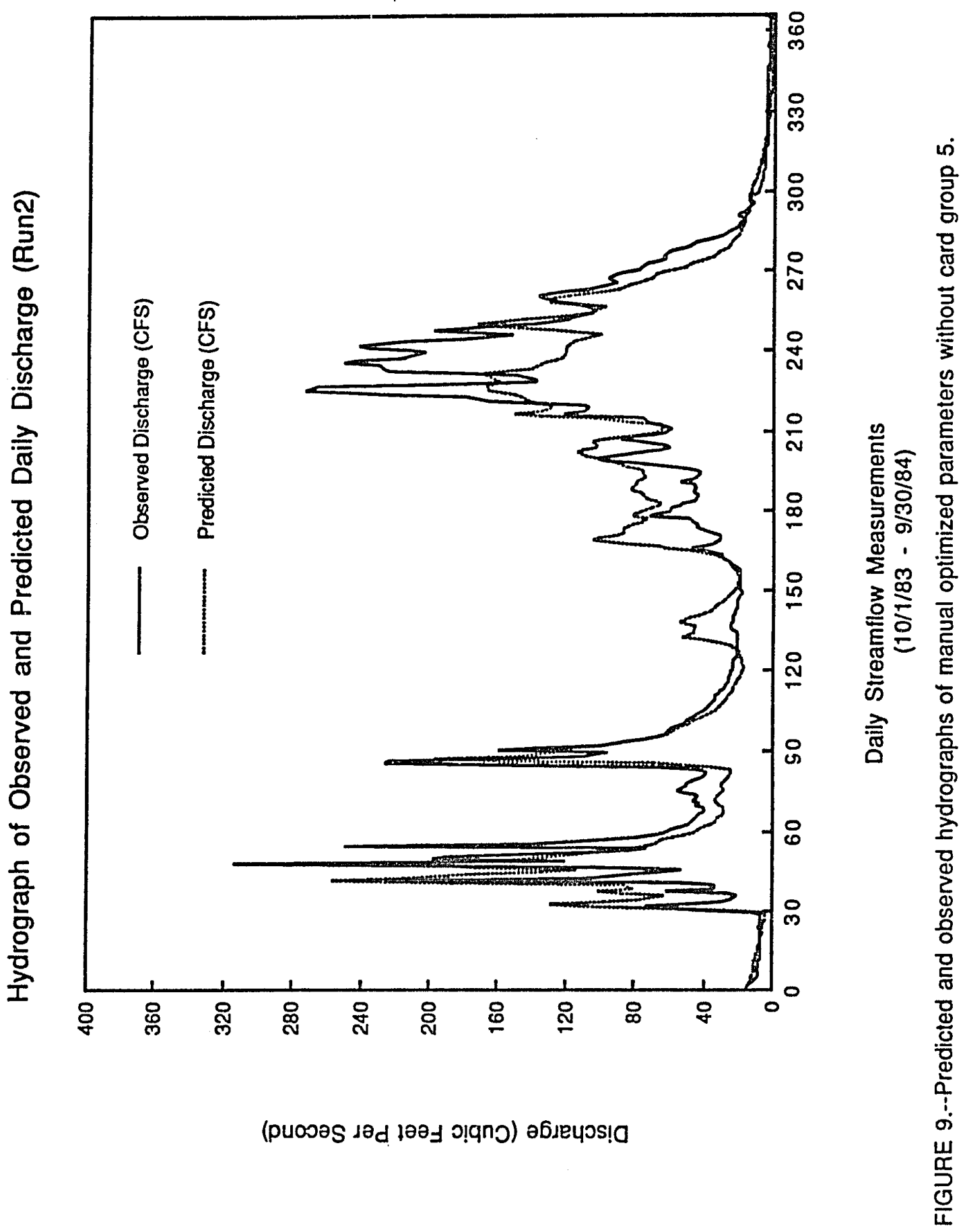




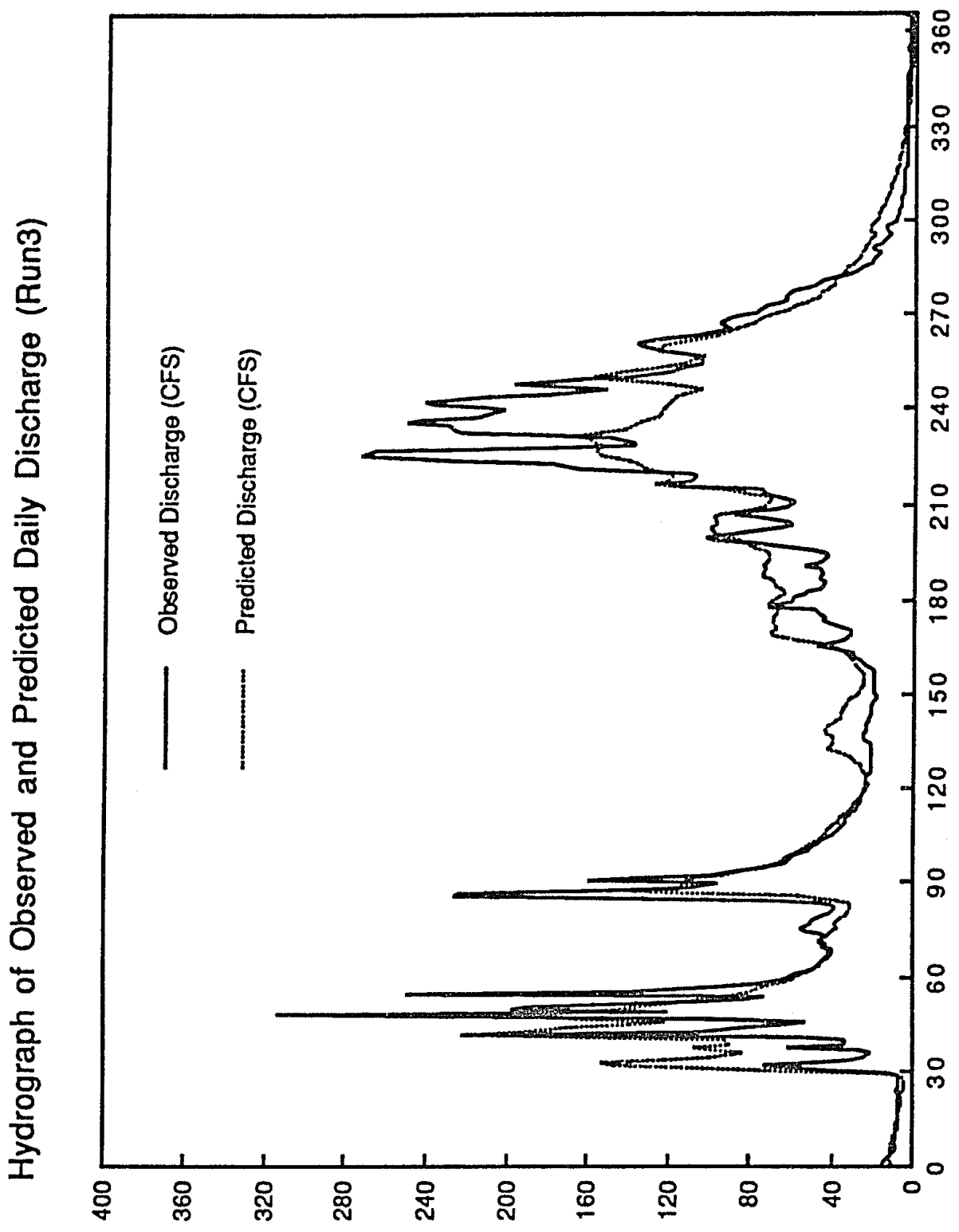

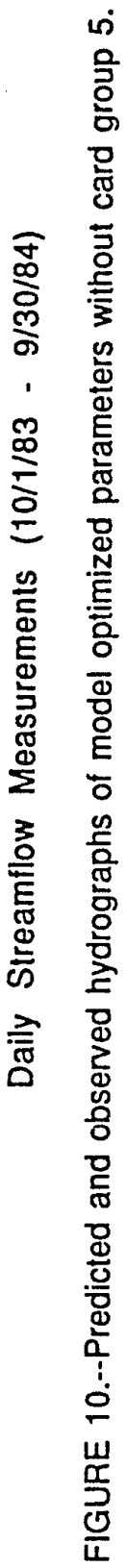




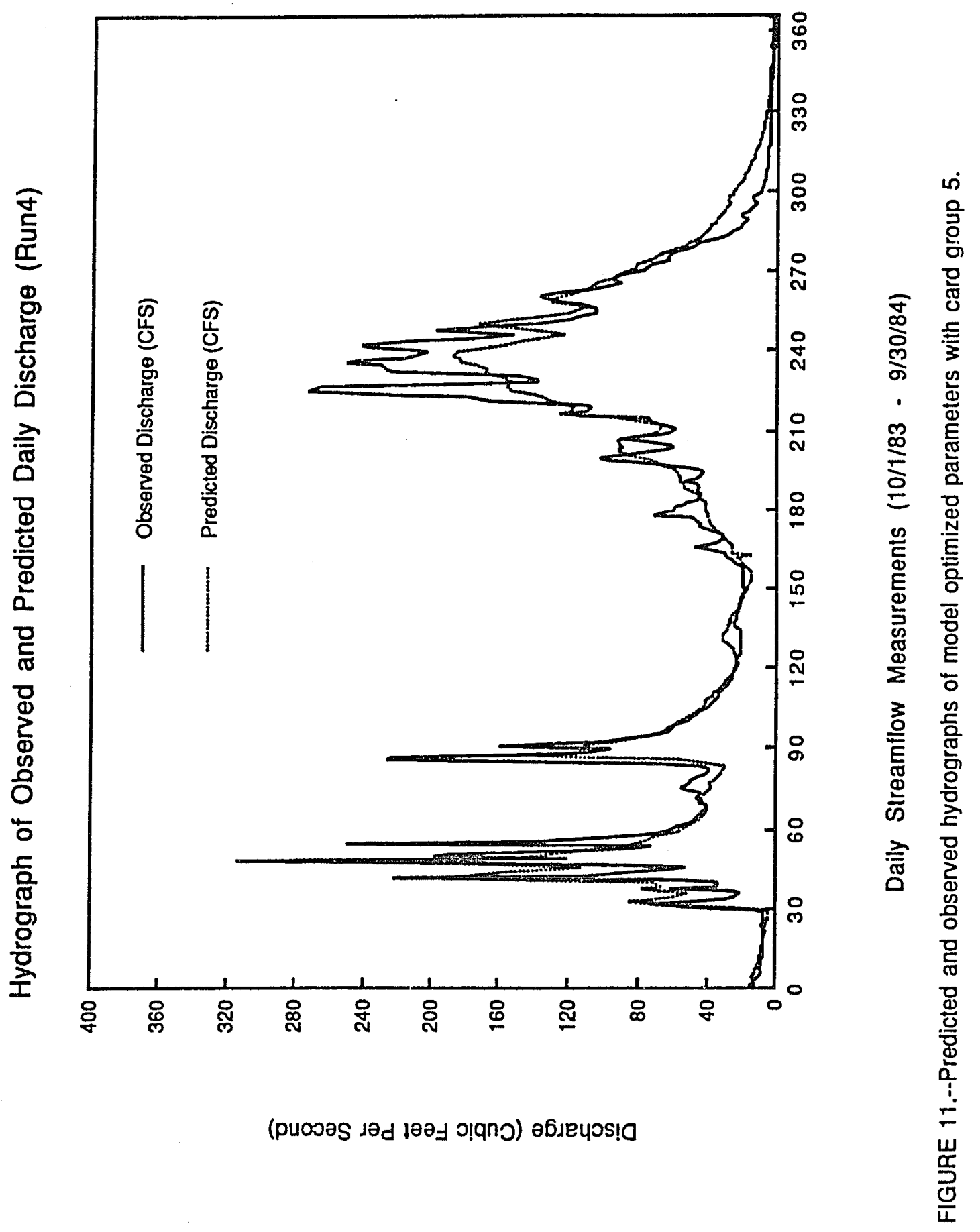




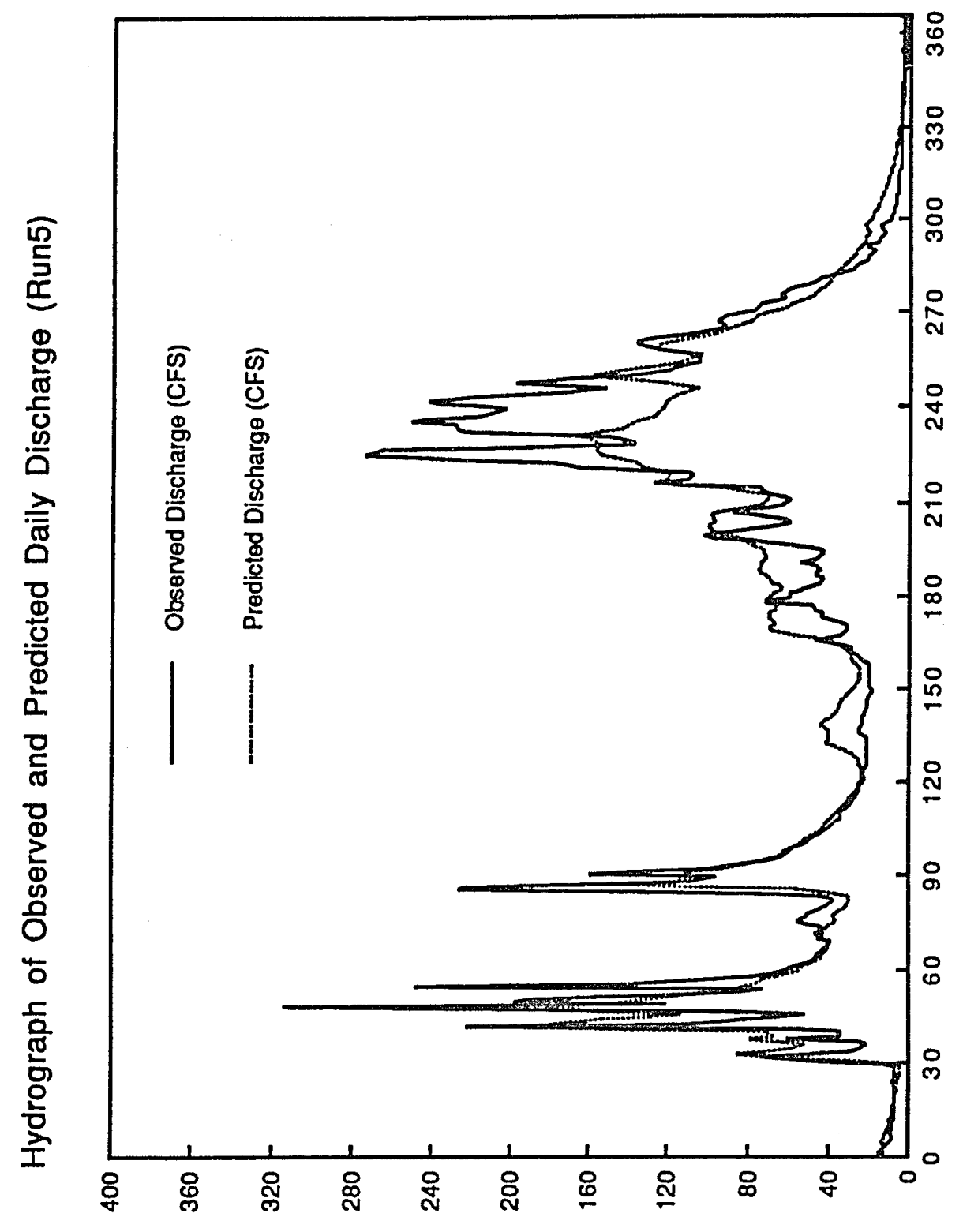

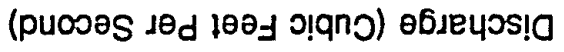

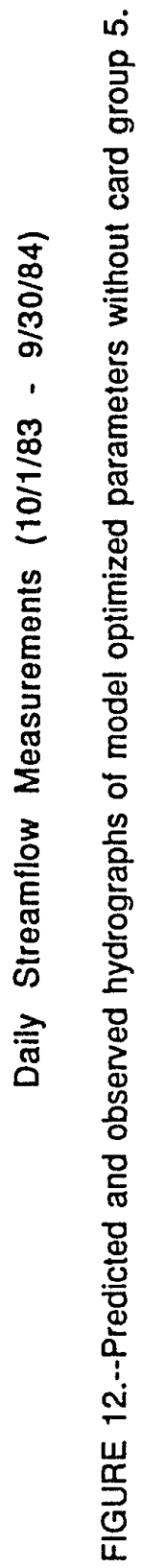


precipitation reached the stream by subsurface flow. The water contributed to the stream by subsurface flow amounted to 38.44 inches, which is approximately 61 percent of the total predicted runoff. Groundwater flow amounted to 24.33 inches which was approximately 39 percent of the total predicted runoff. The surprising result was that no water was contributed to runoff by surface flow.

A comparison of the predicted and observed hydrographs for RUN 2 (fig. 9) indicated the need for card group number 5. The difference between RUN 1 and RUN 2 was the use of card group number 5 . The output totals for RUN 2 were very similar to those of RUN 1, but the predicted discharge hydrographs were much different. This indicates that the amount of water in the basin was the same, but the time at which it was discharged varied.

RUN 3 generated different output than did RUN 1 and RUN 2. As previously stated, RUN 3 was the model run for which the optimization and sensitivity analyses were conducted. The output generated (fig. 10), if compared to RUN 1 (fig. 8), showed an increase in the groundwater contribution from 24.33 inches (38.76 percent) to 35.78 inches (55.82 percent). A decrease also occurred in the subsurface contribution from 38.44 inches (61.24 percent) to 44.17 inches (44.17 percent). A comparison of the predicted and observed hydrographs from the output from RUN 3 reveals that the predicted runoff is not very similar to the observed runoff.

The output generated from RUN 4 (fig. 11) is numerically very similar to that of RUN 3. The major difference seems to be the use of card group number 5 (CG5). The use of CG5 smoothes out the peaks generated by the early spring melt stage around the 150- to 210-day period. A numerical comparison of the observed runoff and the predicted runoff is very similar, but the graphs are not as similar as those represented in figure 8. 
The output for RUN 5 (fig. 12) is similar to the output from RUN 3. The numbers generated are similar, as are the hydrographs. Both graphs of the predicted runoff from RUN 3 and RUN 5 have the same basic similarities. Both do not use CG5, and use the optimized parameters. 


\section{PRMS CONCLUSIONS}

The results of the PRMS indicates that the majority (at least 60 percent) of the water for Blackwood Creek is transferred through the basin by subsurface flow. This correlates fairly well with observations during the spring thaw and during summer rain storms. Determining the flow of water through the basin was the primary objective of the project. All five computer runs of the model support the previous statement. The results also indicate that the use of CG5 is necessary to simulate the runoff and smooth the inconsistencies associated with snowmelt and runoff. The use of CG5 indicates that the model either does not simulate snowmelt accurately, or that the input data, primarily temperature, are from the Ward Creek basin and are not appropriate for the Blackwood Creek basin. Differences between the two basins such as latitude, basin aspect, physiography, or multiple other slight differences could explain the differences in the climatic data between the Blackwood Creek drainage basin and the Ward Creek drainage basin. All slight basin differences as well as model discrepancies probably contribute to the errors associated with the melt stage and the timing of runoff. 


\section{INFILTRATION STUDY}

Because numerous roads are in the basin, a smaller scale study was conducted to compare infiltration rates of new and partly vegetated roads with infiltration rates in the surrounding forest. The objective of this study was to determine the effects of infiltration and the duration of the effects after a logging road is abandoned. Problems were encountered in determining the original state of the forest prior to logging, and in determining when the abandoned logging road was actually abandoned. Because the Blackwood Creek drainage basin is presently designated for offroad recreational vehicles, the amount of use the abandoned roads received following logging is uncertain. Because of the uncertainties of the timing of the closure of the roads, the study was condensed into an infiltration comparison between the forest and roads through the forest.

In order to determine infiltration rates throughout the basin, a measuring device had to be developed. The device chosen was a double ring infiltrometer (fig. 13) which complied with the American Society for Testing and Materials (ASTM) specifications and was designated as D3385-75 (ASTM, 1975). The first design of the infiltrometer followed the directions stated in the ASTM manual. The outer ring consisted of a half of a fifty-five gallon steel drum which had the bottom removed and which had an approximate diameter of 24 inches. The inner ring consisted of a metal five gallon bucket with the top and bottom removed which had an approximate diameter of 12 inches. This design was for measuring infiltration rates in unconsolidated soil and proved to be too flimsy for the type of soil that was encountered in the basin. The second design was constructed of groundwater well casing that was sturdy enough to be driven into the rocky soil throughout the basin. 

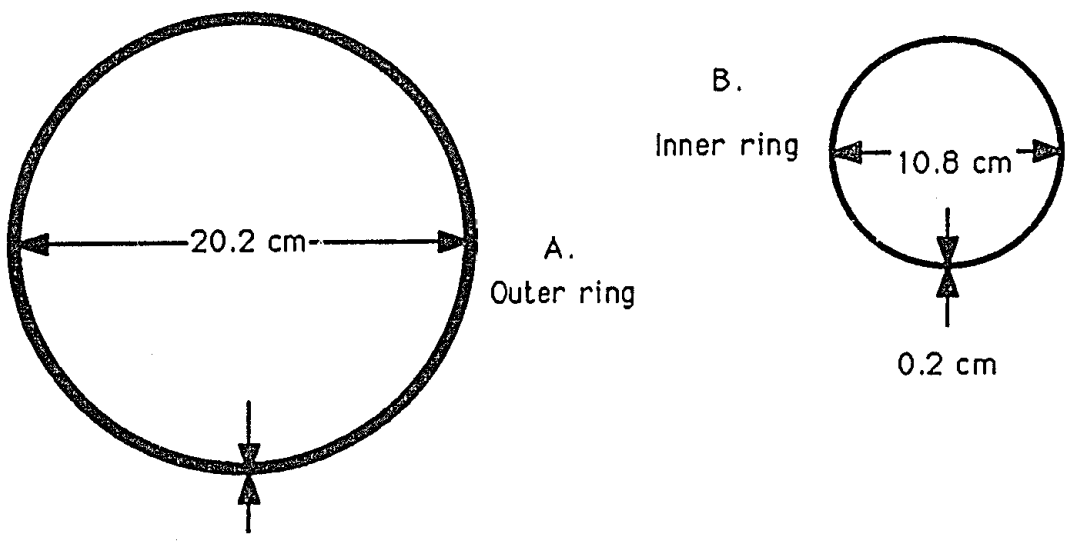

$0.2 \mathrm{~cm}$

$1.3 \mathrm{~cm}$

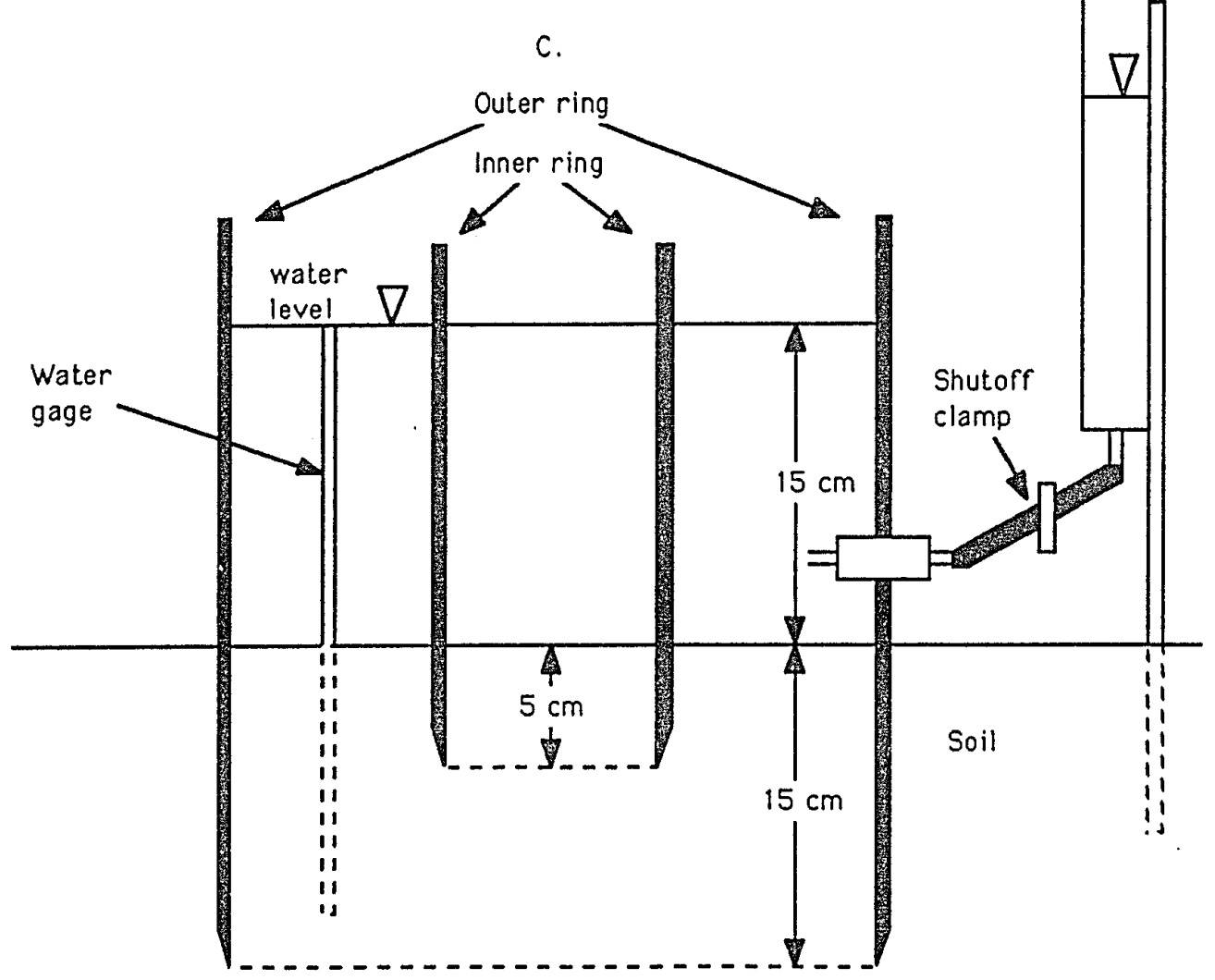

FIGURE 13.--Schematic of a double ring infiltrometer, (A) outer ring dimensions, (B) inner ring dimensions, (C) setup of infiltrometer with dimensions for installation 
The final design of the infiltrometer consisted of an outer ring with an inside diameter of 7.95 inches (20.2 centimeters) constructed of 0.375 inch $(0.95$ centimeter) thick steel casing, and an inner ring with an inside diameter of 4.25 inches (10.8 centimeters) constructed of thin walled stainless steel well casing. According to ASTM specifications, the outer ring was driven into the ground 6 inches (15.24 centimeters) or until refusal with as little disturbance to the ground as possible. The inner ring was placed in the center of the outer ring and driven in the ground 2 inches (5.08 centimeters) or until it could be driven no further.

Once the rings were in place, water was poured into both rings and kept at a constant head. The water added to the inner ring was measured over time and the measured volume of water was used to calculate the infiltration rates. The water in the outer ring functioned as a barrier to keep the water in the inner ring from infiltrating laterally. Water measurements were collected every 10 minutes until a constant value was obtained or the water supply was exhausted. The following Data Analysis section explains the calculation process for the computation of infiltration rates. 


\section{SITE SELECTION}

Four sites were tested in the Fall of 1987 and retested in the summer of 1988 to determine if a change in infiltration rates occured from 1987 to 1988. Ten additional sites were selected and tested in the summer of 1988.

The site locations were primarily determined by vehicle accessibility. Due to the high infiltration rates, a large volume of water was necessary to conduct a single analysis. For this reason sites were chosen by their proximity to an access road. In addition to the proximity to the road, the type of soil and the environment determined a site. For example, well traveled unpaved roads were not analyzed because the soil was so greatly compacted by motorized traffic that the infiltrometer could not be driven into the soil. Abandoned roads with varying degrees of forest regrowth were the primary locations for the small-scale infiltration study. 


\section{FIELDPROCEDURES}

Following the selection of a specific site, the infiltrometer was driven into the soil with a 10 pound sledge hammer. The outer ring was driven to a maximum depth of 6 inches. Due to the presence of glacially deposited gravels, the depth to which the outer ring was driven was sometimes limited. The outer ring was driven into the soil with the least possible disturbance possible. Following the installation of the outer ring, the inner ring was positioned in the center of the outer ring and driven into the soil 2 inches. Following the installation of the two rings, the soil inside of the rings was slightly tamped so that the water did not flow through the slightly disturbed soil and distort the results. After slight compaction of the soil, loose objects that could float on the water were removed. Floating objects made measuring the water levels difficult.

Depth gages, which consisted of brass rods with 1 inch tick marks, were positioned in the center of the inner ring and between the inner and outer ring. Both gages were installed to the same depth so the water level could be kept constant in both rings. A splash guard of shredded burlap was laid on the soil to prevent erosion of the soil when the initial water supply was poured into the rings.

A small pail was used to fill the rings with water to the appropriate level. Once the rings were were filled, the splash guards were removed. The water in both rings was filled to the same level. Depending on the location, the constant head of water in the rings varied. In areas that were difficult to carry water to, the head of water was kept at 3 inches. In areas where the water could be transported easily, the head of water in the rings was kept at 6 inches. The infiltration rates also helped determine the amount of head kept in the rings. High infiltration rates generally required a head of water of 3 inches, whereas lower infiltration rates allowed the head to be elevated to 6 inches. 
The volume of water added to the inner ring was measured every 10 minutes. The water in the inner ring was added and measured using a graduated cylinder. The outer ring was kept at a constant level by a Mariotte' tube with a clamp on the hose to regulate the volume of water which flowed through the tube. In locations with extremely high infiltration rates, a graduated cylinder was used to fill both rings.

The test was continued until several similar readings were obtained. Measurements were collected for approximately 30 minutes following the point when a plateau was reached, to insure completeness of the test. Once the test was believed to be complete, the rings were removed from the soil and the soil was examined. Specific details were evaluated and logged on the data sheet. All notes and information on the infiltration test are listed in Appendix $L$. 


\section{DATA ANALYSIS}

The volume measurements obtained from the field work were converted to infiltration rates calculated in units of centimeters per hour $(\mathrm{cm} / \mathrm{hr})$. The infiltration rates were determined by first calculating the area of infiltration in the inner ring, which is 91.61 square centimeters $\left(\mathrm{cm}^{2}\right)$. The inverse of the measured area, 0.0109 $1 / \mathrm{cm}^{2}$, is the multiplication factor used to calculated the infiltration rates. This factor was then multiplied by the infiltration volume per interval, in this case the interval was 10 minutes, which in turn was multiplied by 60 minutes per hour to give a final infiltration rate in units of centimeters per hour $(\mathrm{cm} / \mathrm{hr})$. Figure 14 summarizes the basic characteristics of each individual site along with the infiltration results. The infiltration rates were then plotted against elapsed time in minutes. Figure 15 represents the graph generated from the site 1-1987 which was the first site investigated. A line drawn along the plateau points to the $y$-axis gives the approximate infiltration rate at the specific site. All individual graphs are located in Appendix $L$ following their respective data sheet. 


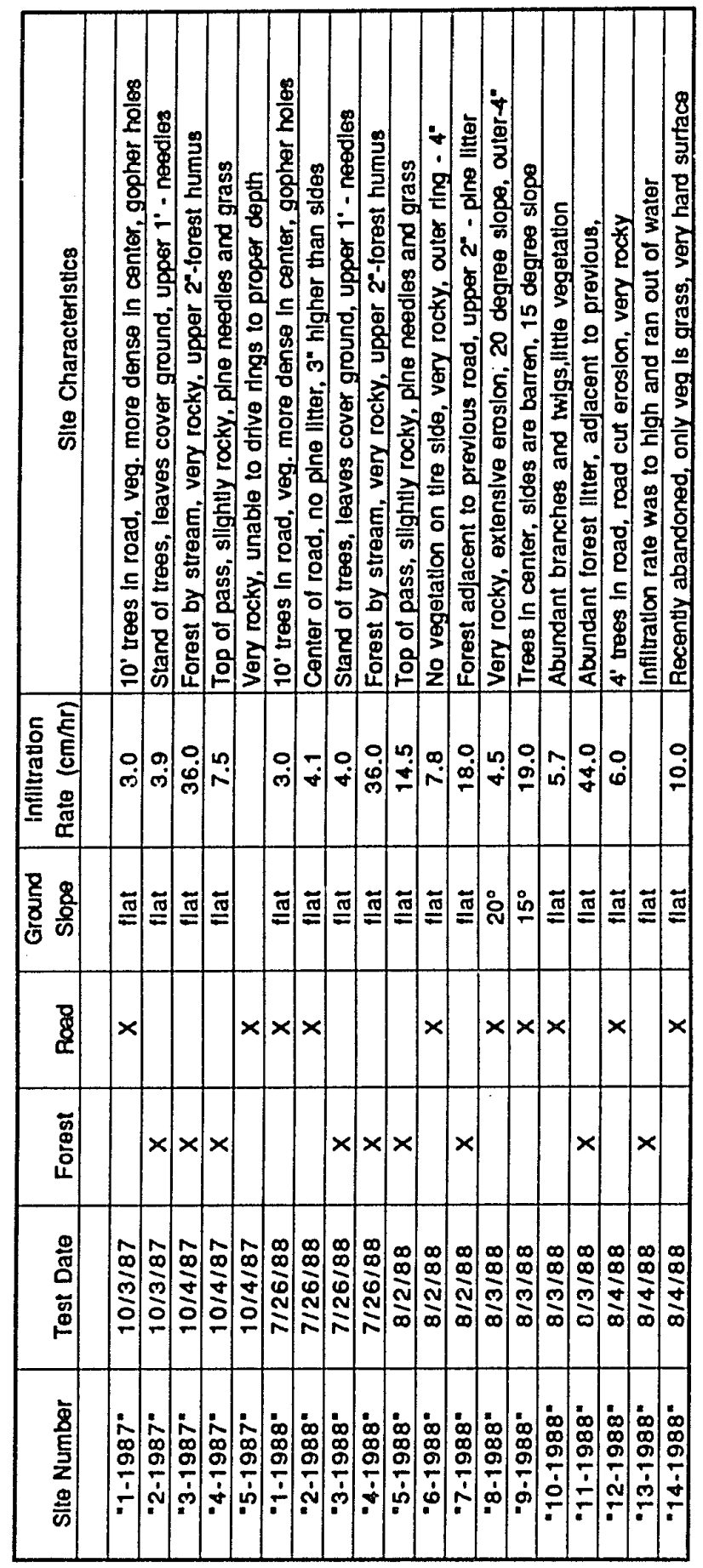

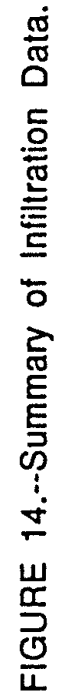


Graph of Infiltration Data (Site 1-1987)

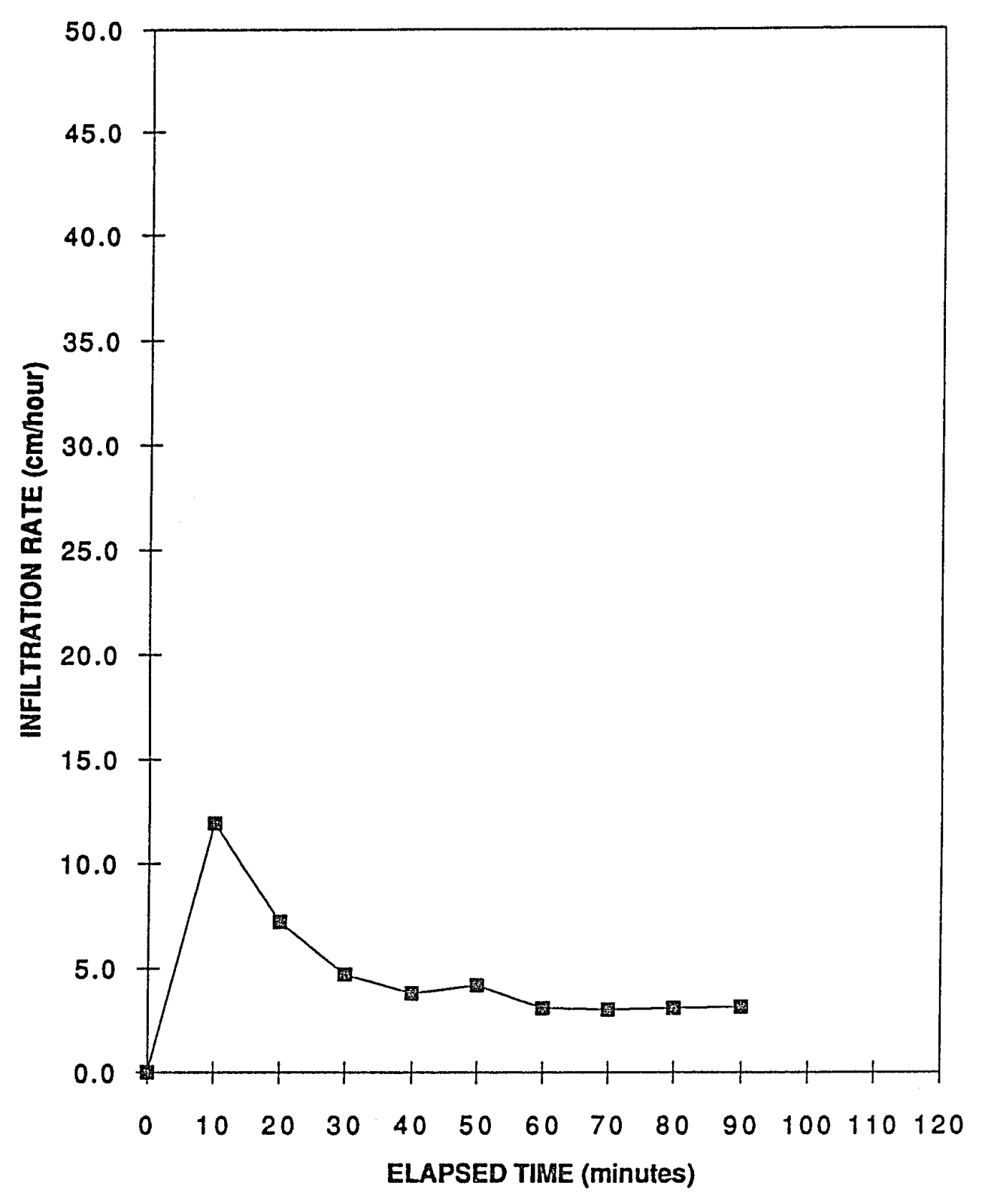

FIGURE 15.--Infiltration Graph of Site 1-1987 (final infiltration rate of $3.0 \mathrm{~cm} / \mathrm{hr}$ ) 


\section{RESULTS AND INTERPRETATIONS}

The results obtained from the infiltration study are consistent with those discussed by Pritchett (1979), who stated that the forest floors act like a sponge and allow very little surface runoff to occur. Infiltration rates in forested areas studied by Pritchett ranged from about $5 \mathrm{~cm} / \mathrm{hr}$ to about $200 \mathrm{~cm} / \mathrm{hr}$. The results obtained from this study ranged from a minimum infiltration rate of approximately $3.0 \mathrm{~cm} / \mathrm{hr}$ to a maximum rate of $44.0 \mathrm{~cm} / \mathrm{hr}$. All of the measured rates fall in the range stated by Pritchett.

A comparison of the calculated rates from the road sites and the forest sites indicates that the forest sites have infiltration rates approximately 8 to 10 times greater than those from road sites. The soil compaction associated with the vehicles driving on the roads is the primary reason for the large difference.

The data from sites 1-1987 and 2-1988 were compared to determine the annual variation in infiltration rates. Both sites were located on a road and recorded approximate infiltration rates of $3.0 \mathrm{~cm} / \mathrm{hr}$, which indicated that a no change in infiltration rates could be determined in one year. Site 2-1988 was located near sites 1-1987 and 1-1988 and was positioned in the center of the road. The center of the road was approximately 3 inches higher than the sides of the road. Vegetation appeared to be more dense in the center of the road. The infiltration rate for site 2-1988 was measured to be $4.1 \mathrm{~cm} / \mathrm{hr}$, which is about a 37 percent increase of the measurements obtained from sites 1-1987 and 1-1988. 


\section{INFILTRATION CONCLUSIONS}

Measured infiltration rates are consistent with forest infiltration rates stated by Pritchett. The infiltration values measured for roads are less than those measured for the forest area. The roads have lower infiltration values because of compaction created by the vehicles on the road. Less than 1 percent of the basin is composed of roads of varying degree of use. The first roads were constructed in the late 1800's when logging was initiated in the basin. The exact location of these first roads is unknown, and only a detailed investigation would produce this information. The infiltration values indicate that surface runoff is not a dominate a factor in determining how the water moves through the basin. Because of the high infiltration values the water probably moves through subsurface flow to the streams. The measured infiltration results support the results generated by PRMS and are consistent with the information obtained from PRMS. 
THESIS CONCLUSIONS

The movement of water through the Blackwood Creek drainage basin was modeled using the U.S. Geological Survey's precipitation-runoff modeling system (PRMS). PRMS utilizes measured data and calculated parameters to simulate runoff from the basin. To calibrate the model, measured runoff was compared with predicted runoff, and non-measured model parameters were adjusted to produce a predicted hydrograph similar to the measured hydrograph. To simulate runoff, the var ious routes of water movement were determined. It became apparent that infiltration of water in the soil was one of the primary factors controlling water movement in the basin. Because of this, a small-scale infiltration study was conducted using a double ring infiltrometer. Infiltration results revealed that water is transfered to the soil very rapidly in the Blackwood Creek drainage basin, which supports the results obtained from the PRMS. The PRMS revealed that the majority of the water that flows through the basin is transferred to Blackwood Creek by subsurface flow and groundwater flow with little of the water moving through the basin by over land flow.

Although many of the parameters used in the model were estimated, the results generated by the model appear to be fairly accurate, because the simulated results are relatively close to the observed data. Little actual measured data from the basin were input into the model, which could explain why the model did not simulate runoff exactly. Additional subsurface information--for example, depth to groundwater, storativity and hydraulic conductivity of the groundwater zone, and soil moisture--would be very beneficial in refining the results generated by the model. These measurements would not be input directly into the model, but would al low the user to more accurately partition the flow of water between the subsurface reservoirs and the groundwater reservoirs 
therefore allowing the user to calibrate the model with greater confidence. The additional subsurface information would also be beneficial in determining if the Hydrologic Response Units are partitioned correctly, or if the boundaries need to be modified to represent the subsurface environment in the basin. 


\section{REFERENCESCTED}

American Society for Testing and Materials (ASTM), 1975, Standard test method for infiltration rate of soils in field using double-ring infiltrometers: Annual Book of ASTM Standards D 3385-75, p. 527-532.

Birman, J.H., 1964, Glacial geology across the crest of the Sierra Nevada, California: Geological Society of America, Special Paper no. 75, 78 p.

Burnett, J.L., 1971, Geology of the Lake Tahoe basin: California Division of Mines and Geology, California Geology, v. 24, no. 7, p. 118-135.

Cary, L.E., Application of the U.S. Geological Survey's precipitation-runoff modeling system to the Prairie Dog Creek basin, Southeastern Montana: U.S. Geological Survey Water-Resources Investigations Report 84-4178, 95 p.

Evans, J.R. and Matthews, R.A., 1968, Geologic studies in the Lake Tahoe area, California and Nevada: Geological Society of Sacramento, Annual field trip guidebook 1968 , $99 \mathrm{p}$.

Fogelman, R.P., Hunter, T.C., Mullen, J.R., Simpson, R.G., and Grillo, D.A., 1985a, Water resources data.-California, water year 1984, Volume 3, Southern Central Valley basins and the Great Basin from Walker River to Truckee River: U.S. Geological Survey Water-Data Report CA-84-3, 393 p.

-...-1985b, Water resources data--California, water year 1984, Volume 3, Southern Central Valley basins and the Great Basin from Walker River 10 Truckee River: U.S. Geological Survey Water-Data Report CA-84-3, 355 p.

Freeze, R.A., and Cherry, J.A., 1979, Groundwater: Prentice-Hall, Englewood Cliffs, N.J., 604 p.

Hill, B.R., Hill, J.R., and Nolan, K.M., 1990, Sediment-source data for four basins tributary to Lake Tahoe, California and Nevada, August 1983-June 1988: U.S. Geological Survey Open-File Report 89-618, 42 p.

Hyne, N.J., Chelminski, P., Court, J.E., Gorsline, D.S., and Goldman, C.R., 1972, Quaternary history of Lake Tahoe, California-Nevada: Geological Sociely of America Bulletin, v. 83 , p. 1435-1448.

Iwatsubo, R.T., Nolan, K.M., Harden, D.R., Glysson, G.D., and Janda, R.S., 1975, Redwood National Park studies, Data Release number 1, Redwood Creek, Humboldt County, California, September 1, 1973-April 10, 1974: U.S. Geological Survey OpenFile Report, $120 \mathrm{p}$.

Leavesley, R.W., Lichty, R.W., Troutman, B.M., and Saindon, L.G., 1983, Precipitationrunoff modeling system: user's manual: U.S. Geological Survey Water-Resources Investigations Report 83-4238, 207 p. 
Nolan, K.M., Hill, B.R., 1991, Suspended-sediment budgets for four drainage basins tributary to Lake Tahoe, California and Nevada, 1984-1987: U.S. Geological Survey Water-Resources Investigations Report 91-4054, 40 p.

Pritchett, W.L., 1979, Properties and management of forest soils: John Wiley \& Sons, Inc., $500 \mathrm{p}$.

Rogers, J.H., 1974, Soil survey of the Tahoe basin area, California and Nevada: U.S. Department of Agriculture, Soil Conservation Service and Forest Service, 84 p.

Sharp, R.P., Birman, J.H., 1963, Additions to classical sequence of Pleistocene glaciations, Sierra Nevada, California: Geological Society of America Bulletin, v. 74, p. $1079-1086$.

Tahoe Regional Planning Agency, 1971, Geology and geomorphology of the Lake Tahoe Region, a guide for planning: South Lake Tahoe, California, Tahoe Regional Planning Agency, $53 \mathrm{p}$.

U.S. Army, 1956, Snow hydrology, Summary report of the snow investigations: North Pacific Division, Corps of Engineers, $437 \mathrm{p}$.

U.S. Army, 1959, Hydrometeorological logs of the Central Sierra snow laboratory: South Pacific Division, Corps of Engineers, San Francisco, California, 157p.

Wentworth, C.K., 1930, A simplified method of determining the average slope of land surfaces: American Journal of Science, 5 th series, v. 20, p. 184-194. 
Appendix A

Definitions of Card Group 1 Parameters 
Definitions of Card Group 1 Parameters

\begin{tabular}{|c|c|c|c|}
\hline & & & \\
\hline & & Number of & \\
\hline Card & Parameter & values & Definition \\
\hline & & & \\
\hline 1 & ISIM & 1 & Simulation mode switch. \\
\hline 1 & LOBS & 1 & Observed discharge data switch. \\
\hline 1 & IOPT & 1 & Optimization mode switch. \\
\hline & & & \\
\hline 1 & ISEN & 1 & Sensitivity analysis switch. \\
\hline 1 & IDOUT & 1 & Store predicted daily mean streamflow values switch. \\
\hline 1 & IUOUT & 1 & Store predicted stormflow values switch. \\
\hline 1 & SCOOE & 1 & State code for daily or unit values output. \\
\hline 1 & IPSW & & Precipitation form data switch. \\
\hline 1 & Irow & 1 & Precipltation rorm data swicn. \\
\hline 2 & IPET & 1 & Potential evapotranspiration (ET) calculation switch. \\
\hline 2 & ISSR1 & 1 & Daily surface runoff computation method switch. \\
\hline & & & \\
\hline 2 & MPDC & 1 & Solar radiation computation method switch. \\
\hline 2 & ISUN & 1 & Switch for unit subsuface and groundwater flow \\
\hline & & & routing. \\
\hline 3 & TITL & 1 & Any title user wishes to print as heading for all output. \\
\hline & & & \\
\hline 4 & NDS & 1 & Number of rain-gage data sets. \\
\hline 4 & NRU & 1 & Number of hydrologic response units (HRU's). \\
\hline 4 & NPD & 1 & Number of solar radiation planes. \\
\hline 4 & NRES & 1 & Number of subsurface flow routing reservoirs. \\
\hline 4 & NGW & 1 & Number of groundwater flow routing reservoirs. \\
\hline & & & \\
\hline 4 & NSTOR & 1 & Number of surface-water detention storage reservoirs. \\
\hline 4 & DAT & 1 & Total basin drainage area (acres). \\
\hline
\end{tabular}


Definitions of Card Group 1 Parameters

\begin{tabular}{|c|c|c|c|}
\hline & & & \\
\hline & & Number of & \\
\hline Card & Parameter & values & Definition \\
\hline & & & \\
\hline & & & \\
\hline 5 & BYR & 1 & Beginning year of data set. \\
\hline & & & \\
\hline 5 & BMO & 1 & Beginning month of data set. \\
\hline 5 & BDY & 1 & Beginning day of data set. \\
\hline & & & \\
\hline 5 & EYR & 1 & Ending year of data set. \\
\hline 5 & ENO & 1 & Ending month of data set. \\
\hline & & & \\
\hline 5 & EDY & 1 & Ending day of data set. \\
\hline 6 & MFS & 1 & Beginning month of objective function computation. \\
\hline 6 & MAN & 1 & Endina month of objective function computation. \\
\hline & & 1 & \\
\hline 7 & IPOP1 & 1 & Daily mean values print switch. \\
\hline 7 & IPUN3 & 1 & Beginning month for printing daily basin average values. \\
\hline & & & \\
\hline 7 & IPUN4 & 1 & Ending month for printing daily basin average values. \\
\hline 7 & IPOP2 & 1 & Individual HRU values print switch. \\
\hline & & & \\
\hline 7 & IPUN1 & 1 & Julian date to start printing individual HRU values. \\
\hline 7 & IPUN2 & 1 & Julian date to stop printing individual HRU values. \\
\hline 7 & ISTAT & 1 & Statistical summary print switch. \\
\hline & & & \\
\hline 8 & IPLOT & 1 & Plot switch. \\
\hline 8 & IPLTYP & 1 & Plot type switch. \\
\hline 8 & IMPLB & 1 & Month plot begins. \\
\hline & & & \\
\hline 8 & IDPLB & 1 & Day plot brgins. \\
\hline & & 1 & Month niat ends. \\
\hline 8 & MPLE & 1 & Month plot ends. \\
\hline
\end{tabular}




\begin{tabular}{|c|c|c|c|}
\hline & & Number of & \\
\hline Card & Parameter & values & Definition \\
\hline & & & \\
\hline & & & \\
\hline 8 & IDPLE & 1 & Day plot ends. \\
\hline 8 & PLMX & 1 & Maximum plot value. \\
\hline 8 & PLMN & 1 & Minimum plot value. \\
\hline 9 & NDTY & 1 & Number of data types used in the simulation. \\
\hline 9 & IDUS & & \\
\hline & 1000 & 10 & Daily pan evaporation. \\
\hline & & & Daily maximum air temperaiure. \\
\hline & & & Daily minimum air temperature. \\
\hline & & & Daily solar radiation. \\
\hline & & & Daily, user defined. \\
\hline & & & Daily, user defined. \\
\hline & & & Storm discharge. \\
\hline & & & Daily precipitation. \\
\hline & & & Storm precipitation. \\
\hline 10 & PARMCA & 10 & Parameter code used with data types. \\
\hline 11 & STATCA & 10 & Statistic code corresponding to parameter codes. \\
\hline & & & 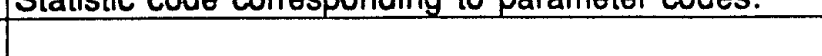 \\
\hline 12 & STAIDC & 10 & Station I.D. for data types. \\
\hline 13 & STAIDP & 2 & Station I.D. for precipitation data types. \\
\hline 14 & 1 & \# of planes & Index of this solar radiation plane. \\
\hline 14 & SA(I) & \# of planes & Slope and aspect of this plane. \\
\hline 14 & $\mathbf{S L}$ & \# of planes & Slope of plane (decimal $\mathrm{ft} / \mathrm{ft}$ ). \\
\hline & & & \\
\hline 14 & ASP & \# of planes & Aspect of plane (degrees clockwise from north). \\
\hline 14 & ALAT & \# of planes & Latitude of basin (degrees). \\
\hline 15 & RDM & 12 & Slope of maximum air temperature $(x)$ - degree day $(y)$ \\
\hline & & (monthly) & relationship for months $1-12$ \\
\hline
\end{tabular}




\begin{tabular}{|c|c|c|c|}
\hline & & & \\
\hline & & Number of & \\
\hline Card & Parameter & values & Definition \\
\hline & & & \\
\hline & & & \\
\hline 16 & $\mathrm{PDC}$ & 12 & $Y$ intercept of maximum air temperature $(x)$ - degree \\
\hline & & (monthly) & day $(y)$ relationship for months $1-12$. \\
\hline 17 & PARS & 1 & Predicted solar radiation correction factor for summer \\
\hline & & & day with precipitation. \\
\hline 17 & PARW & 1 & Predicted solar radiation correction factor for \\
\hline & & & winter day with precipitation. \\
\hline 18 & & & Climate station elevation (ft). \\
\hline 18 & cse & 1 & \\
\hline 18 & PAMXA & 1 & Proportion of rain in amixed rain-snow event above \\
\hline & & & which albedo is not resest (snow pack accumulation). \\
\hline 18 & PDDOM & 1 & Proportion of rain in amixed rain-snow event above \\
\hline & & & which albedo is not resest (melt stage). \\
\hline 19 & $\overline{\text { CTS }}$ & 12 & Air temperature coefficient in Jensen-Haise potential \\
\hline & & (monthly) & evapotranspiration equation. \\
\hline 19 & CTW & 1 & Proportion of potential evapotranspiration that is \\
\hline & & & sublimated from a snowpack \\
\hline 20 & PAT & 12 & Maximum air temperature, which when exceeded forces \\
\hline & & (monthly) & precipitation to be rain regardless of minimum air \\
\hline & & & temperature. \\
\hline 21 & AJMX & 12 & Adjustment proportion of rain in a rain-snow mix event. \\
\hline & & (monthly) & \\
\hline & & & \\
\hline 22 & $\pi x$ & 12 & Lapse rate for daily maximum temperature (degree \\
\hline & & (monthly) & Fahrenheit per 1,000 feet). \\
\hline 23 & TLN & 12 & Lapse rate for daily minimum temperature (degree \\
\hline & & (monthly) & Fahrenheit per 1,000 feet). \\
\hline 24 & EVC & 12 & Evaporation pan coefficient. \\
\hline & & (monthly) & \\
\hline & & & \\
\hline
\end{tabular}




\begin{tabular}{|c|c|c|c|}
\hline & & & \\
\hline & & Number of & \\
\hline Card & Parameter & values & Definition \\
\hline & & & \\
\hline \multirow[t]{2}{*}{25} & ISP1 & 1 & Julian date to start looking for spring snowmelt stage. \\
\hline & ISP2 & 1 & Jullan date to force snowpack to spring snowmelt stage. \\
\hline 25 & EAP & 1 & Emissivity of dry air. \\
\hline \multirow[t]{2}{*}{25} & FWCAP & 1 & Free-water holding capacity of snowpack (decimal \\
\hline & & & form). \\
\hline \multirow[t]{2}{*}{25.} & DEN & 1 & Initial density of new fallen snow (gram/cubic \\
\hline & & & centimeter). \\
\hline \multirow[t]{2}{*}{25} & DENMX & 1 & Average maximum snowpack density (gram/cubic \\
\hline & & & centimeter). \\
\hline 25 & SETCON & 1 & Snowpack settlement constant. \\
\hline \multirow[t]{2}{*}{25} & BST & 1 & Base temperature below which all precipitation is \\
\hline & & & snow, above which it is all rain ( degree Fahrenheit). \\
\hline \multirow[t]{2}{*}{26} & CEON & 12 & Convection-condensation energy coefficient (calories \\
\hline & & (monthly) & per degree Celcius above zero). \\
\hline \multirow[t]{2}{*}{27} & INPK & 1 & Julian dates for adjusting computed snowpack water \\
\hline & & & equivalents from snowcourse data. \\
\hline 28 & RES & 1 & Storage in each subsurface reservoir (inches). \\
\hline \multirow[t]{2}{*}{29} & GW & 1 & Storage in each groundwater flow reservoir (inches). \\
\hline & & & \\
\hline \multirow[t]{2}{*}{30} & KRSR & 1 & Index of the groundwater reservoir receiving recharge \\
\hline & & & from subsurface reservoirs. \\
\hline \multirow[t]{2}{*}{31} & RESMX & 1 & Coefficient for computing recharge from subsurface \\
\hline & & & to designated groundwater reservoir. \\
\hline \multirow[t]{3}{*}{31} & REXP & 1 & Exponent coefficient for computing recharge from \\
\hline & & & subsurface reservoir to designated groundwater \\
\hline & & & reservoir. \\
\hline & & & \\
\hline
\end{tabular}




\begin{tabular}{|c|c|c|c|}
\hline & & & \\
\hline & & Number of & \\
\hline Card & Parameter & values & Definition \\
\hline & & & \\
\hline 32 & RSEP & 1 & Coefficient used in computing recharge rate from \\
\hline & & & subsurface reservoir to designated groundwater \\
\hline & & & reservoir. \\
\hline & & & \\
\hline 33 & GSNK & 1 & Coefficient used in computing the recharge rate from \\
\hline & & & groundwater reservoir to groundwater sink. \\
\hline 34 & $\mathbf{R O B}$ & 1 & Groundwater routing coefficient for each groundwater \\
\hline & & & reservoir. \\
\hline 35 & $\mathrm{RCF}$ & 1 & Subsurface flow routing coefficient for each subsurface \\
\hline & & & reservoir. \\
\hline 35 & $\mathrm{ROP}$ & 1 & Subsurface flow routing coefficient for each subsurface \\
\hline & & & reservoir. \\
\hline & & & \\
\hline 36 & $\mathbf{F}$ & 1 & HRU identification number. \\
\hline 36 & RD & 1 & Solar radiation plane index. \\
\hline 36 & SP & 1 & Slope of HRU (decimal form). \\
\hline & & & \\
\hline 36 & ELV & 1 & Mean elevation of HRU (above sealevel). \\
\hline 36 & $\mathrm{KCOV}$ & 1 & Predominant vegetation. \\
\hline 36 & COVDNS & 1 & Summer vegetation cover density. \\
\hline & & & \\
\hline 36 & COVDNW & 1 & Winter vegetation cover density. \\
\hline 36 & TPNCF & 1 & Transmission coefficient for short wave radiation \\
\hline & & & through winter vegetation canopy. \\
\hline 36 & SNST & 1 & Interception storage capacity of major vegetation \\
\hline & & & (inches). \\
\hline 36 & RNSTS & 1 & Summer rain interception storage capacity of major \\
\hline & & & vegetation. \\
\hline 36 & RNSTW & 1 & Winter rain interception storage capacity of major \\
\hline
\end{tabular}




\begin{tabular}{|c|c|c|c|}
\hline & & & \\
\hline & & Number of & \multirow[b]{2}{*}{ Definition } \\
\hline \multirow[t]{3}{*}{ Card } & Parameter & values & \\
\hline & & & \\
\hline & & & vegetation. \\
\hline & & & \\
\hline 36 & TIST & 1 & Month to look for start of transpiration. \\
\hline 36 & mND & 1 & Month transpiration ends. \\
\hline & & & \\
\hline 36 & ITSW & 1 & Starting value for transpiration switch. \\
\hline & & & Air tomporature cofficiont for ovanotranspiration \\
\hline 36 & CTX & 1 & Air temperature coefficient for evapotranspiration \\
\hline & & & computations. \\
\hline 36 & TXAJ & 1 & Adjustment for maximum air temperature for slope and \\
\hline & & & aspect. \\
\hline & & & \\
\hline 36 & TNAJ & 1 & Adjustment for minimum air temperature for slope and \\
\hline & & & aspect. \\
\hline 37 & $\mathbf{R U}$ & 1 & HRU identification number. \\
\hline & & & \\
\hline 37 & ISOIL & 1 & Soil type. \\
\hline 37 & SMAX & 1 & Maximum available water holding capacity of soil profile. \\
\hline 37 & SMAV & 1 & Current available water in soil profile (inches). \\
\hline & & & \\
\hline 37 & PEMX & 1 & Maximum available water-holding capacity of recharge \\
\hline & & & zone (inches). \\
\hline 37 & PECAR & 1 & Current available water holding capacity of recharge \\
\hline & & & zone (inches). \\
\hline & & & \\
\hline 37 & SFX & 1 & Maximum daily snowmellt infiltration capacity of soil \\
\hline & & & profile when profile is at field capacity. \\
\hline 37 & $\operatorname{sex}$ & 1 & Maximum possible contributing area as proportion of \\
\hline & & & total HRU area. \\
\hline 37 & SON & 1 & Coefficient in contributing area moisture index \\
\hline & & & relationship. \\
\hline & & & \\
\hline
\end{tabular}




\begin{tabular}{|c|c|c|c|}
\hline & & & \\
\hline & & Number of & \\
\hline Card & Parameter & values & Definition \\
\hline & & & \\
\hline 37 & SC1 & 1 & Coefficient in contributing area moisture index \\
\hline & & & relationship \\
\hline 37 & IMPERV & 1 & Effective impervious area as proportion of total HRU. \\
\hline & & & \\
\hline 37 & RETRP & 1 & Maximum retention storage on impervious area (inches). \\
\hline 37 & $\mathbf{S P}$ & 1 & Maximum daily recharge from soil moisture excess to \\
\hline & & & designated groundwater reservoir (inches per day). \\
\hline 37 & KRES & 1 & Index of subsurface reservoir receiving recharge from \\
\hline & & & HRU. \\
\hline 37 & KGW & 1 & Index of groundwater reservoir receiving recharge from \\
\hline & & & HRU. \\
\hline 37 & KSTOR & 1 & Index of surface water detention storage reservoir \\
\hline & & & receiving runoff from HRU. \\
\hline 38 & RU & 1 & HRU identification number. \\
\hline & & & \\
\hline 38 & KDS & 1 & Index of rain gage. \\
\hline 38 & DARU & 1 & Drainage area for HRU (acres). \\
\hline 38 & UPCOR & 1 & Rain correction for storm preparation for rain gage. \\
\hline 38 & DRCOR & 1 & Rain correction for daily precipitation for rain gage. \\
\hline & & & \\
\hline 38 & DSOOR & 1 & Snow correction for daily precipitation for rain gage. \\
\hline 38 & TST & 1 & Temperature index to determine specific date of start \\
\hline & & & of transpiration. \\
\hline
\end{tabular}




\section{Appendix B}

Input of PRMS Run 1

Input for PRMS utilizes a card format previously discussed in the text of this document. The first two digits of each line correlate to the card group which contains the various parameters. The following text indicates what part of the model the parameters influence, so the user can read the input printout with referencing the users manual. The remaining text and digits are the input variables for the specific parameters. 
Input Data for BLCK.CG1 Run 1

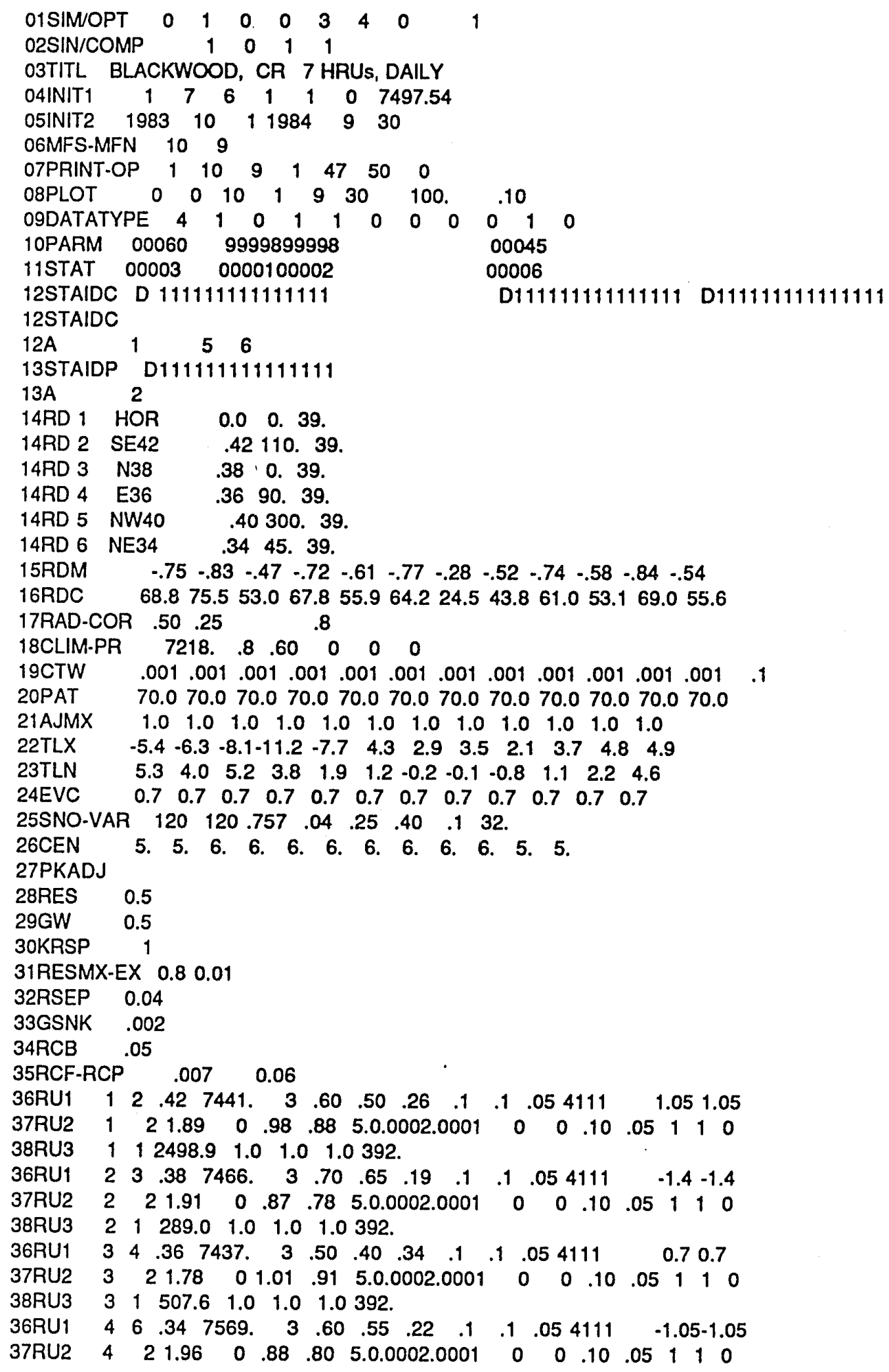


Input Data for BLCK.CG1 Run 1

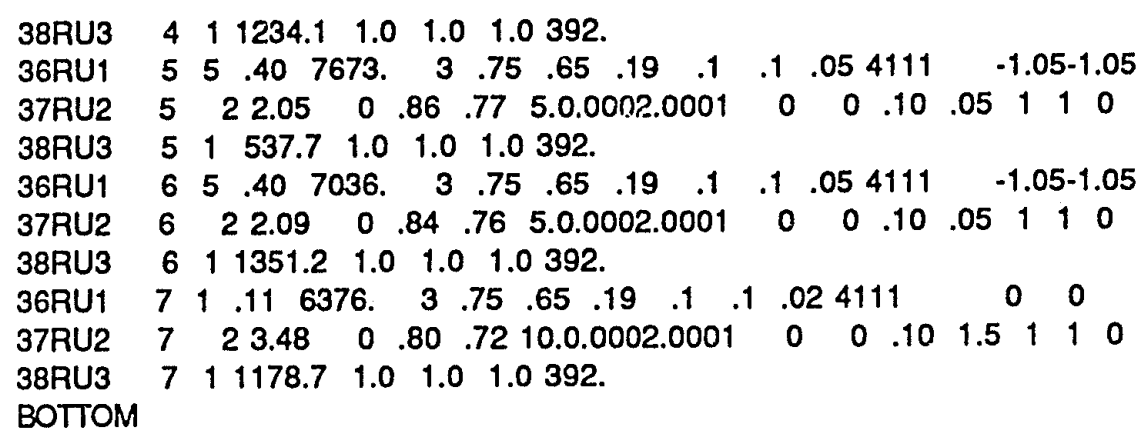


Appendix C

Input of PRMS Run 2 
Input Data for BLCK.CG1 Run 2

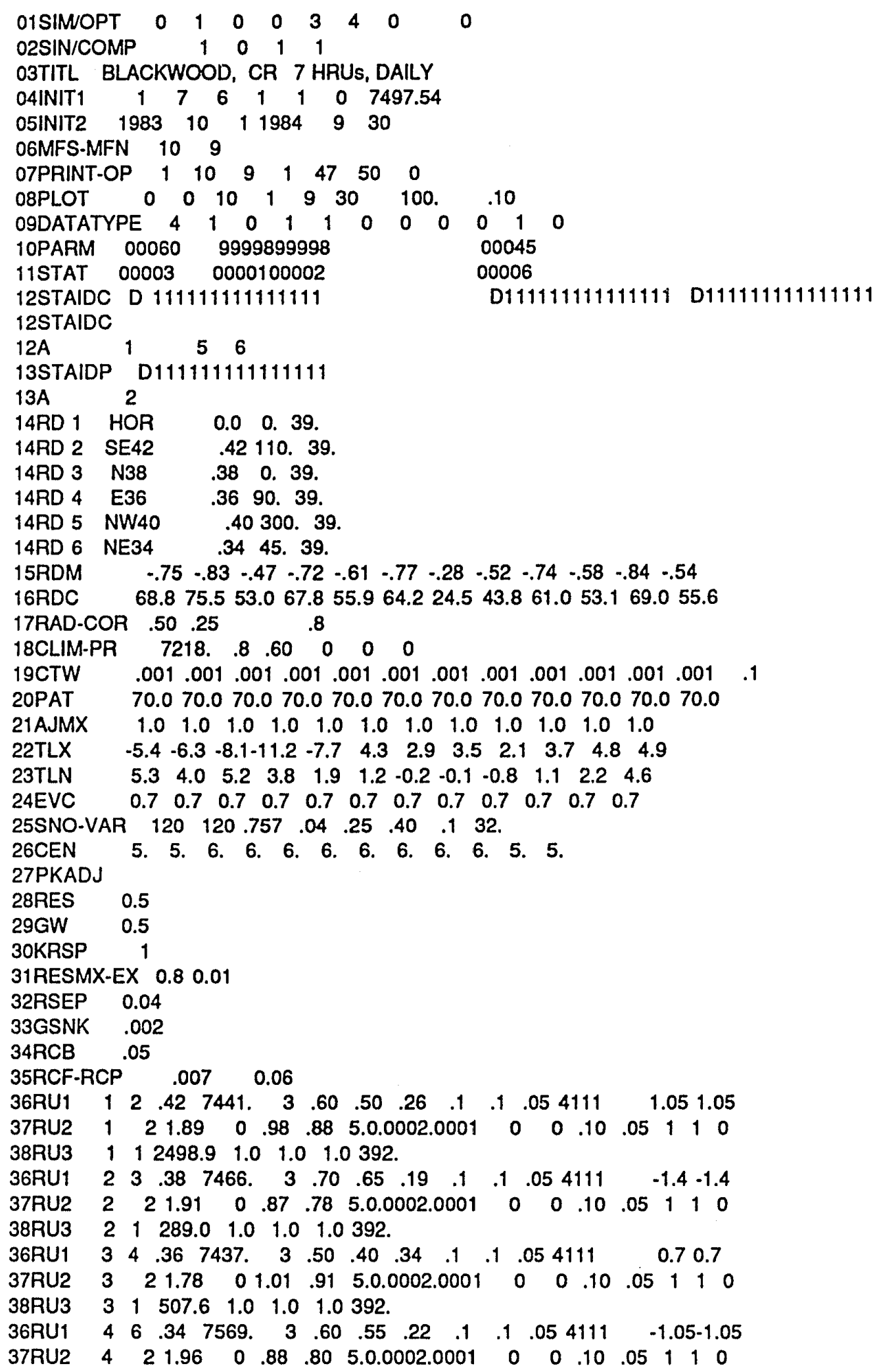


Input Data for BLCK.CG1 Run 2

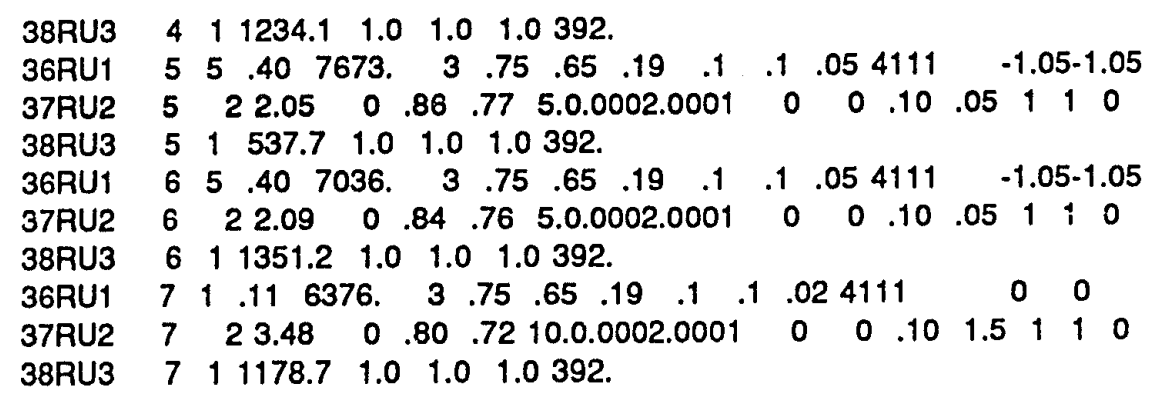


Appendix D

Input of PRMS Run 3 
Input Data for BLCK.CG1 Run 3

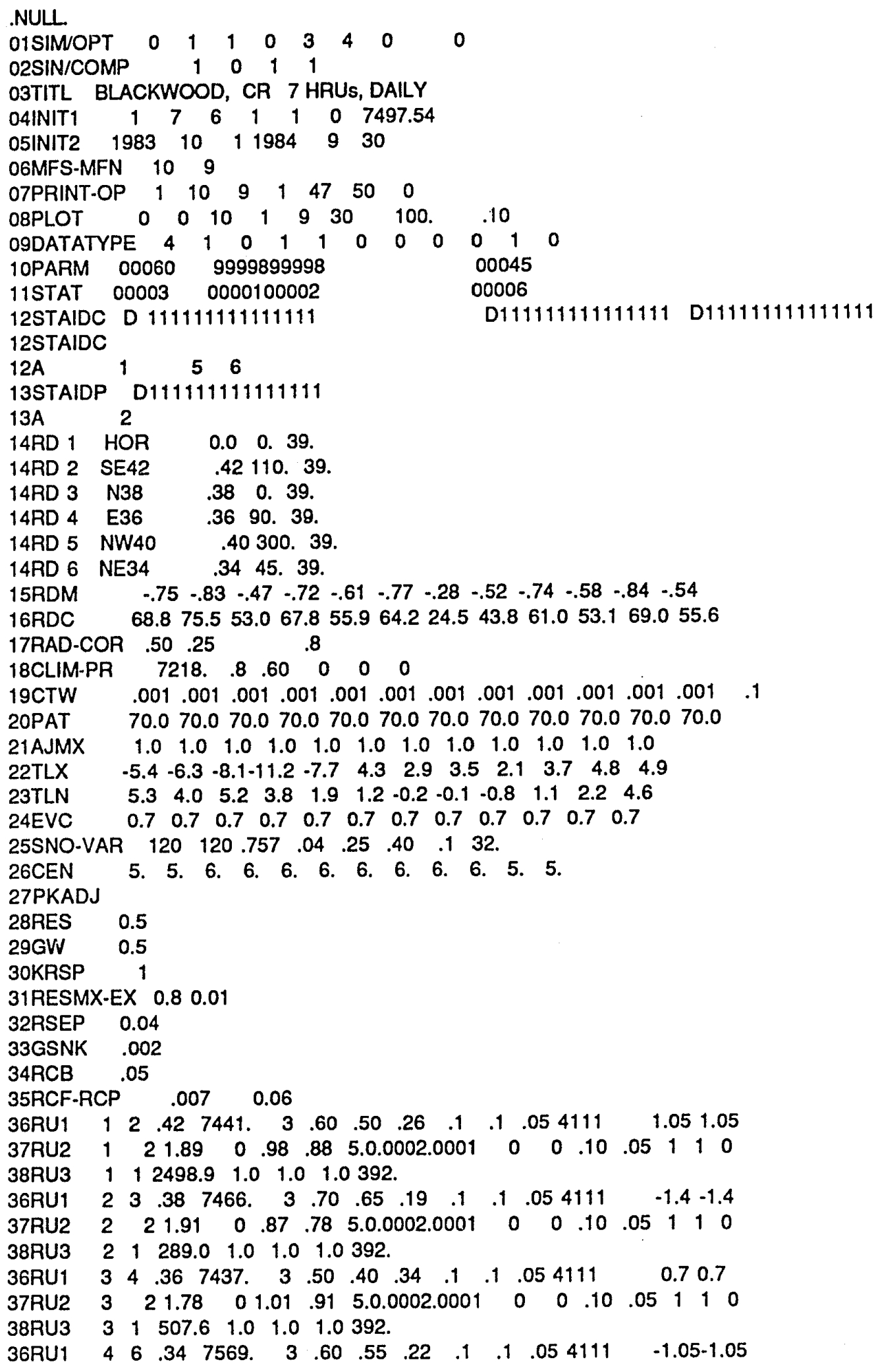


Input Data for BLCK.CG1 Run 3

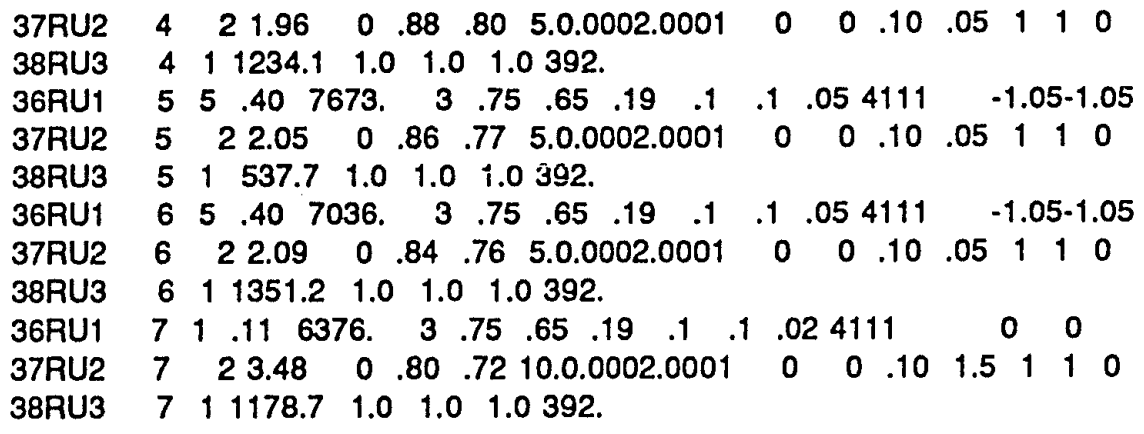


Appendix E

Input of PRMS Run 4 


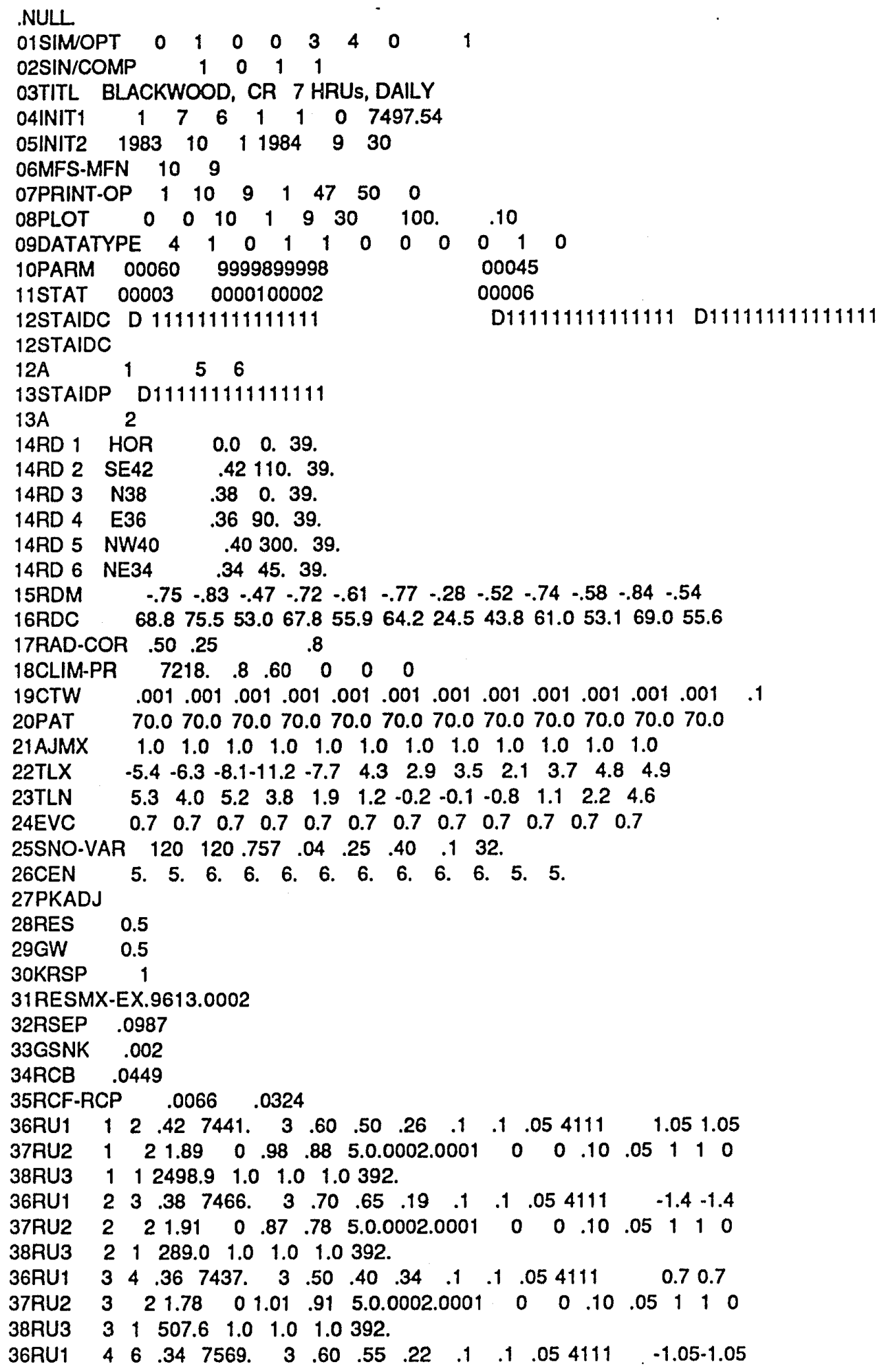


Input Data for BLCK.CG1 Run 4

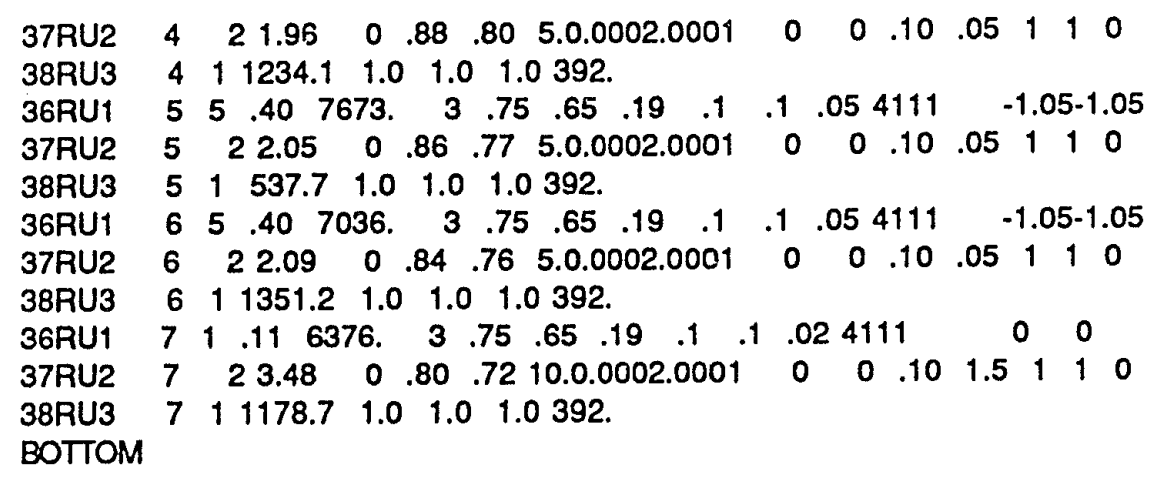


Appendix F

Input of PRMS Run 5 
Input Data for BLCK.CG1 Run 5

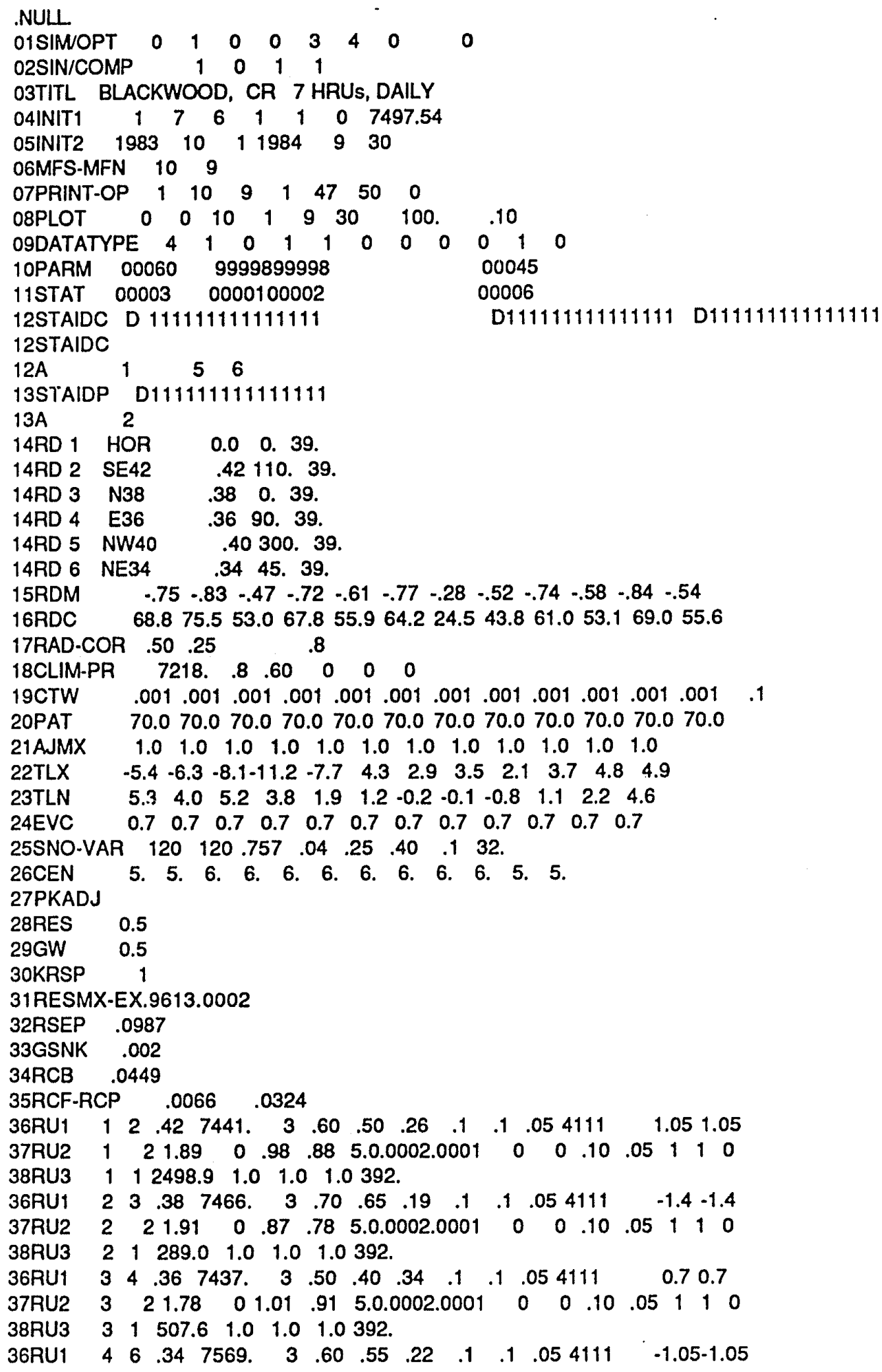




\section{Input Data for BLCK.CG1 Run 5}

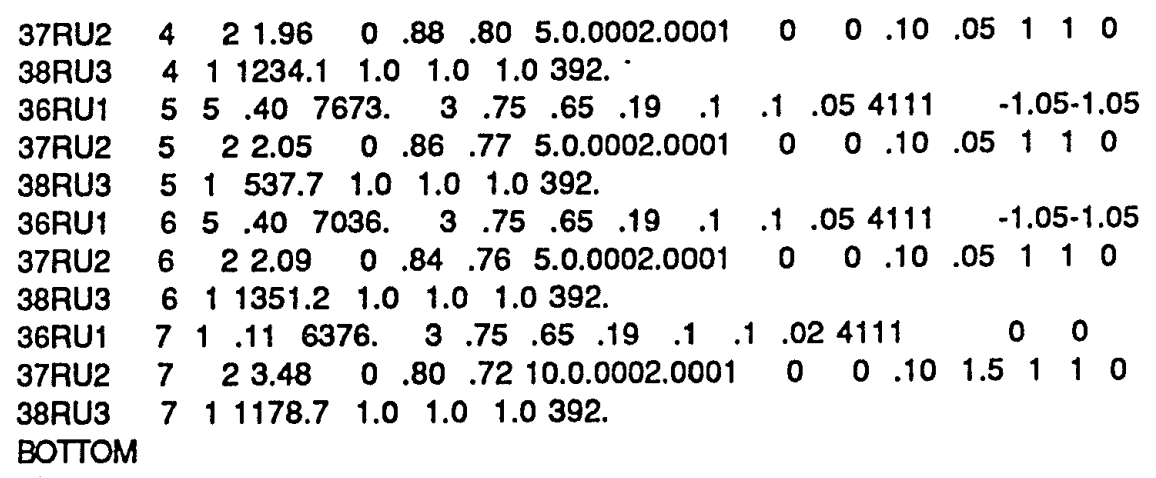




\section{Appendix G}

\section{Output of PRMS Run 1}

Output for PRMS is controlled by input switches in the model. The following output consists of 6 pages, with the first 3 pages consisting of input and model calculated parameters. Page 4 and 5 consist of the daily comparison between the observed and the predicted runoff values, and the final page represents the annual results of the model. 


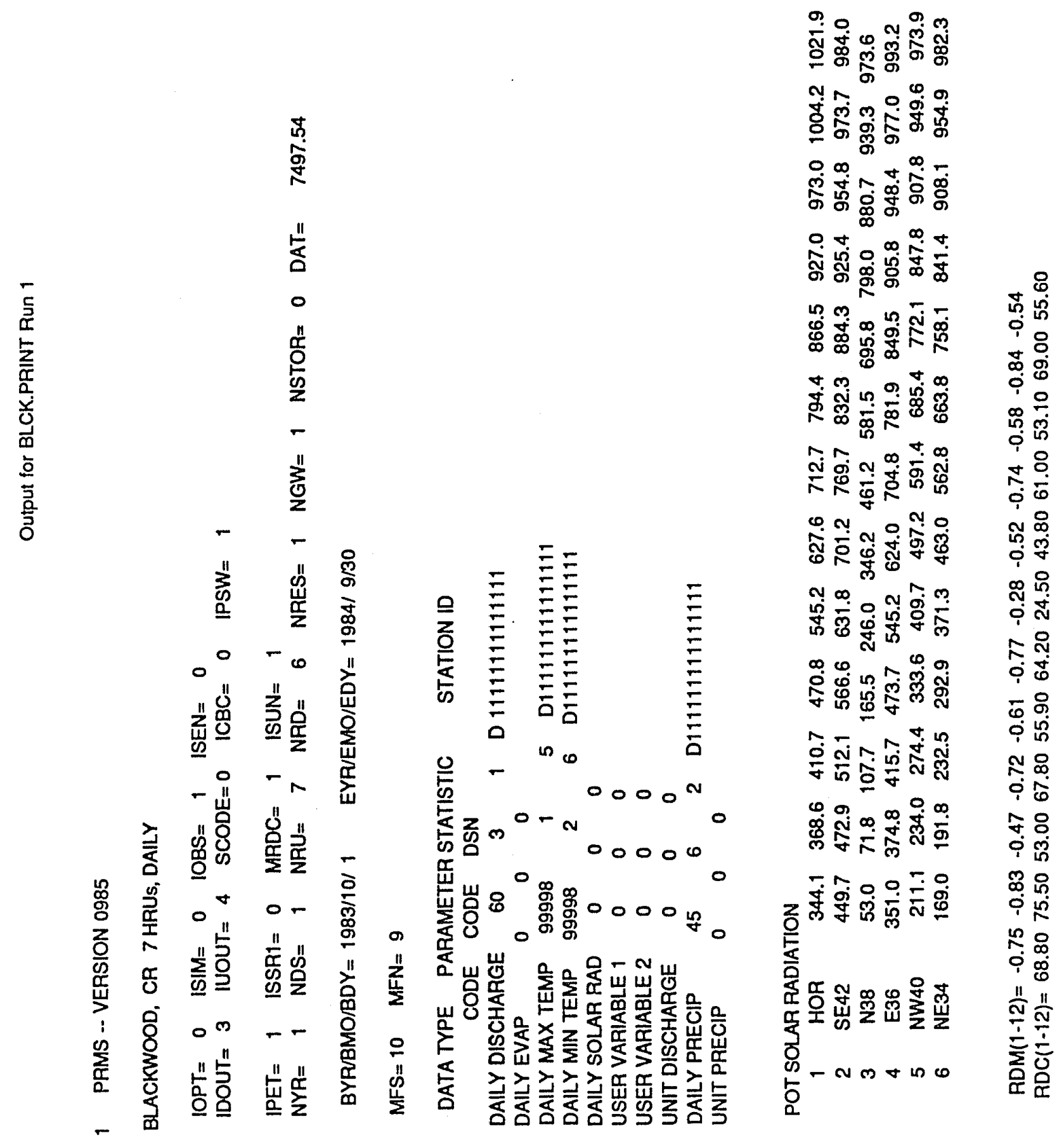




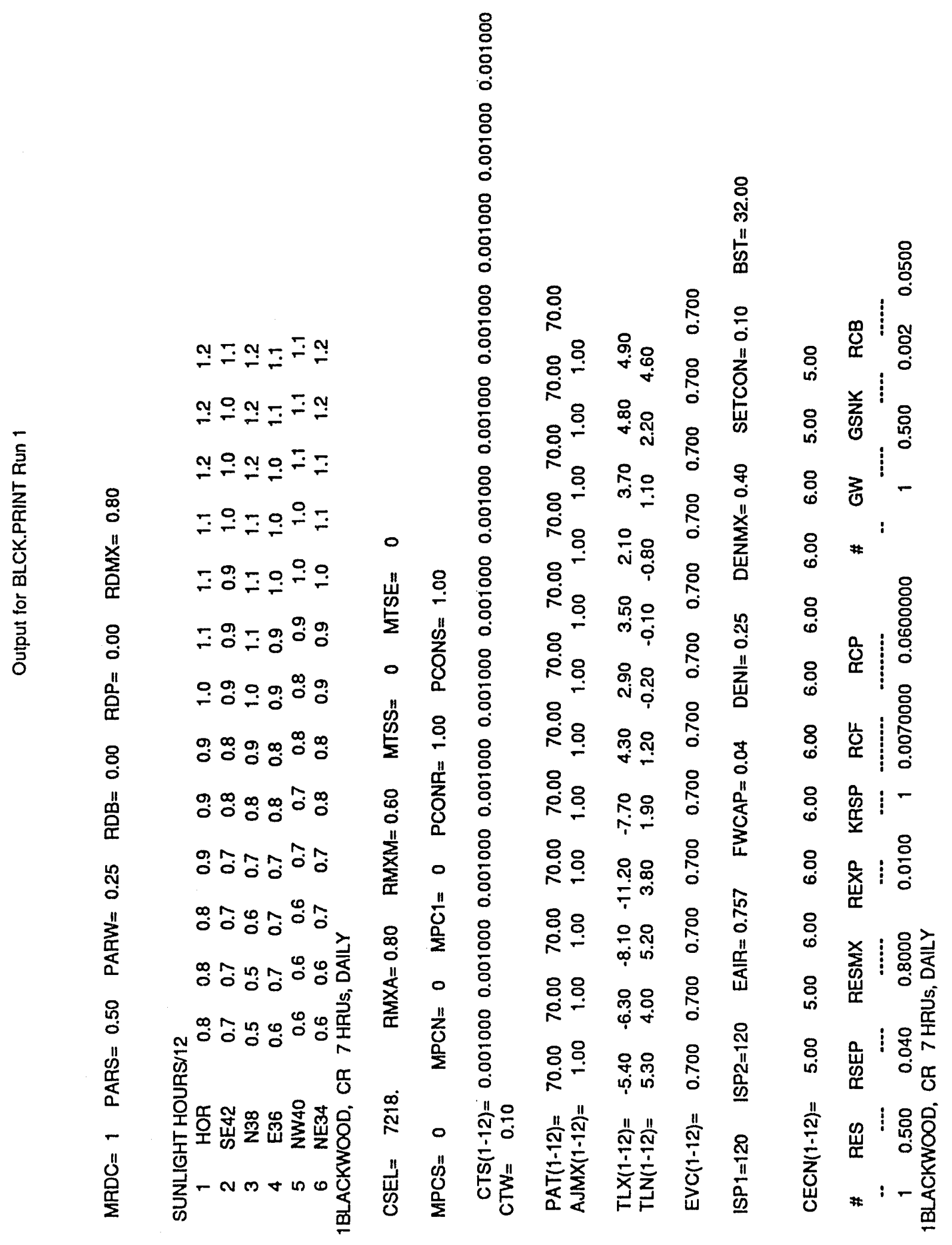




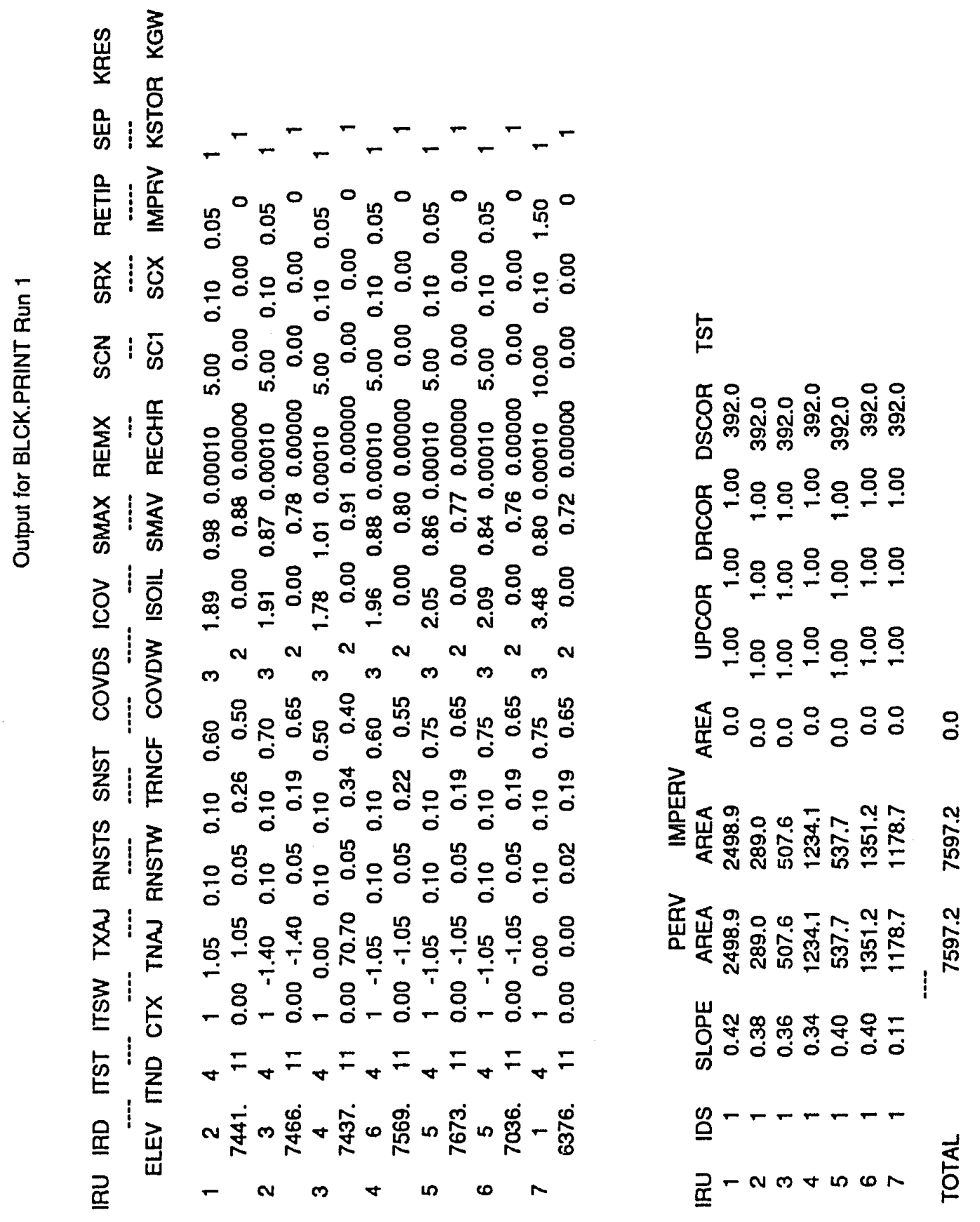




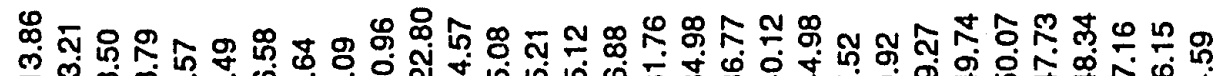
I

ஸ以 湈

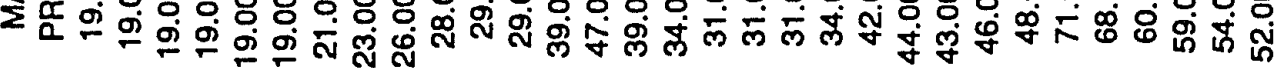

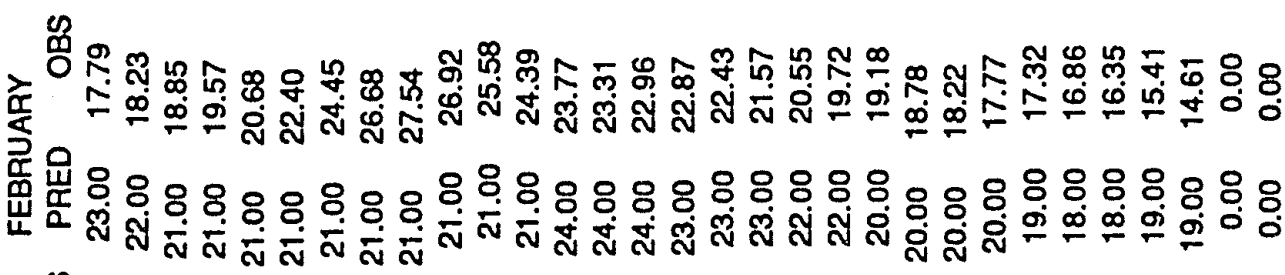

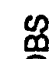

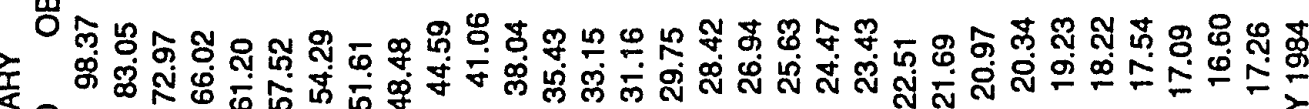
之㟧

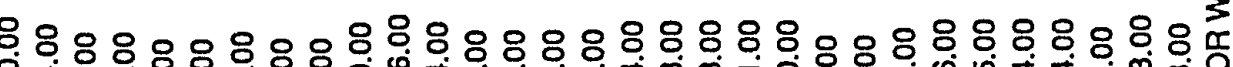

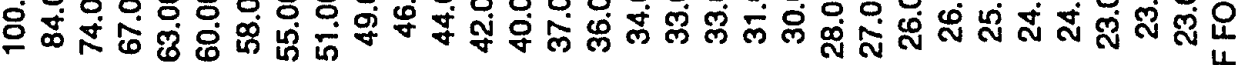

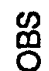

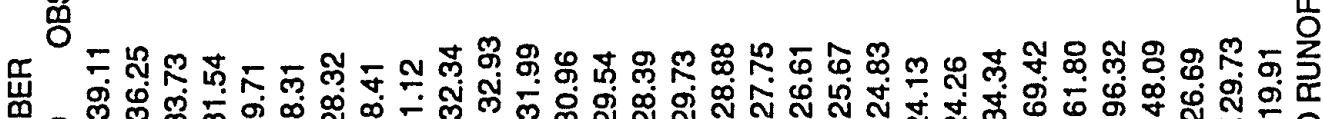

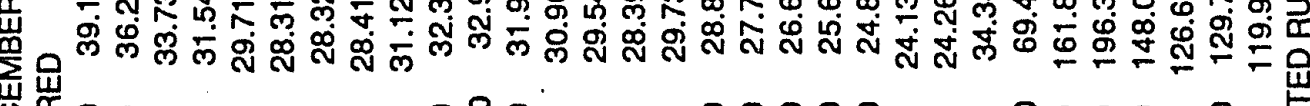
㟧 חึ

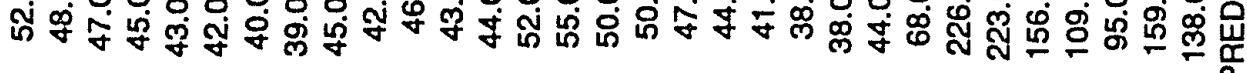

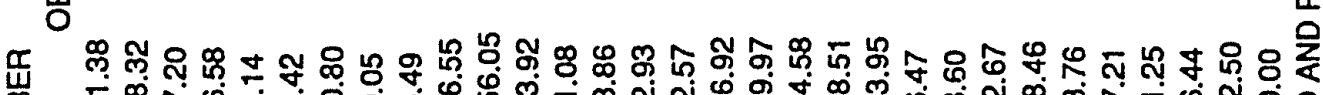

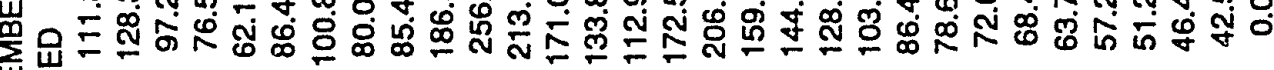
㟧 $\frac{w}{0}$ Oे 2

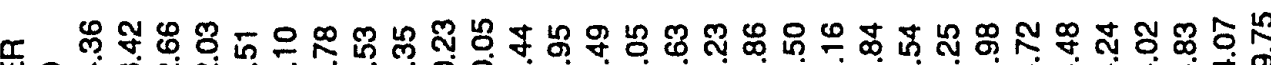

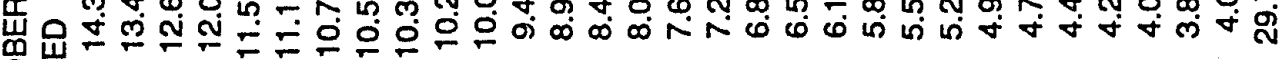
앙 郘

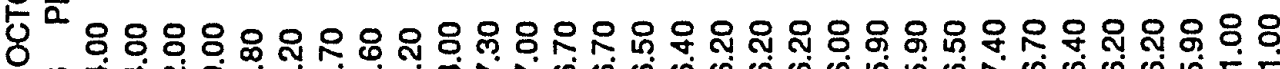

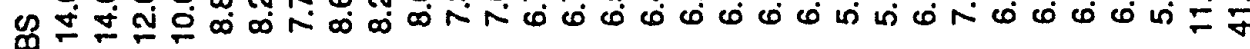
爻 - Nm 


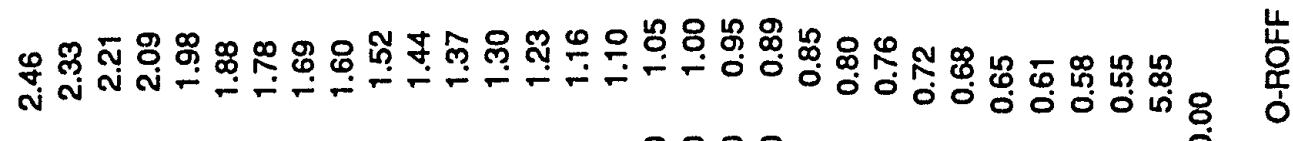

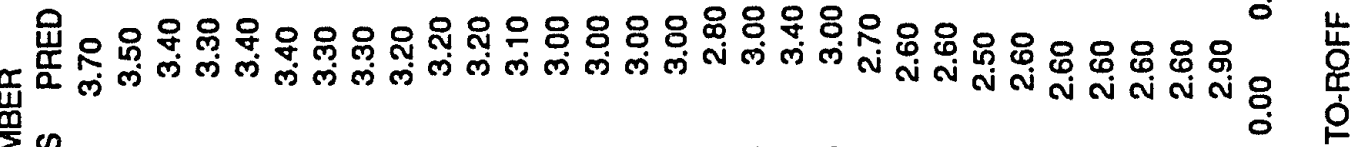

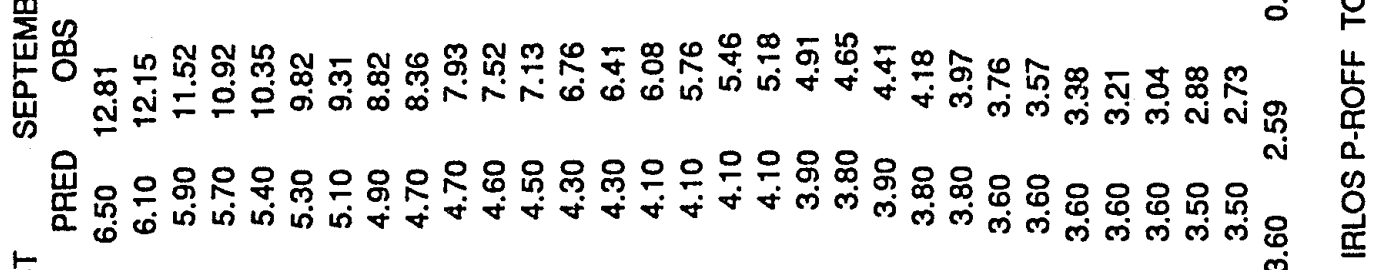
氜遌

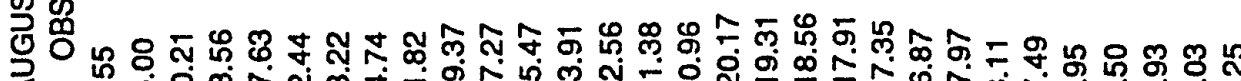

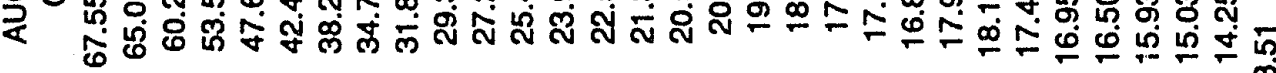

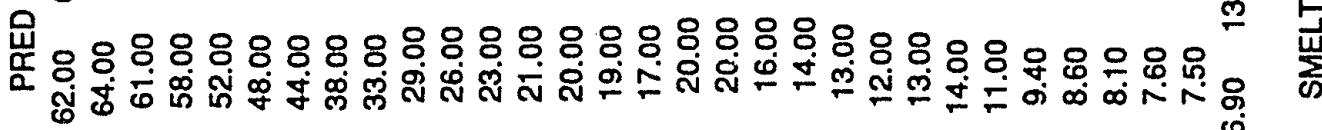
う号

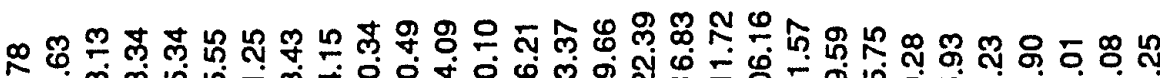

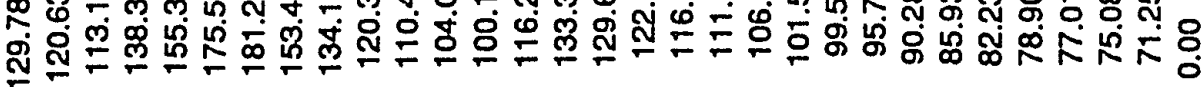



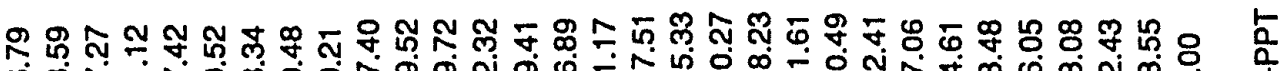

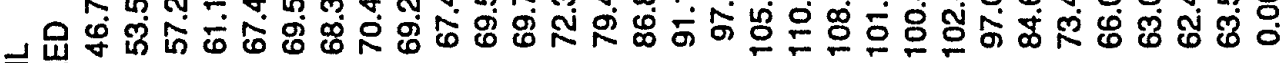

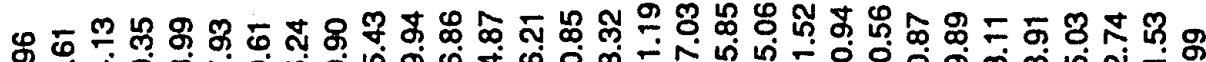

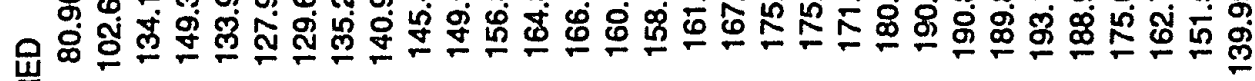

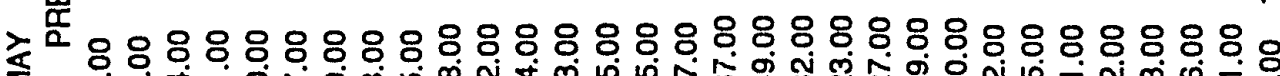

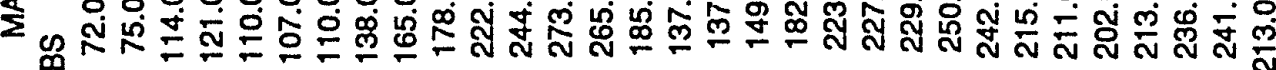

绥

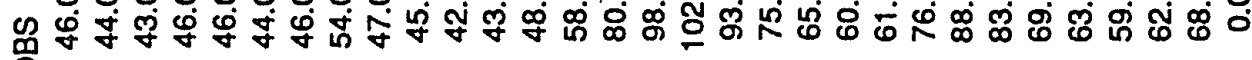
希 - Nm+4 o 


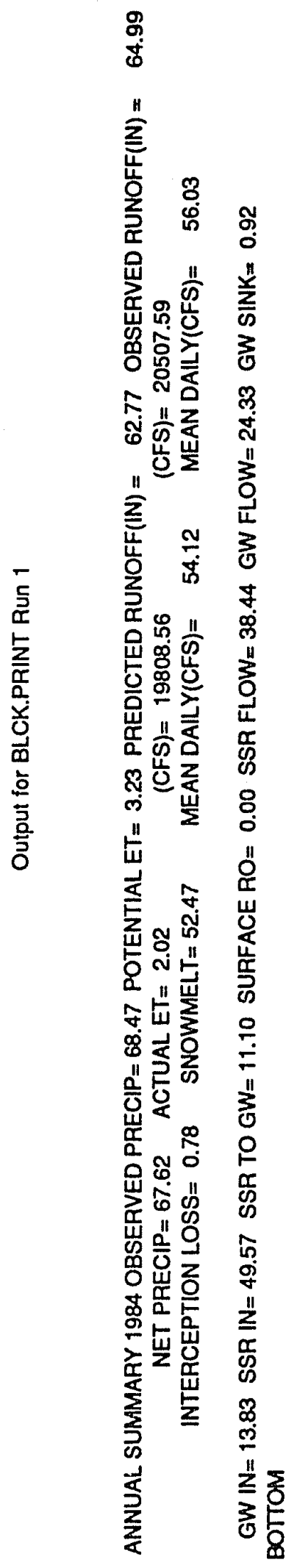




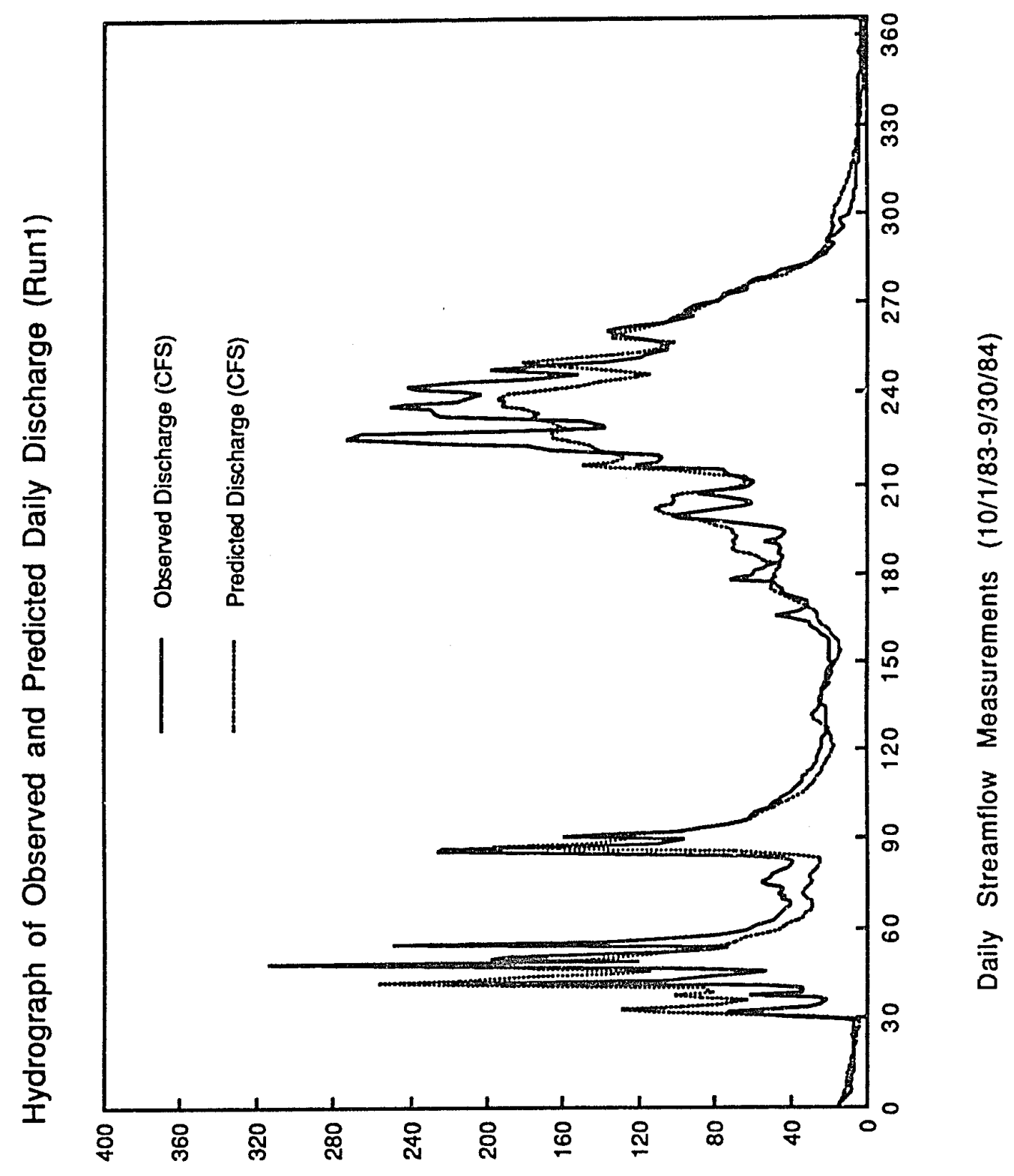

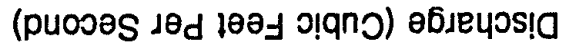


Appendix $\mathrm{H}$

Output of PRMS Run 2 


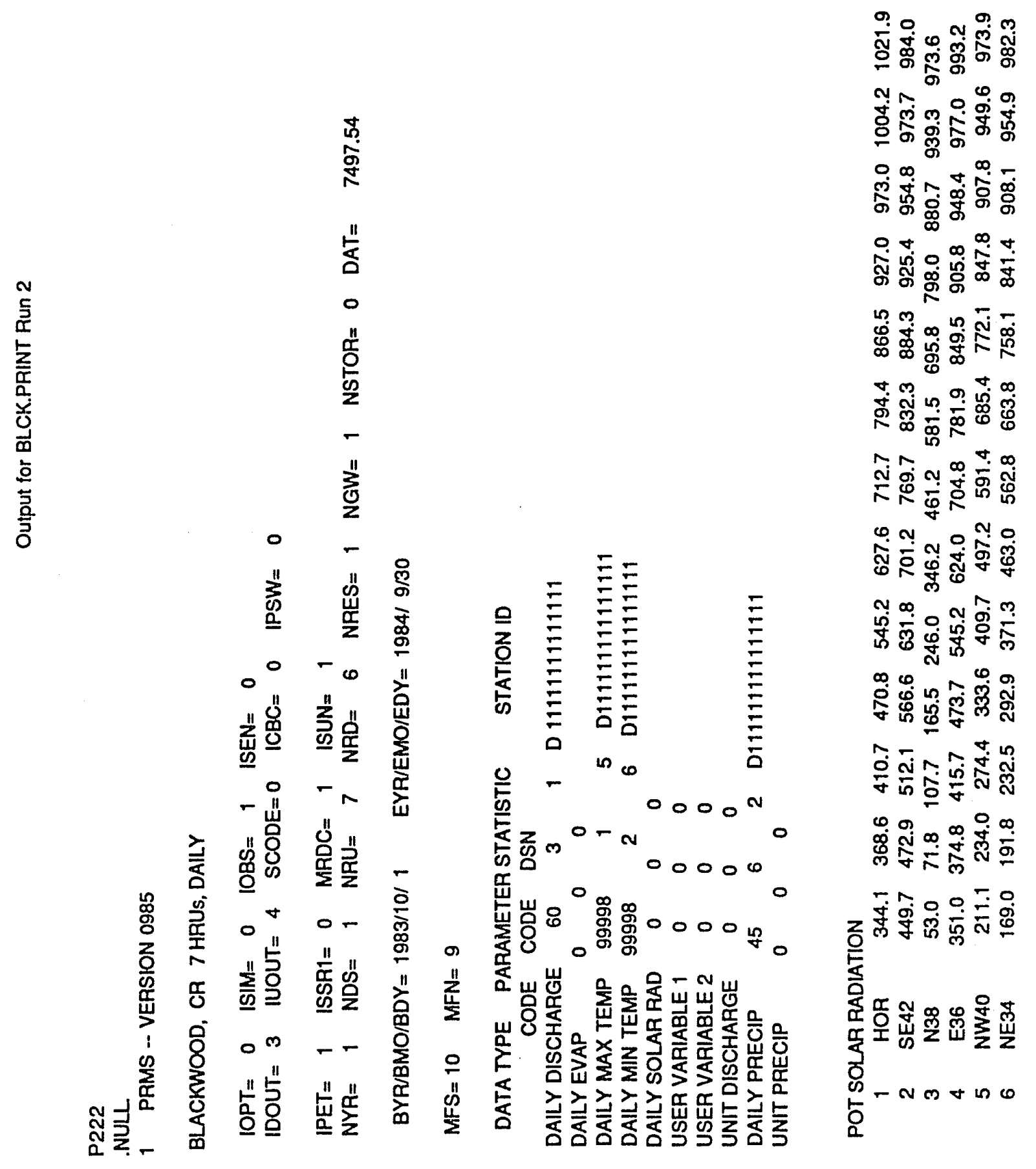




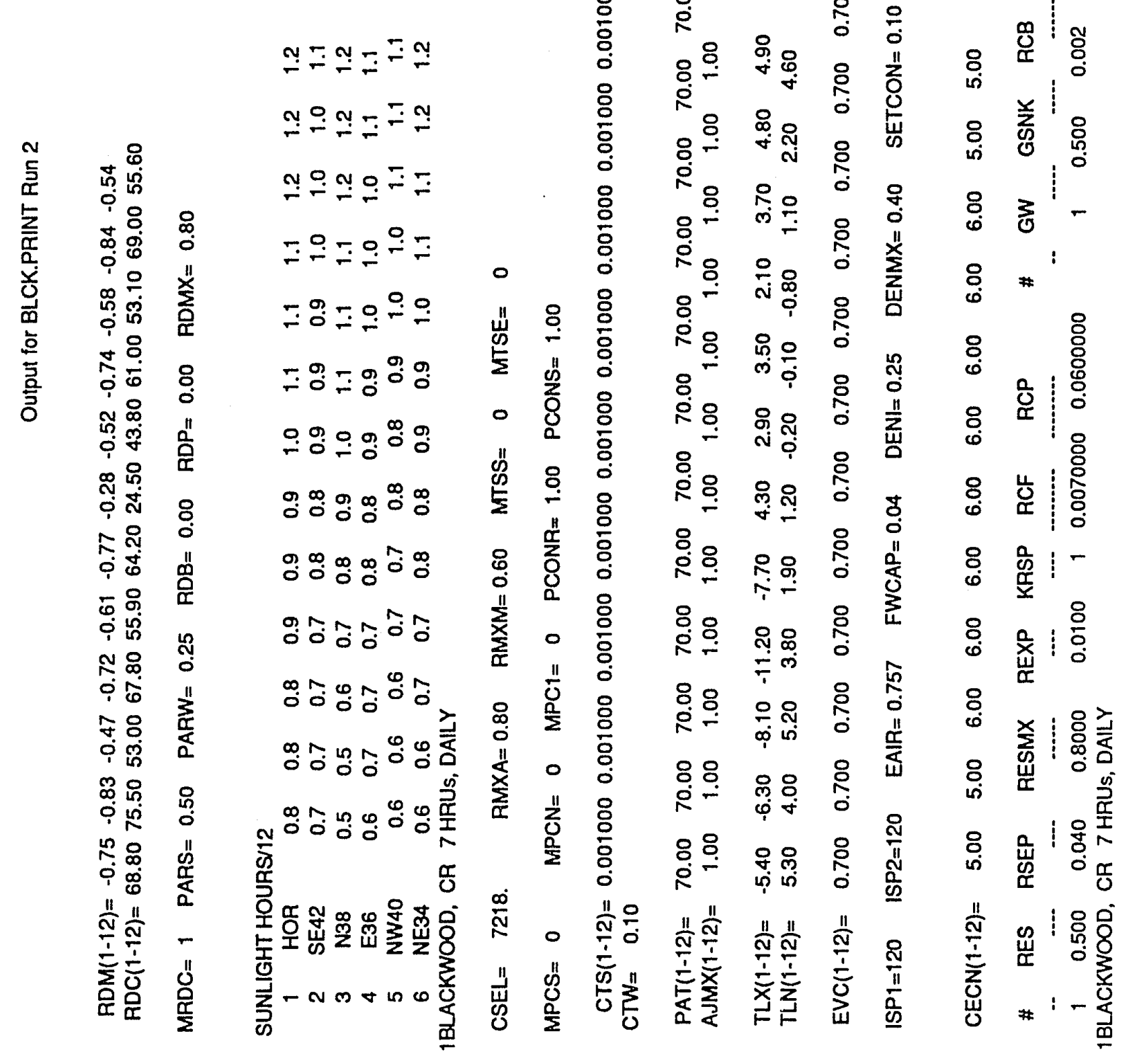




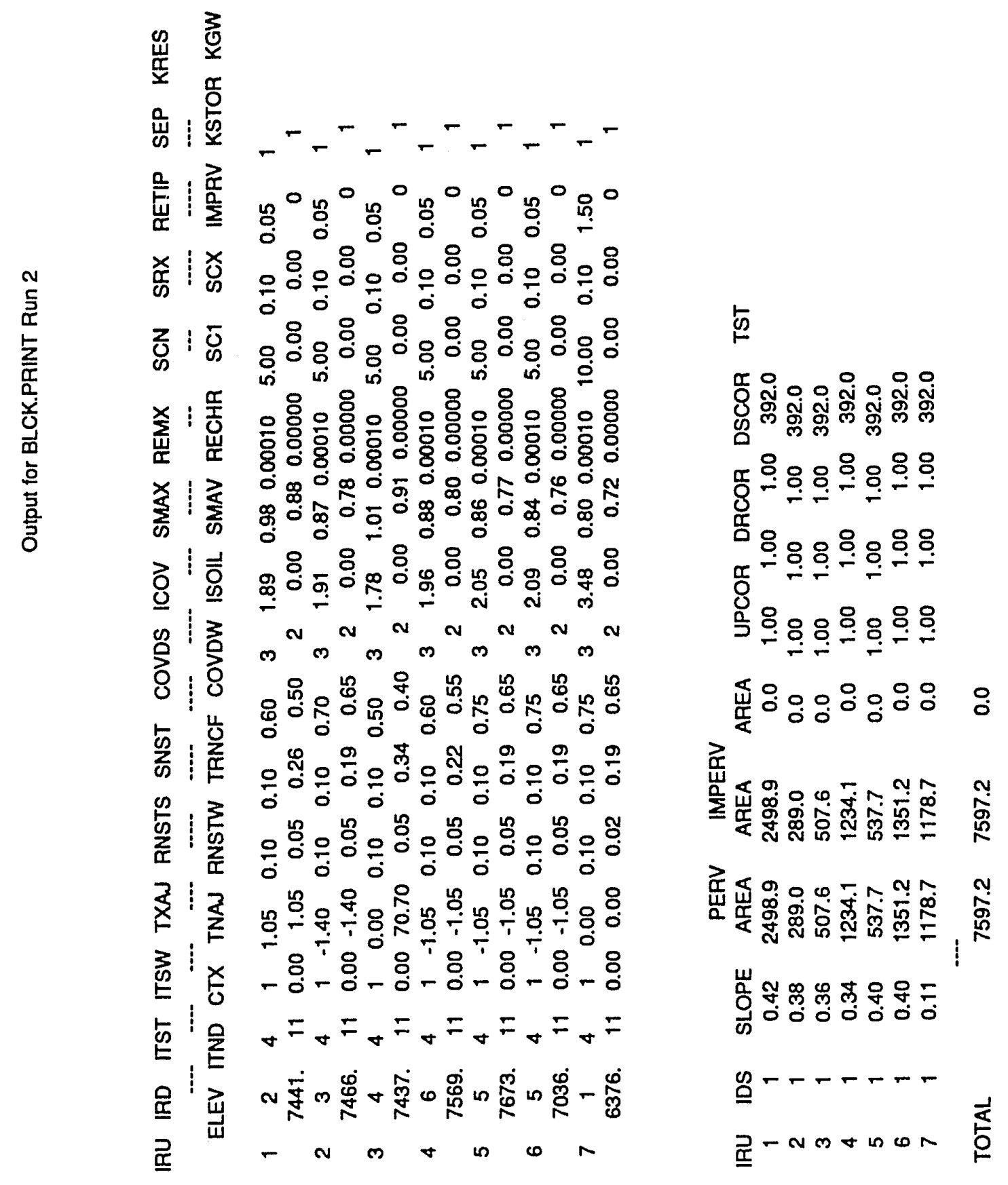




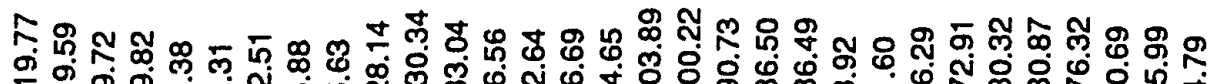
I 选湈 之婴

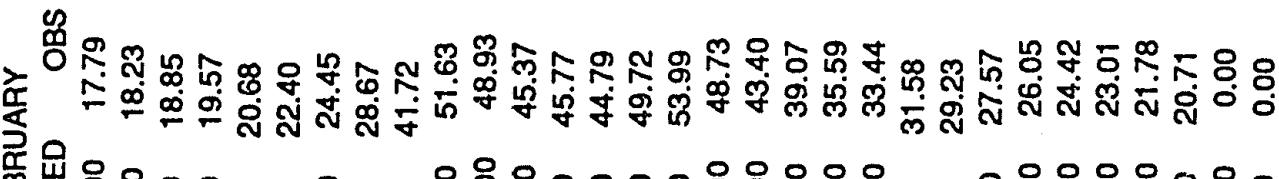

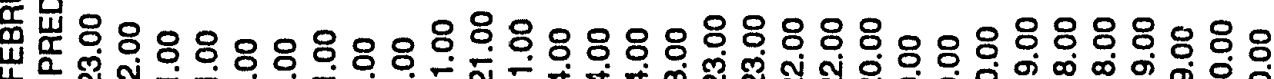

ณ

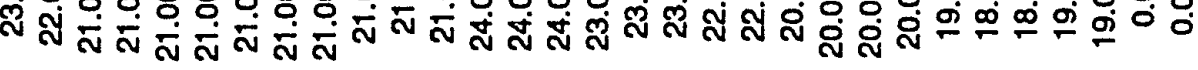

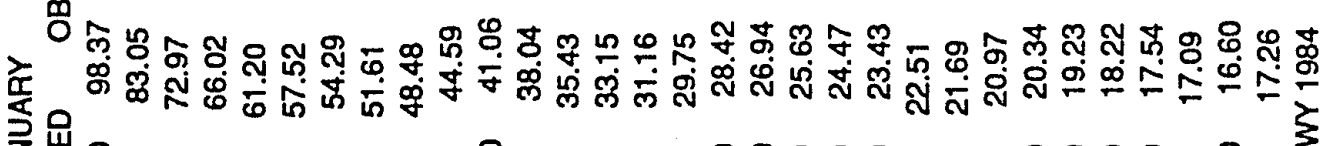

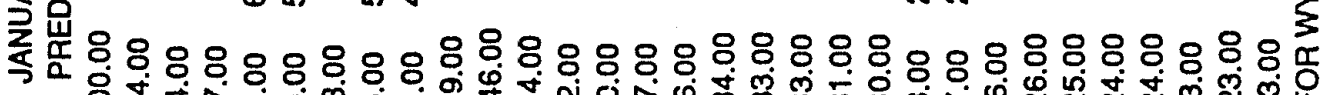
品

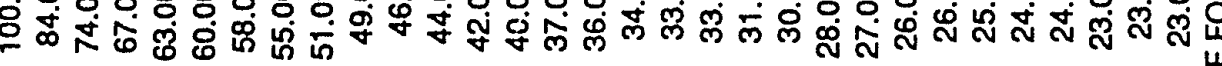

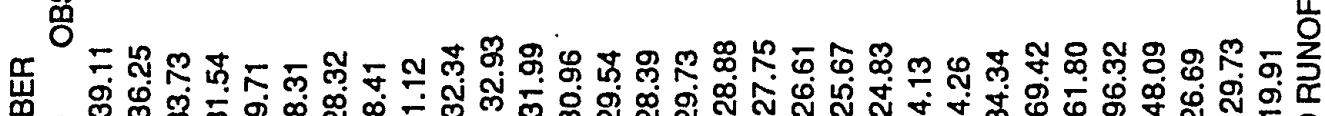

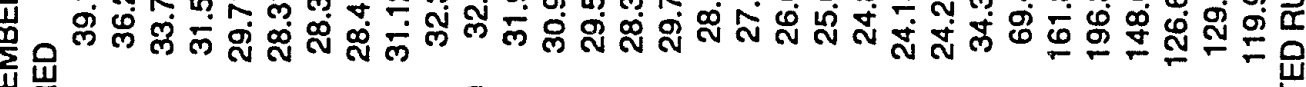

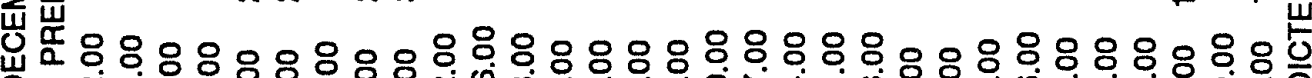
禺

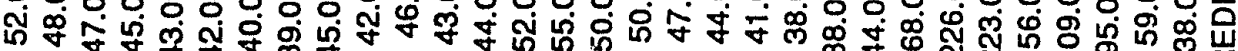

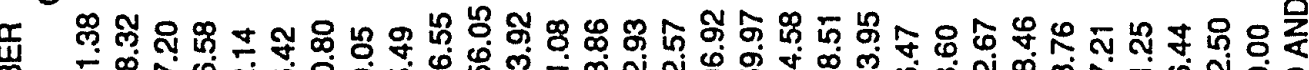

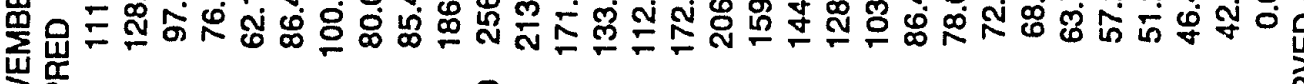

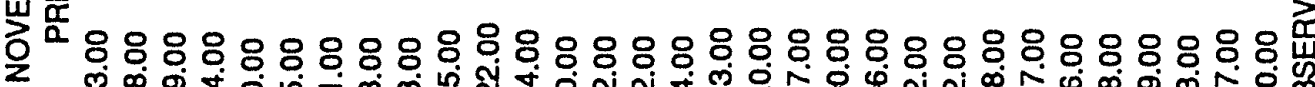

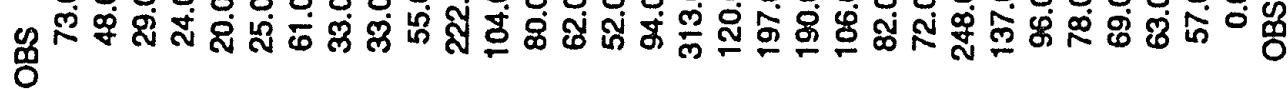

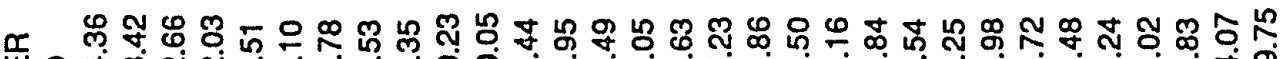

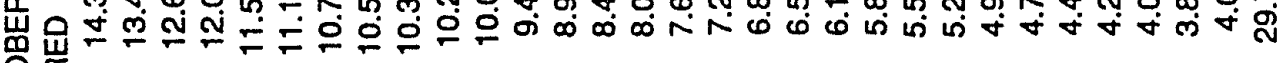
음

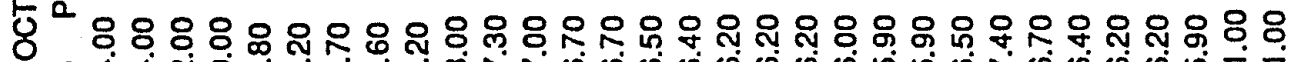

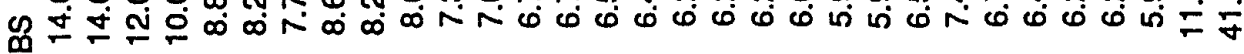
$\gtrless$

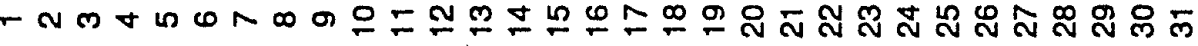




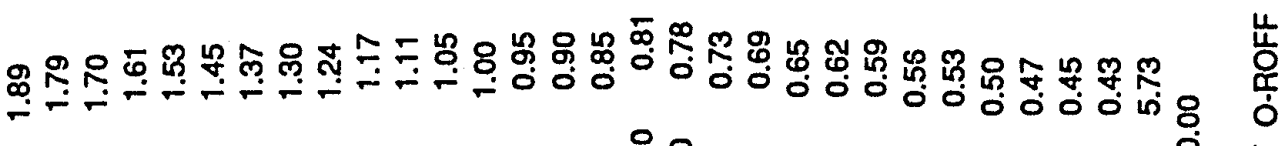

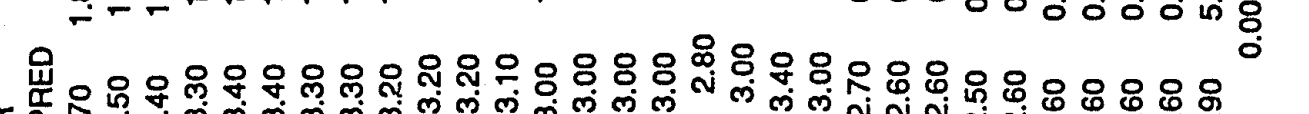

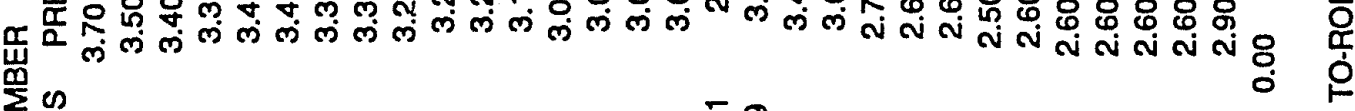

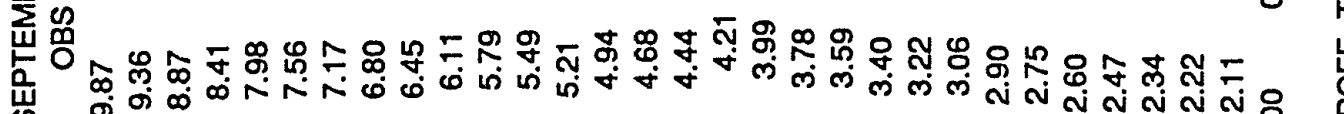
䧄

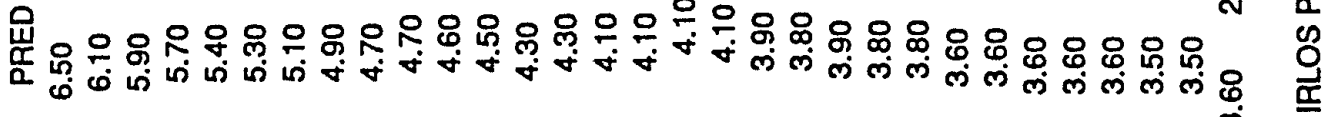

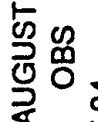

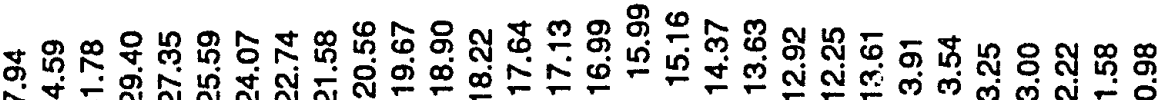

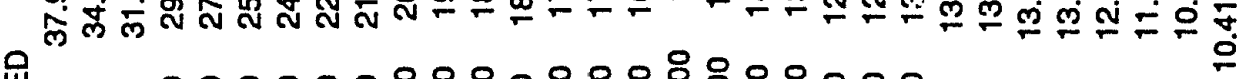

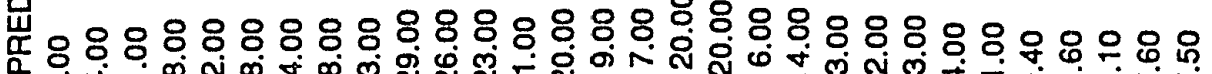
方号

نั่

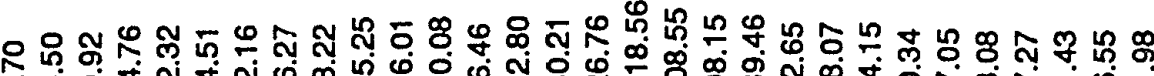

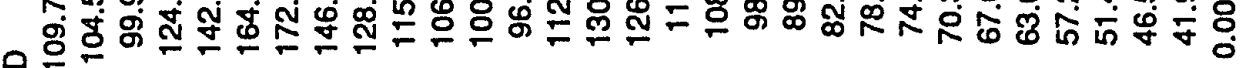

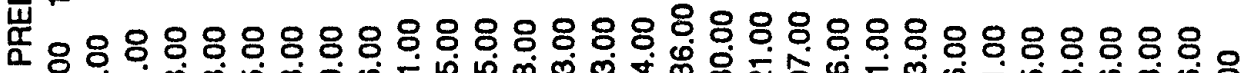

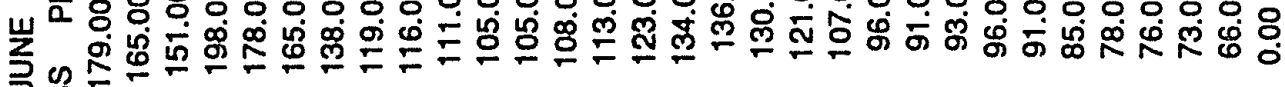
ơ

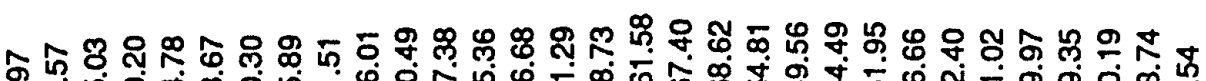

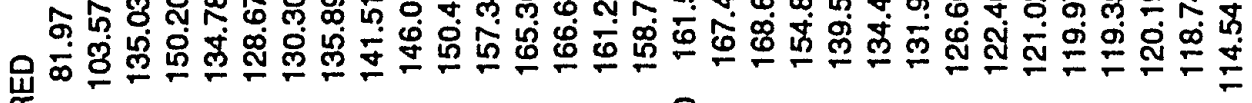

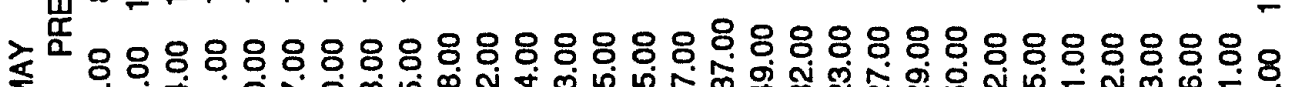

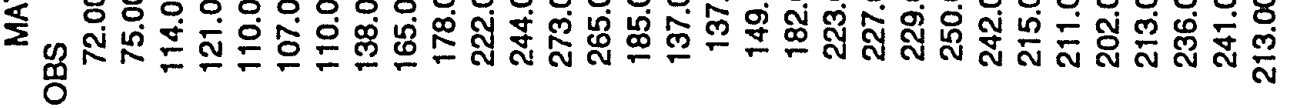

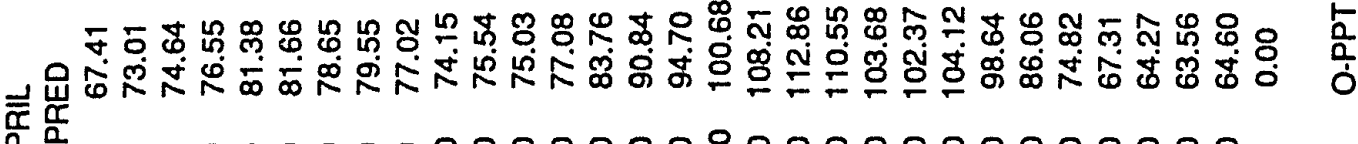

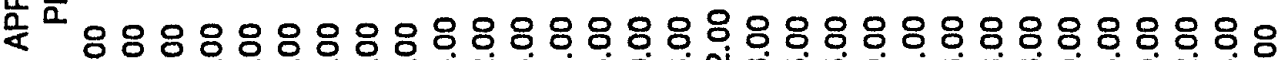

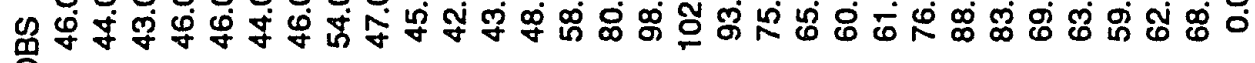
2 O

- Nm+แ 


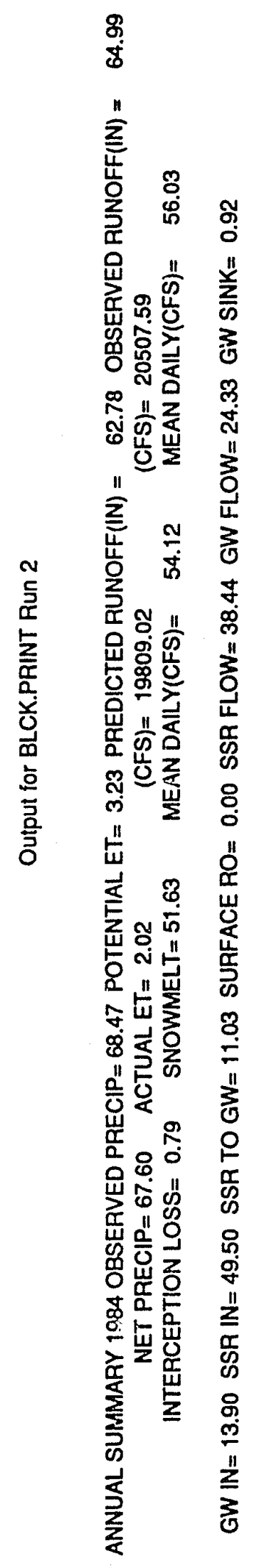




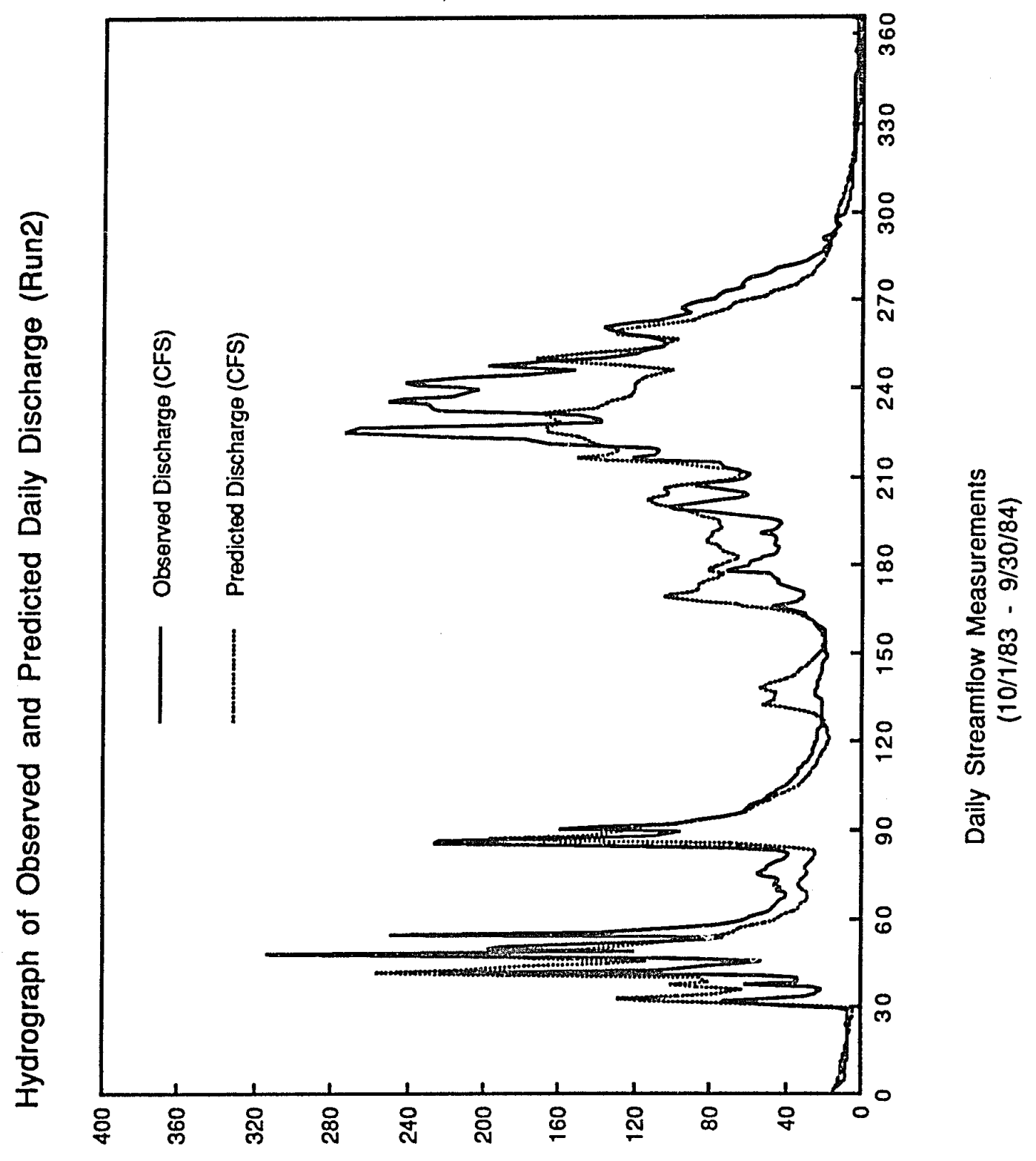

(puojas dad läy o!qno) abıeuos!a 
Appendix 1

Output of PRMS Run 3 







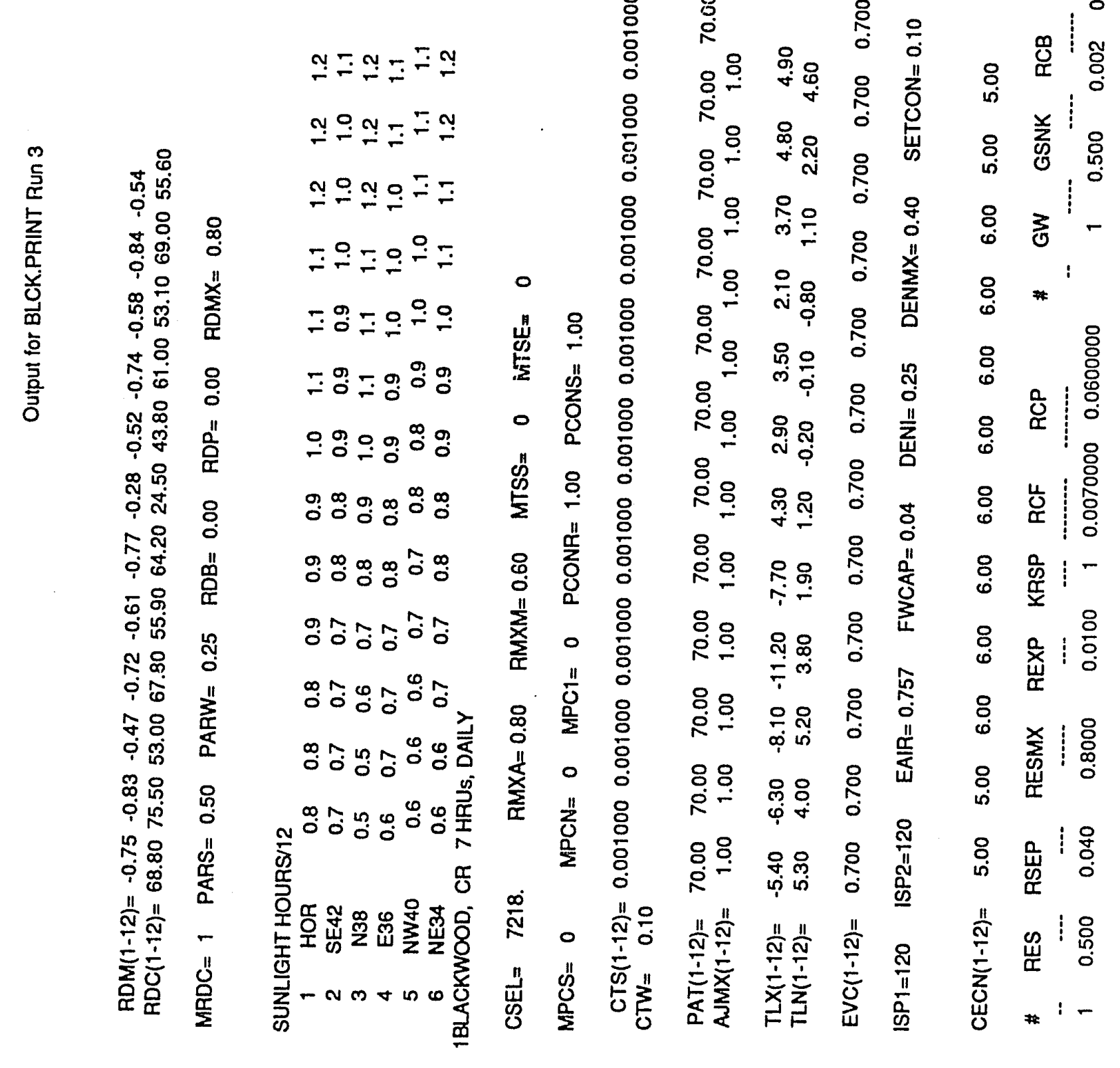




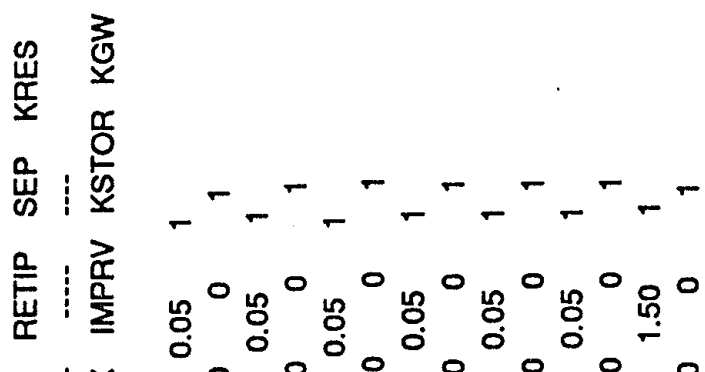

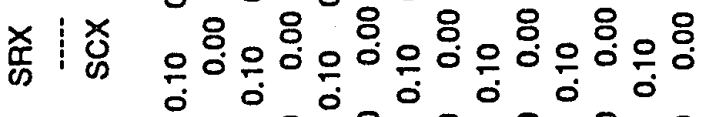
胥 ㄴㅣㄸ 希

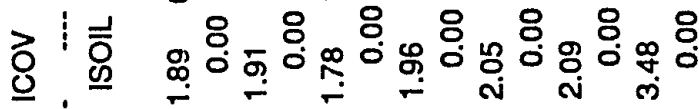

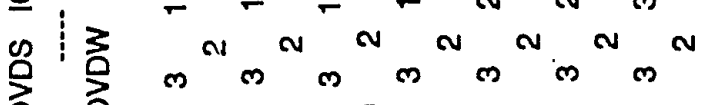
$8: 8$

융융용요 勿, 岁 冓 点 息: 点 II $\sum_{\text {II }}$ 웅 尔: 矛

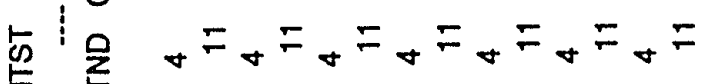
E, E

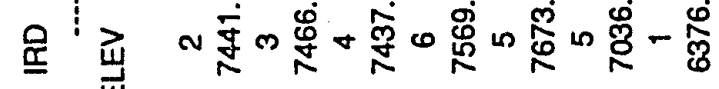
吕 - N $D+$ n $\infty$

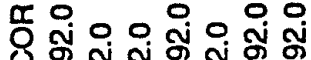

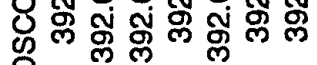

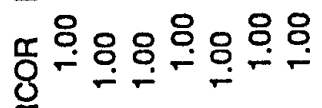

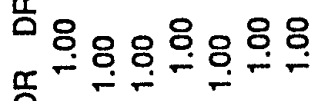

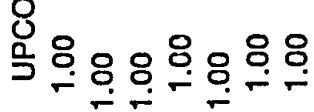

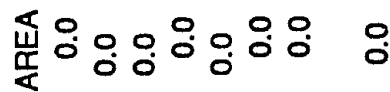
端

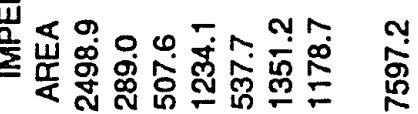

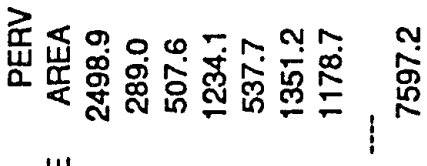

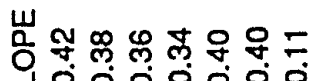

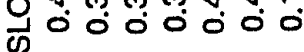

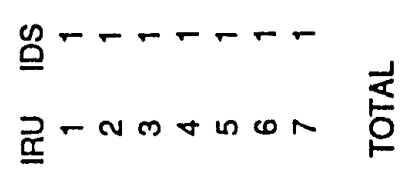




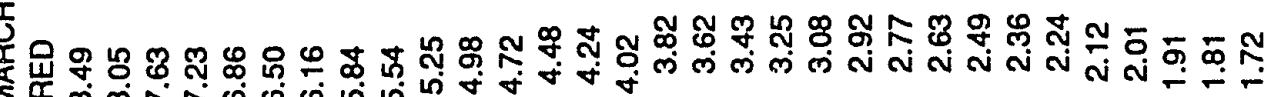

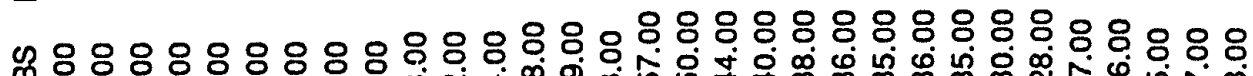

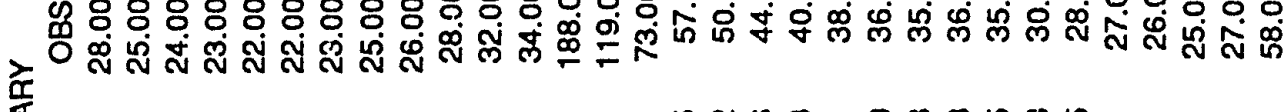

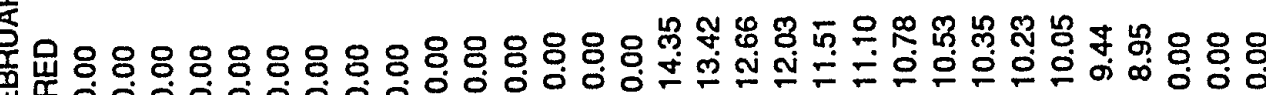

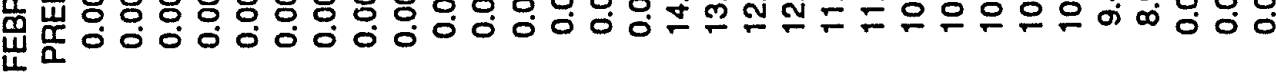

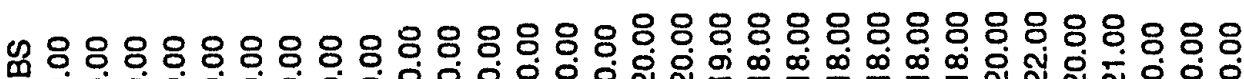

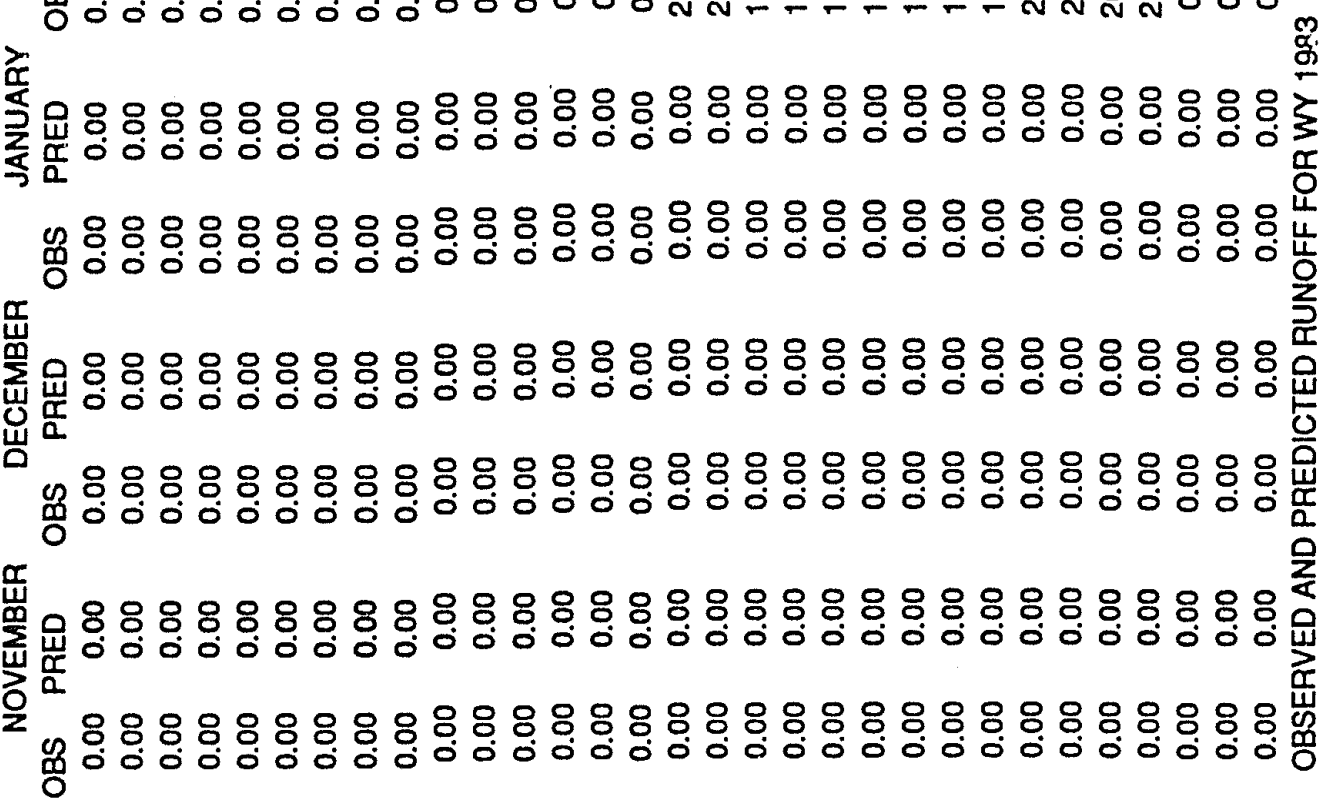

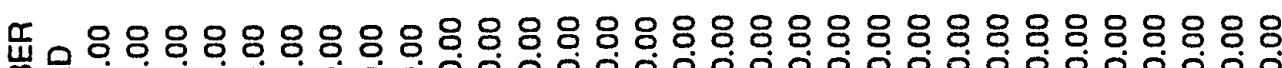

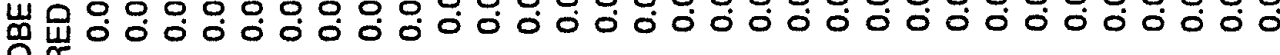
웅

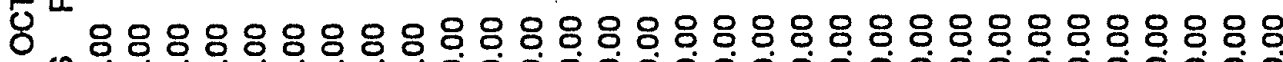

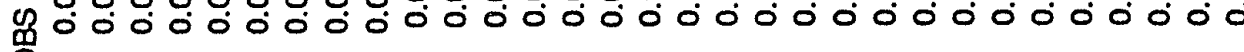

$$
\text { ๖ั }
$$

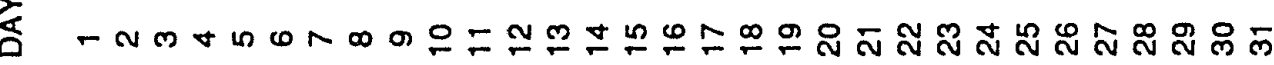




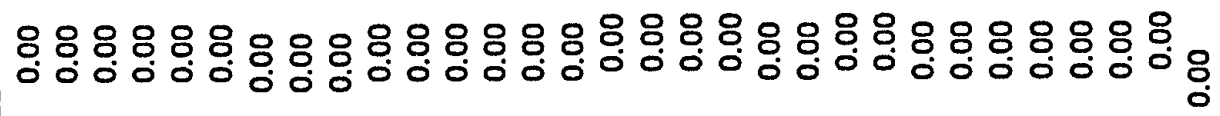

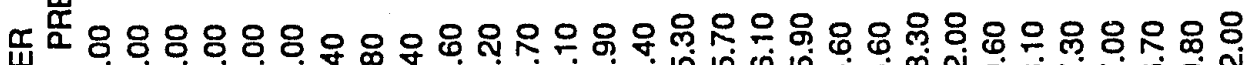

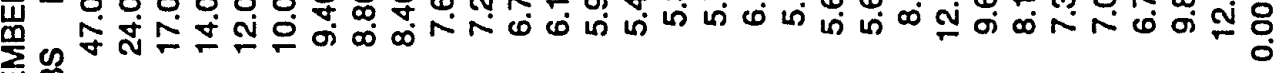
岕号

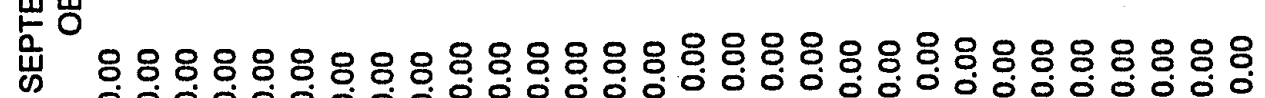
垔

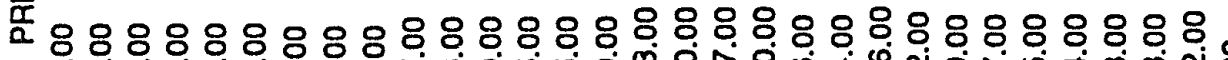

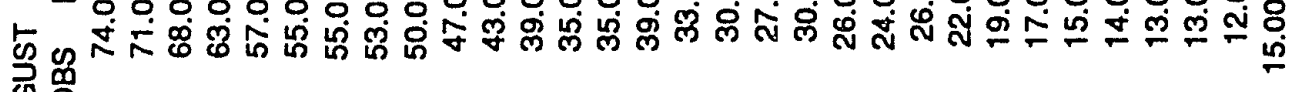
过

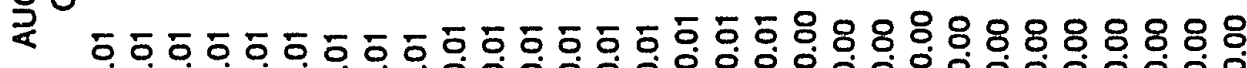
윰

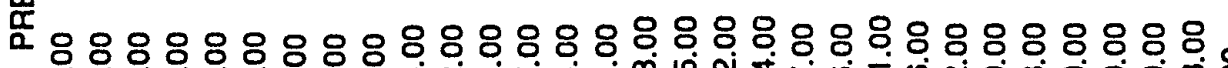

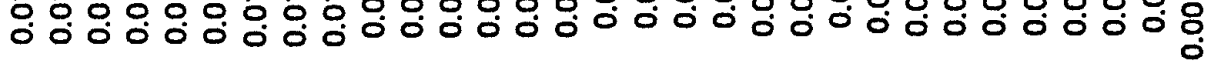

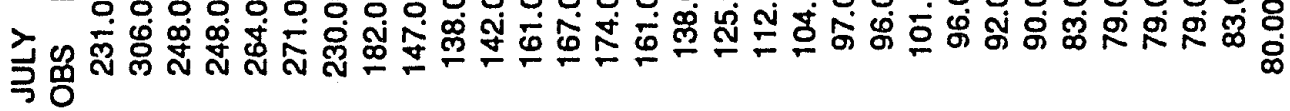

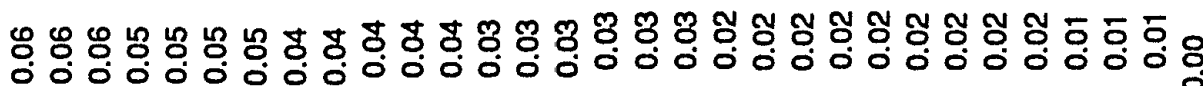
س

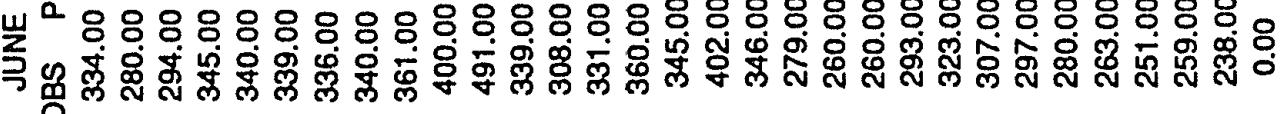

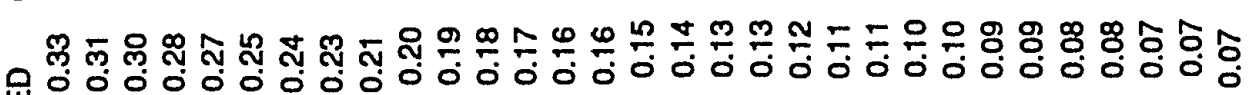
خ

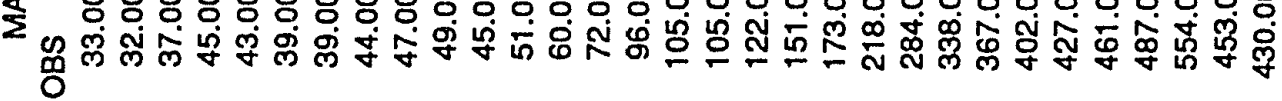

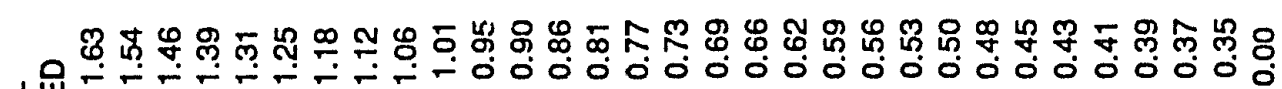
层

द 8888888888888888888988888888888

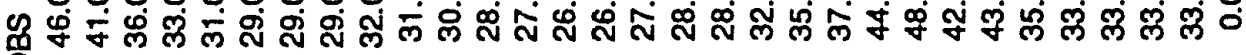
ชั

III

志

岃

잉

능

崖年

范 8 


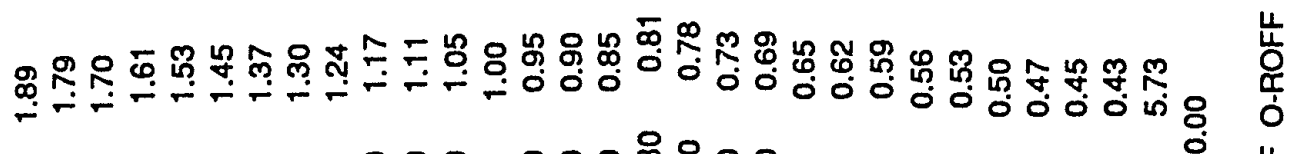

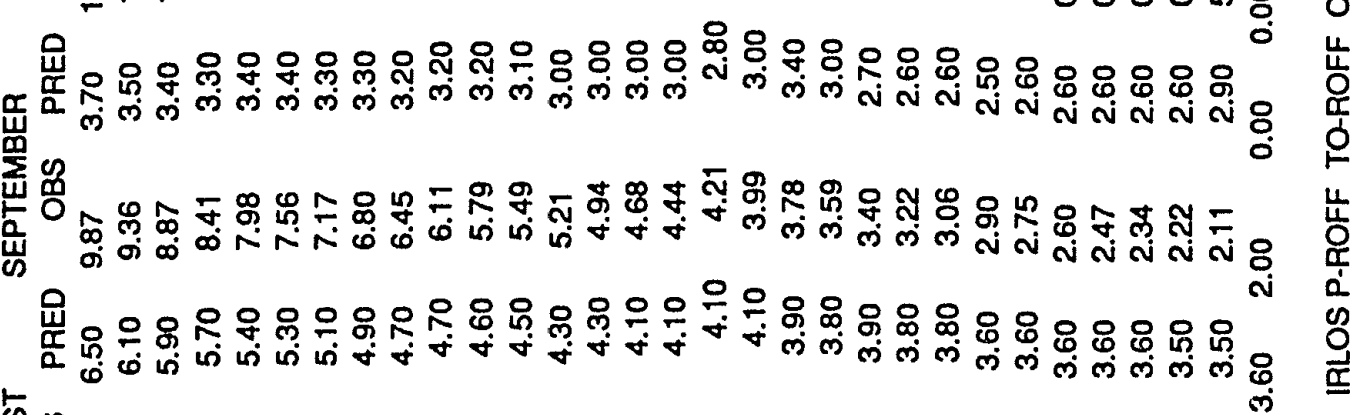
邪吕

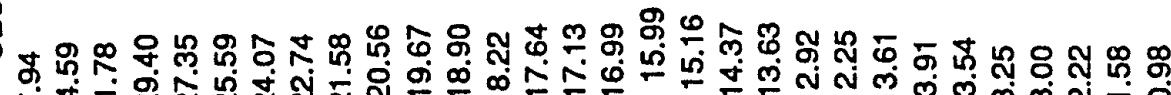

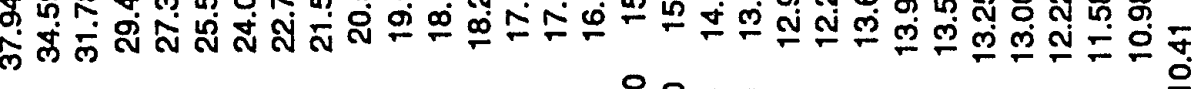

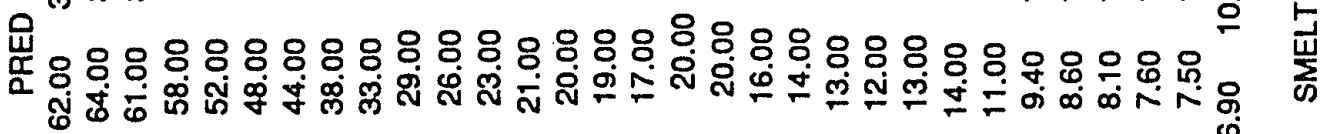
㝋哭

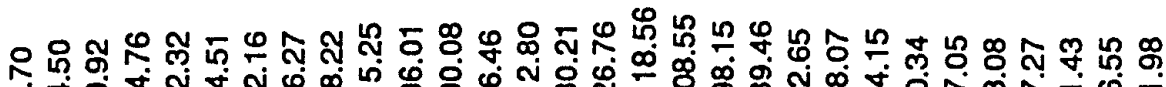

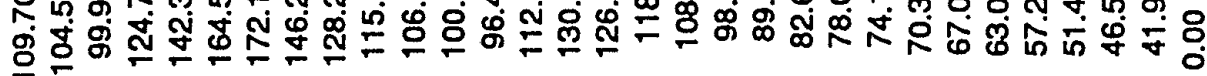

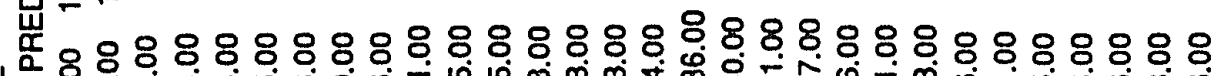

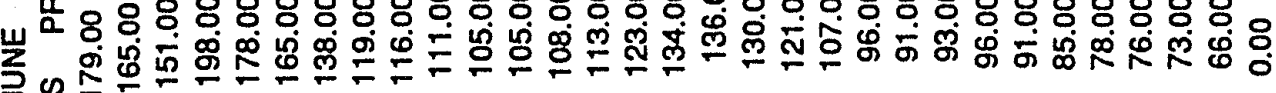
哭

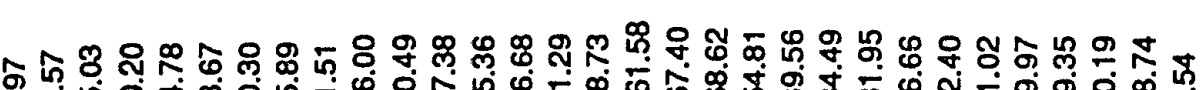

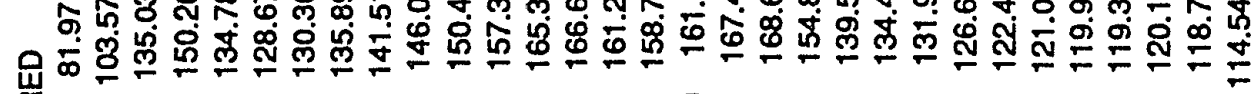

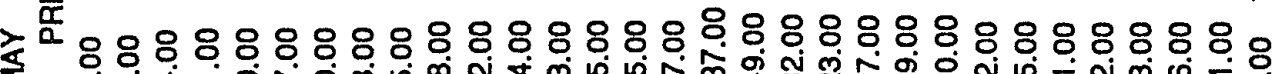

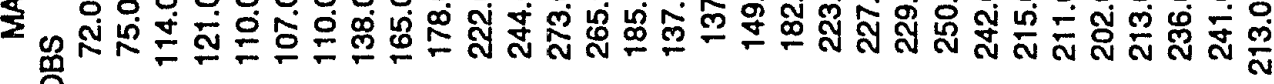

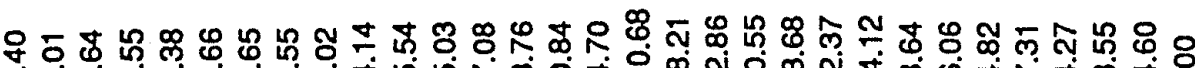

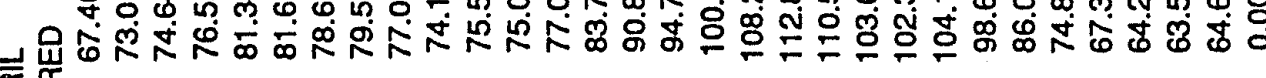
뜸돔

8888888888888880888808888888888

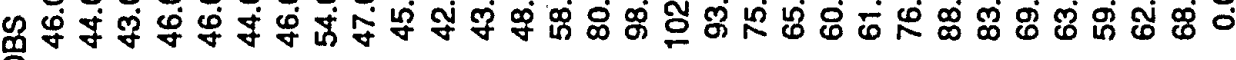
文

ー ผ 


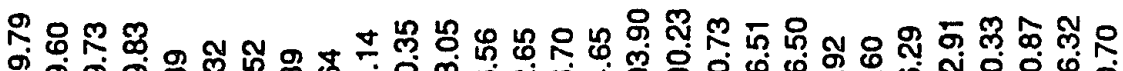

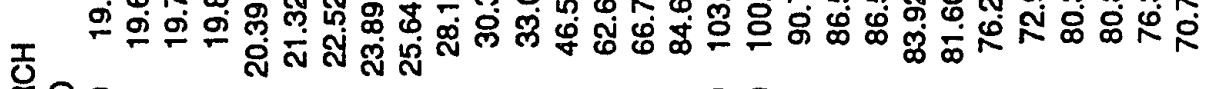

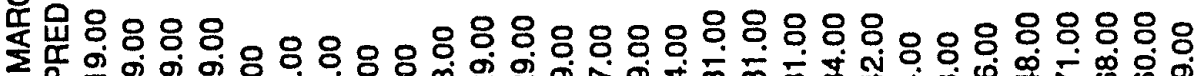

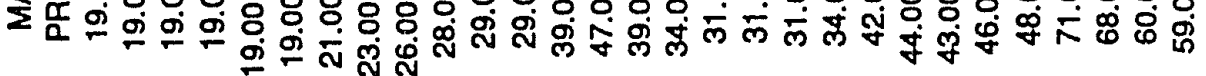

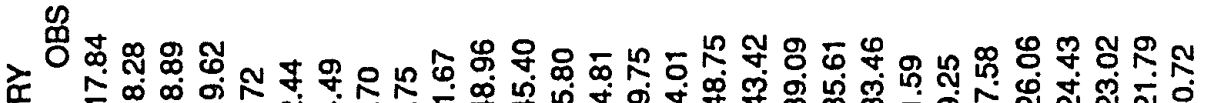

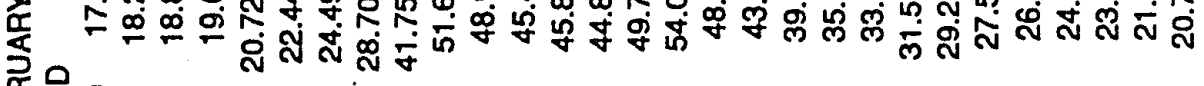

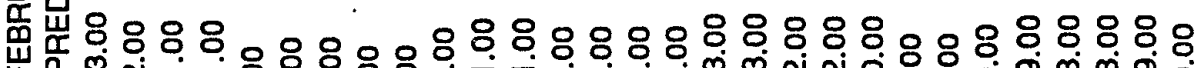

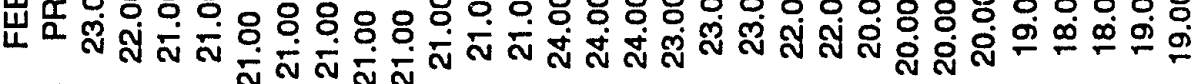
边

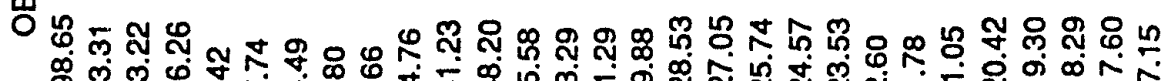

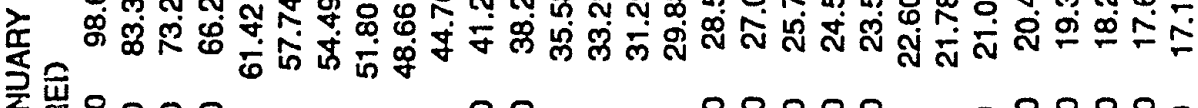

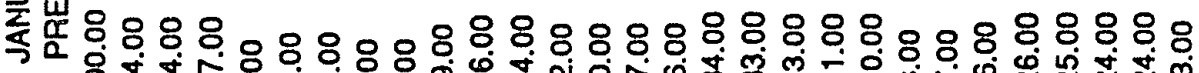

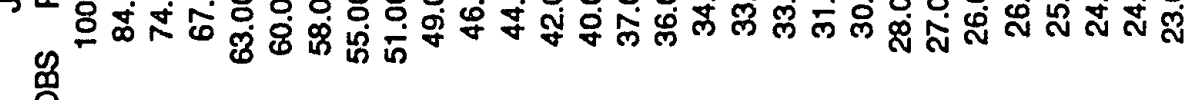

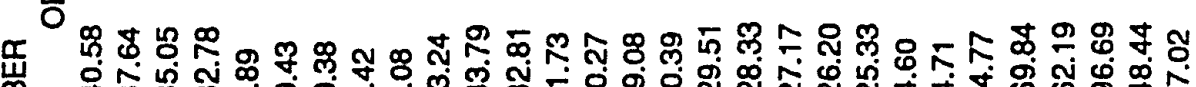

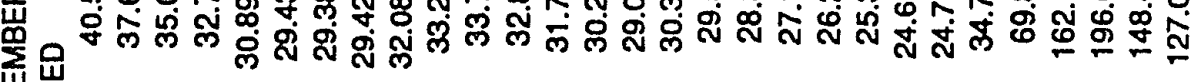
岀崖

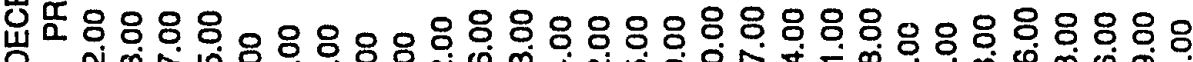

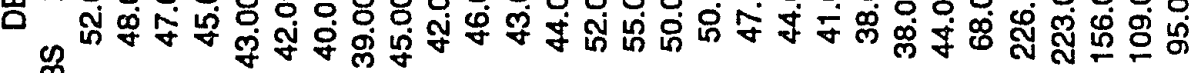
o

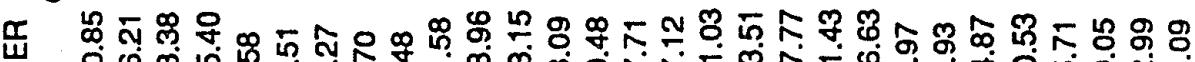

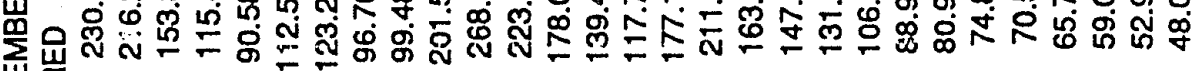
फ岴

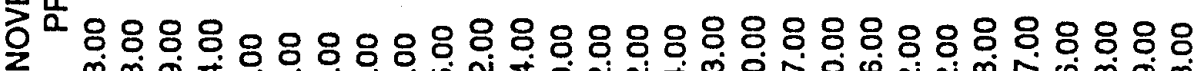

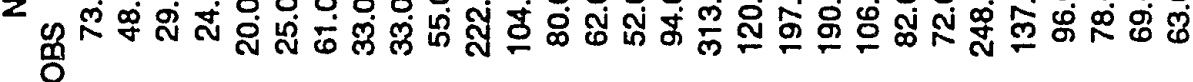
丘 苟

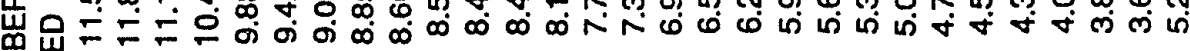
응 $\frac{\pi}{2}$

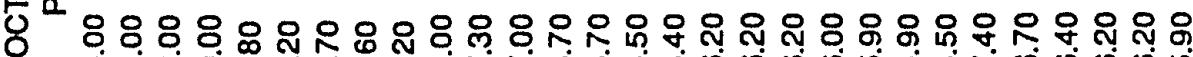

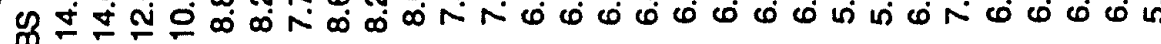
\ 
g용

வீ

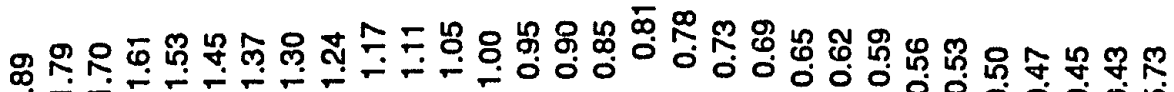

8.8

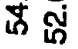

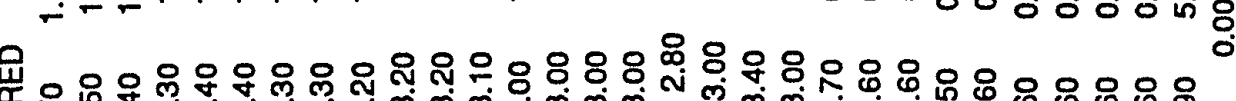

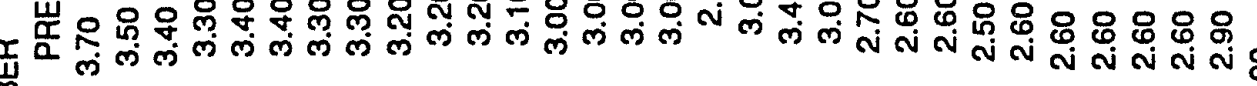
罦

$\sum_{W}^{\infty}$

용요

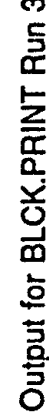

8

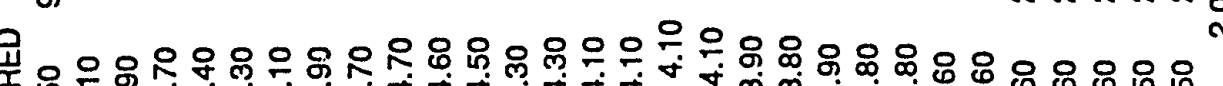

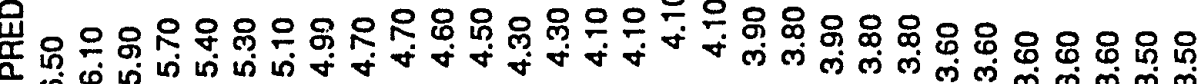

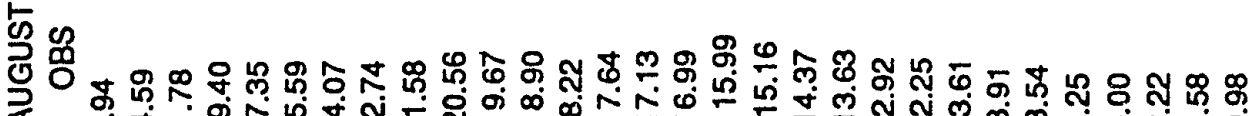

禺芦

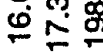

$8 .{ }^{3}$

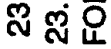

士

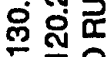

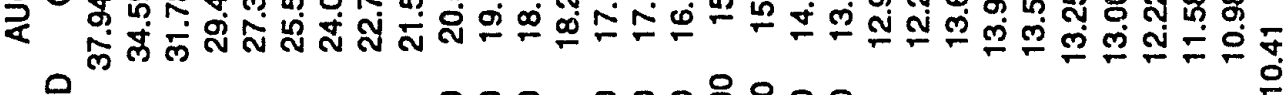

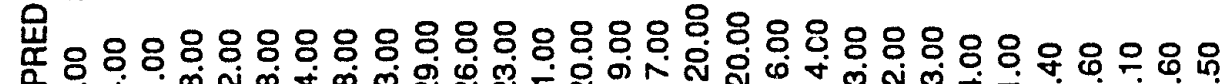

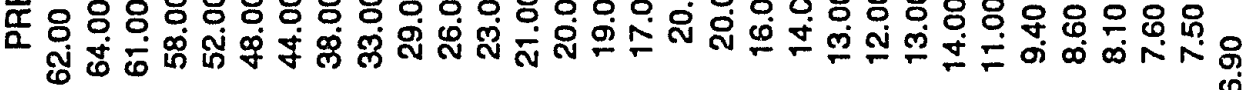
总

$8 \circ \frac{15}{80}$

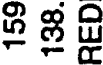

눙 8 웅

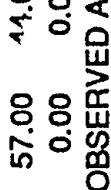

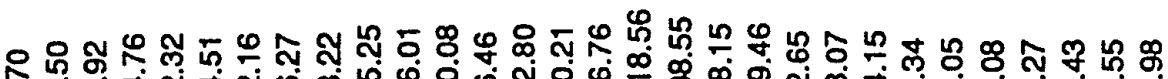

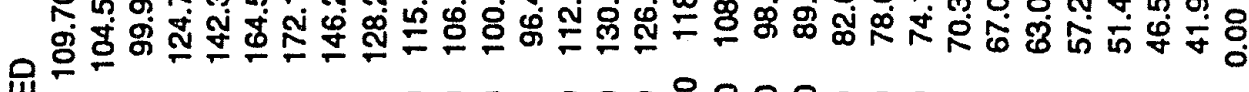

世

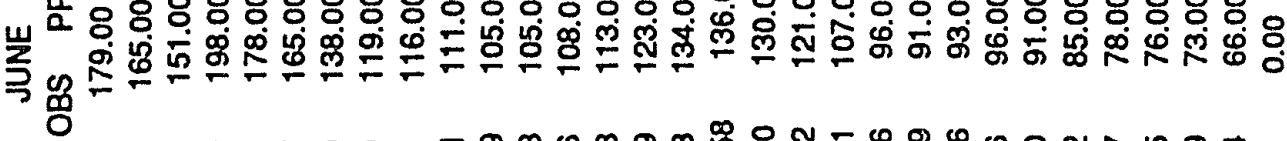

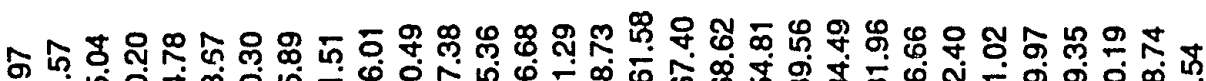

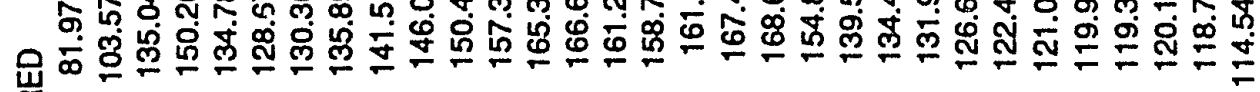

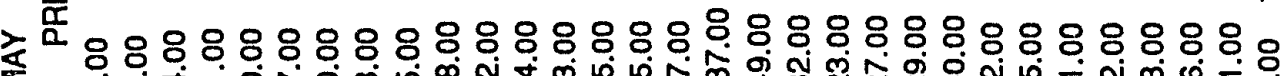
吕 N

우 우

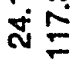

88

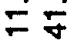

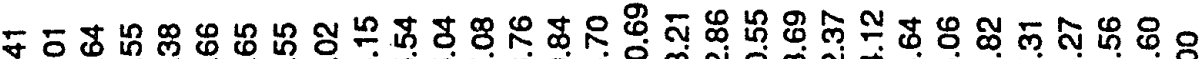
룸

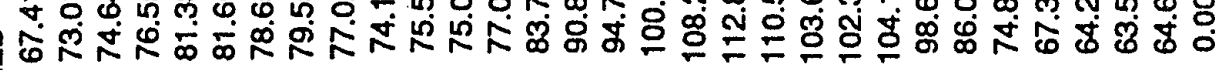
$\frac{\pi}{2} \frac{\pi}{\alpha}$

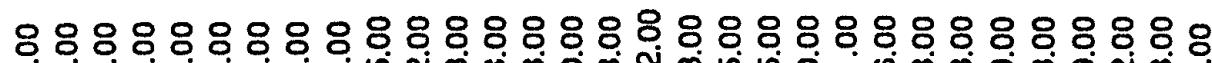

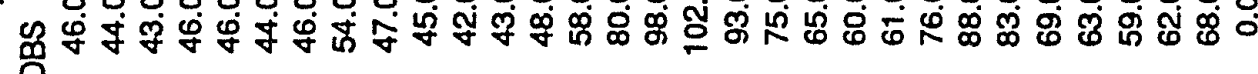

하 - 







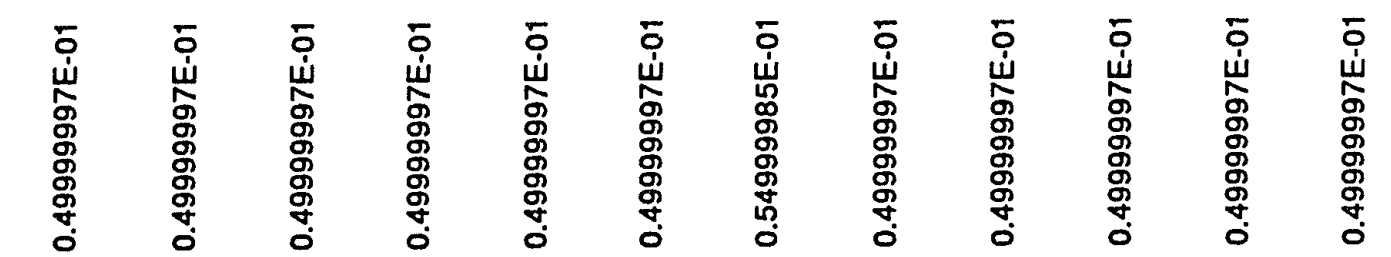

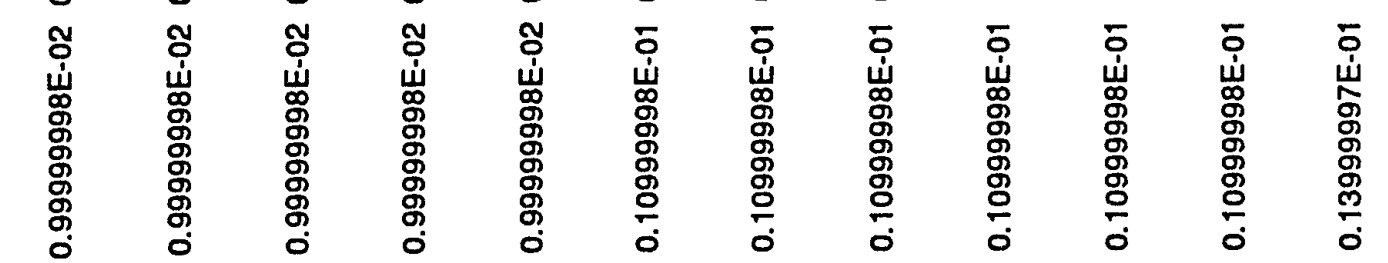

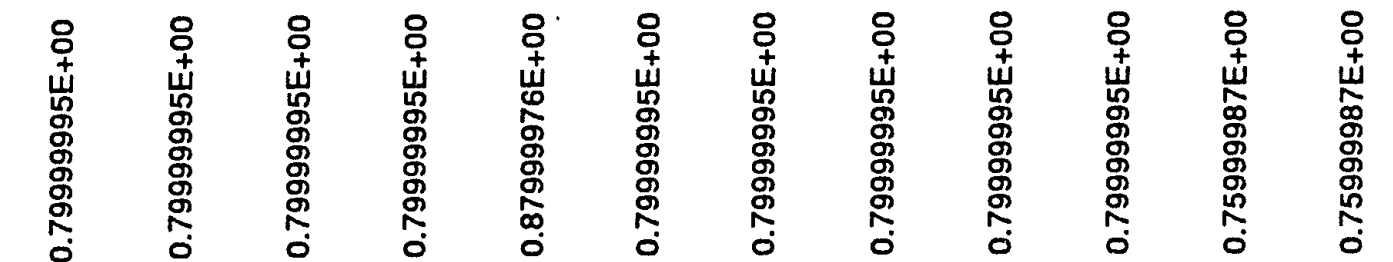

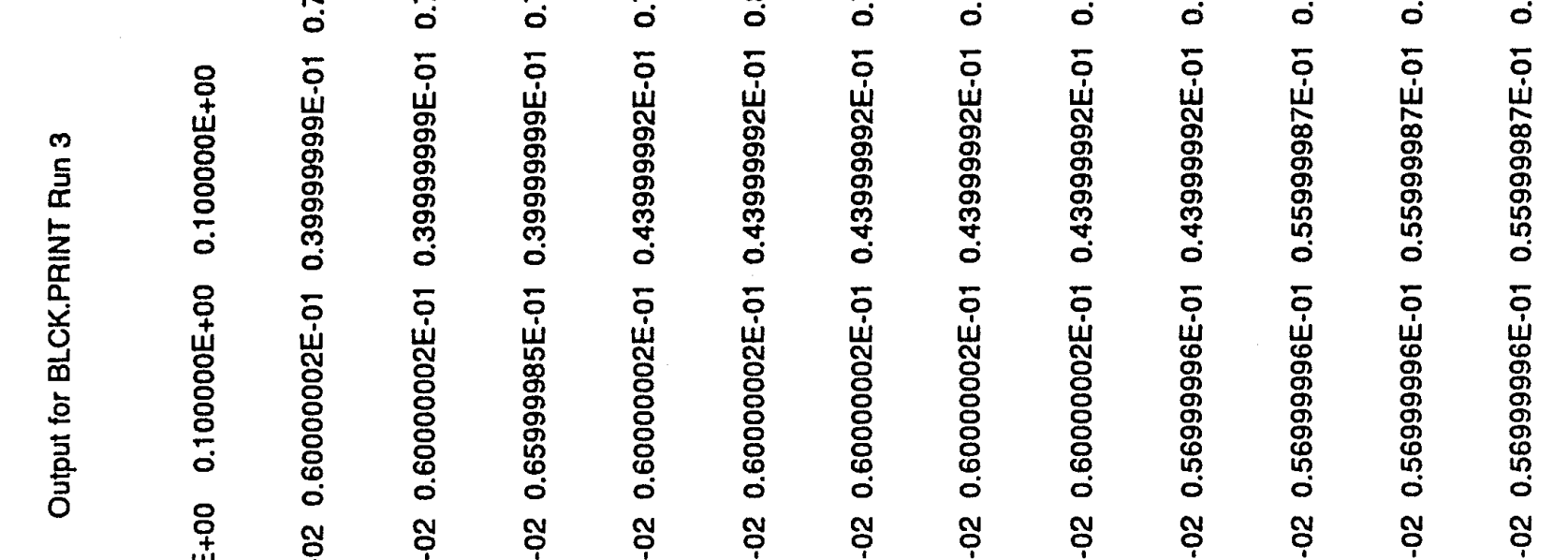

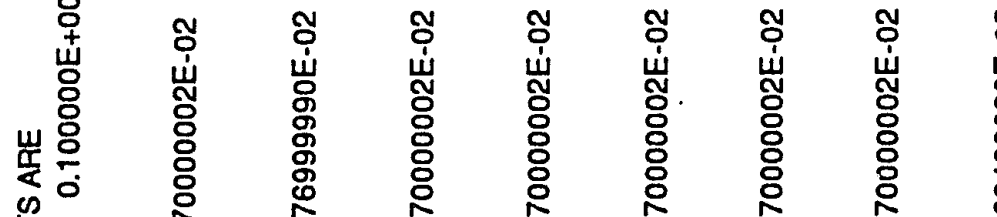

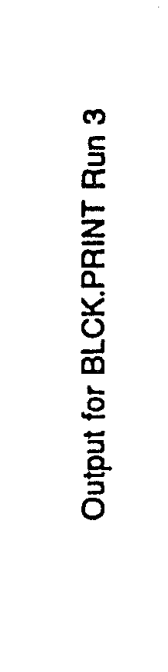

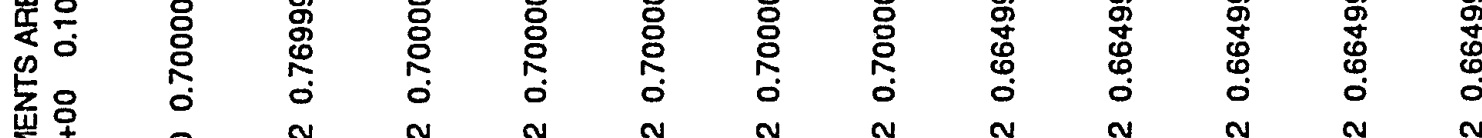

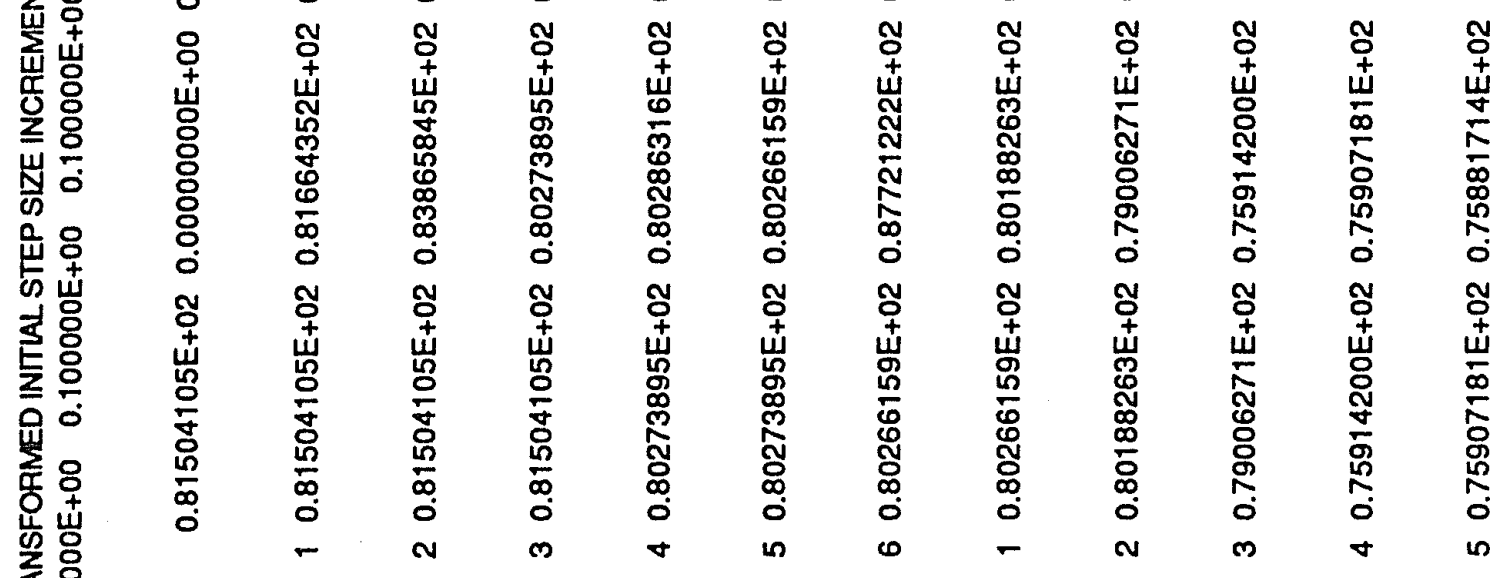

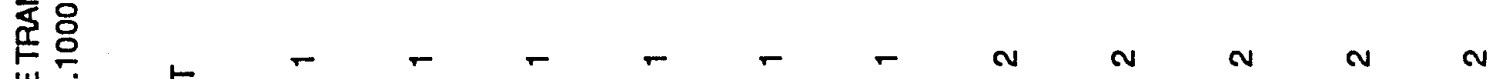

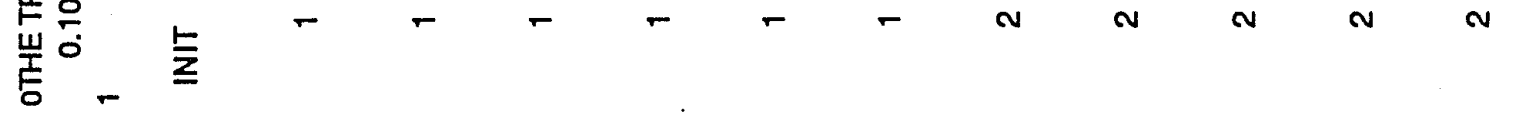




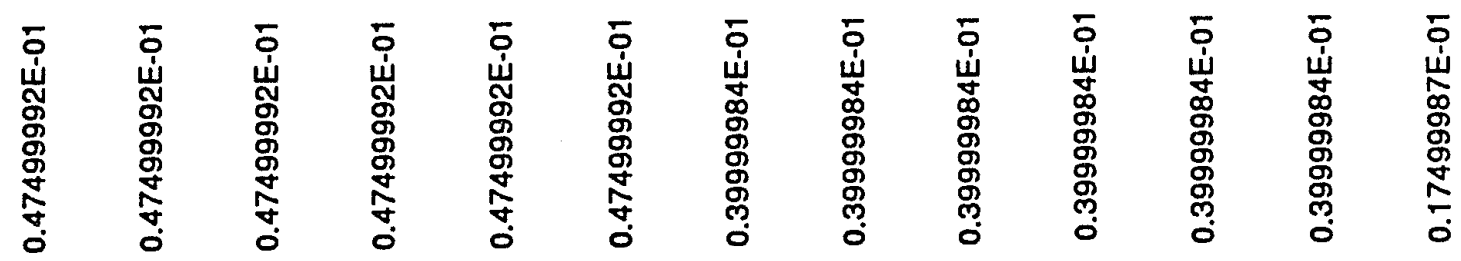

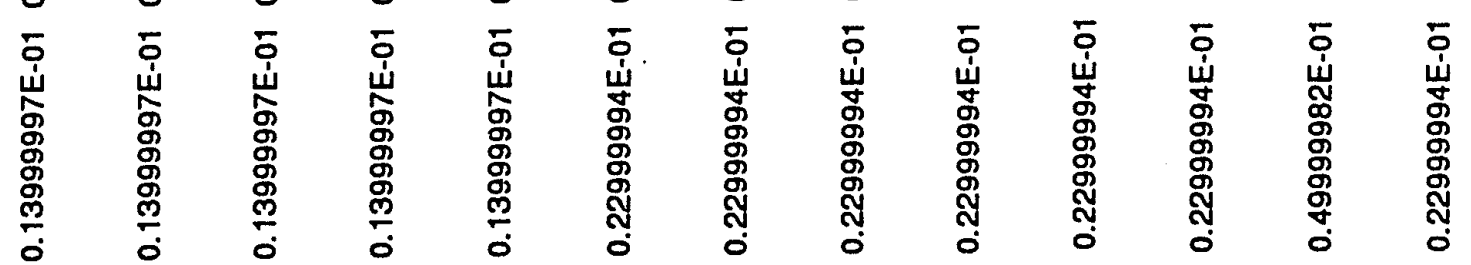

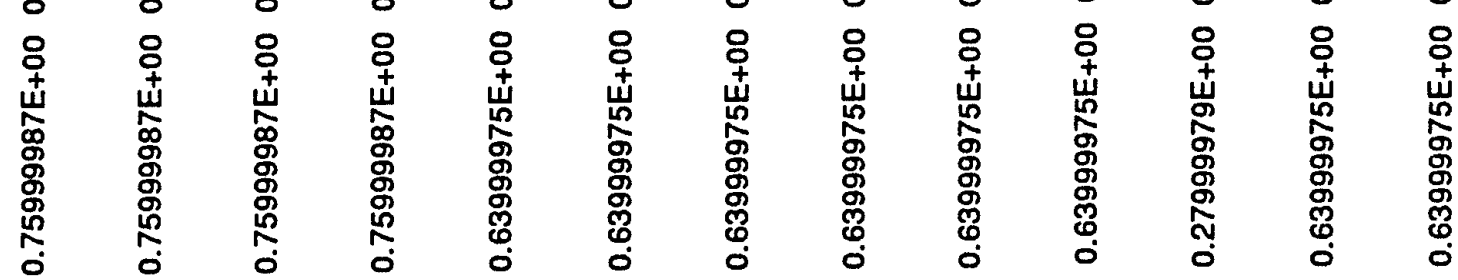

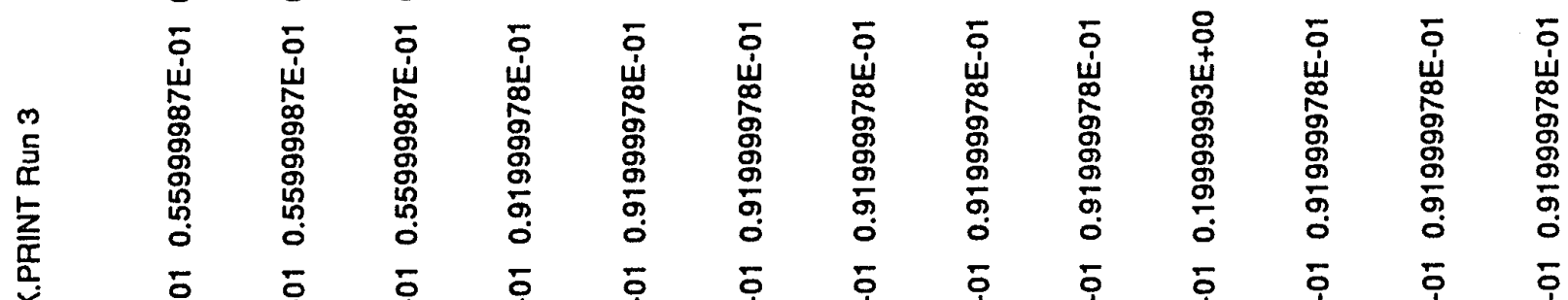

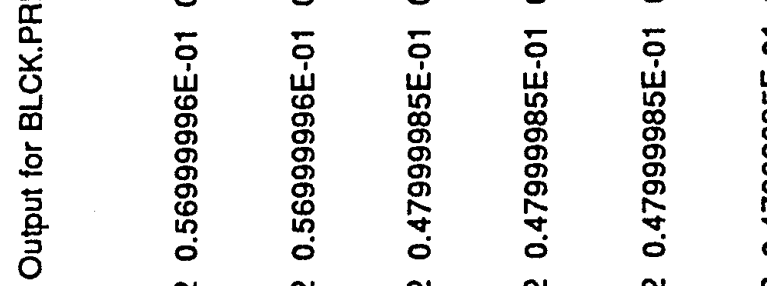

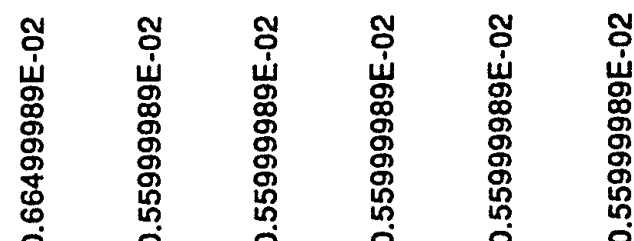

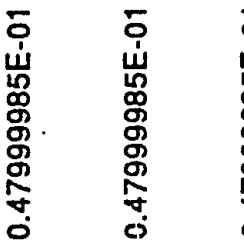

总

$\overline{0} \quad \overline{0} \quad \overline{0}$

ช ชิ ชิ ชิ ชิ ชิ ชิ ชิ

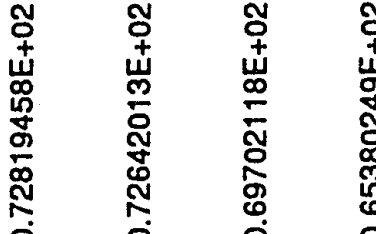

ㅇำ ป

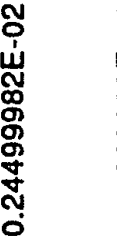

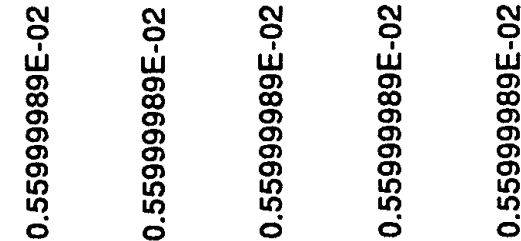
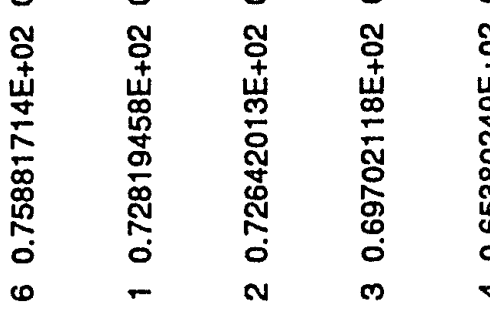

$\frac{0}{0}$

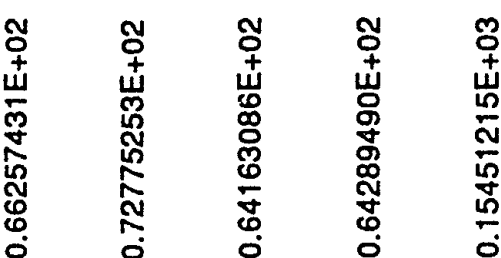

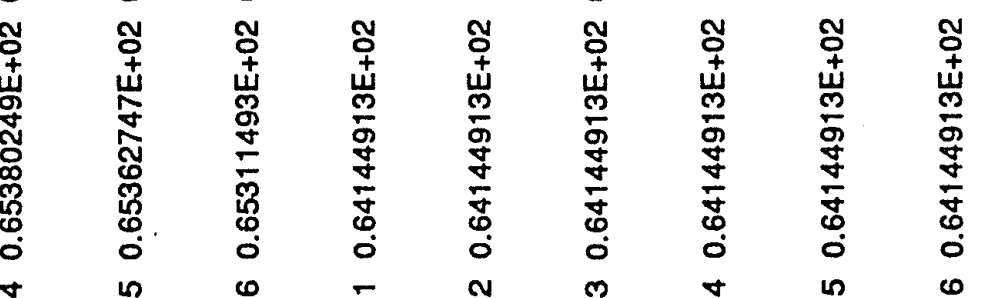

N $\infty m$ 


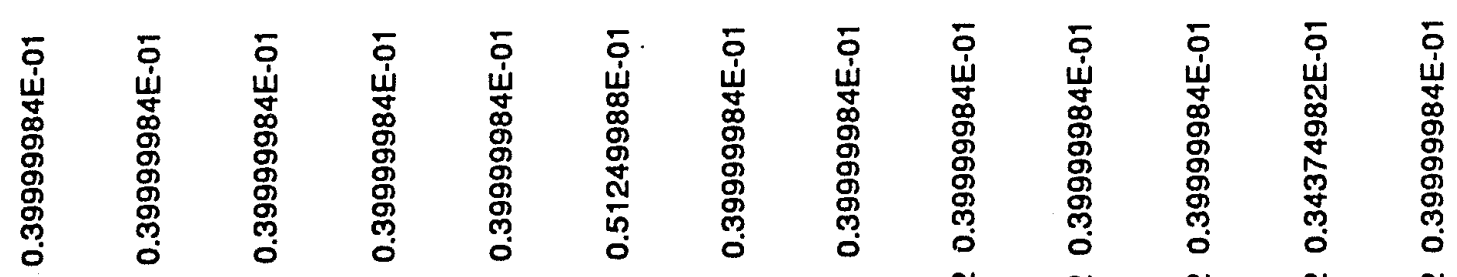

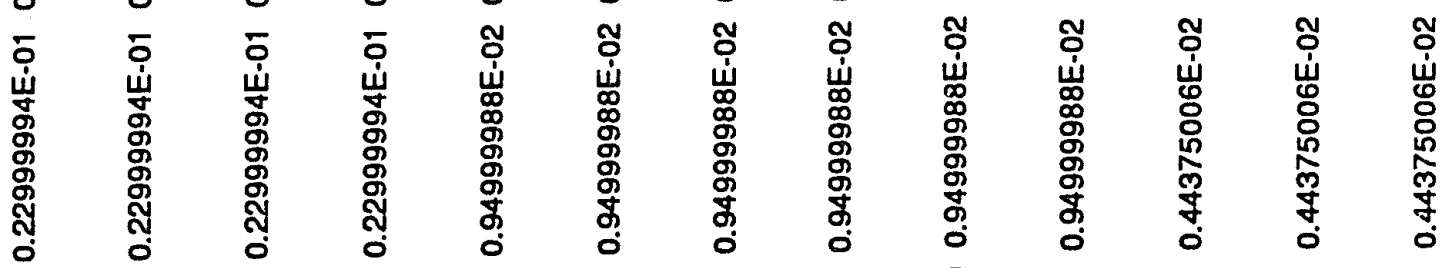

$8 \quad 8 \quad 8 \quad 8 \quad 8$

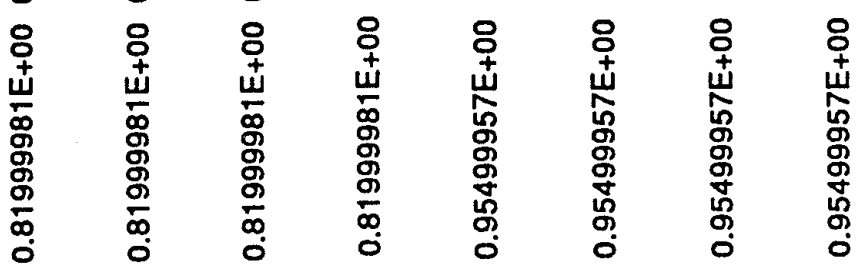

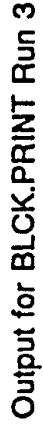

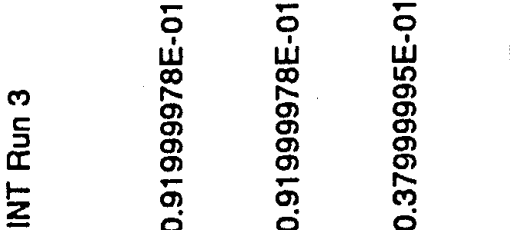

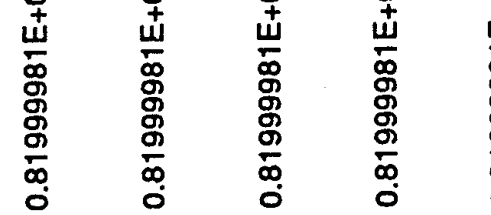

它

$\begin{array}{llll}0 & 0 & 0 & 0 \\ 0 & \overline{0} & \overline{0} & 0\end{array}$

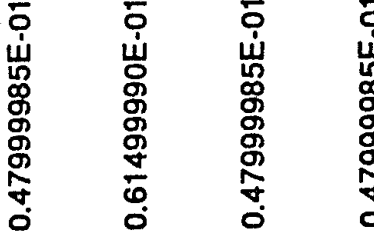

ชิ ชิ

西

$\overline{0} \overline{0}$

б $\bar{i} \quad \overline{0}$

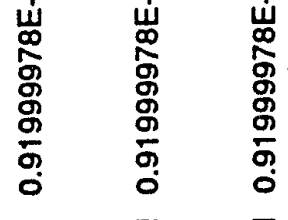

苫

岕

\%

备

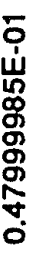

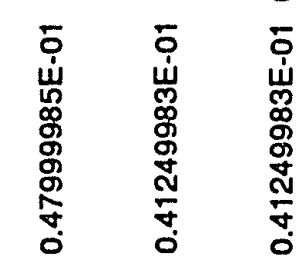

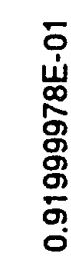

- $\overline{0} \quad \overline{0} \quad \overline{0}$

㟧

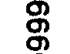

\%

\%ั.

후 $\overline{0} \overline{0}$

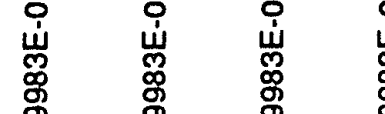

守

ঙั่

$\overline{0}$

ชิ

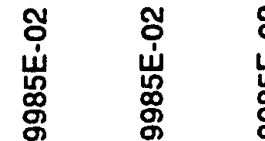

方 $\stackrel{0}{\frac{1}{5}} \stackrel{\frac{1}{5}}{\frac{1}{5}}$

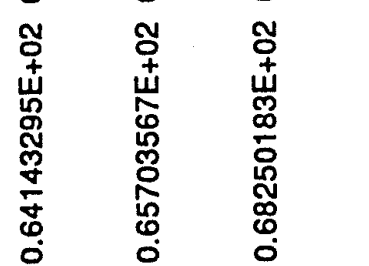

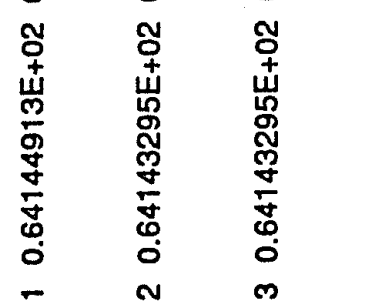

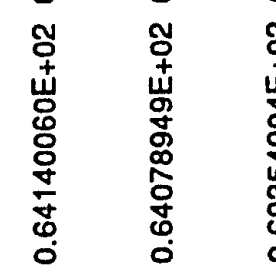

ס

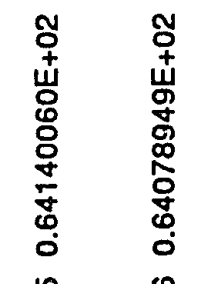

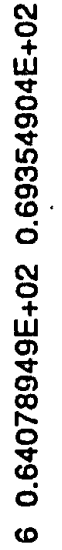

ช

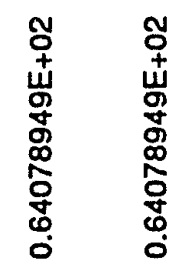

嵩

告

ชิ ชั ช

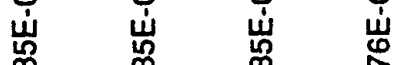

号

:

ลิ

م.

n n in $n$ 


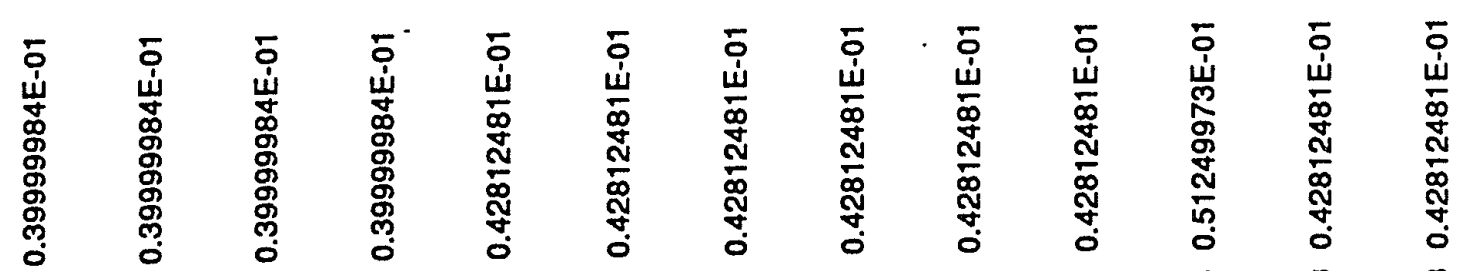

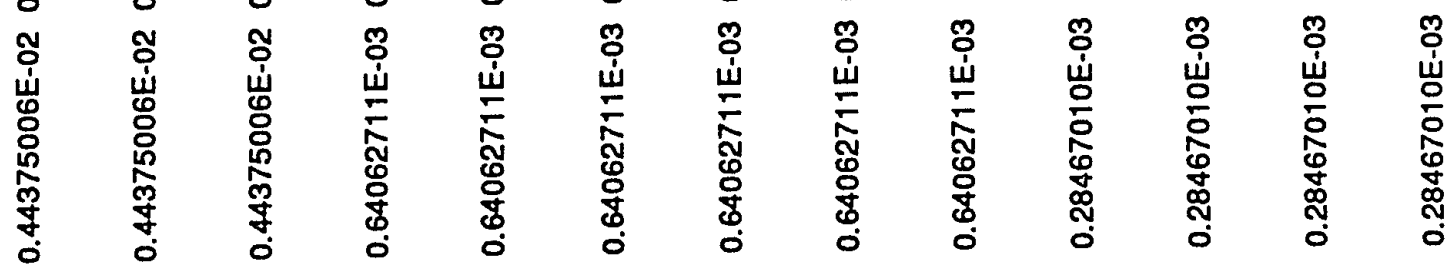

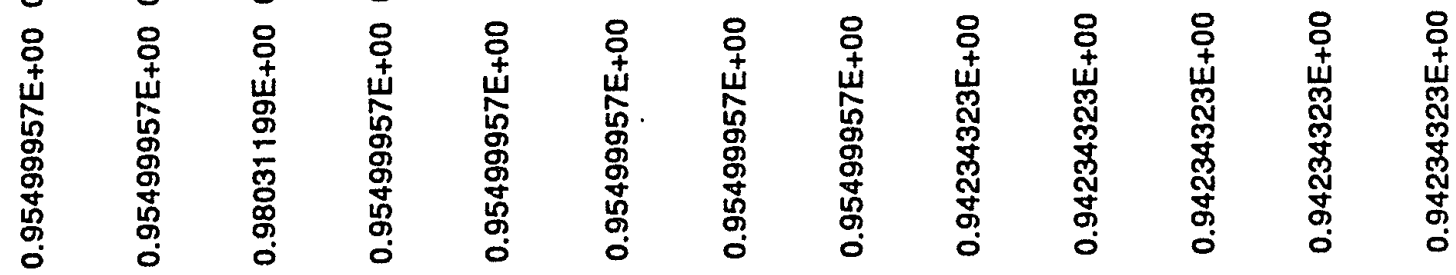

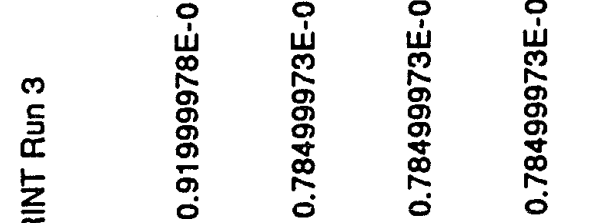

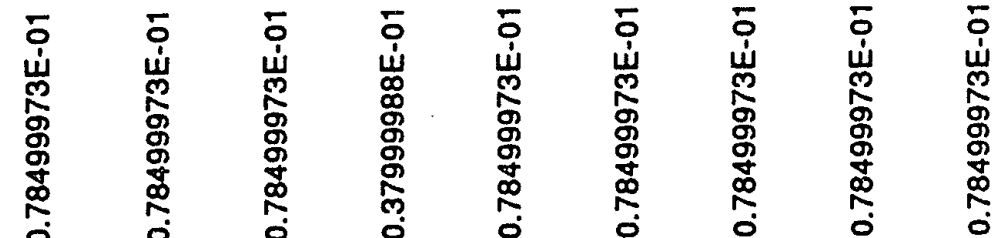




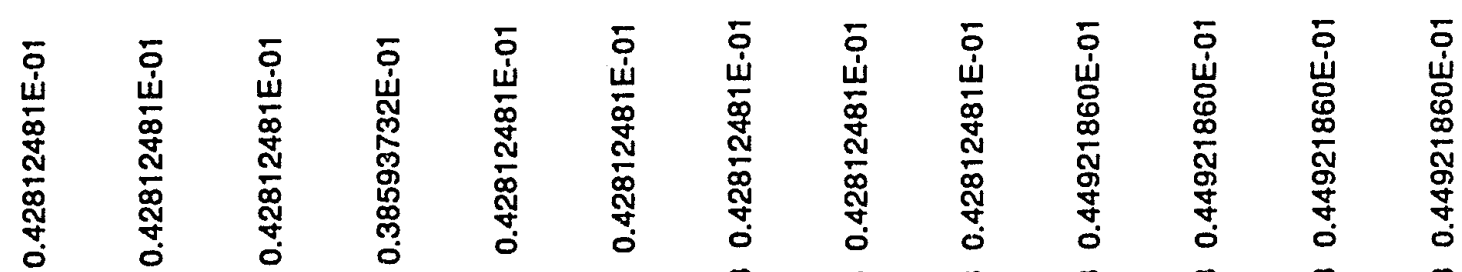

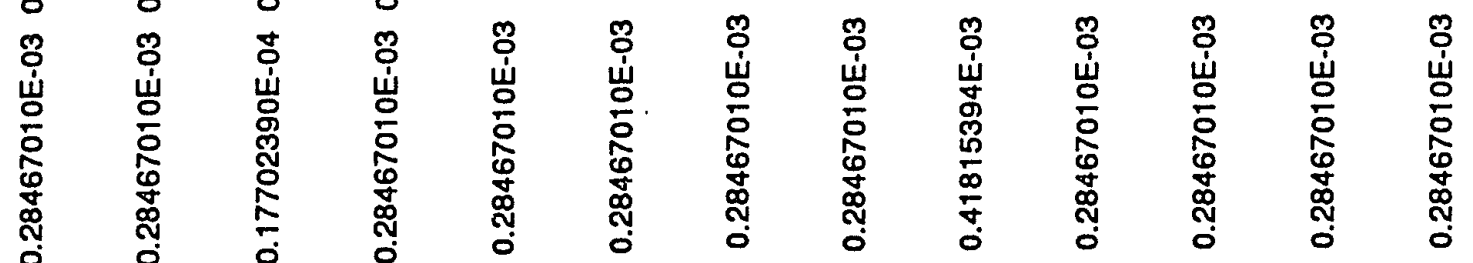
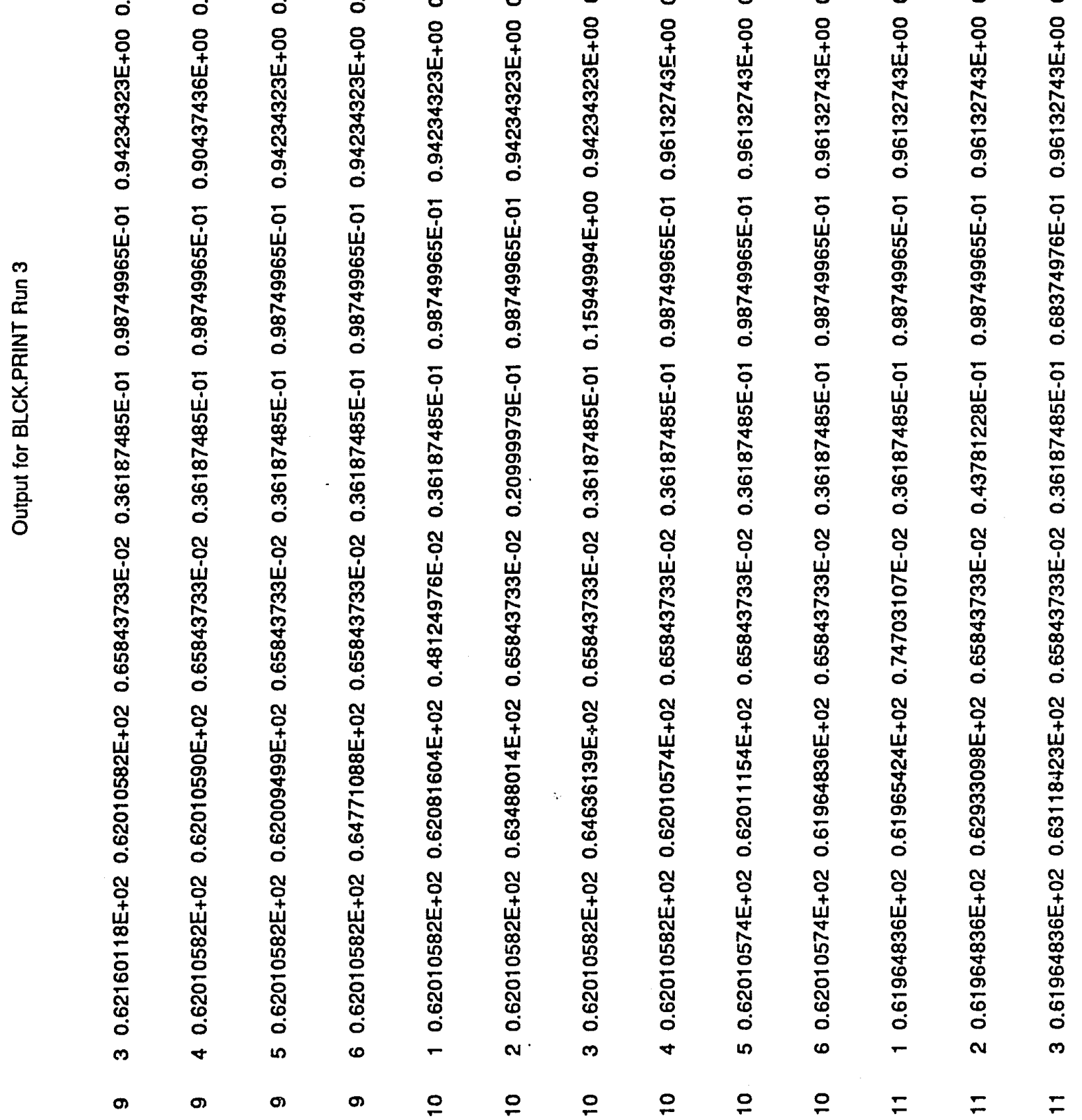


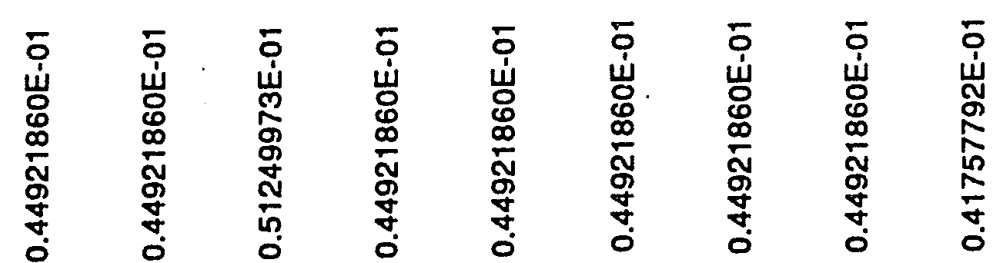

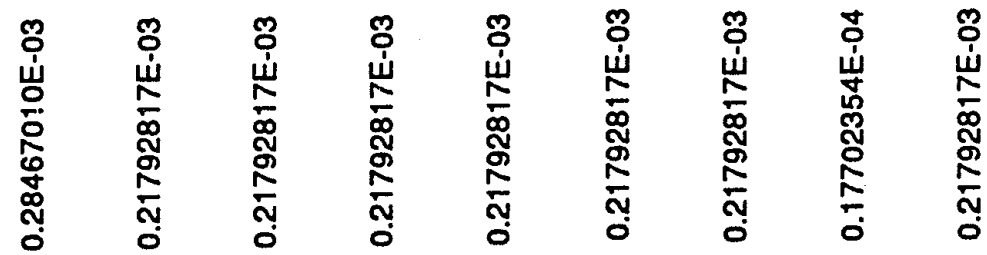

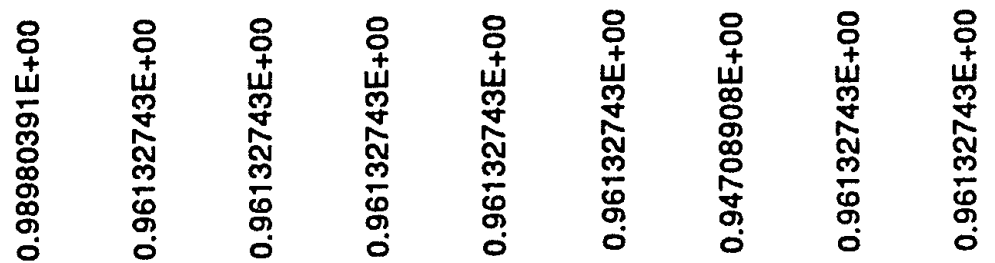

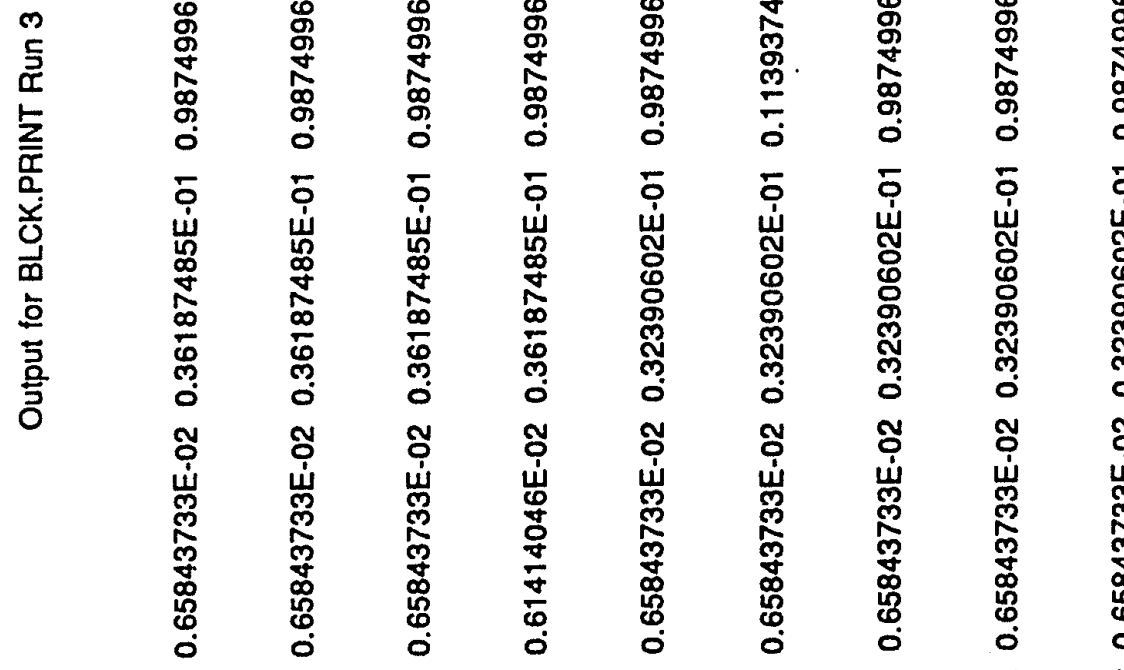

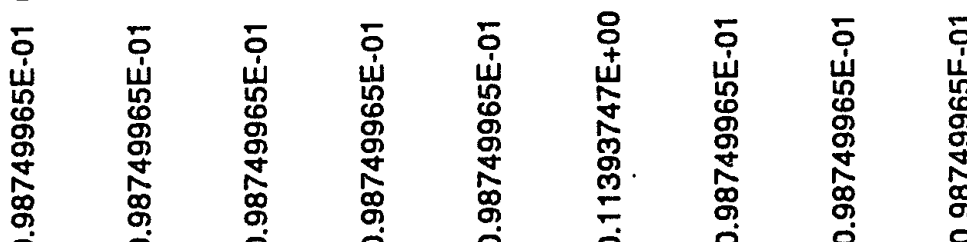

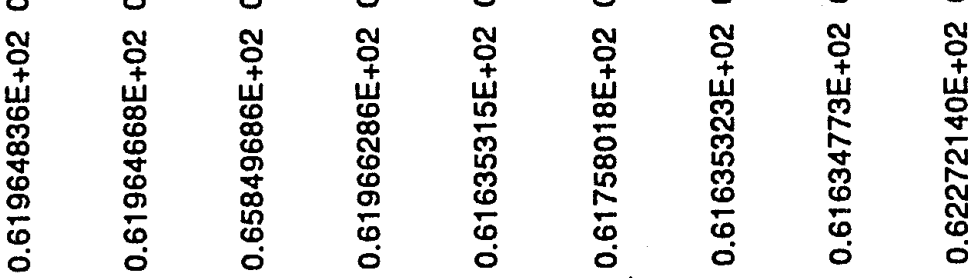

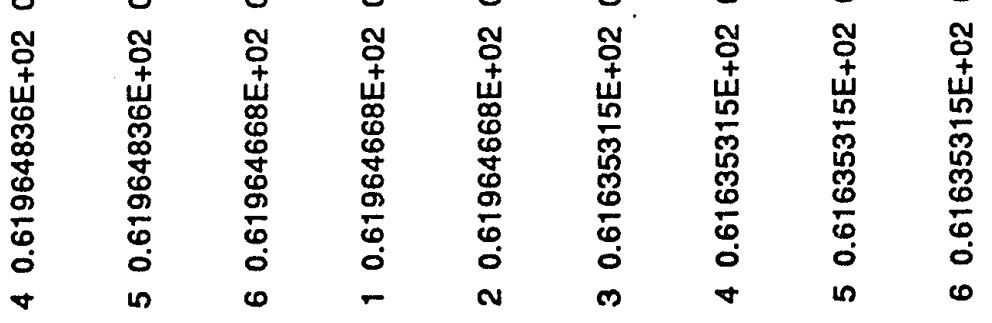

$=\mp \cong \cong \cong \cong \cong$

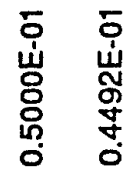

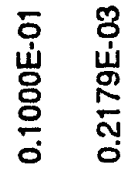

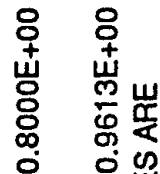

б

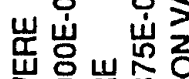

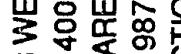

出 0 品

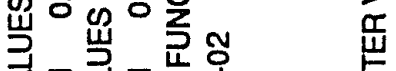

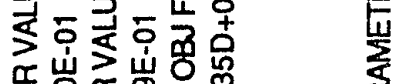

岳岩岳峞击苋

फ

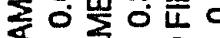

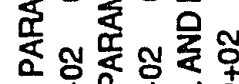

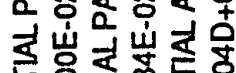

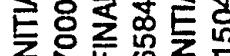

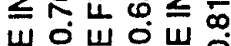




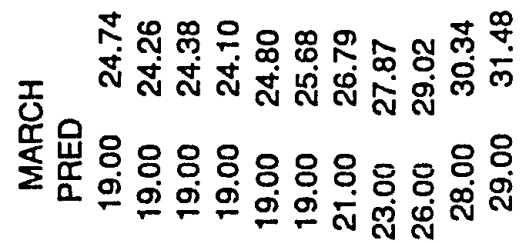

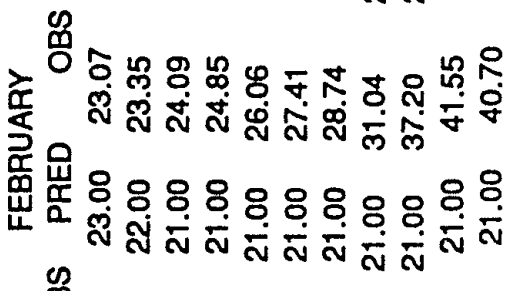
品
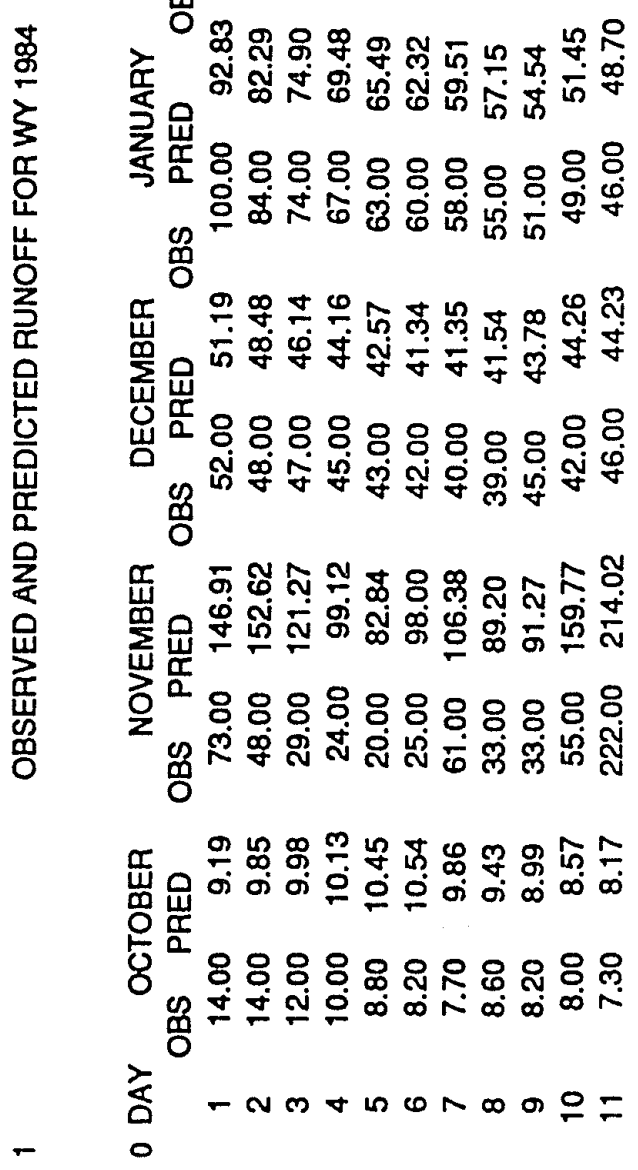
๗ त्र

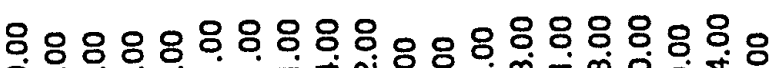

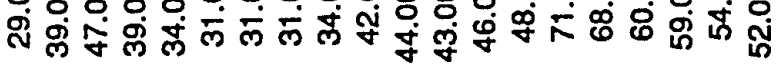

象

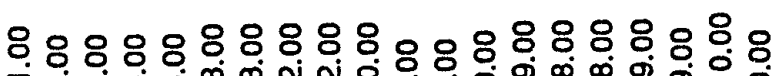
ล

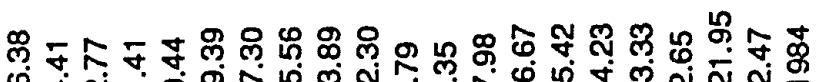

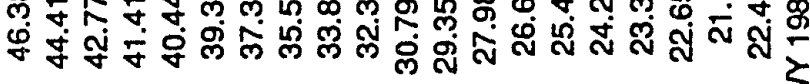

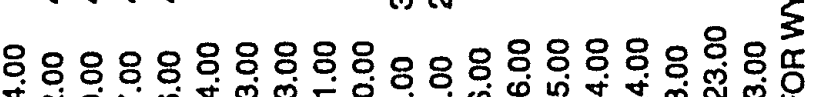

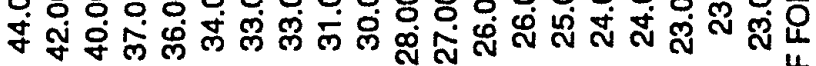

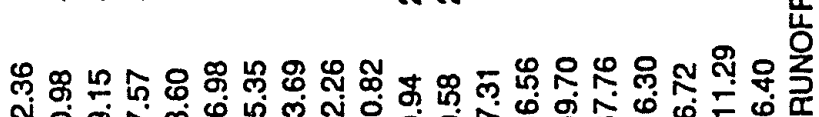

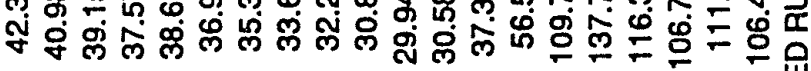

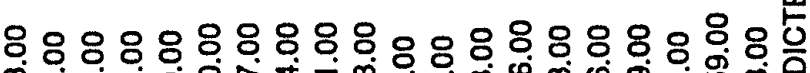

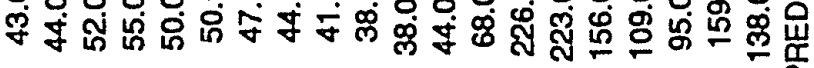

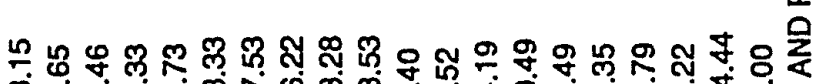

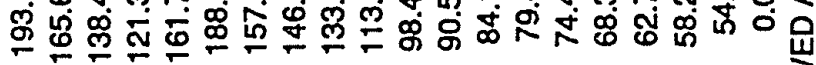

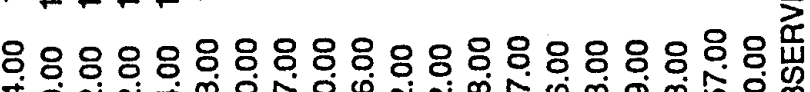

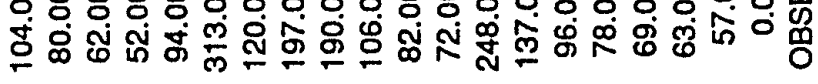

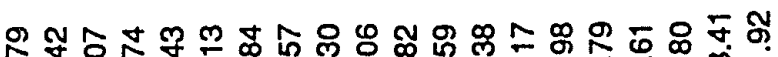

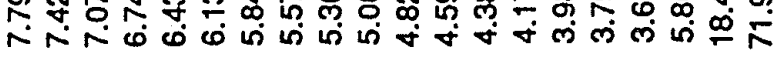

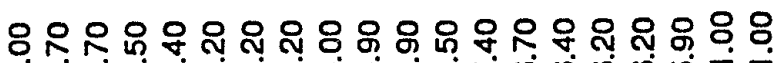

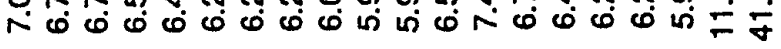

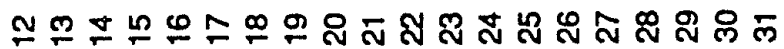

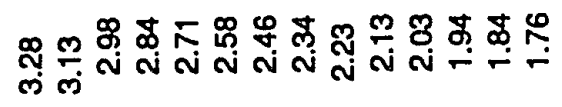

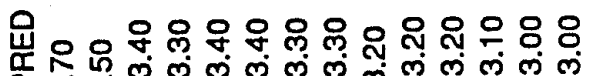

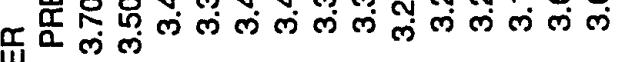
稀

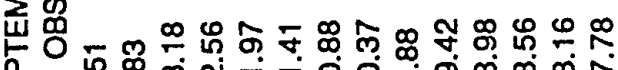

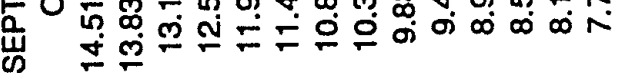

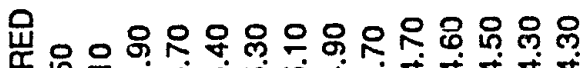

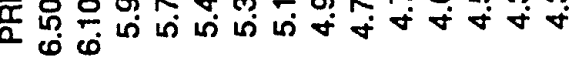
卢串

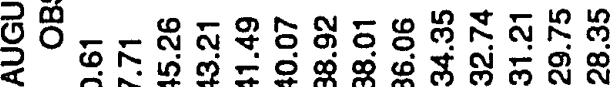

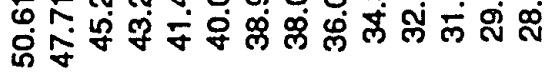

崖 8.888 .88 .88 .88$. ชู่ 壱哭

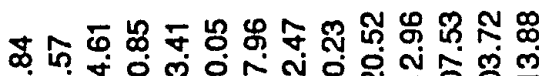

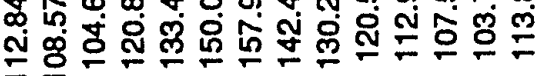

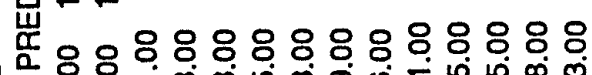

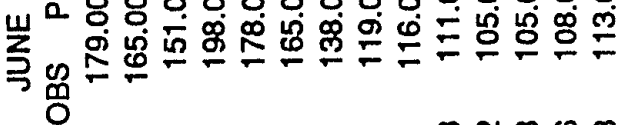

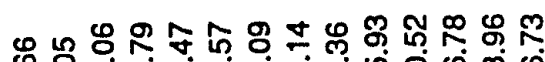

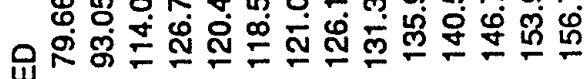
$\gtrless^{\frac{\pi}{2}} 88888.888 .8888$

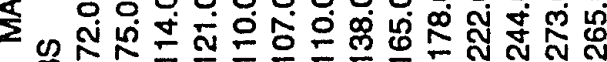
罚

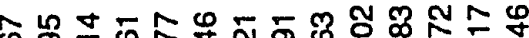

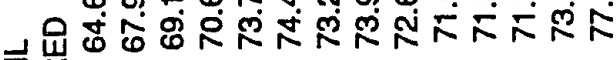
菭 $\frac{\pi}{0}$

К

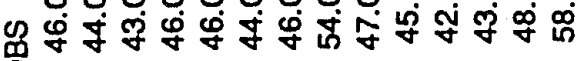

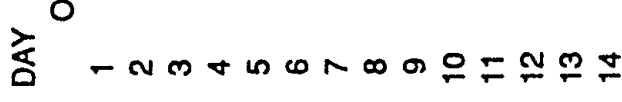




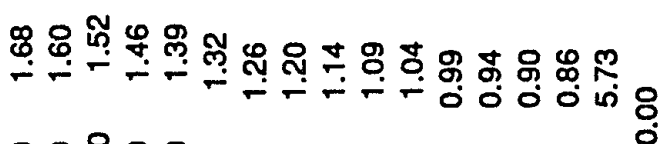

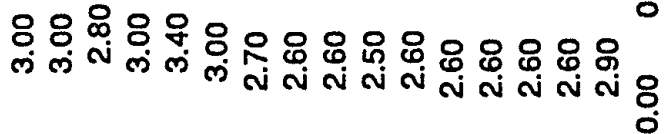

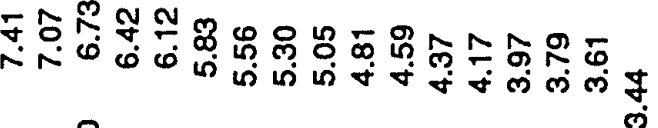

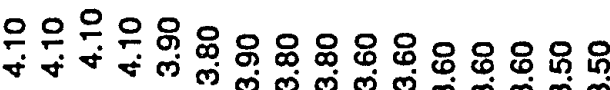

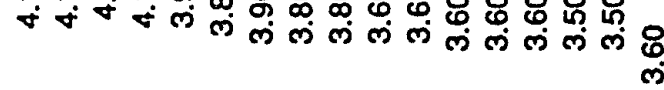

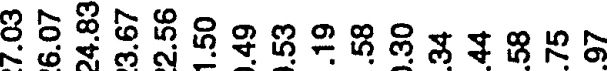
สั่

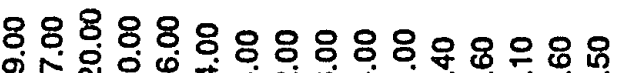

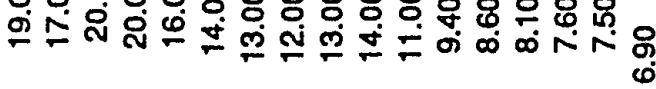

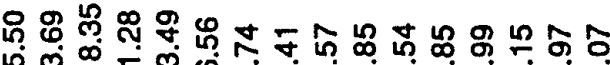

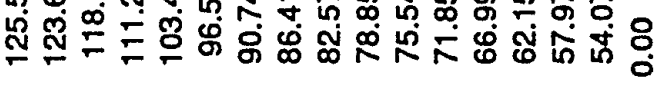

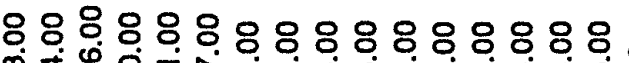

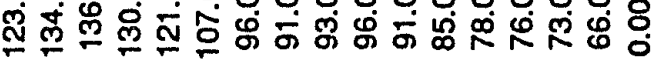

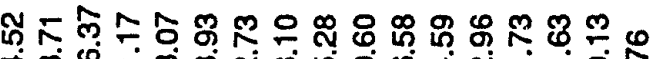

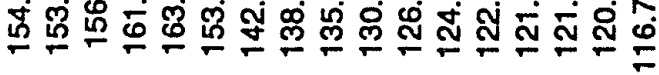

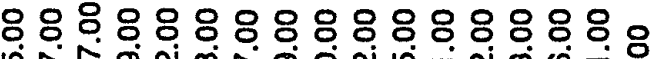

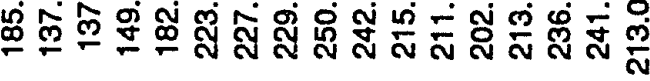

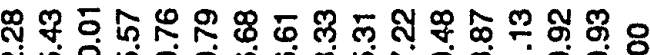

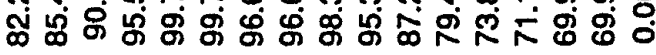

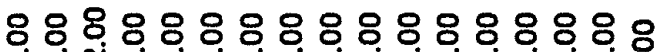

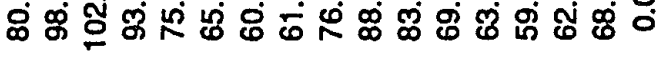

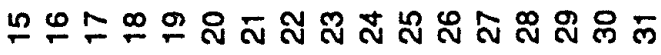

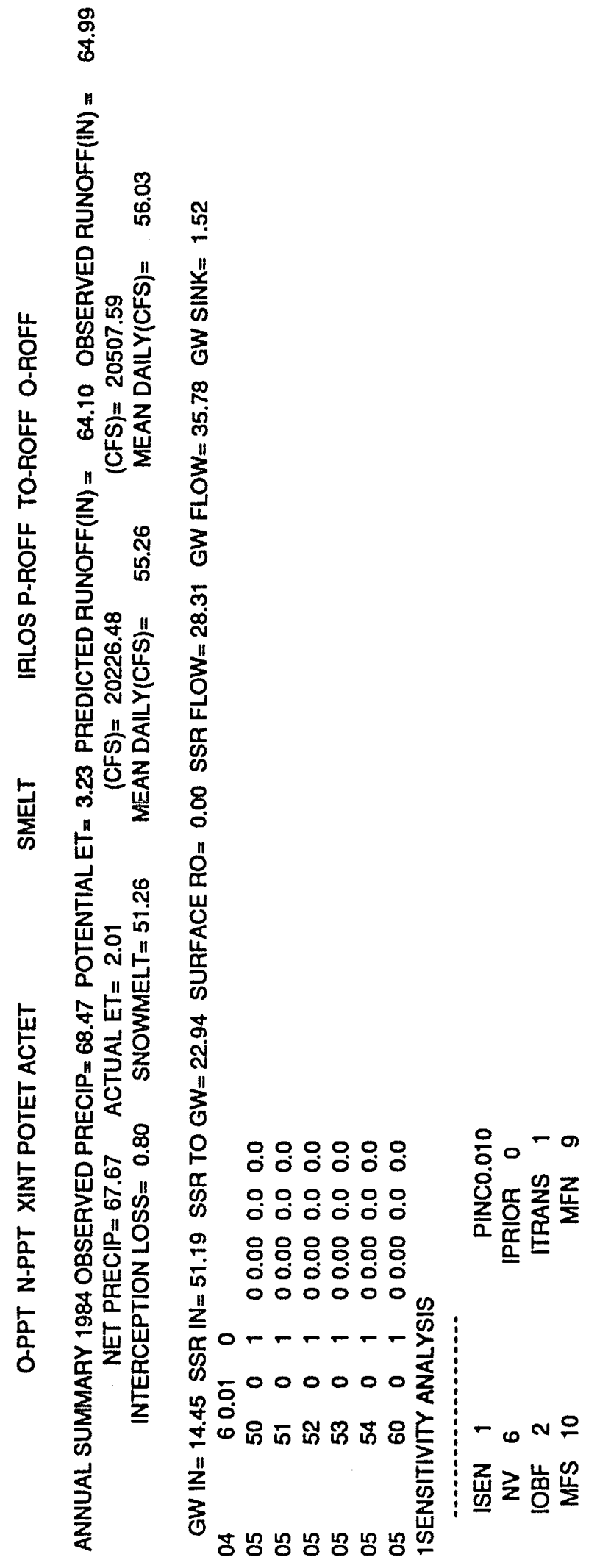




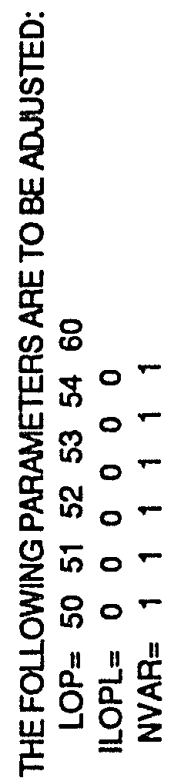

ธᄄ丨

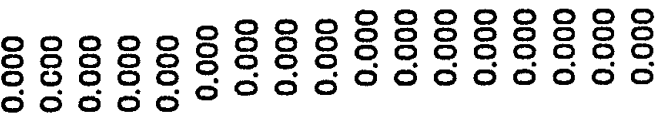

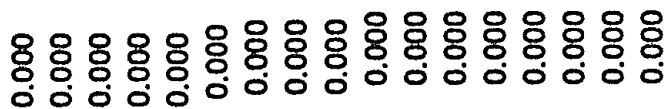
๓

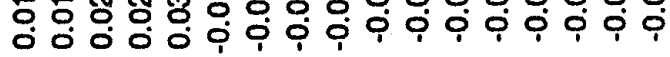

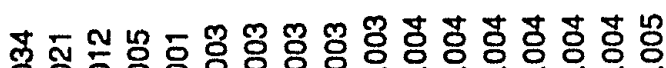

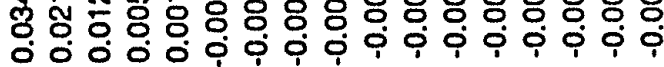

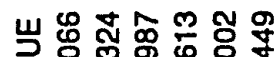

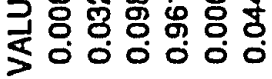

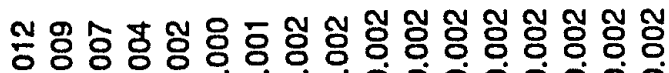

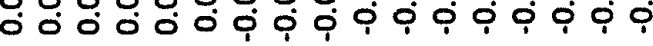

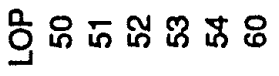




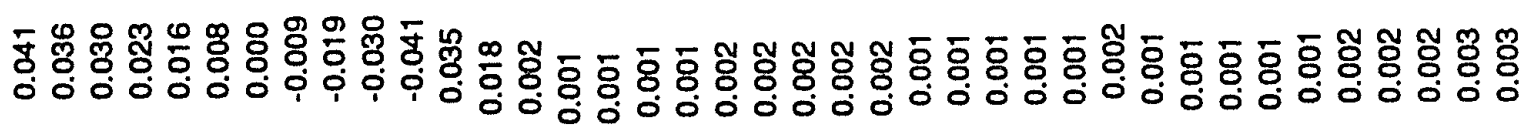

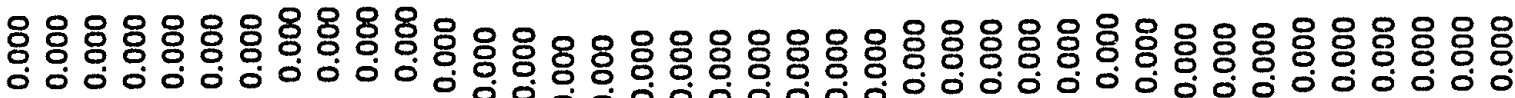

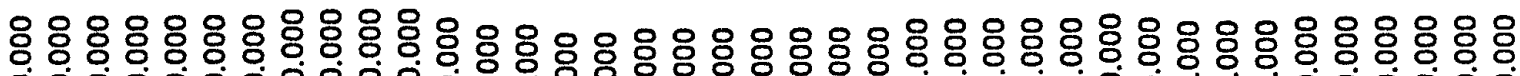

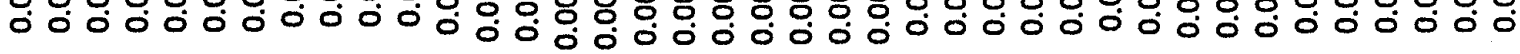

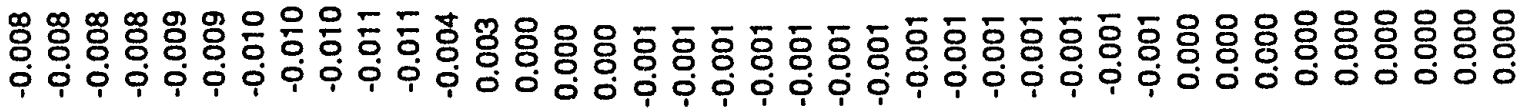

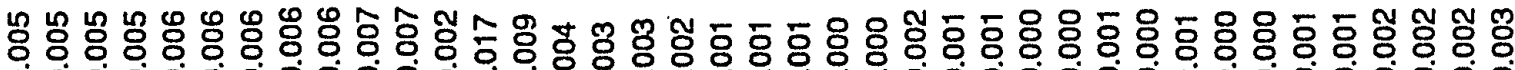

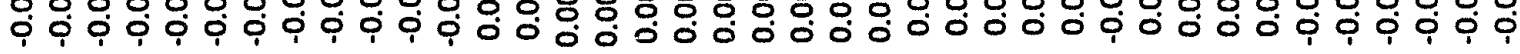

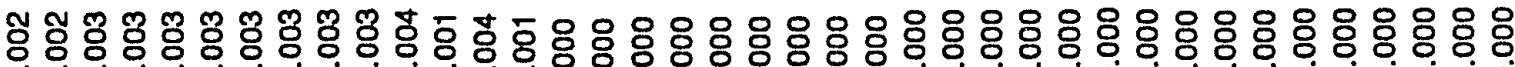

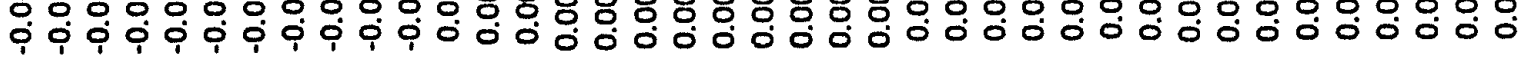

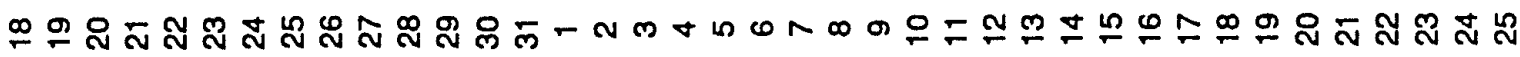




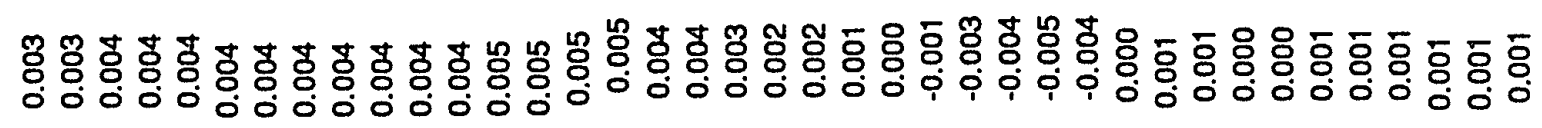

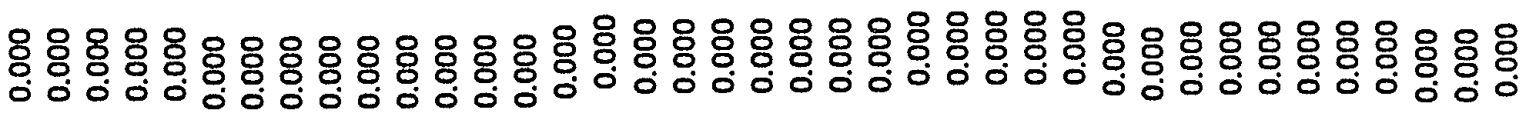

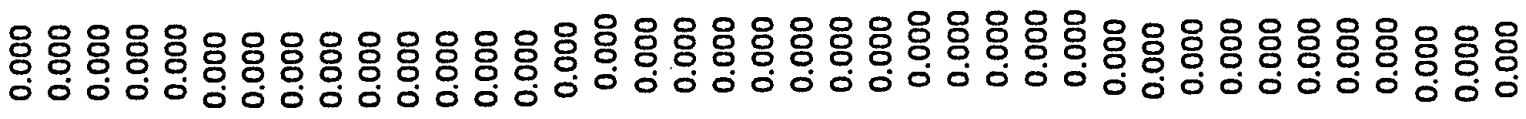

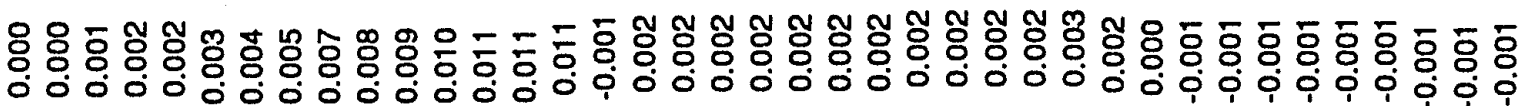

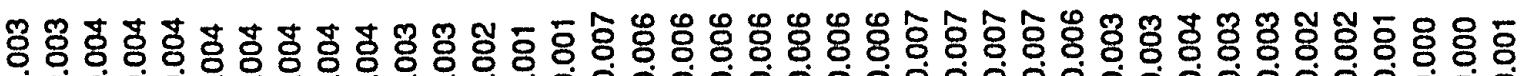

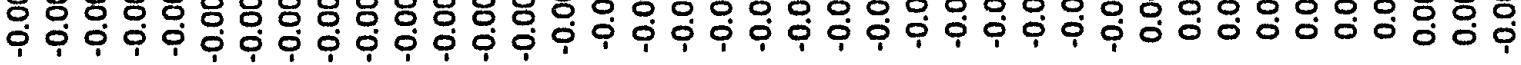

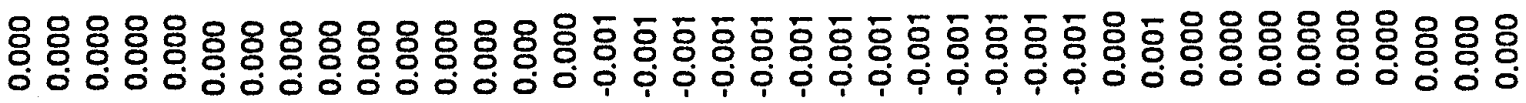
ำล ลึ ำ 


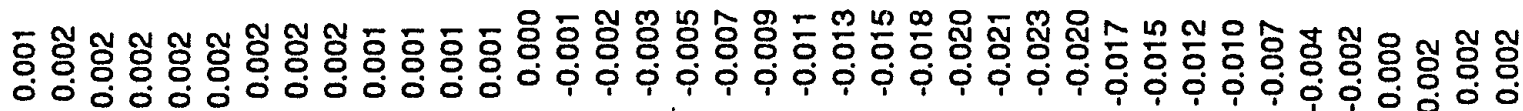

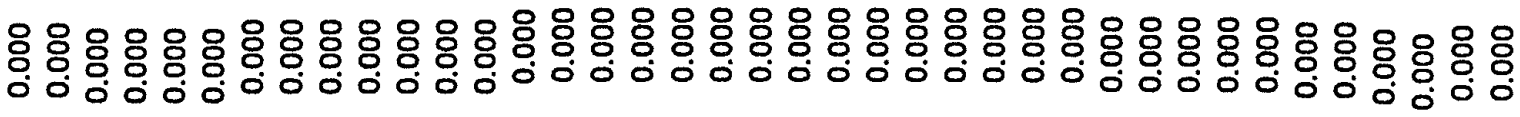

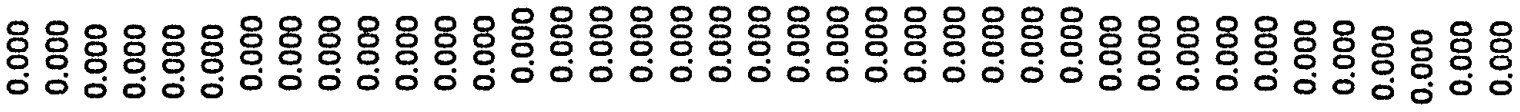

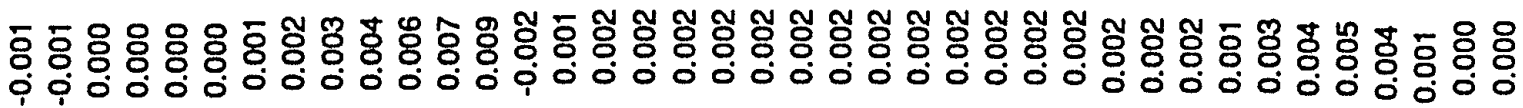

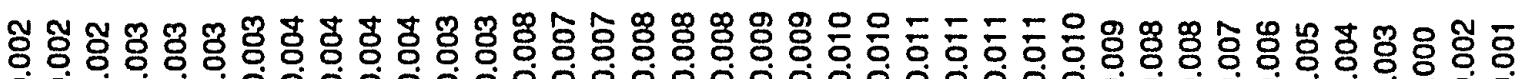

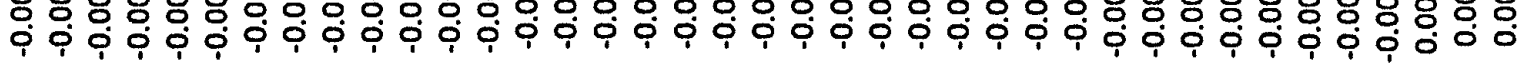

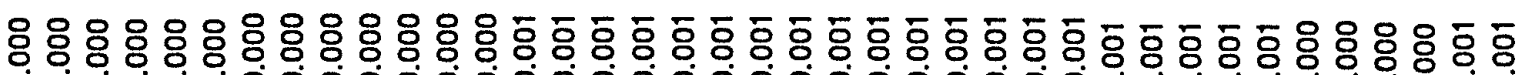

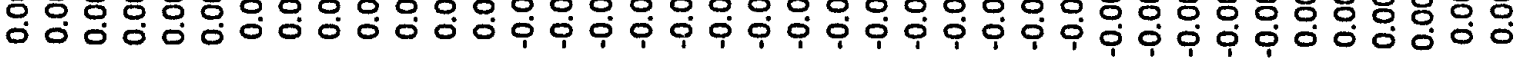
十 


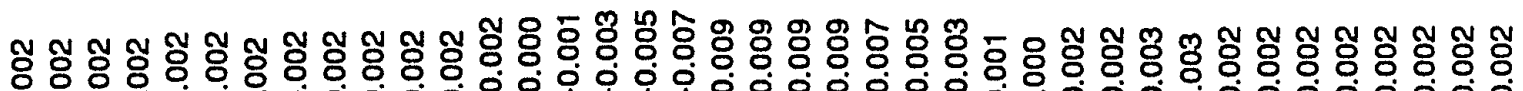

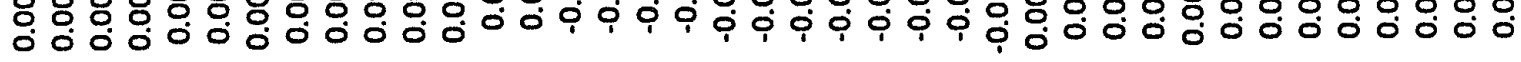

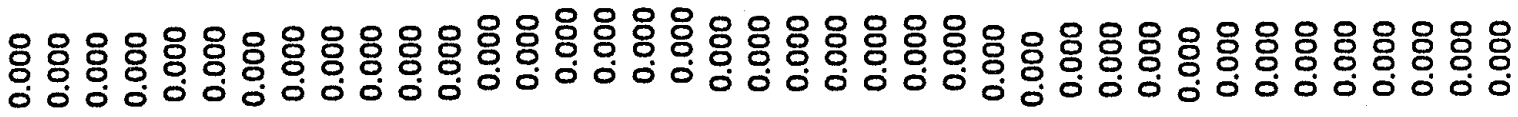

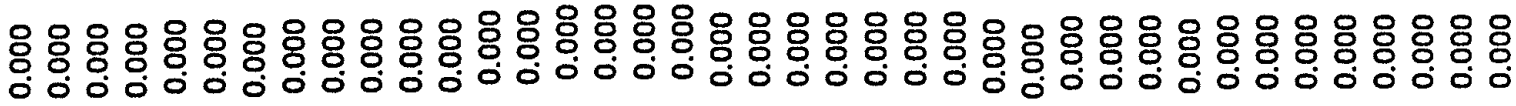

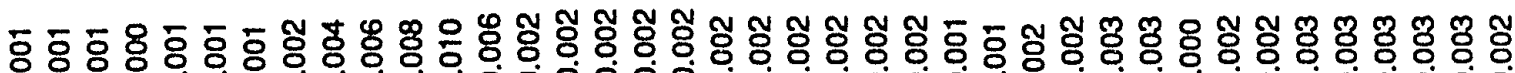

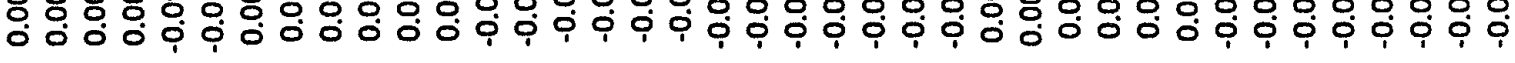

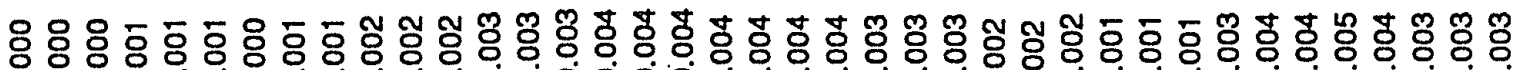

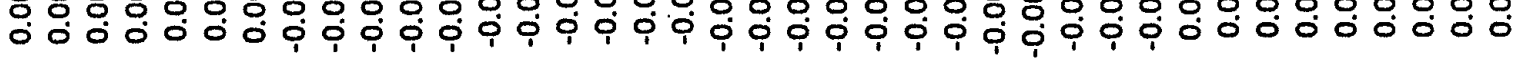

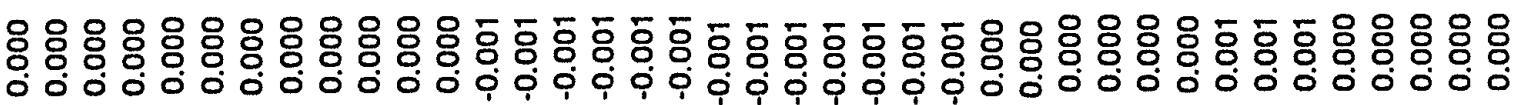

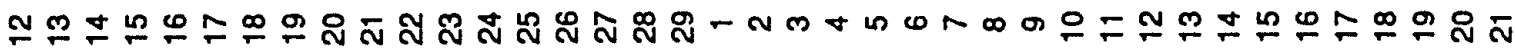




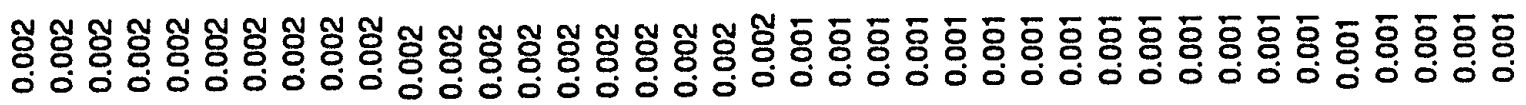

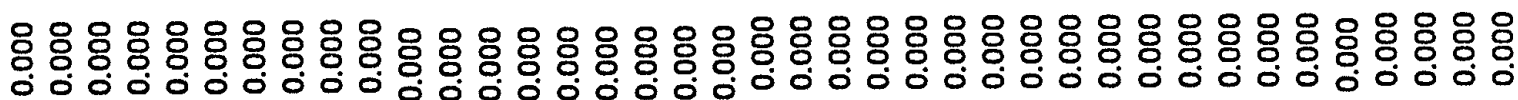

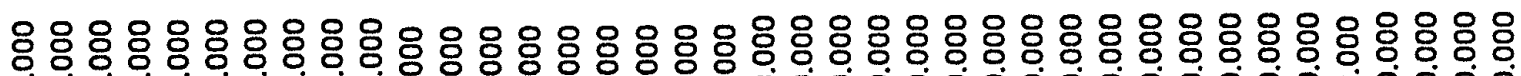

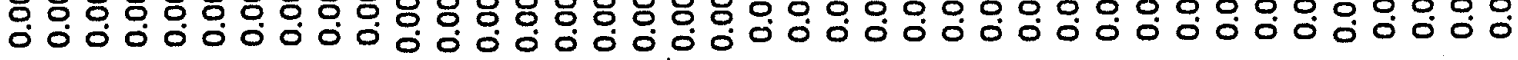

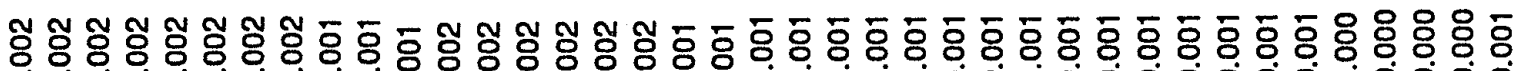

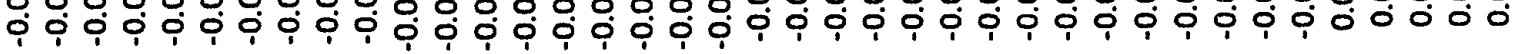

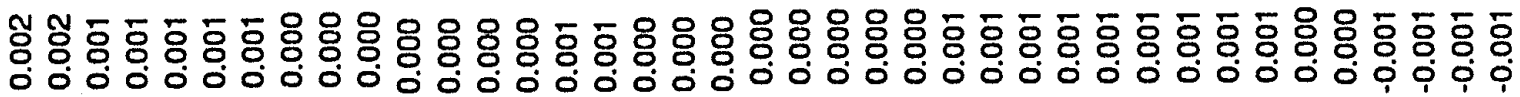

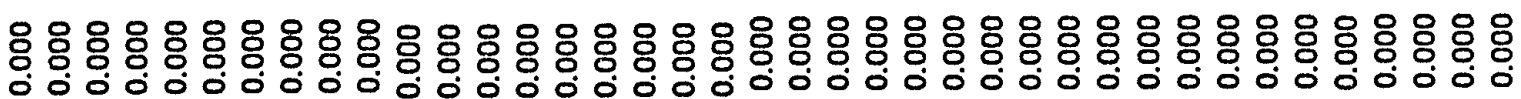

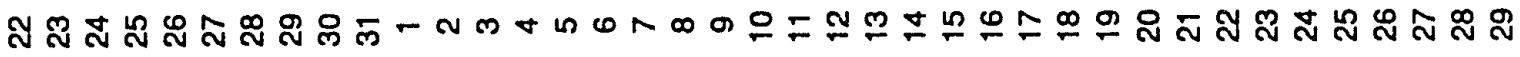




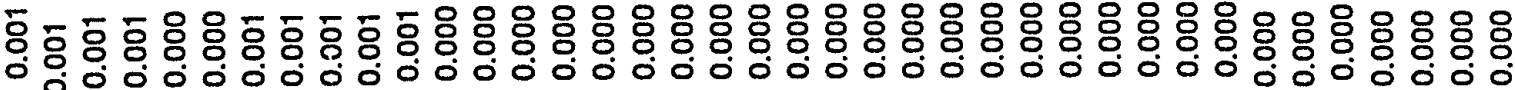

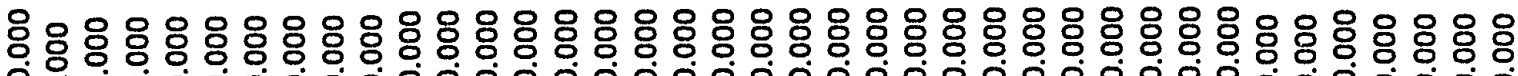

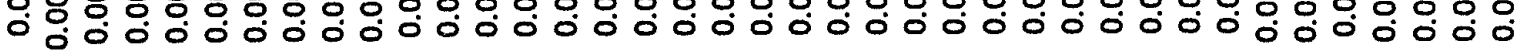

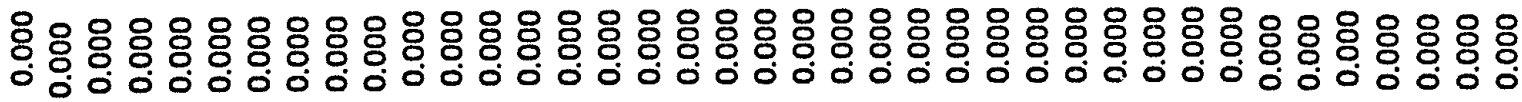

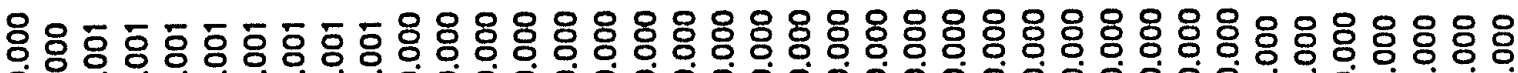

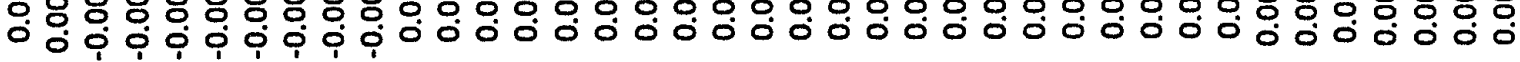

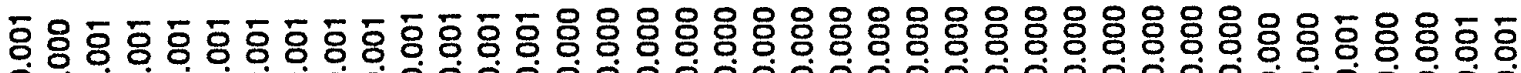

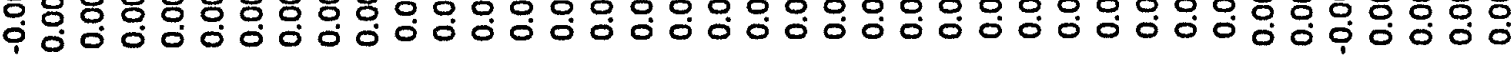

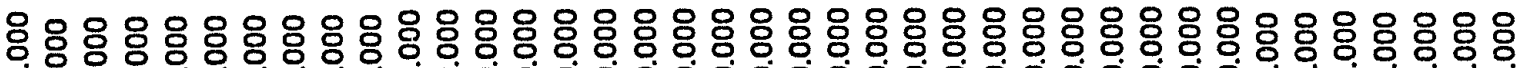

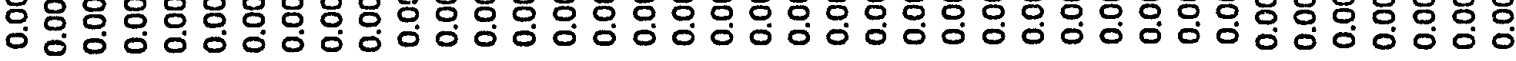

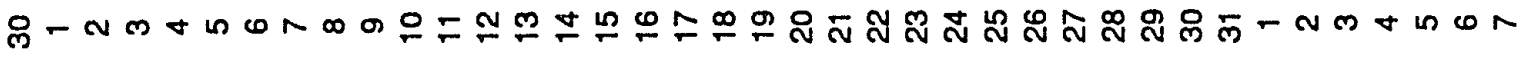




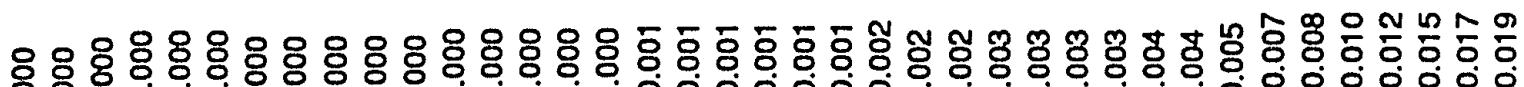

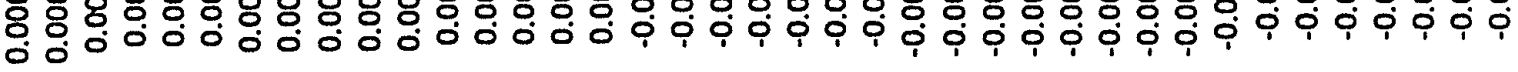

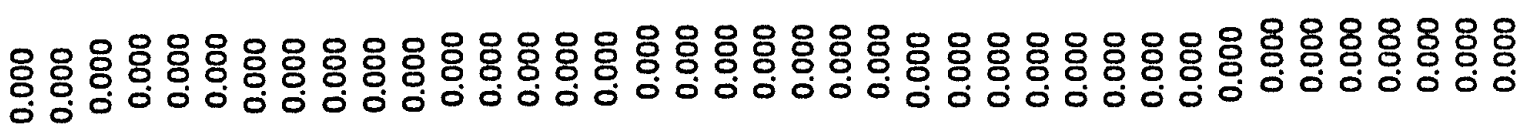

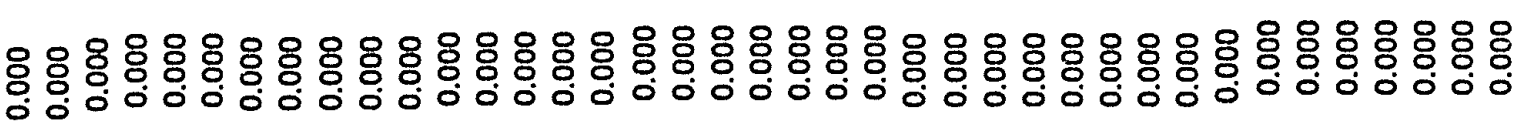

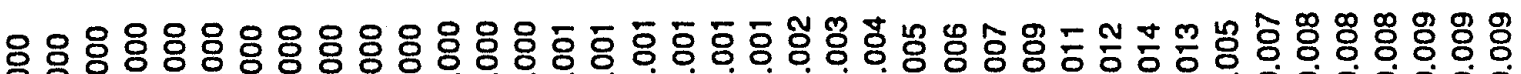

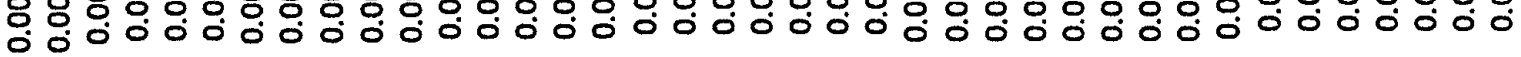

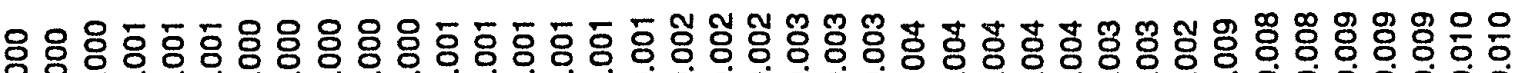

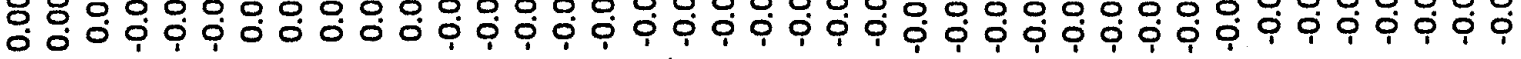

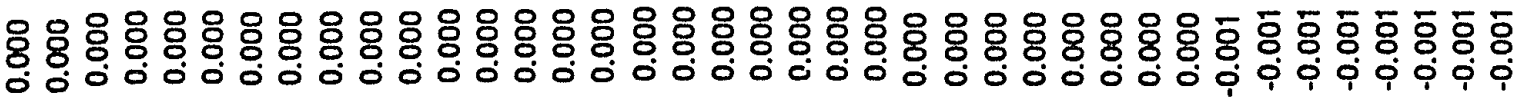

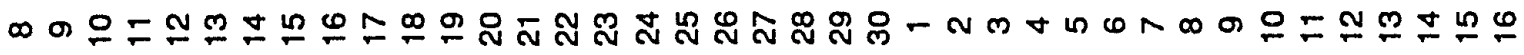




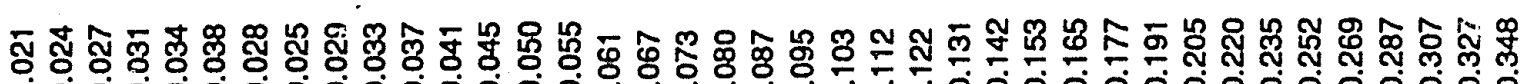

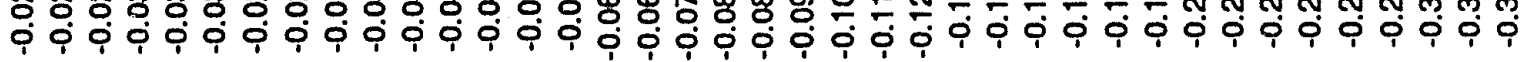

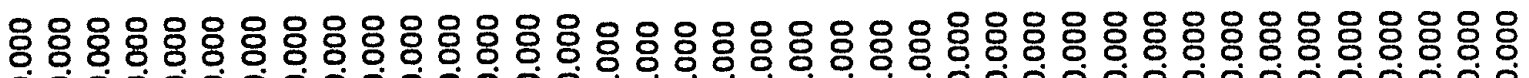

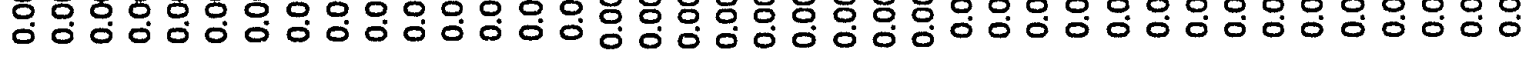

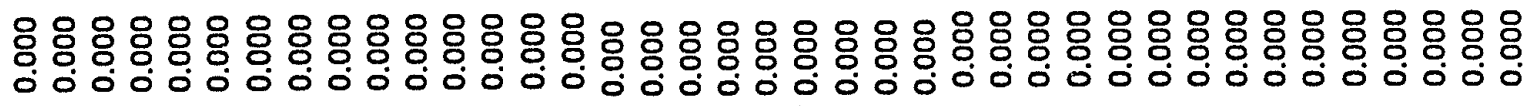

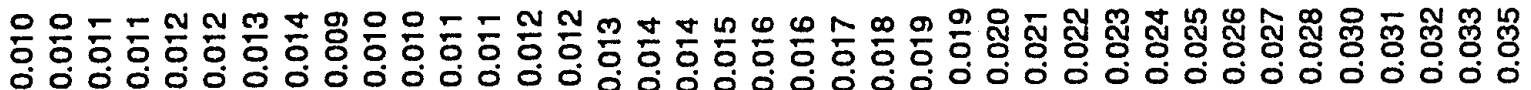

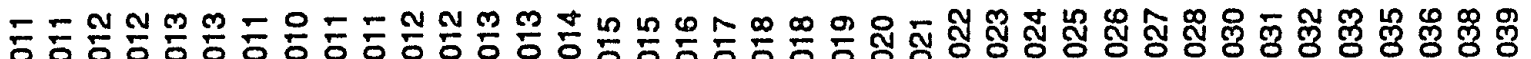

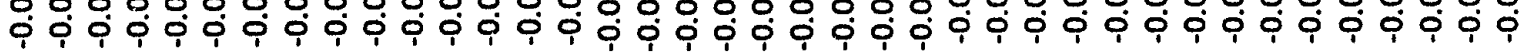

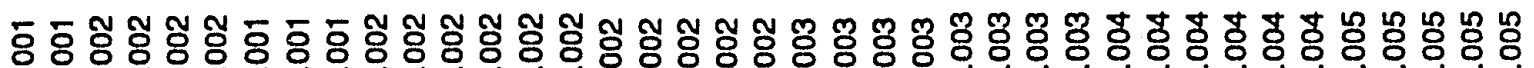

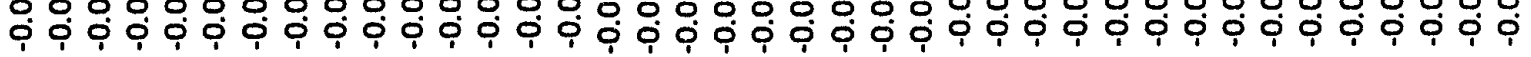

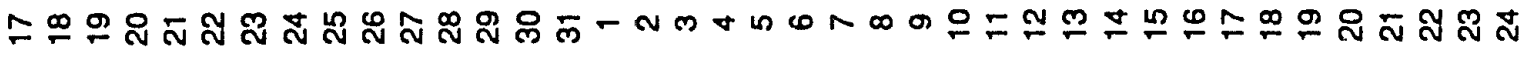




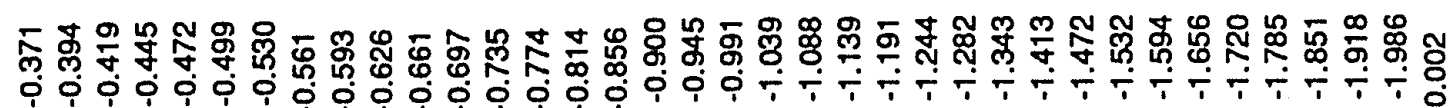

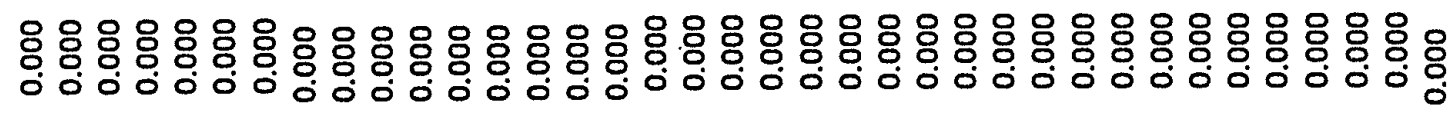

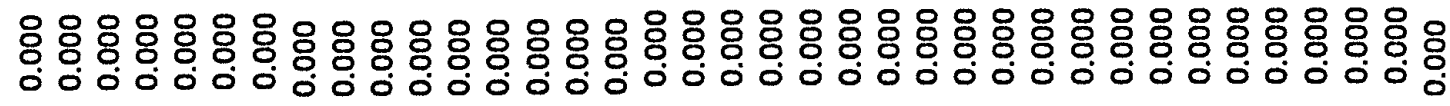

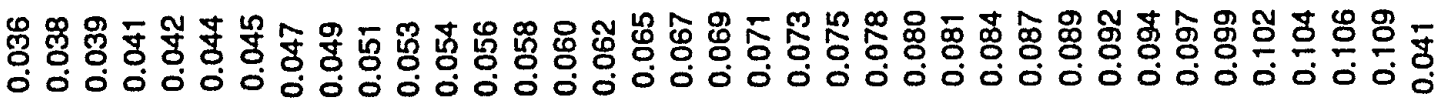

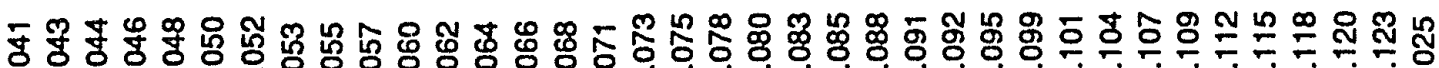

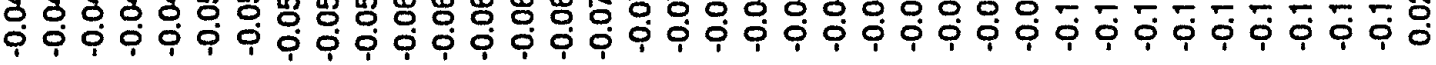

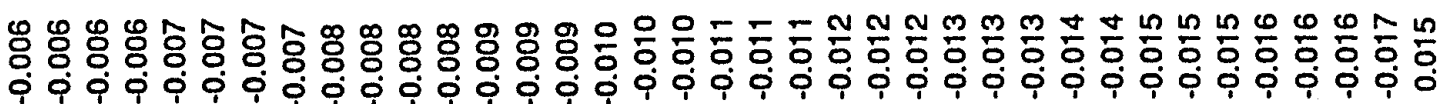

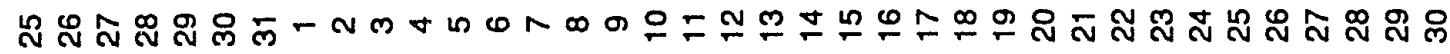




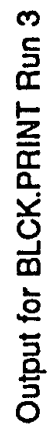

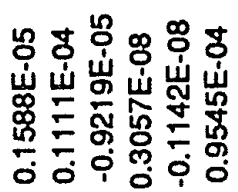

으용우ㄹㅜㅜ웅

㟧㟧岁㟧嵌

ํํㅁ용요

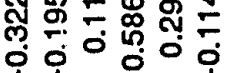

응ㅇㅇ용 웅

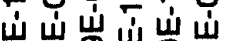

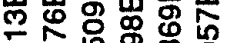

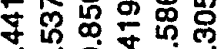

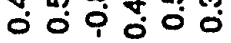

눙 낭눙용용 농

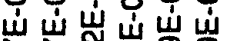

청 岁佥

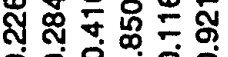

웅ㅇㅇ

잉뇽농용요웡

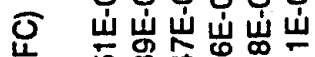

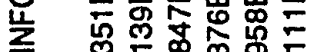

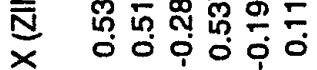

중ㅎㅇㅇㅇㅇ으으용

乙

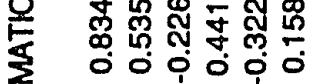

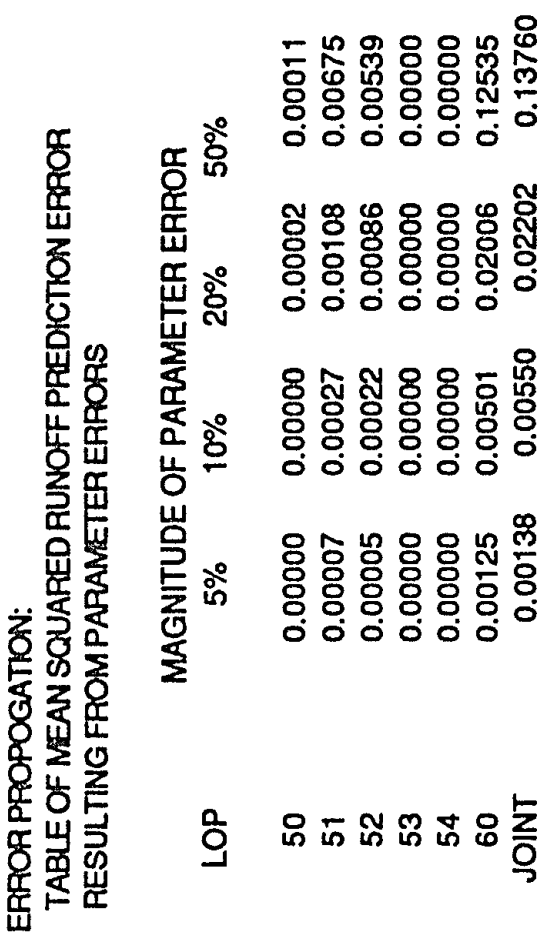




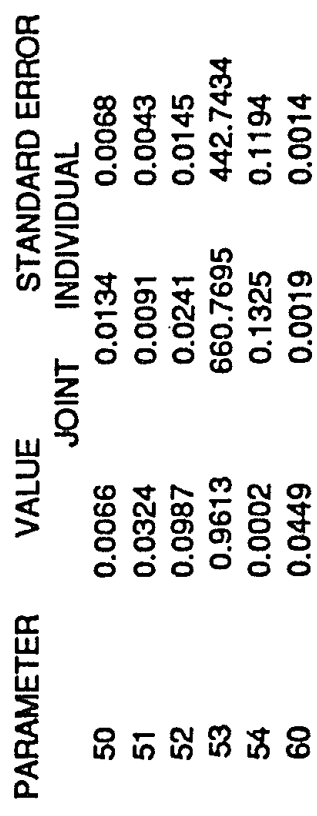

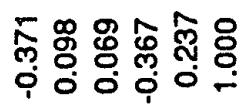

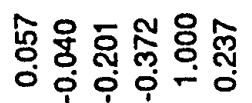

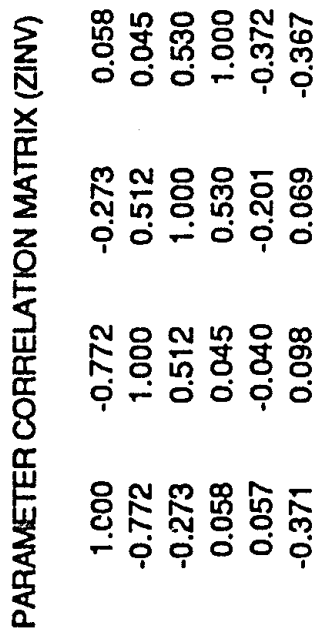




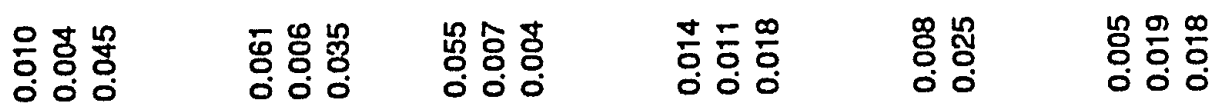

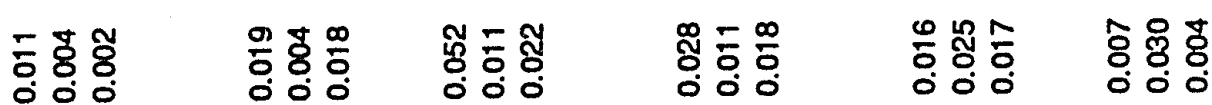

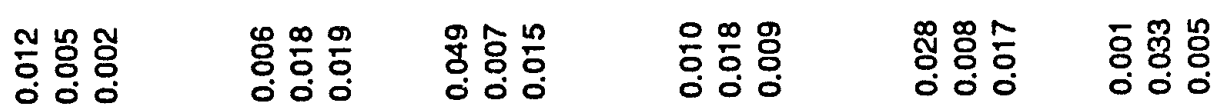

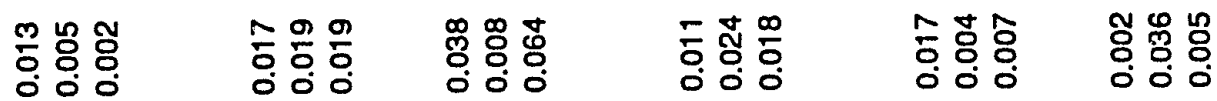

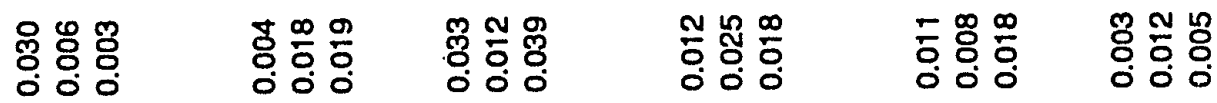

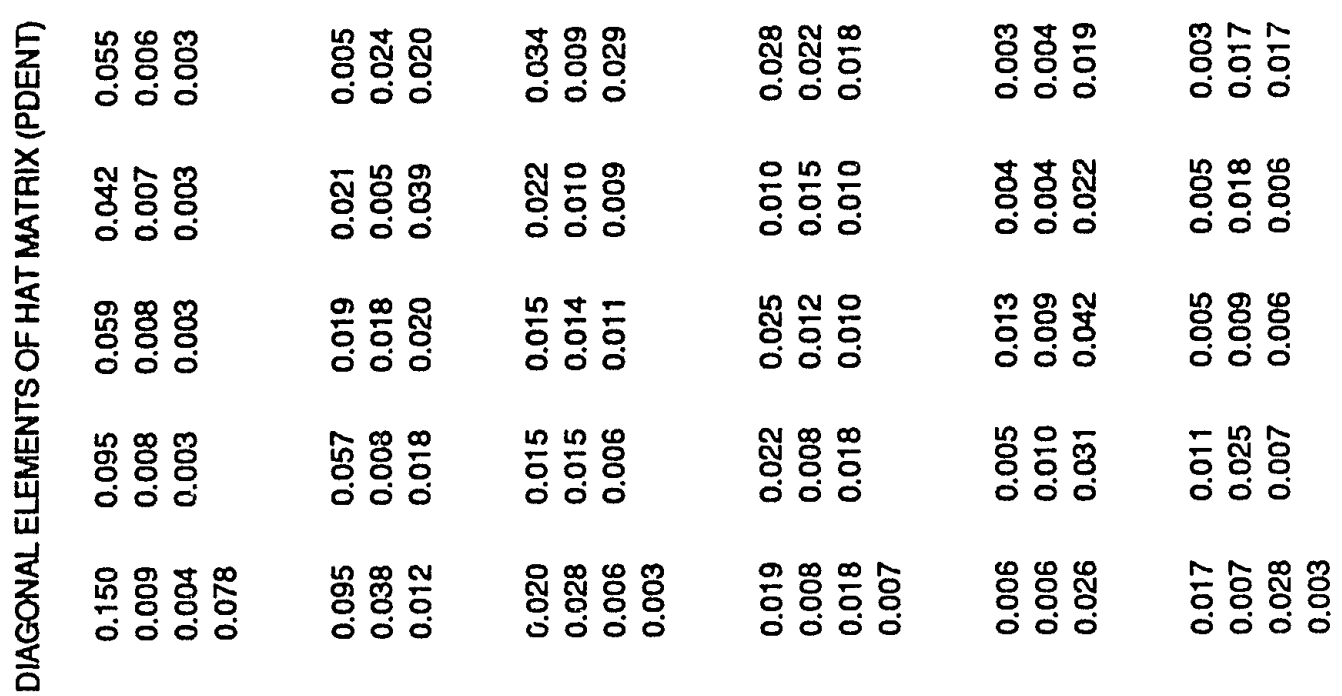




\begin{tabular}{|c|c|c|c|c|}
\hline 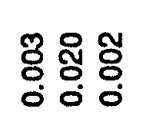 & 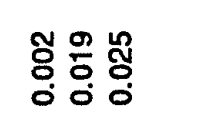 & 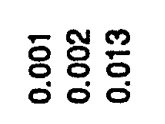 & 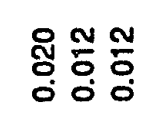 & 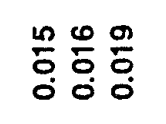 \\
\hline 형명영 & รั:̊̊ & 韋 & 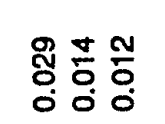 & 善言高 \\
\hline 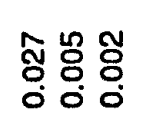 & 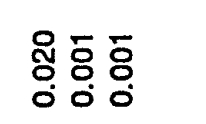 & 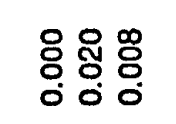 & 器器言 & 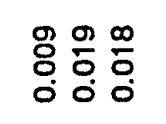 \\
\hline 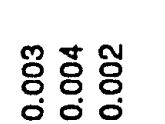 & šs̆ḡas & 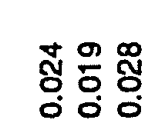 & 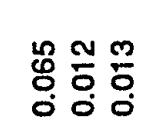 & $\frac{8}{85 \%}$ \\
\hline 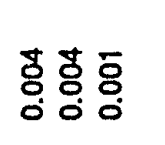 & 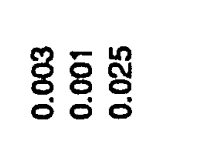 & 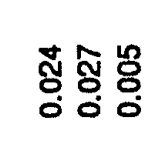 & 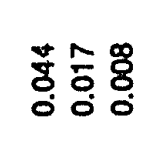 & รัฐั \\
\hline 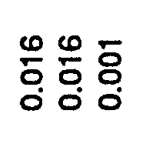 & รีฐ̆ีั & 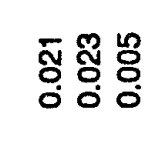 & ํํํำ & รัฐริ \\
\hline 害器器 & รัฐ๊ & 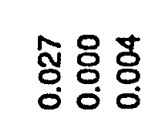 & 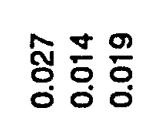 & 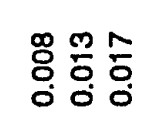 \\
\hline 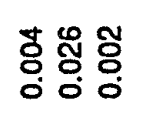 & 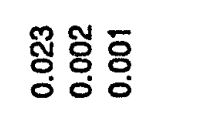 & ระํํำ & 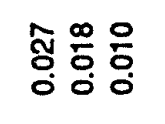 & 童 \\
\hline 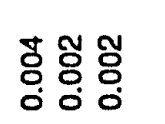 & 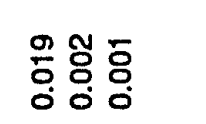 & 옹몽형 & 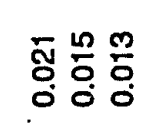 & 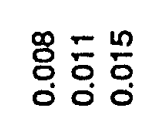 \\
\hline รั & 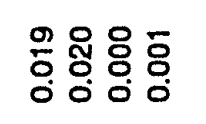 & 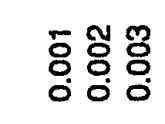 & 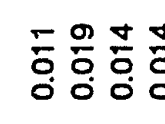 & 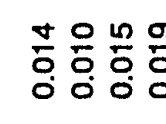 \\
\hline
\end{tabular}




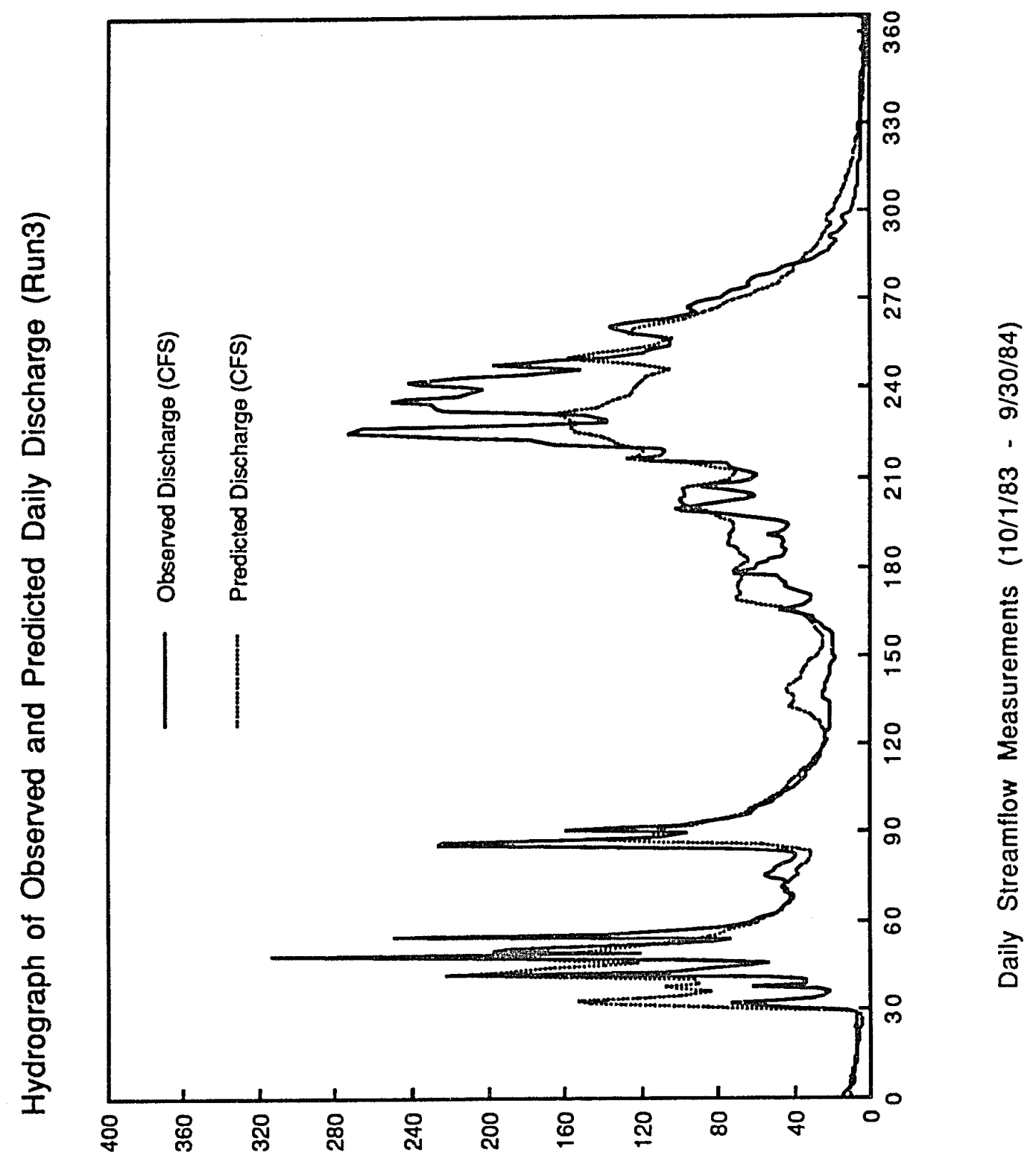

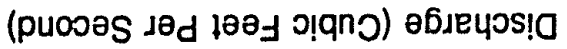


Appendix J

Output of PRMS Run 4 


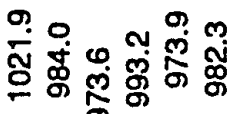

$$
\text { 蒙 }
$$

บ ${ }^{\circ} \circ \%$

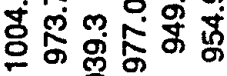

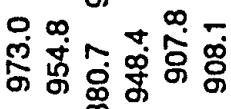

百

ㅇ. సิ่

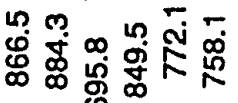

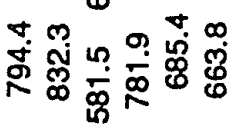
수 $\infty$

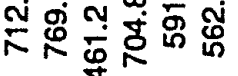

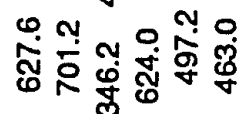
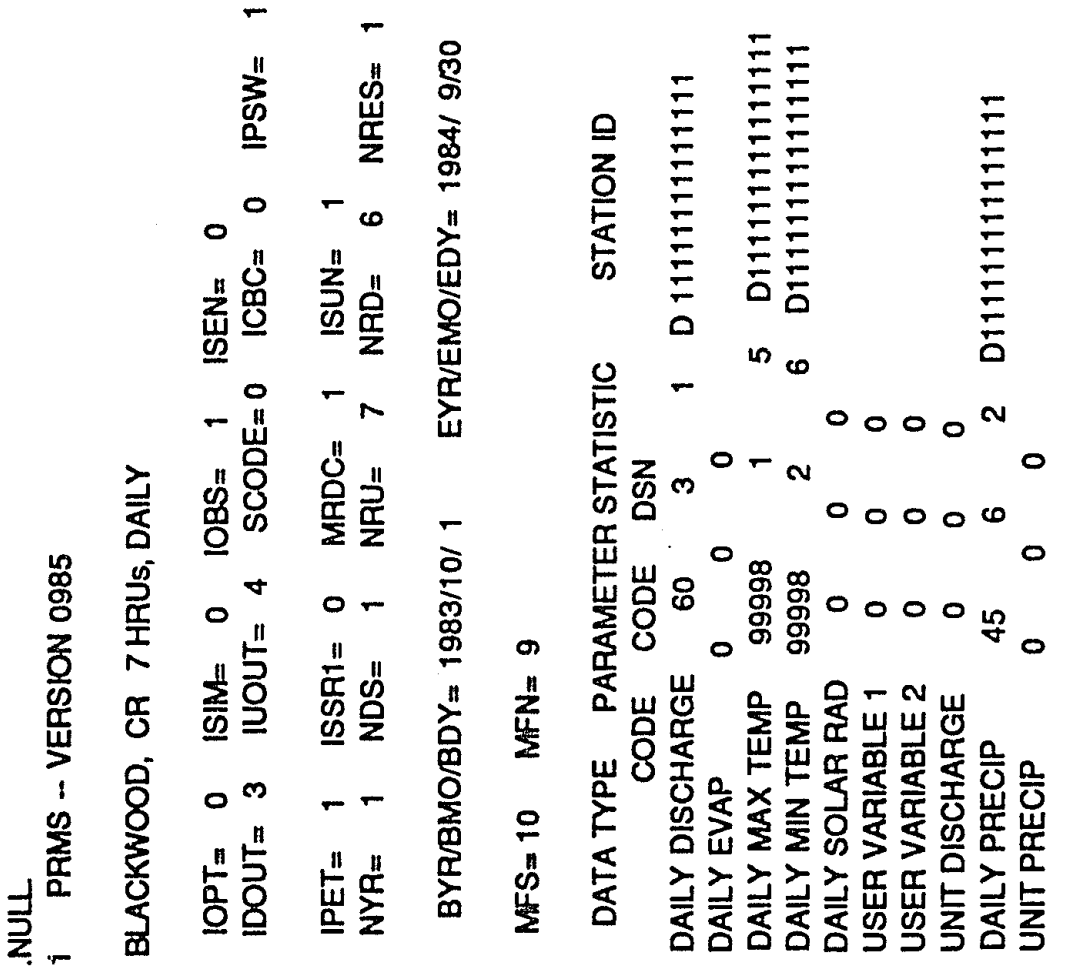

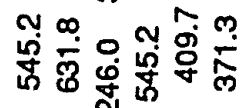
$\infty \omega$ 守总出色尊兽

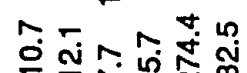

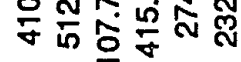

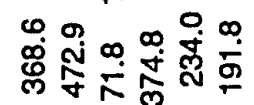

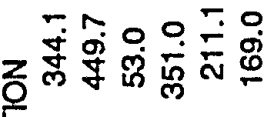
言

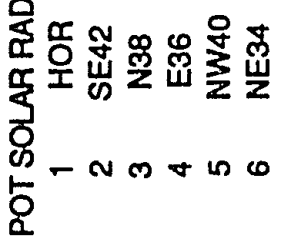


ำ

꿈

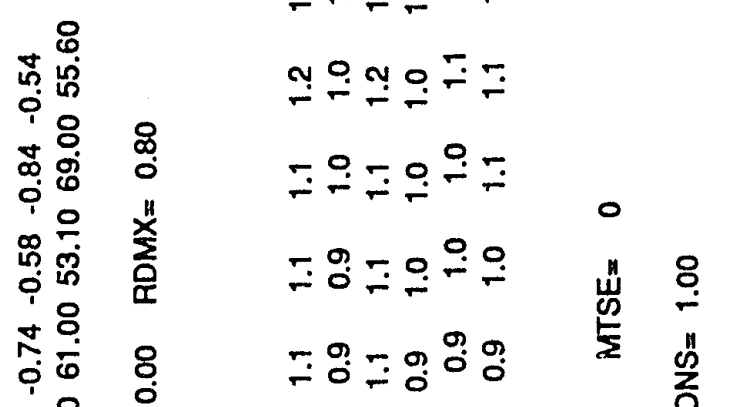

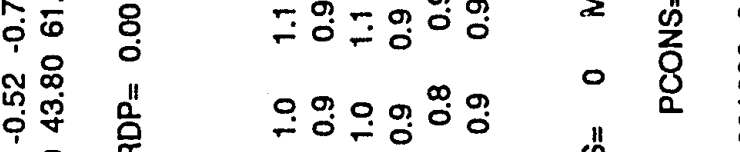

离

ஸ़่

^尺 ํำ

영

ธ우 움

ำ

Nㅛㅇํำ

i

f

宁品

苾员

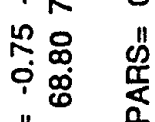

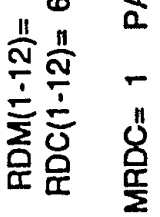

뭉 :

oriñ

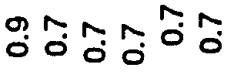

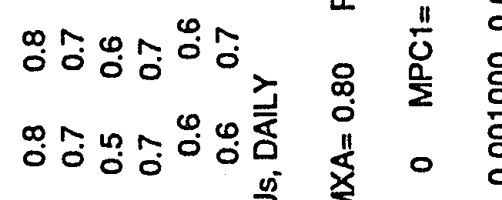

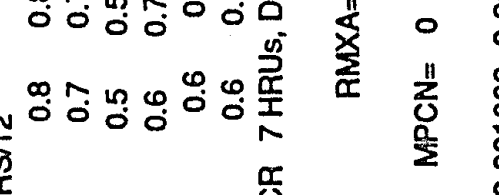

告
뭉 $\stackrel{\infty}{0}_{0}^{\infty} \underset{0}{\infty} \stackrel{0}{0} \stackrel{\infty}{0}$ 苞

$\frac{8}{8}$

$\frac{8}{8}$

$\frac{8}{8}$

웅

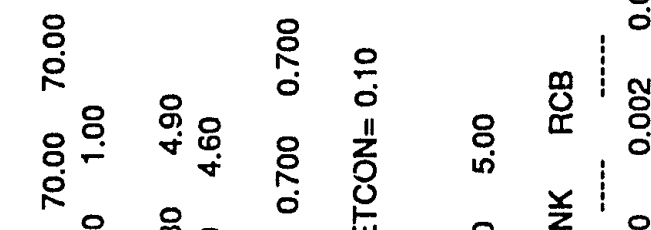

8

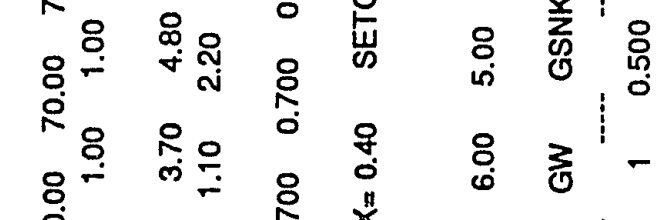

용

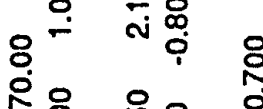

응

운 祭

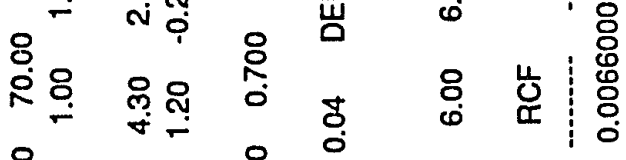

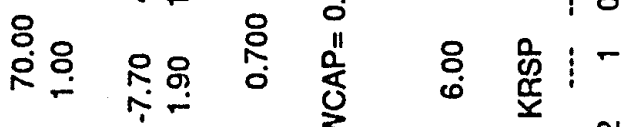

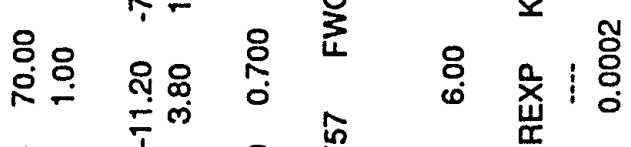

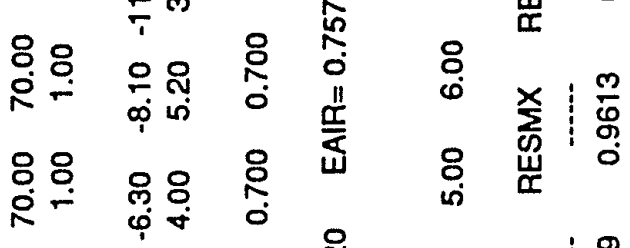

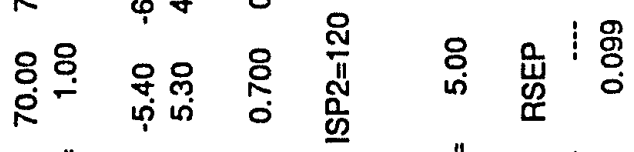

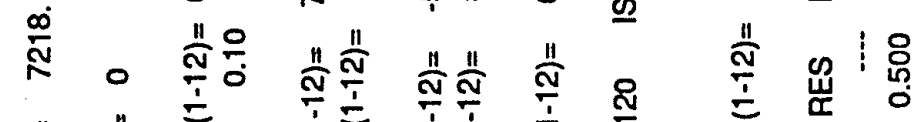
岁 


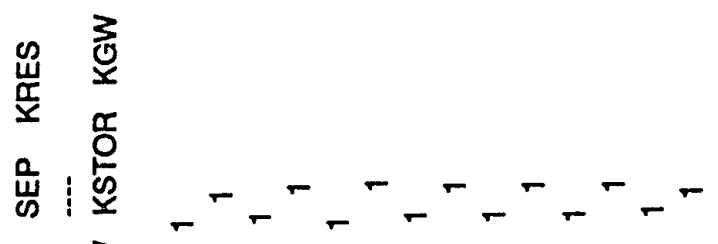

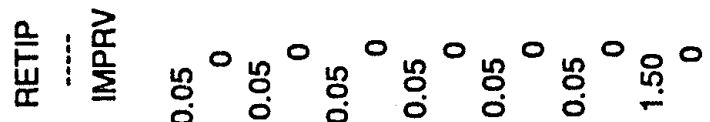

质 希

z

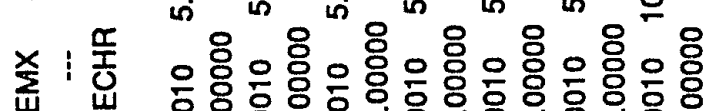

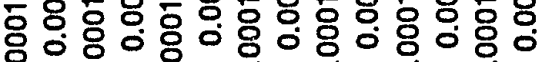

$\times \quad \geqslant \quad 0 \%$

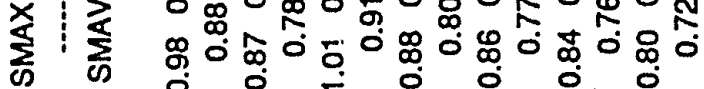

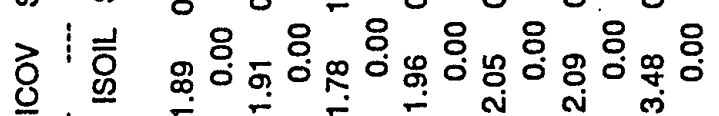

N

ग

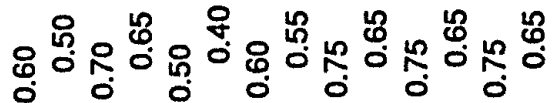

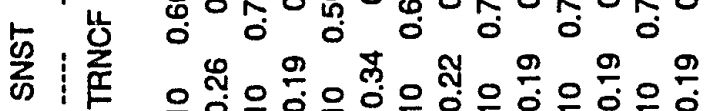

兵: 年

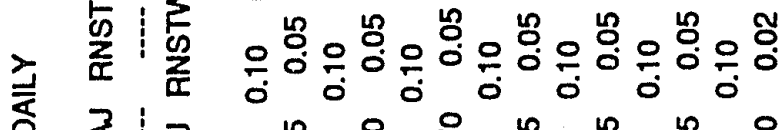

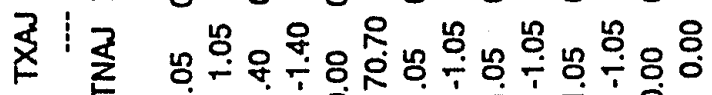

‘

多

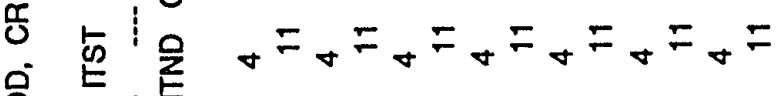

8

$\stackrel{\infty}{\infty}$

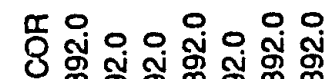

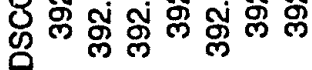

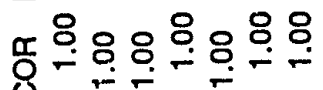

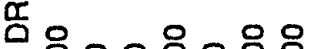

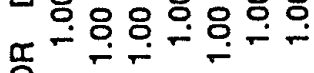

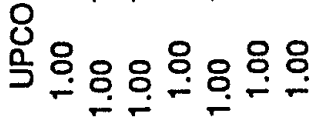

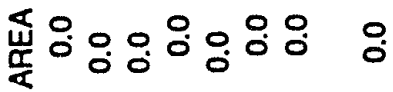
端

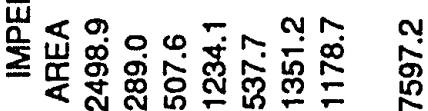

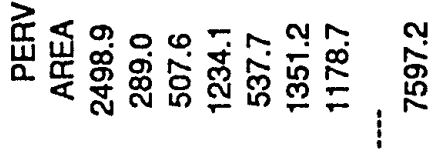

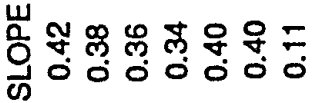

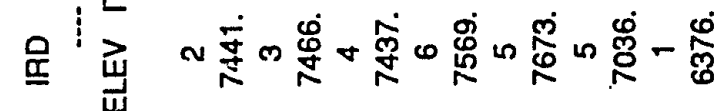

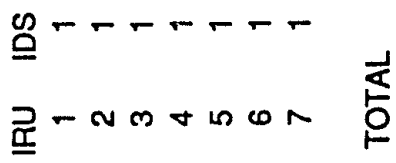




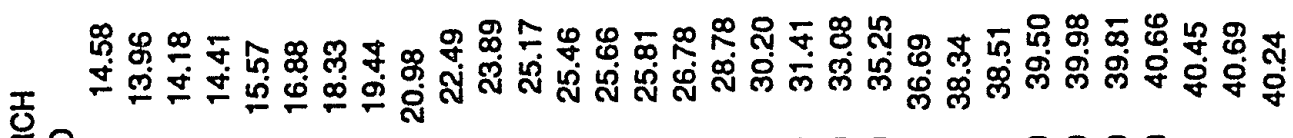

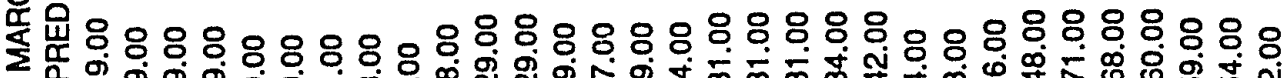

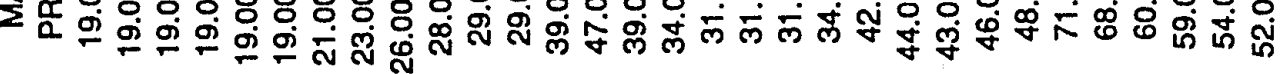

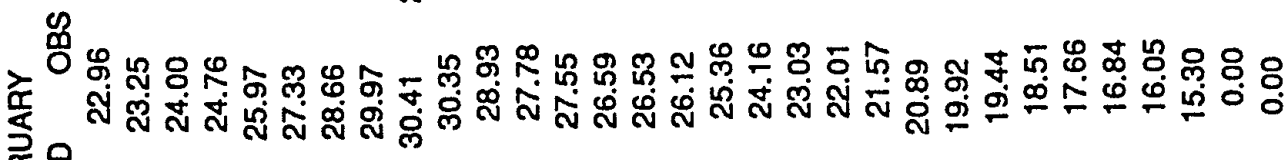

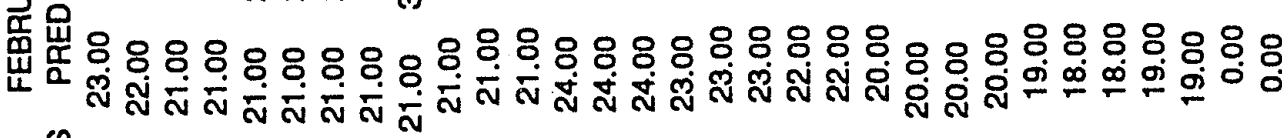
品

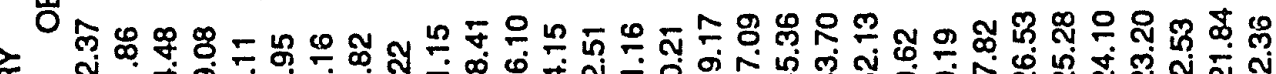

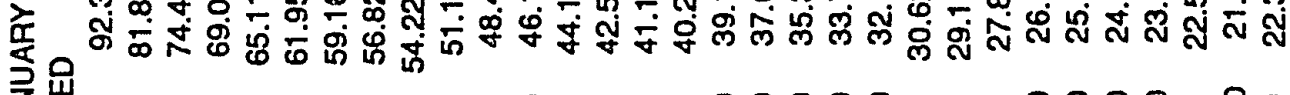
之崖

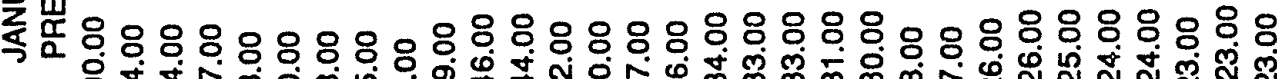

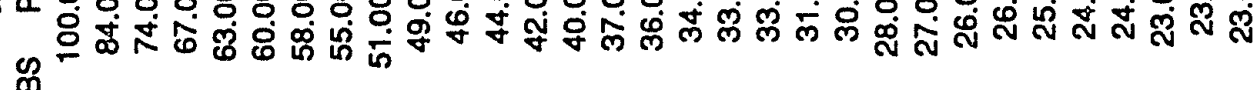
눈

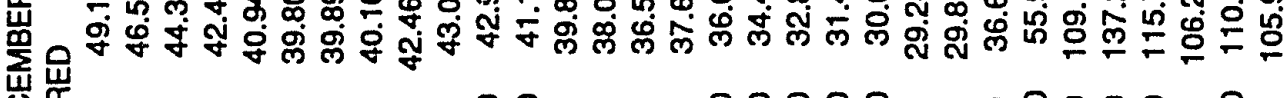

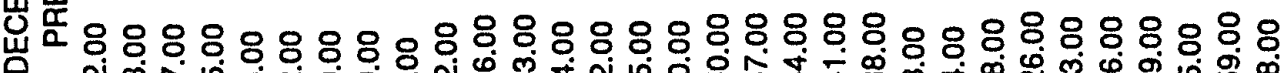

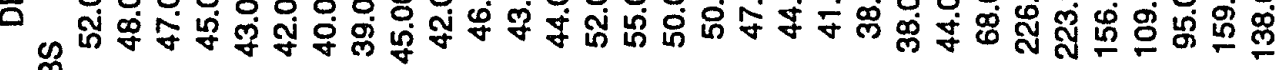
品

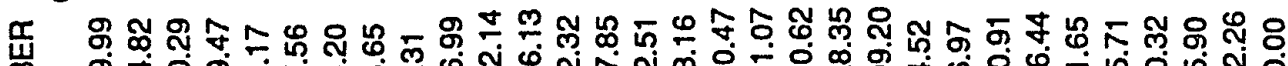

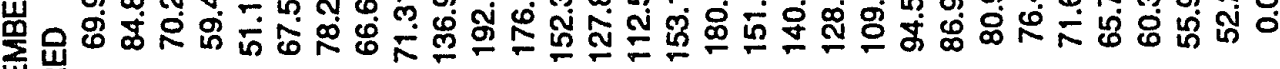
㟧

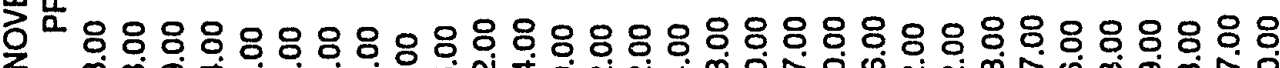

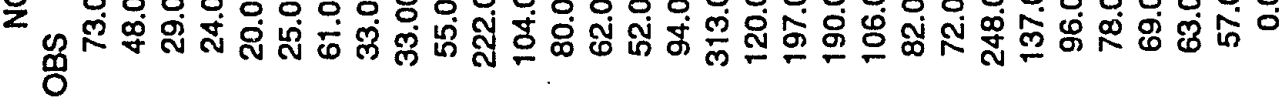

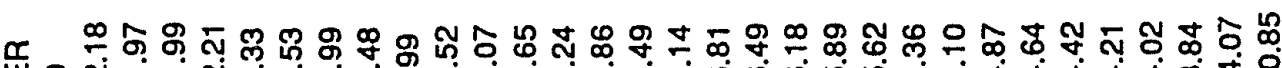

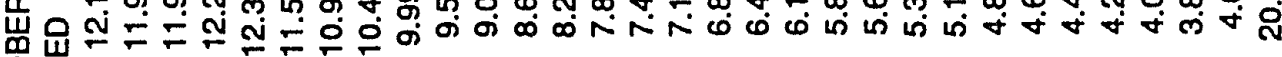
앙

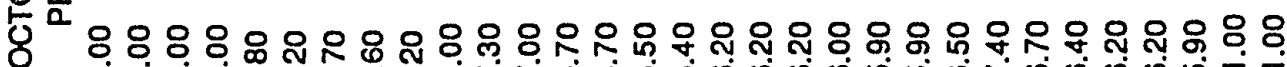

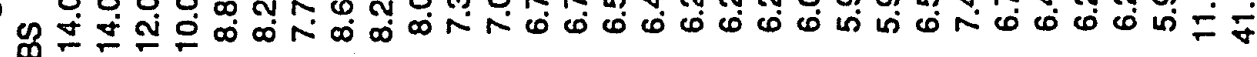
希 - 


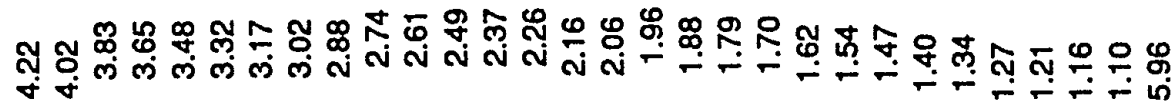

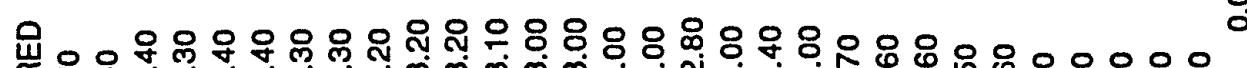

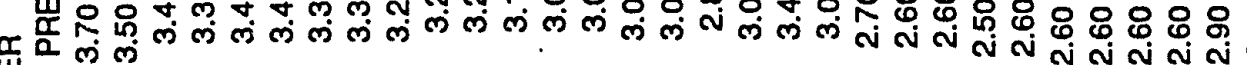

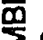

崖总

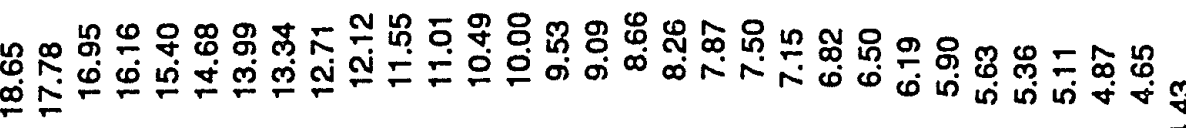

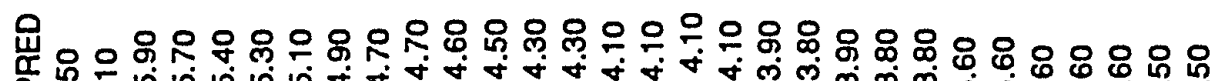

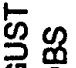

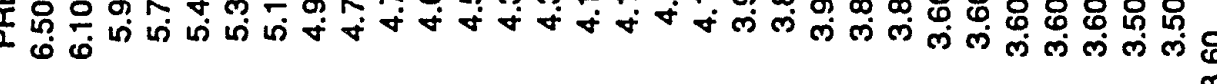

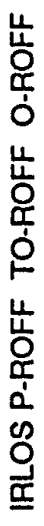

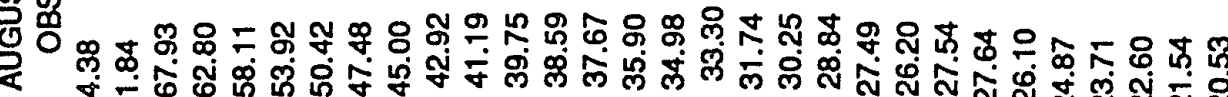

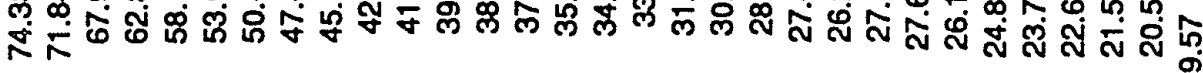

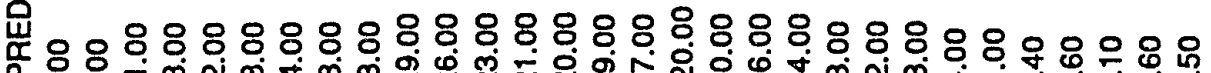

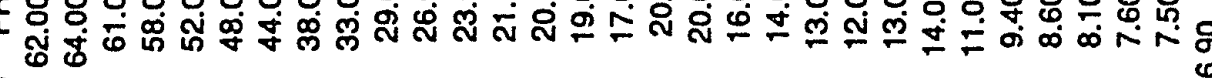
党要

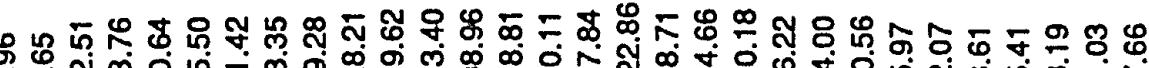

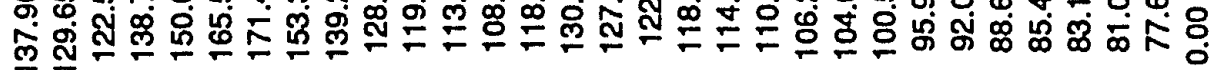

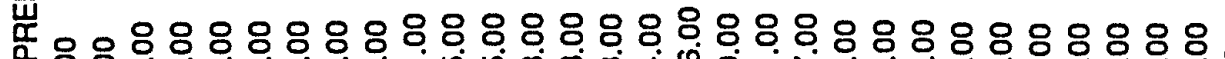

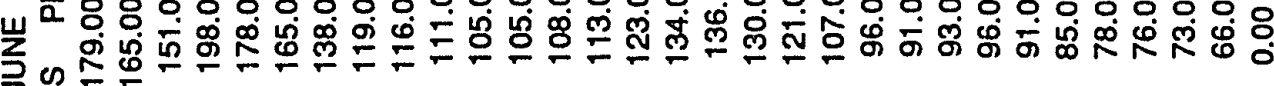

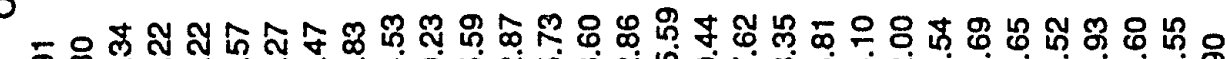
क

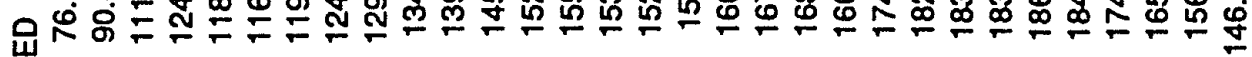
$>$ 茫

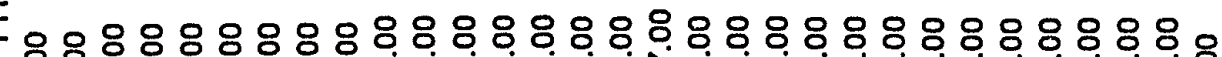

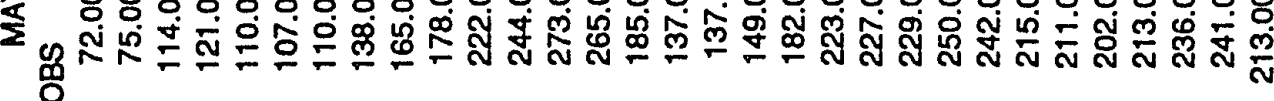

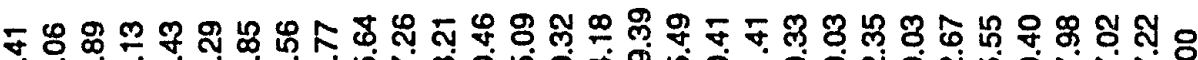

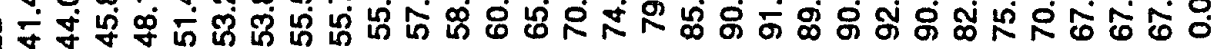

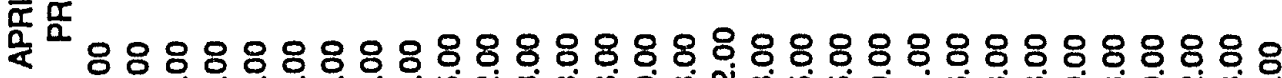

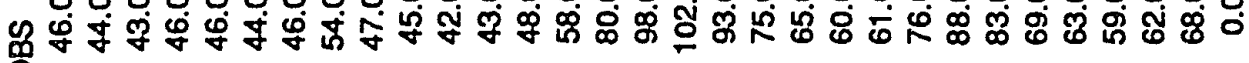
¿

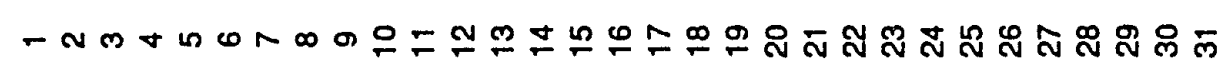




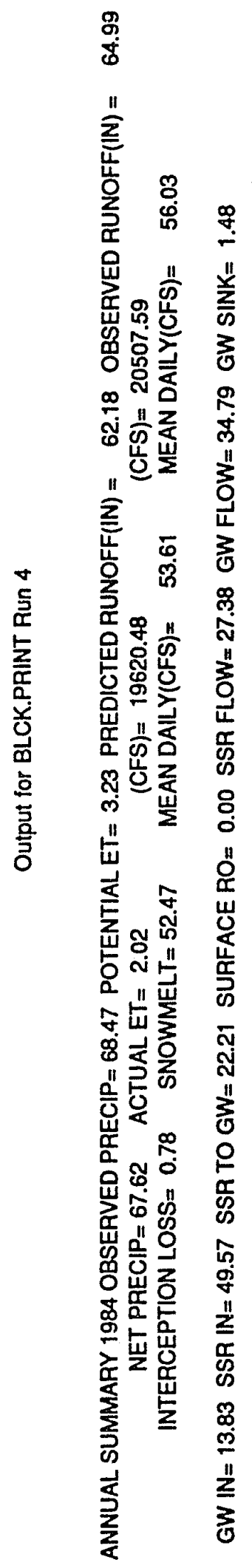




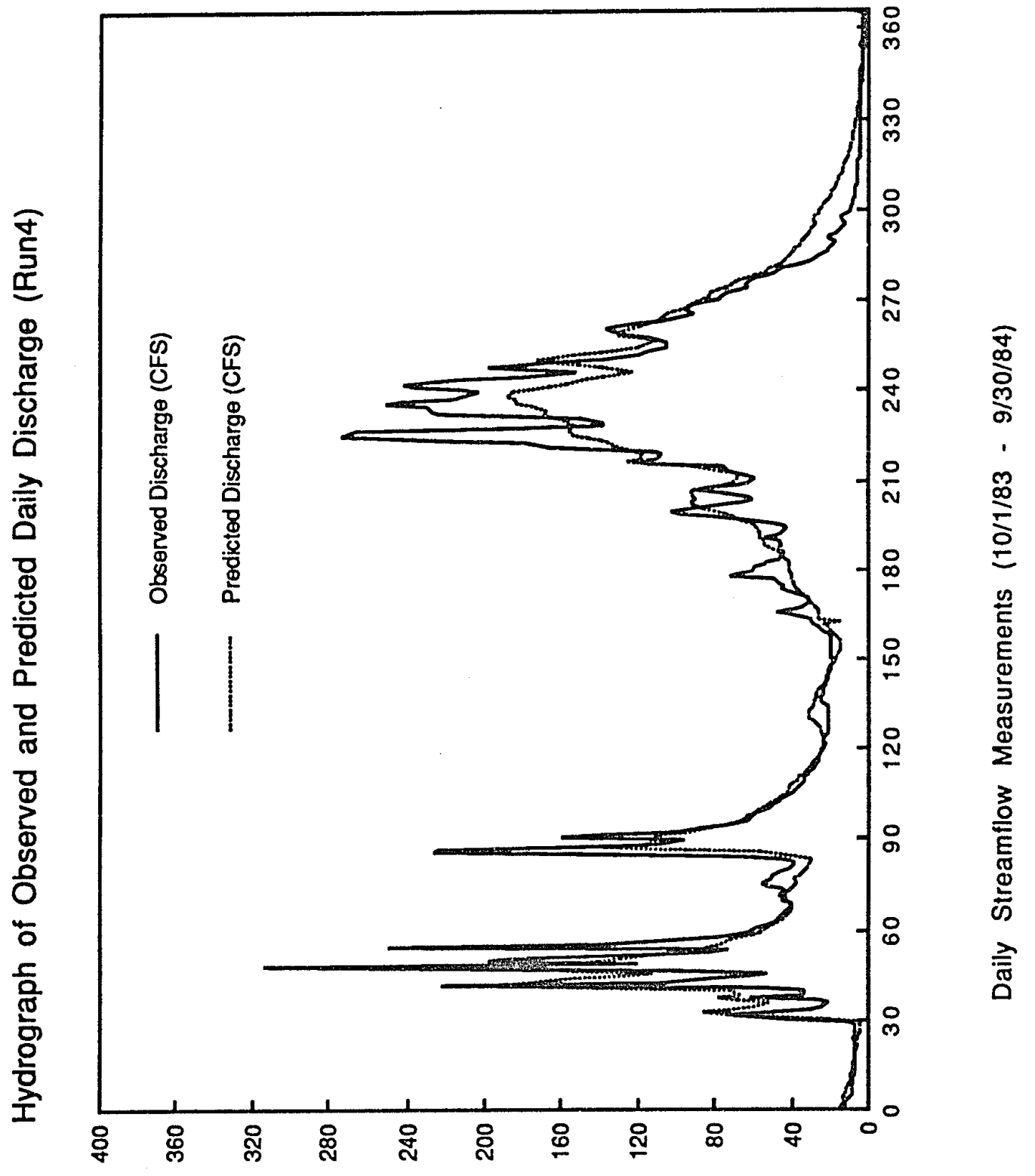

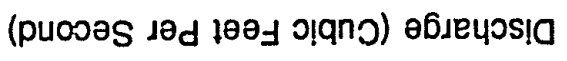


Appendix K

Output of PRMS Run 5 


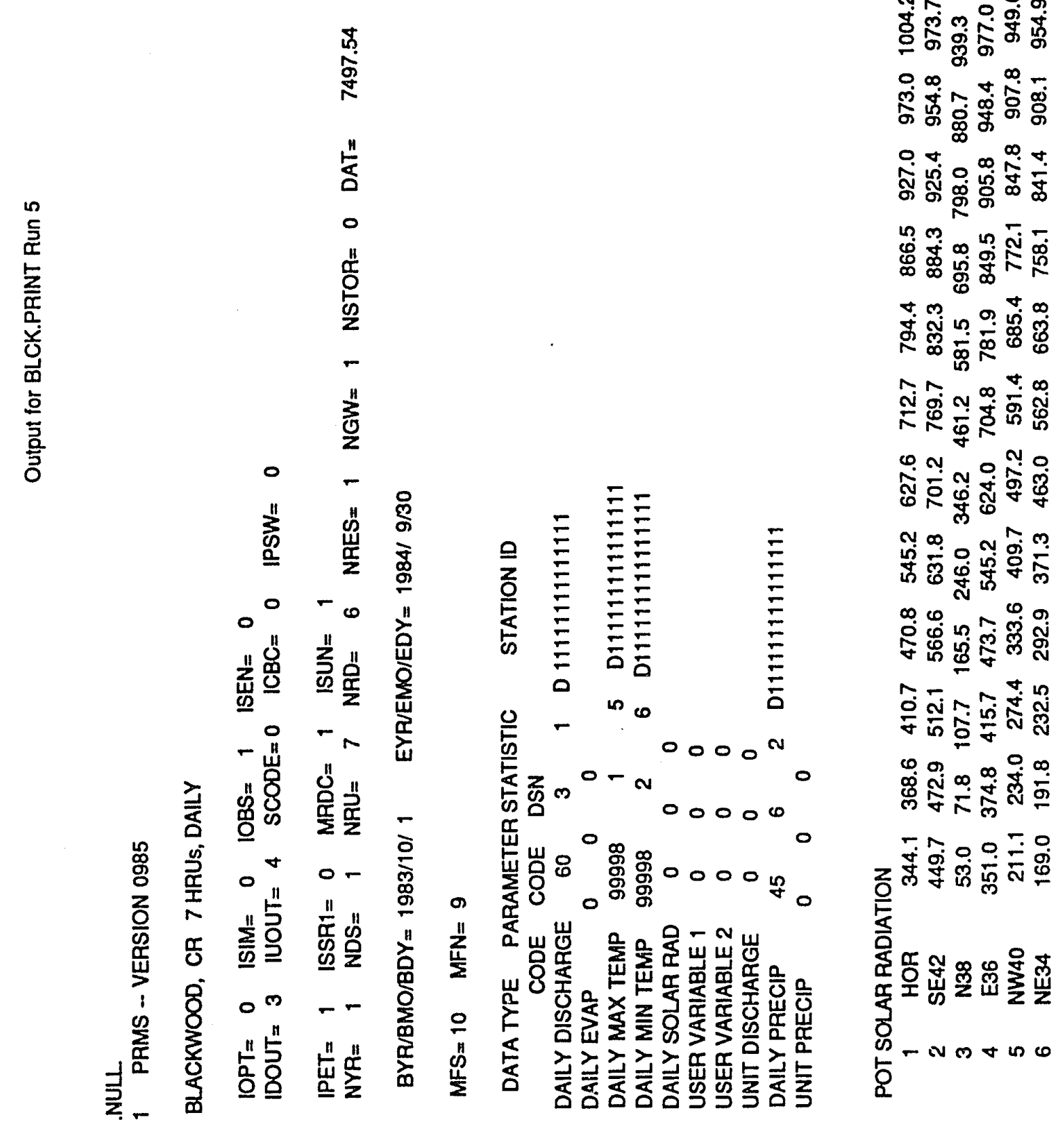


บำ

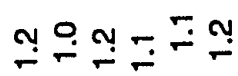

$\stackrel{8}{\circ}$

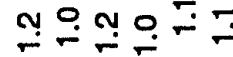

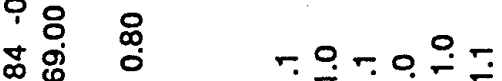

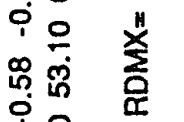

i8

त产 8

กั

웅

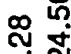

워

숭

요 웅

ํํㅇ

용 잉

둥

紫号

용

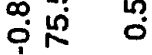

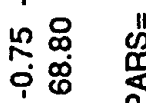

茎产

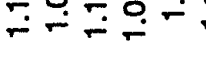

풍두움웅

웅웅움웅 웅

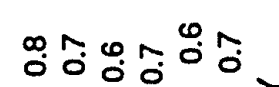

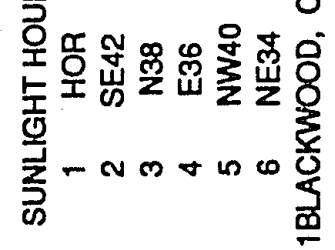

응

응

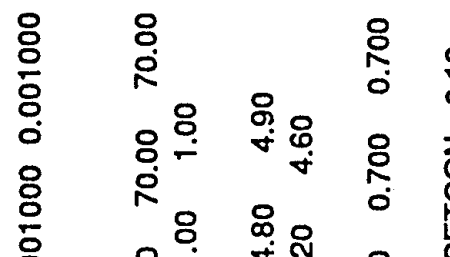

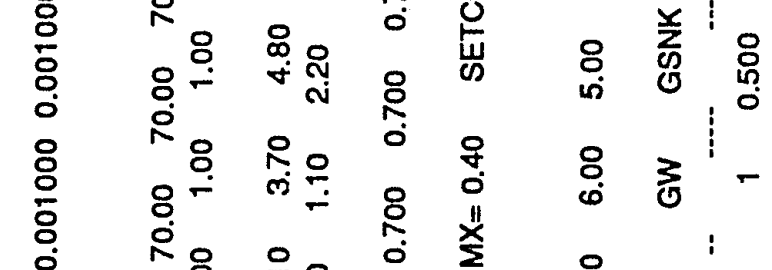

岁

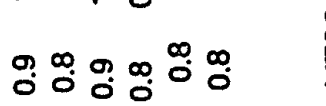

웅웅

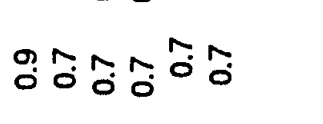

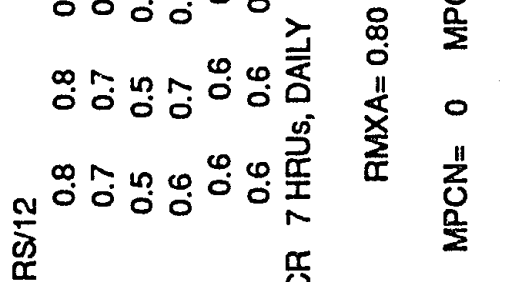

응

娄

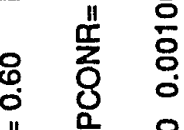

宕品

$8 \div$ 땡유 8 ஸ़

ㅇ․ㅇ 웡

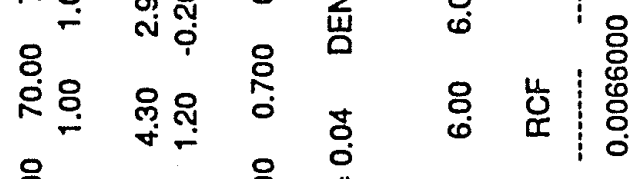

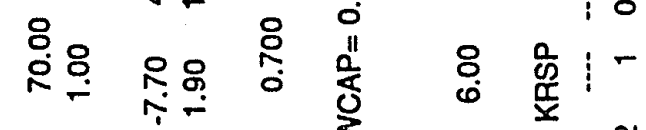

융유용

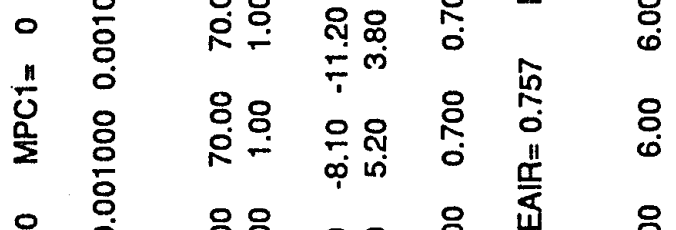

융요

尛

에 은

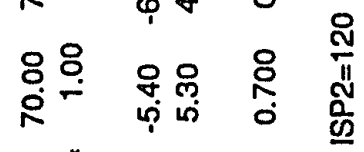

呈: 号

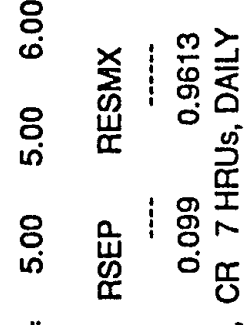

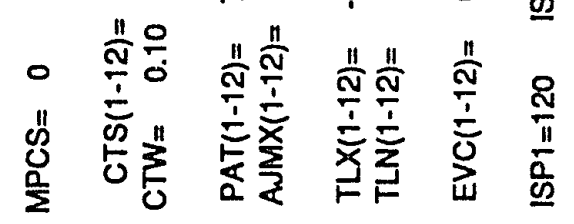

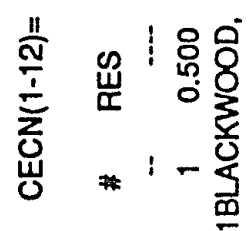




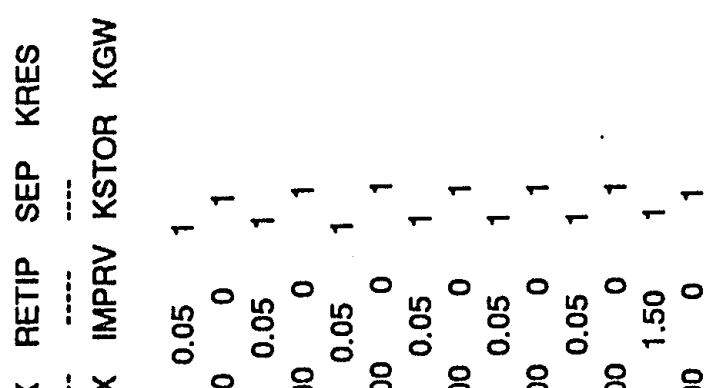
存 z্ল্য 肴䜿 辛 至

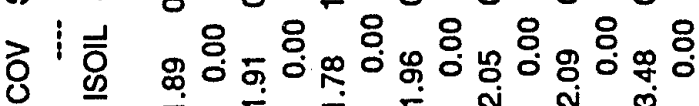

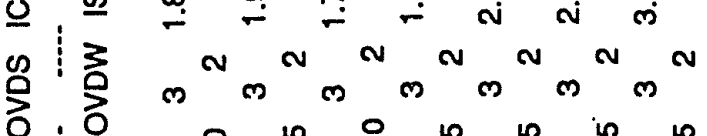
४ 㐌: 崔 告: त 万人

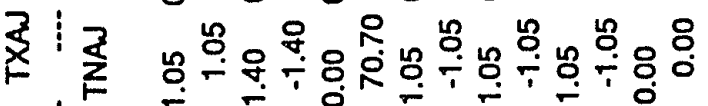

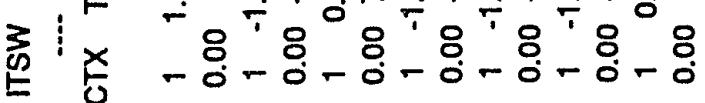

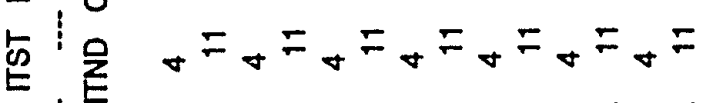

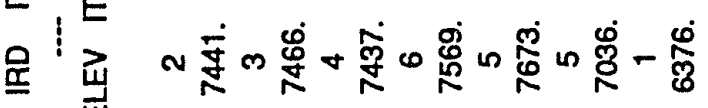

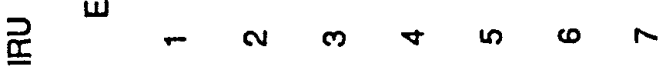
包

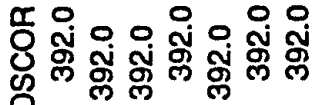

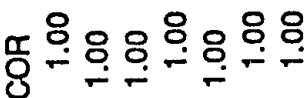

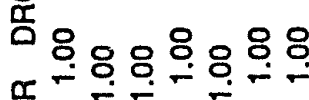
徐-

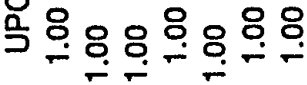
岸엉영영영영영영 离

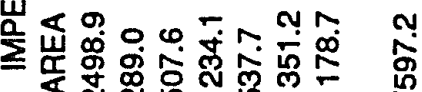

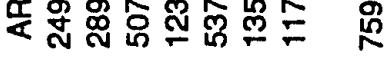

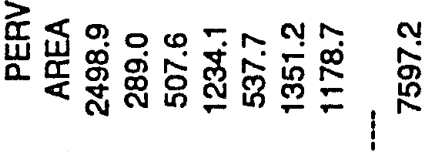

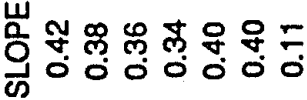

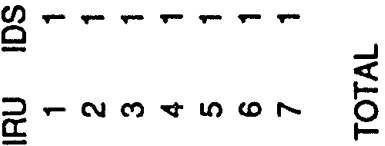




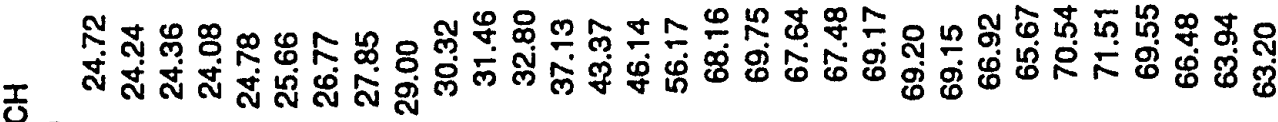
专

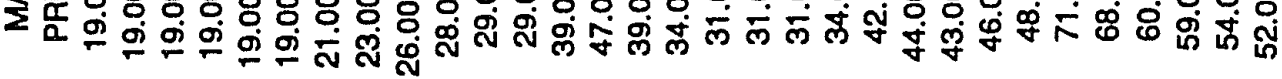

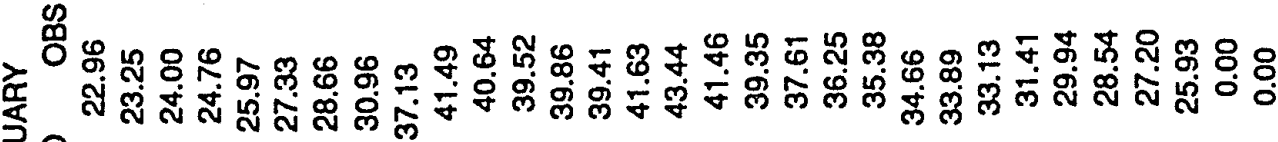

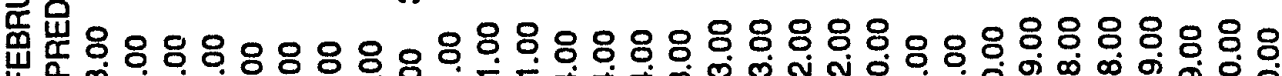

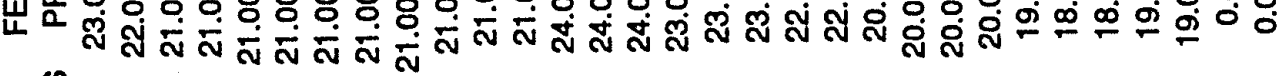

品

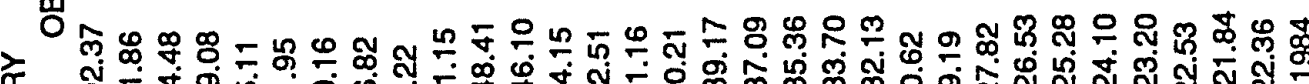

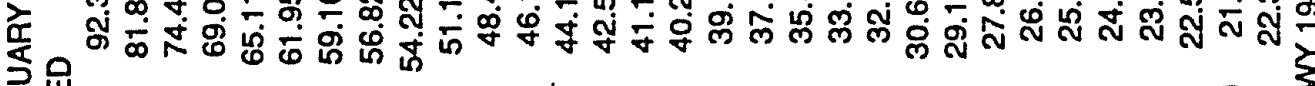

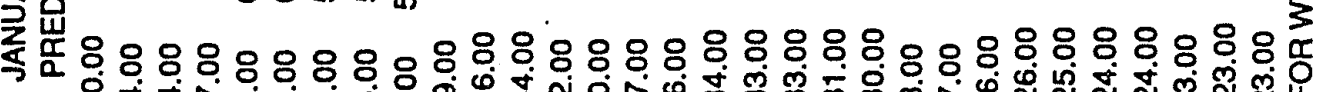

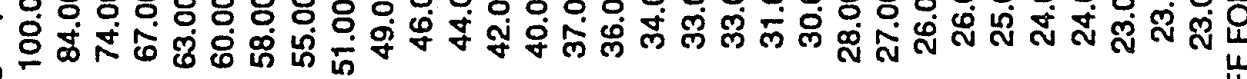

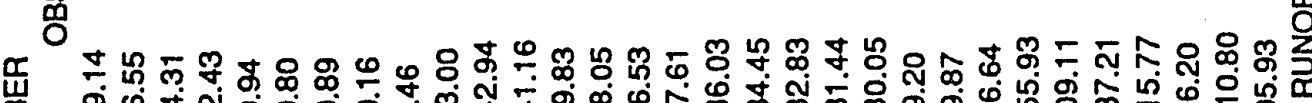

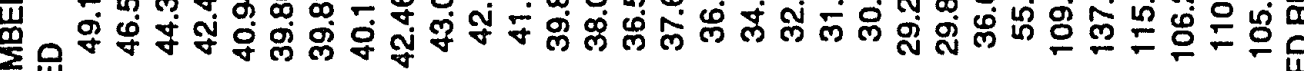
㞫 0 ơ

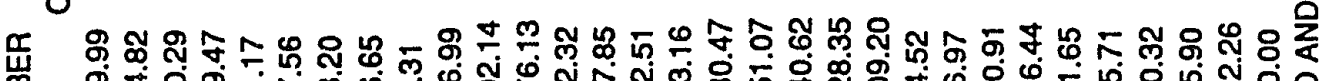

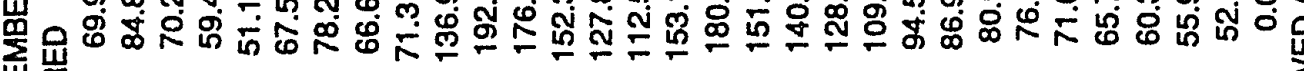
山ै

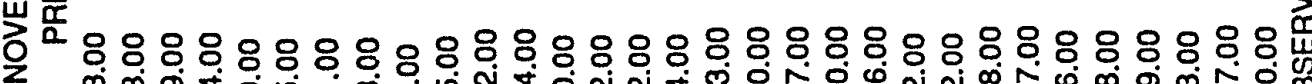

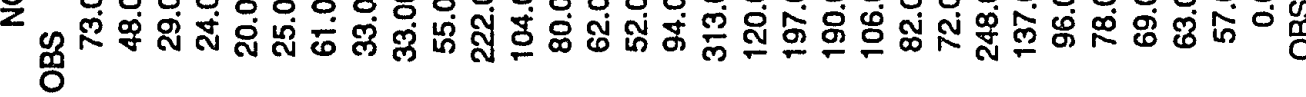

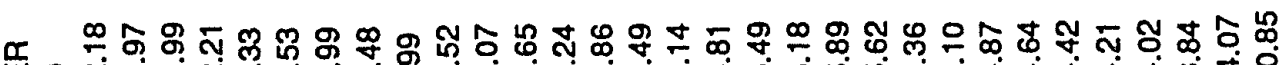

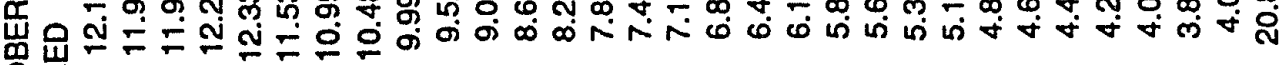
은뜸

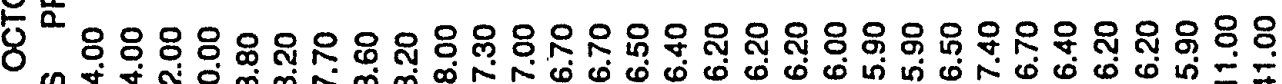

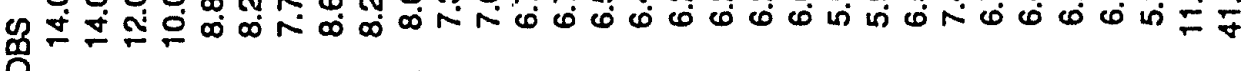

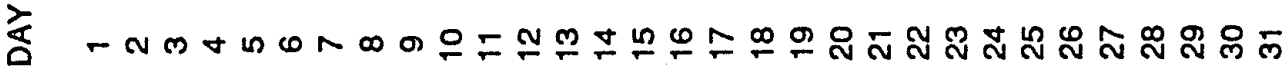




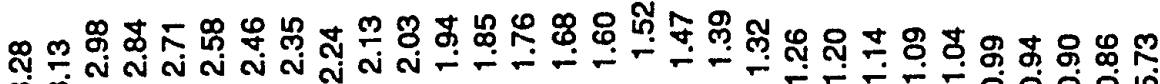

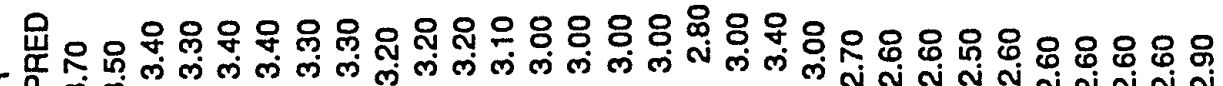
䔡

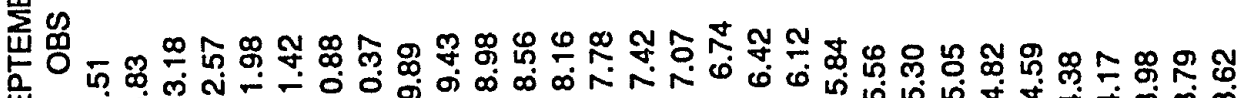
क

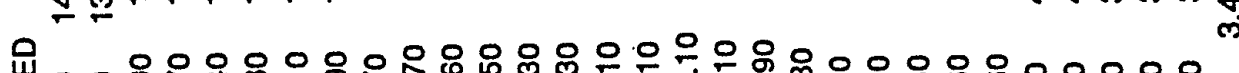

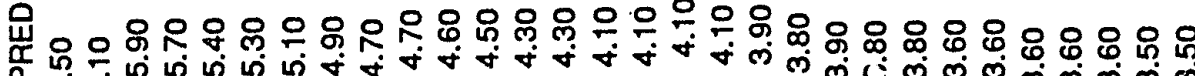
遂 包

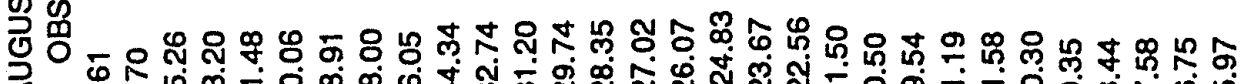

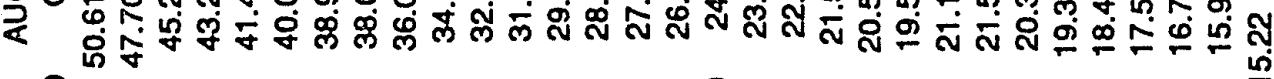

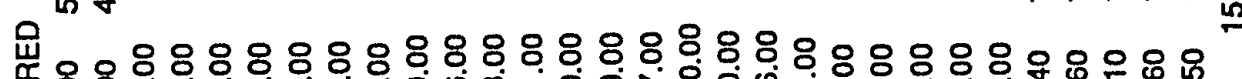

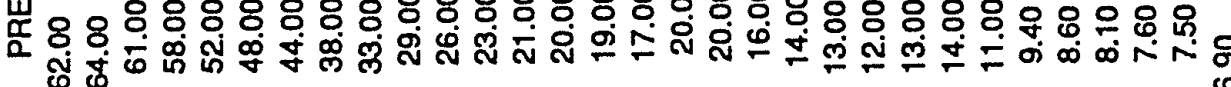
う吕

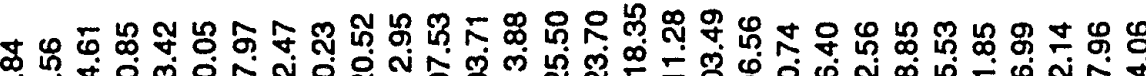

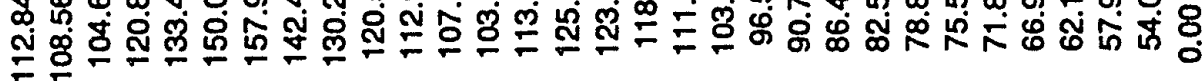

崖

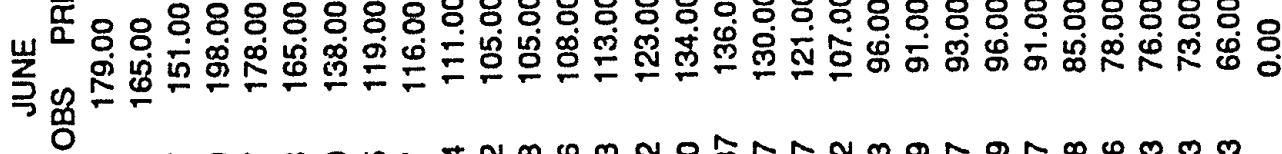

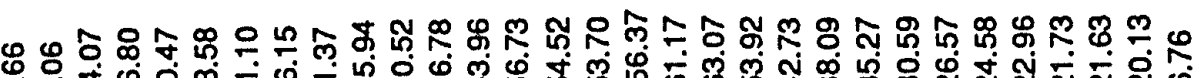

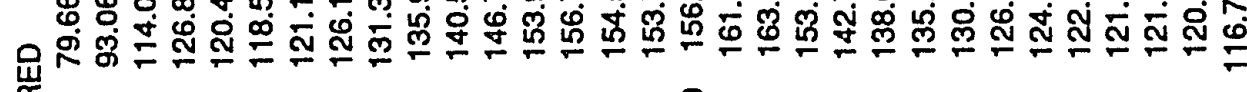

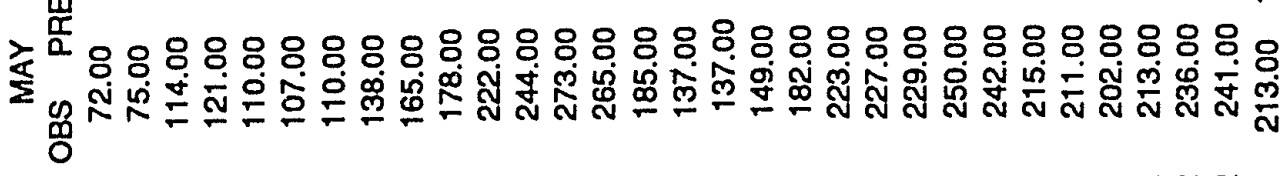

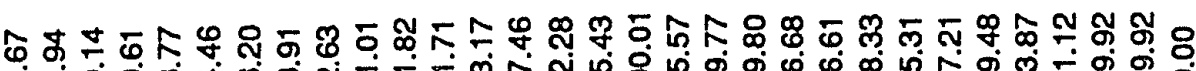

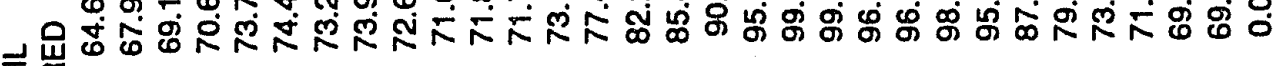
产罂

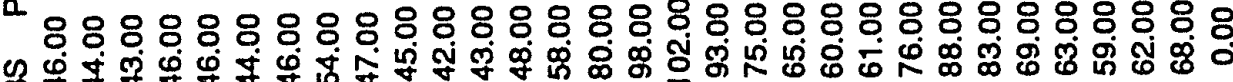

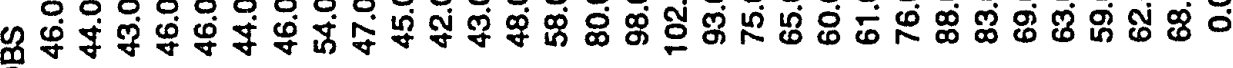
を 


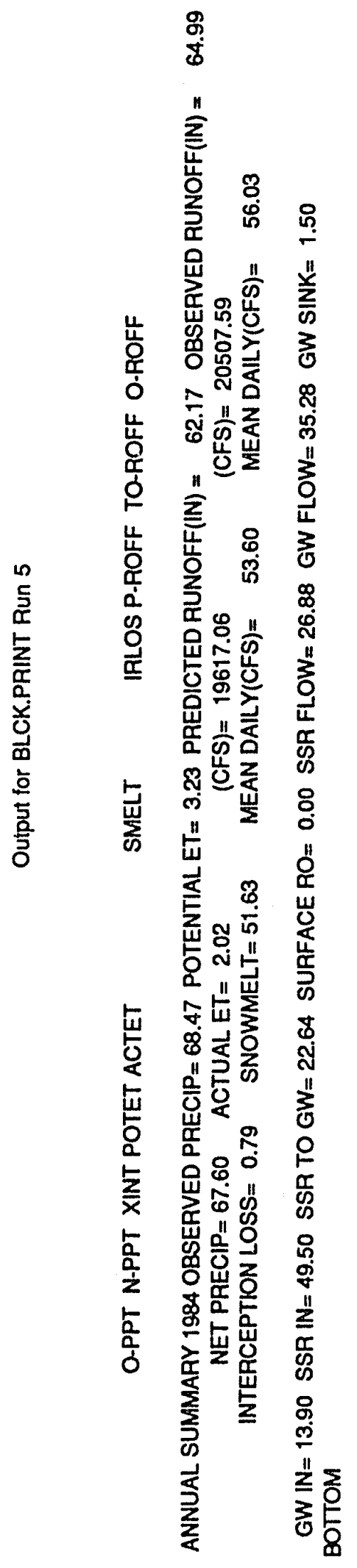




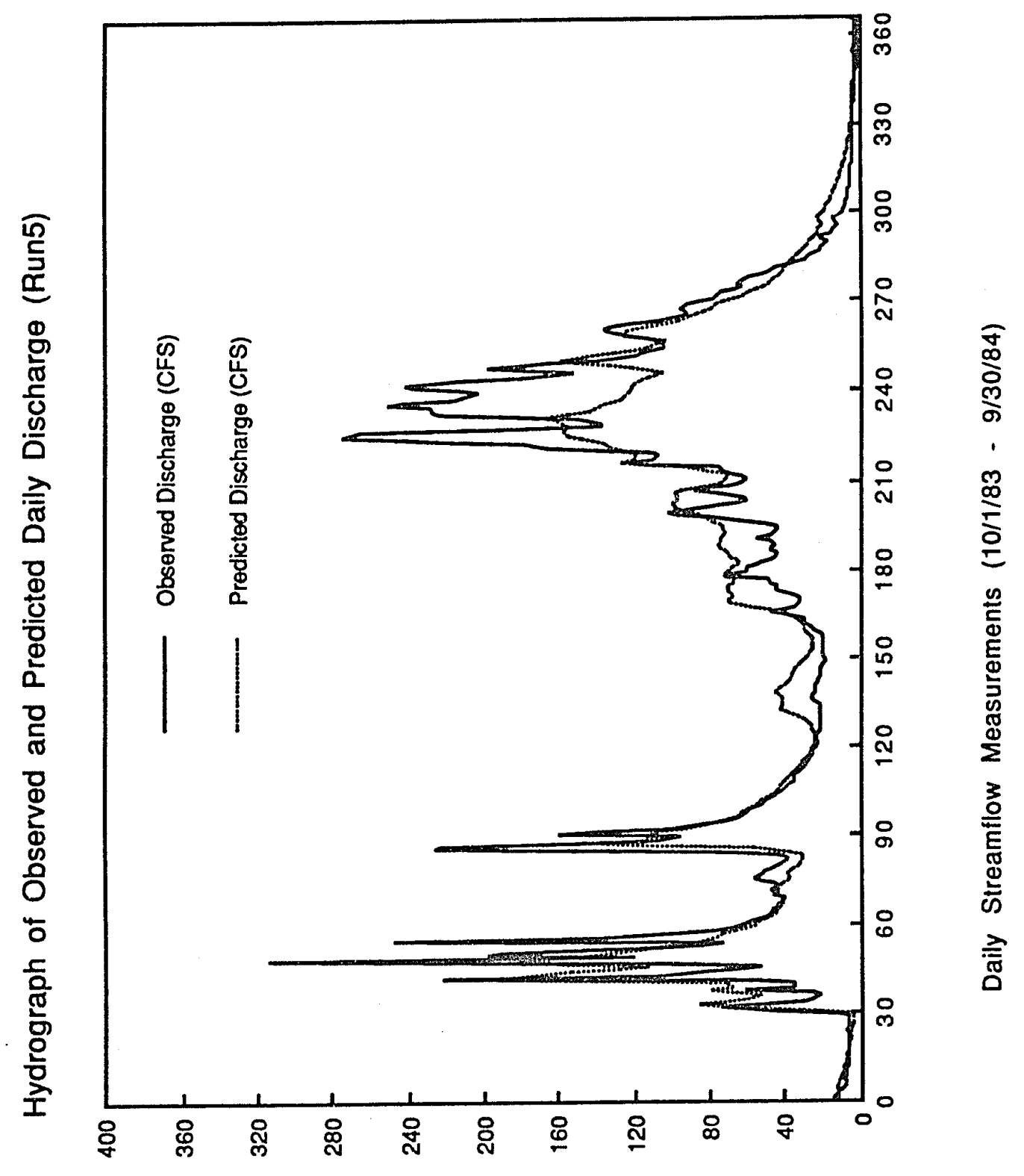

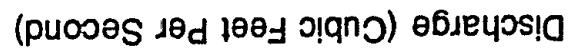


Appendix L

Infiltration Study Data and Figures 
Dimensions of Inner ring

Radius (cm)
Area (square $\mathrm{cm})$
Multiplier (1/area)
Infiltration Rate $(\mathrm{cm} / \mathrm{hr})$

$=5.4$

$=91.61$

$=0.01092$

$=$ Infiltration (ml/10 minutes) * Multiplier * $60 \mathrm{~min} / \mathrm{hr}$

\begin{tabular}{ccc} 
Time & $\begin{array}{c}\text { Infiltration } \\
\text { Volume per }\end{array}$ & $\begin{array}{c}\text { Infiltration } \\
\text { Rate }(\mathrm{cm} / \mathrm{hr})\end{array}$ \\
\hline
\end{tabular}

Notes Associated with Site 1-1987

- 10/3/87

- sunny, warm, clear

- approximately 75 degreas fahrenheit

- abandoned road

- trees growing on road rangeing from 5 to 20 feet tall

- slight vegetation on road surface

- trees appear to be more dense in the center of the road

- gopher holes are abundant

- 3n head was used for test 
Graph of Infiltration Data (Site 1-1987)

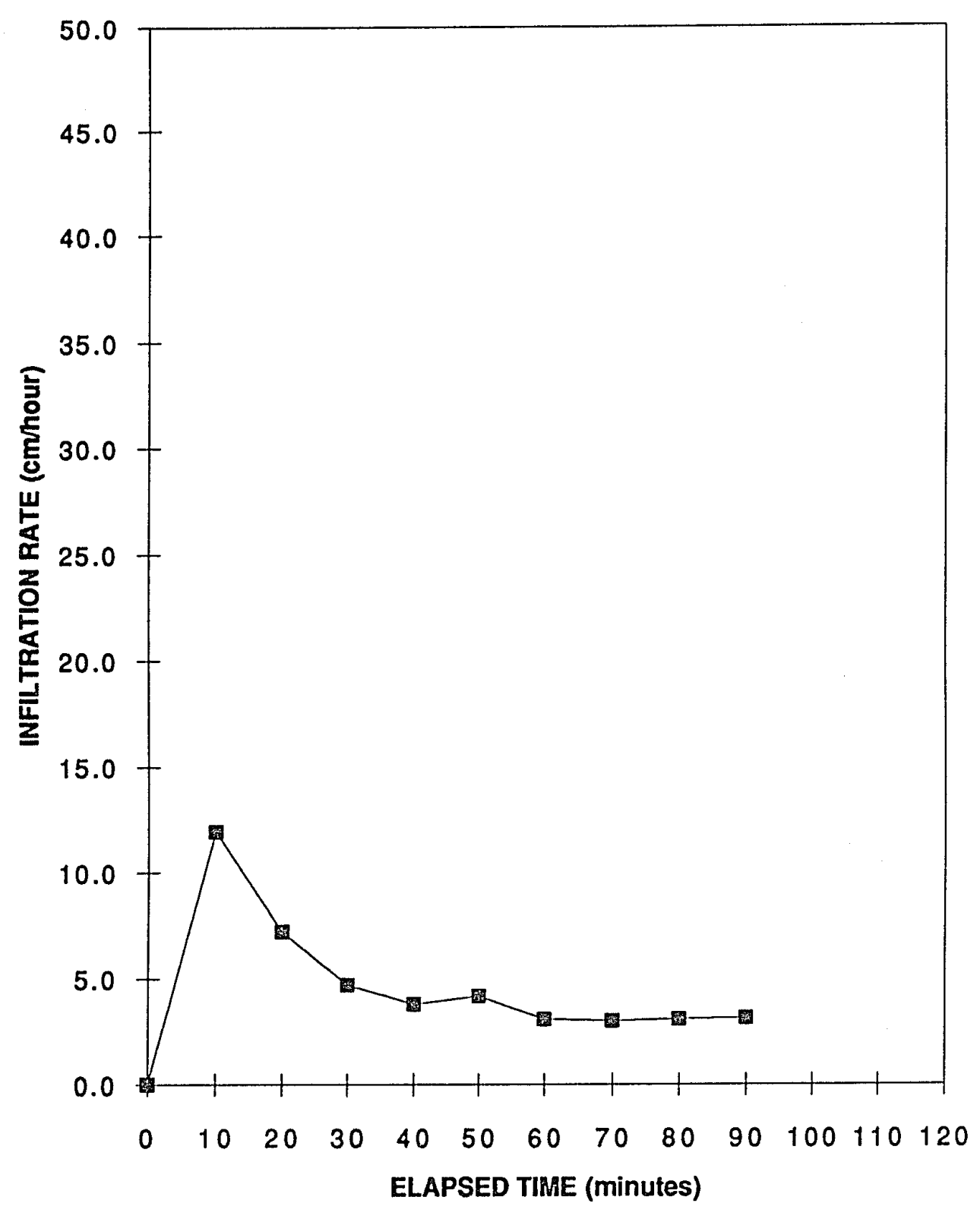


Infiltration Data (Site 2-1987)

Dimensions of Inner ring

\begin{tabular}{|c|c|c|}
\hline $\begin{array}{l}\text { Radius (cm) } \\
\text { Area (square } \\
\text { Multiplier (1/ }\end{array}$ & & $=$ \\
\hline Infiltration $R$ & $(\mathrm{~cm} / \mathrm{hr})$ & $=$ \\
\hline $\begin{array}{c}\text { Time } \\
\text { (Minutes) }\end{array}$ & $\begin{array}{l}\text { Infiltration } \\
\text { Volume per } \\
\text { Time (ml) }\end{array}$ & $\begin{array}{c}\text { Infiltration } \\
\text { Rate }(\mathrm{cm} / \mathrm{hr})\end{array}$ \\
\hline 0 & 0 & 0.000 \\
\hline 10 & 269 & 17.618 \\
\hline 20 & 76 & 4.978 \\
\hline 30 & 60 & 3.930 \\
\hline 40 & 61 & 3.995 \\
\hline 50 & 62 & 4.061 \\
\hline 60 & 78 & 5.109 \\
\hline 70 & 59 & 3.864 \\
\hline 80 & 61 & 3.995 \\
\hline
\end{tabular}

Notes Associated with Site 2-1987

- 10/3/87

- sunny, warm, clear

- approximately 75 degrees fahrenheit

- large stand of trees

- upper $1^{\text {" }}$ of soil consists of leaves and pine needles

- outer ring driven only $5^{n}$ (refusal)

- leaves and needles float which caused a measureing problem

$-3^{n}$ head was used for test 
Graph of Infiltration Data (Site 2-1987)

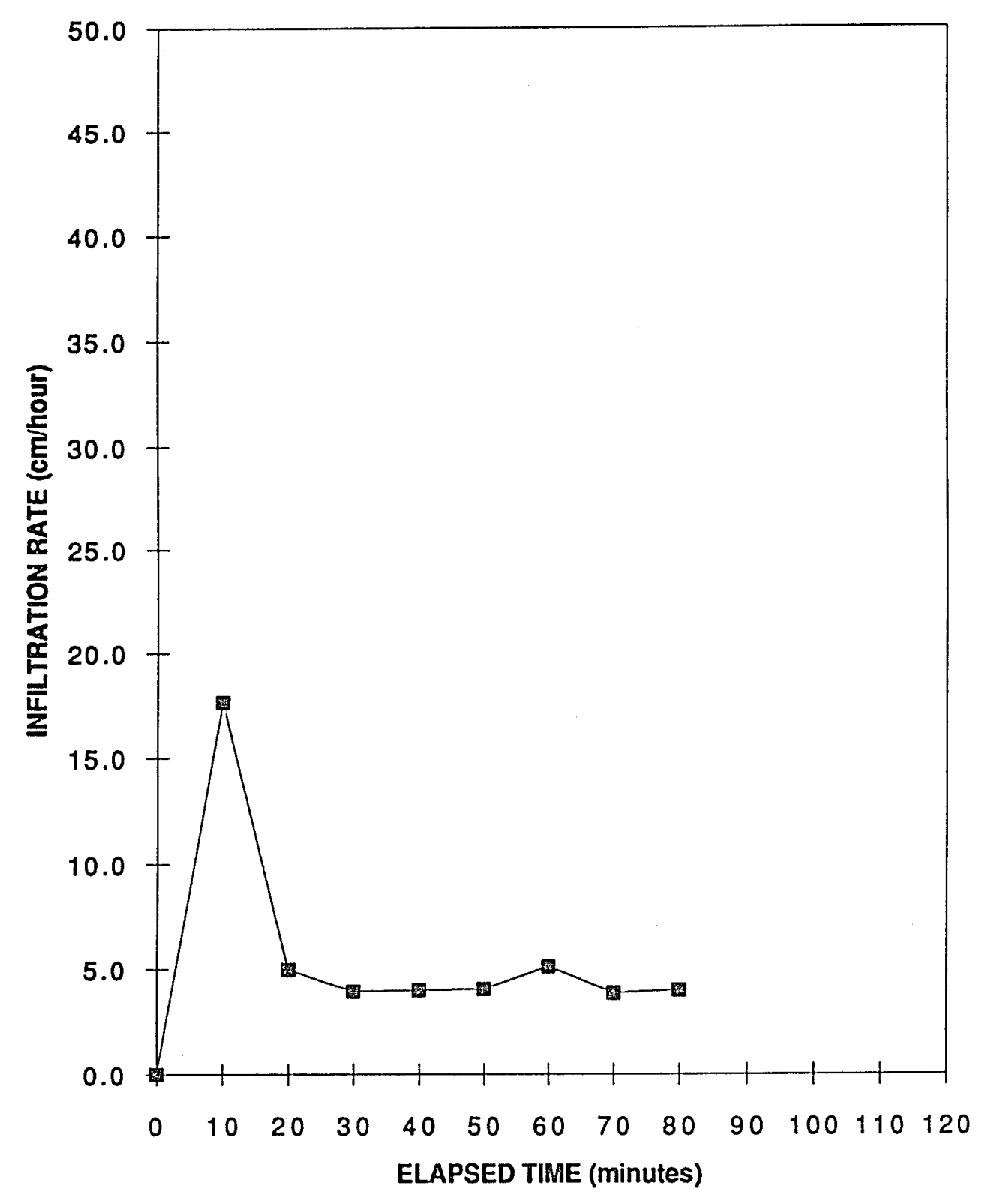


Infiltration Data (Site 3-1987)

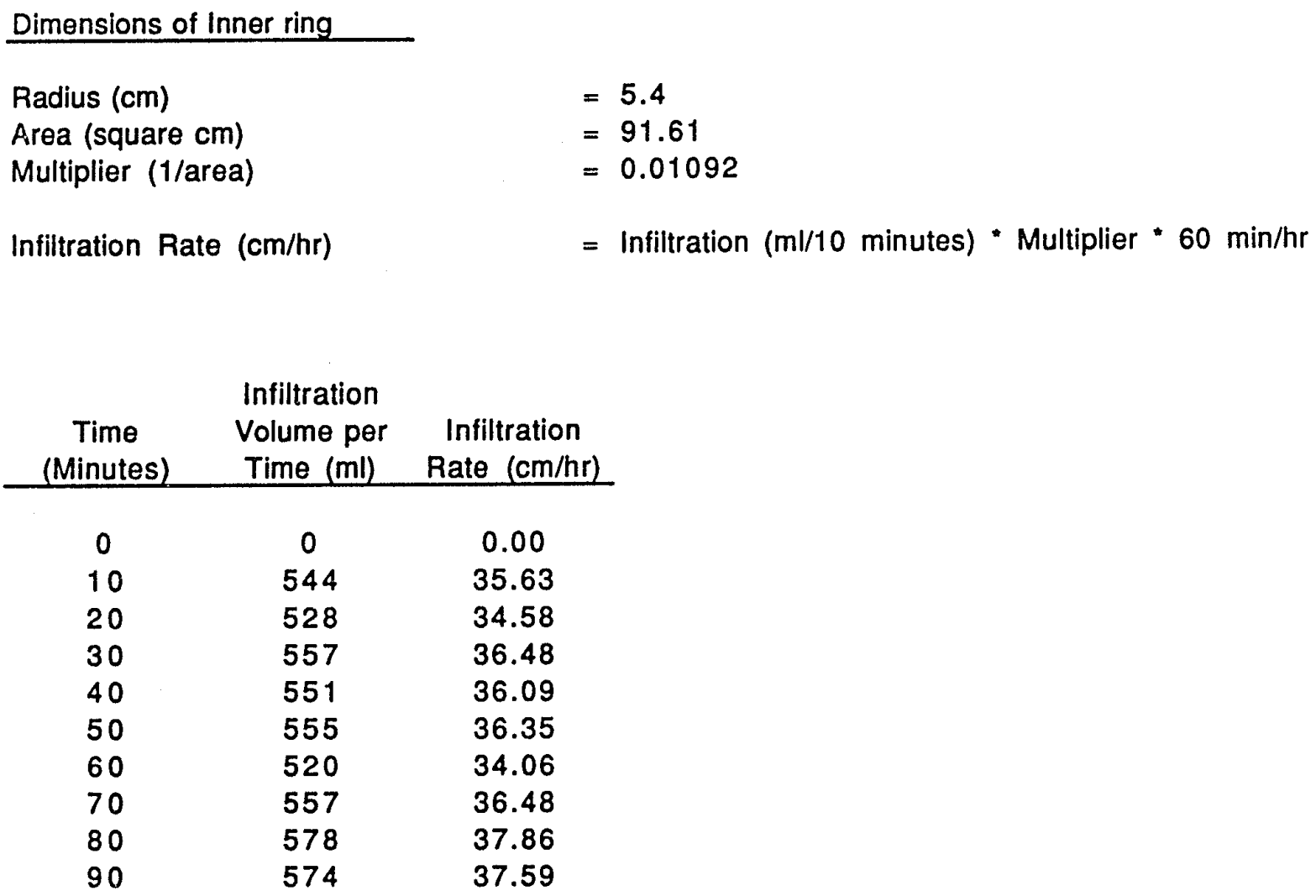

Notes Associated with Site 3-1987

- 10/4/87

- site is near stream

- very rocky area (moraine)

- upper 1 to 2 inches is forest humus

- rings were very hard to drive in

-rocks were cobble to boulder size

- $3^{n}$ head was used for test

- upper humus floated and was taken out of ring prior to measuring

- no leakage around rings 
Graph of Infiltration Data (Site 3-1987)

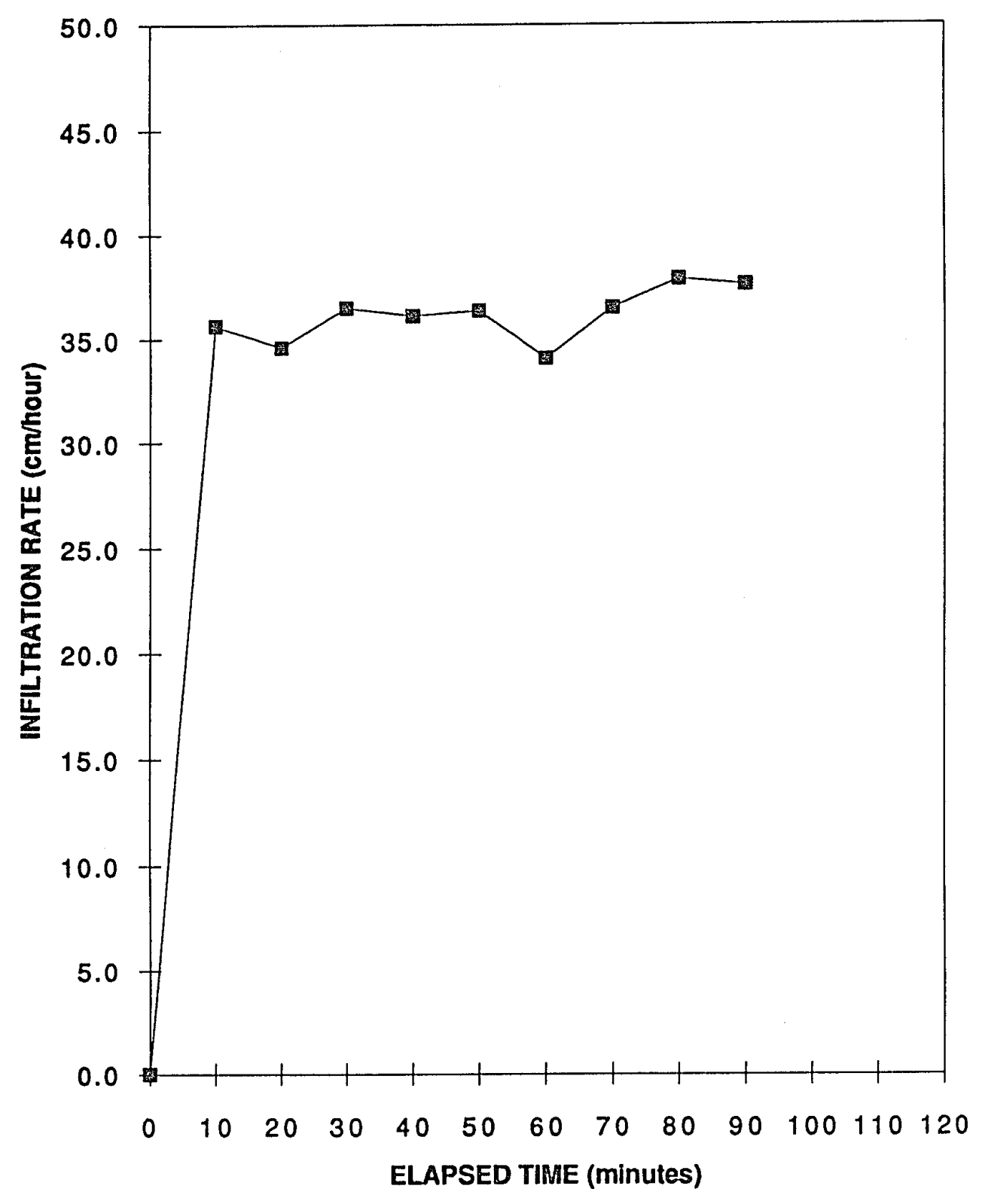


Dimensions of Inner ring

Radius (cm)

Area (square cm)

Multiplier (1/area)

Infiltration Rate $(\mathrm{cm} / \mathrm{hr})$
$=5.4$

$=91.61$

$=0.01092$

$=$ Infiltration (ml/10 minutes) * Multiplier * $60 \mathrm{~min} / \mathrm{hr}$

\begin{tabular}{ccc} 
Time & $\begin{array}{c}\text { Infiltration } \\
\text { Volume per }\end{array}$ & $\begin{array}{c}\text { Infiltration } \\
\text { Rate }(\mathrm{cm} / \mathrm{hr})\end{array}$ \\
\hline
\end{tabular}

$\begin{array}{rrc}0 & 0 & 0.00 \\ 10 & 264 & 17.29 \\ 20 & 186 & 12.18 \\ 30 & 143 & 9.37 \\ 40 & 132 & 8.65 \\ 50 & 119 & 7.79 \\ 60 & 116 & 7.60 \\ 70 & 118 & 7.73 \\ 80 & 111 & 7.27 \\ 90 & 116 & 7.60 \\ 100 & 117 & 7.66\end{array}$

Notes Associated with Site 4-1987

- 10/4/87

- site is near stream

- sunny, warm, windy at top of pass

- forested area on Barker Pass

- slightly rocky

- trees are smaller (harsher environment)

- pine needles and sparse grass in area 
Graph of Infiltration Data (Site 4-1987)

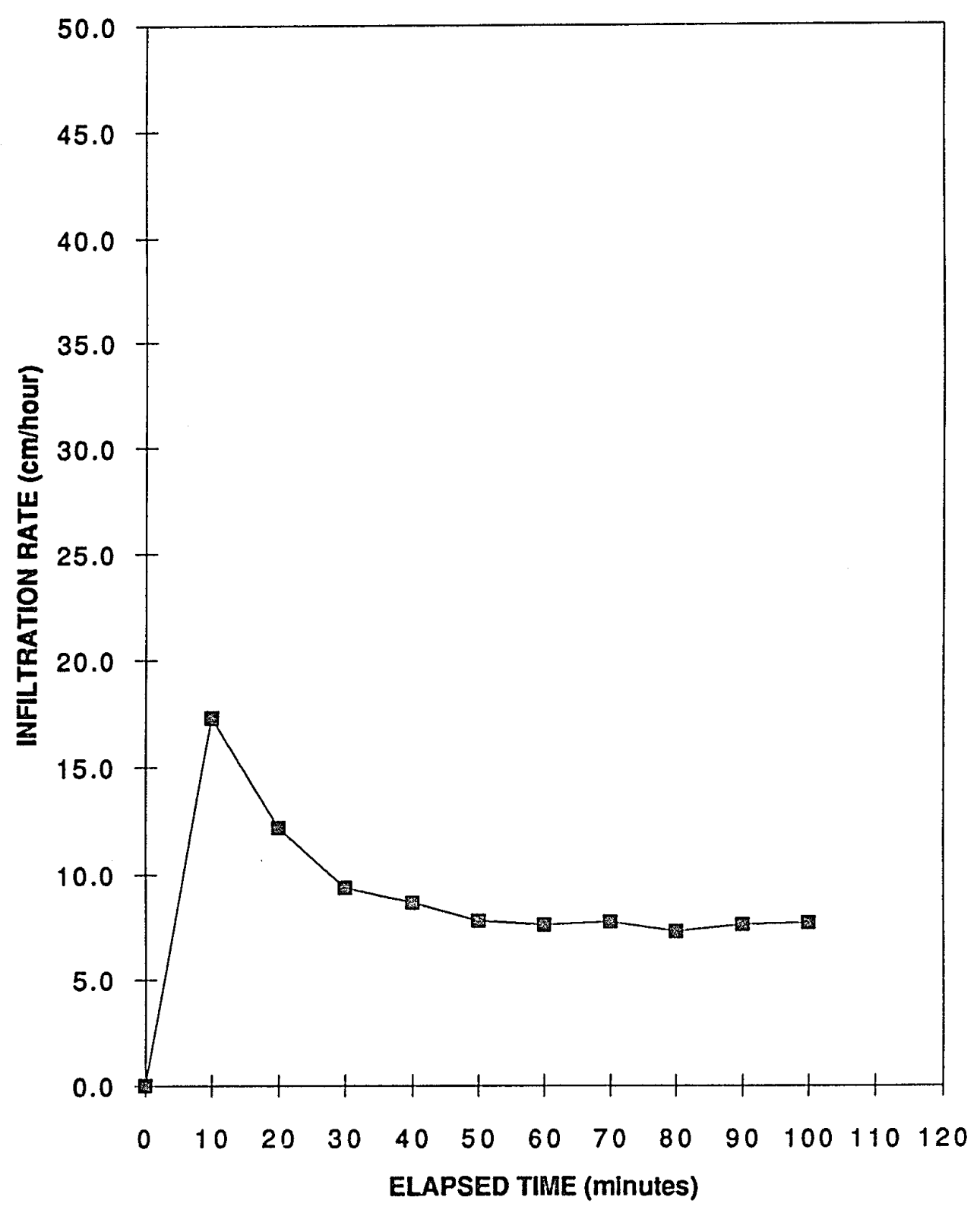


Infiltration Data (Site 5-1987)

Dimensions of Inner ring

Radius (cm)

Area (square $\mathrm{cm}$ )

Multiplier (1/area)

Infiltration Rate $(\mathrm{cm} / \mathrm{hr})$
$=5.4$

$=91.61$

$=0.01092$

$=$ Infiltration (ml/10 minutes) * Multiplier * $60 \mathrm{~min} / \mathrm{hr}$

\begin{tabular}{ccc} 
Time & $\begin{array}{c}\text { Infiltration } \\
\text { Volume per } \\
\text { Infiltration } \\
\text { (Minutes) }\end{array}$ & Time $(\mathrm{ml})$ \\
\hline
\end{tabular}

Notes Associated with Site 5-1987

- $10 / 4 / 87$

- 2 attempts made at driving rings failed

- old road near site 3-1987

- old saw mill area

- probably moraine or terrace

- abundant amount of rocks prevented the rings from making a good seal 
Dimensions of Inner ring

Radius (cm)

Area (square cm)

Multiplier (1/area)

Infiltration Rate $(\mathrm{cm} / \mathrm{hr})$
$=5.4$

$=91.61$

$=0.01092$

$=$ Infiltration (ml/10 minutes) * Multiplier * $60 \mathrm{~min} / \mathrm{hr}$

Infiltration

Time Volume per Infiltration

(Minutes) Time (ml) Rate (cm/hr)

$\begin{array}{ccc}0 & 0 & 0.00 \\ 10 & 257 & 16.83 \\ 20 & 80 & 5.24 \\ 30 & 59 & 3.86 \\ 40 & 47 & 3.08 \\ 50 & 44 & 2.88 \\ 60 & 47 & 3.08 \\ 70 & 47 & 3.08 \\ 80 & 47 & 3.08 \\ 90 & 47 & 3.08\end{array}$

Notes Associated with Site 1-1988

- $7 / 26 / 88$

- cool, cloudy

- approximate 75 degrees fahrenheit

- soil is dry

- stream channel shows moist soil at approximately 3' depth

- test began at 9:30 a.m.

- 6" head was used for test

- test conducted approximately 1 ' from test 1-1987

- no water leakage around outer ring

- little pin litter

- some weeds and some very small pine seedlings at location

- right side of road is gullied approximately 6 to 8 feet in this section

- maximum wetting depth was approximately $11^{\text {" }}$

- fewer gopher holes than last year

- site is 0.3 miles from crossroads 
Graph of Infiltration Data (Site 1-1988)

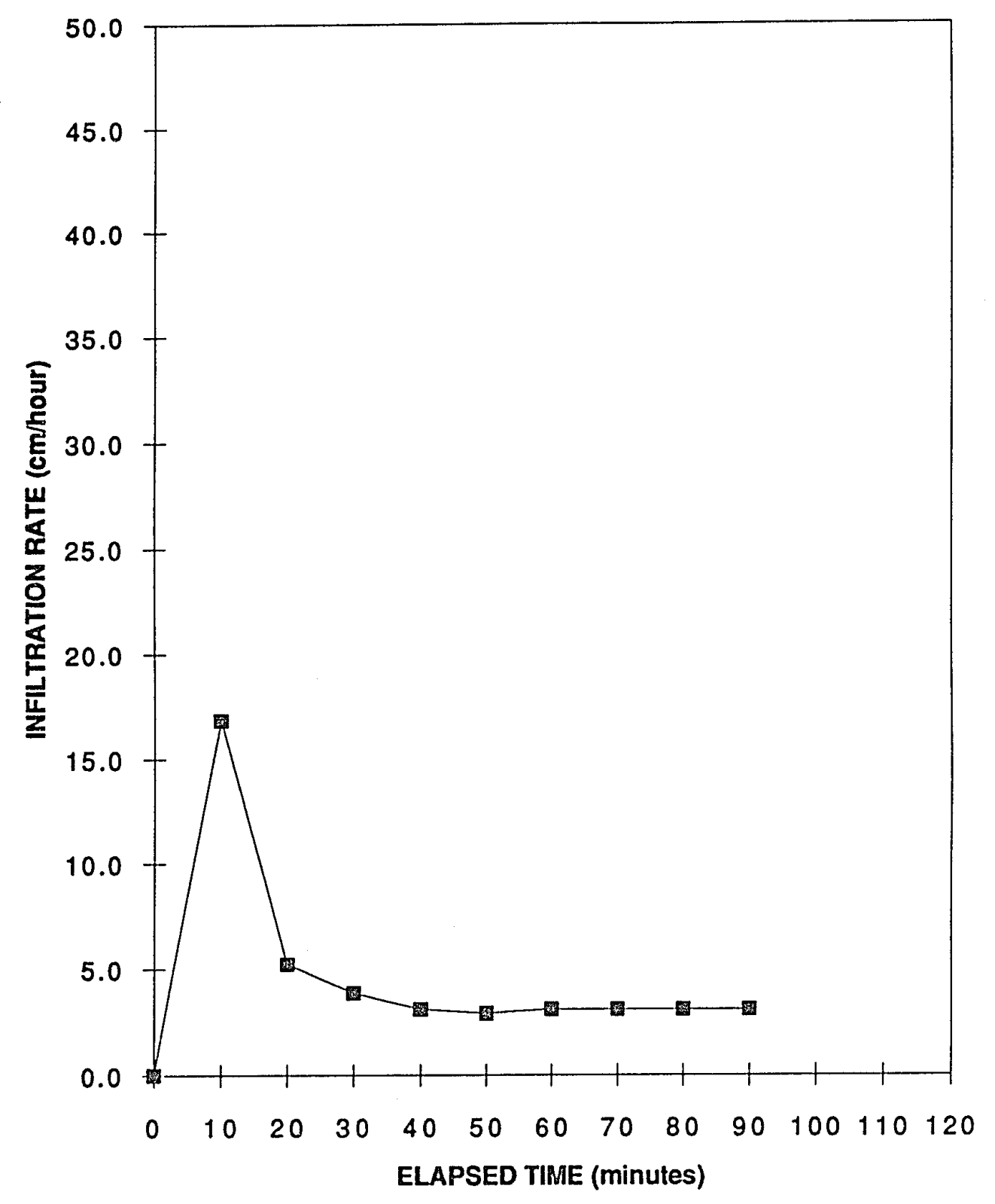


Infiltration Data (Site 2-1988)

Dimensions of Inner ring

Radius (cm)

Area (square $\mathrm{cm}$ )

Multiplier (1/area)

Infiltration Rate $(\mathrm{cm} / \mathrm{hr})$
$=5.4$

$=91.61$

$=0.01092$

$=$ Infiltration (ml/10 minutes) * Multiplier * $60 \mathrm{~min} / \mathrm{hr}$

\begin{tabular}{ccc} 
Time & $\begin{array}{c}\text { Infiltration } \\
\text { Volume per }\end{array}$ & $\begin{array}{c}\text { Infiltration } \\
\text { Rate }(\mathrm{cm} / \mathrm{hr})\end{array}$ \\
\hline
\end{tabular}

Notes Associated with Site 2-1988

- $7 / 26 / 88$

- center of road near 1-1988

- no rocks or pine litter

- center of road is approximately $3^{n}$ higher than sides

- test began at 11:45 a.m.

- 6" head was used for test

- test conducted approximately 1 ' from test 1-1987 
Graph of Infiltration Data (Site 2-1988)

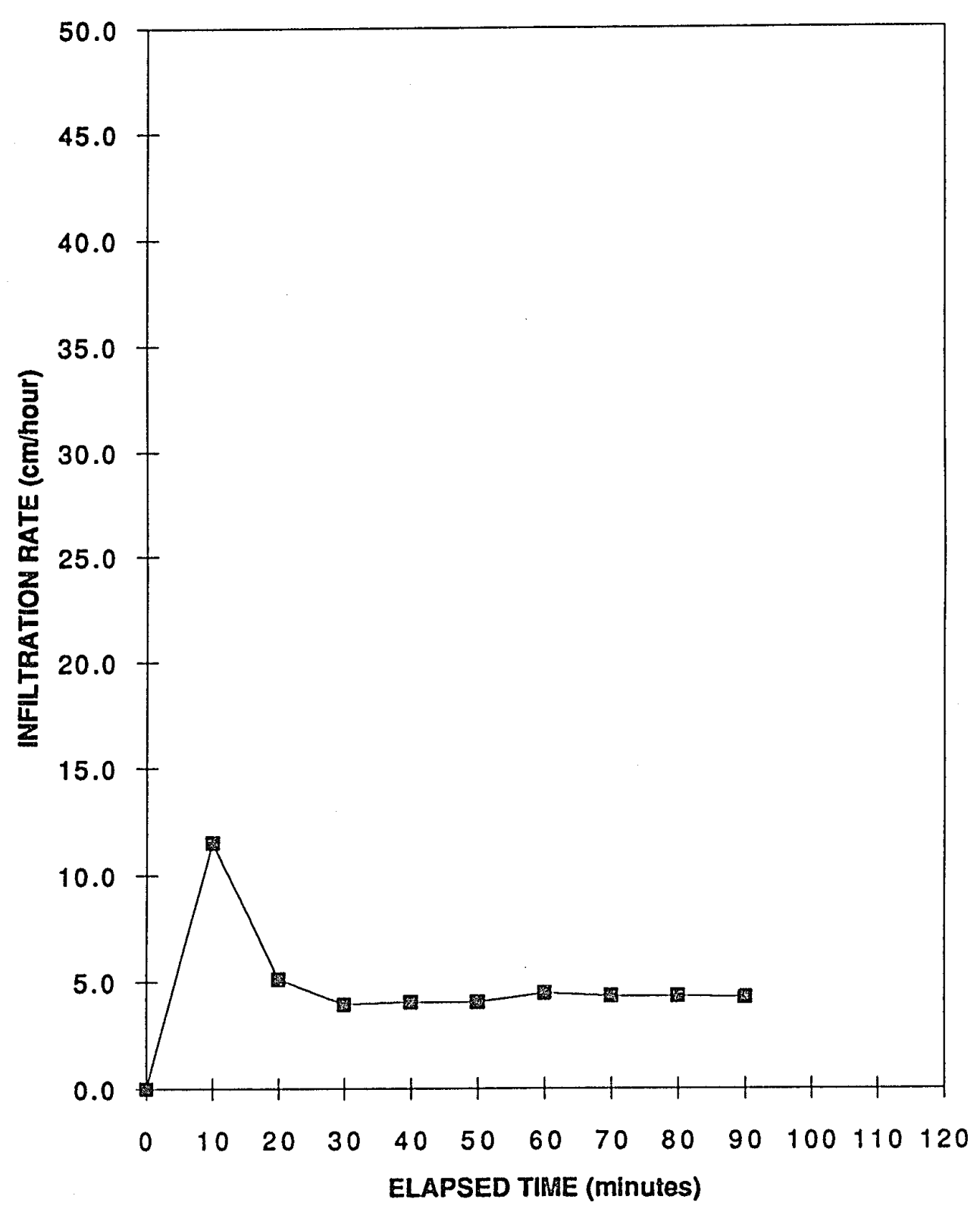


Infiltration Data (Site 3-1988)

Dimensions of Inner ring

Radius (cm)

Area (square cm)

Multiplier (1/area)

$=5.4$

$=91.61$

$=0.01092$

Infiltration Rate $(\mathrm{cm} / \mathrm{hr})$

$=$ Infiltration $(\mathrm{ml} / 10$ minutes $) *$ Multiplier * $60 \mathrm{~min} / \mathrm{hr}$

\begin{tabular}{ccc} 
Time & Infiltration & \\
Volume per & Infiltration \\
(Minutes) & Time (ml) & Rate $(\mathrm{cm} / \mathrm{hr})$ \\
\hline
\end{tabular}

Notes Associated with Site 3-1988

- $7 / 26 / 88$

- same location as 2-1987

- large stand of trees

-upper 1 to 2 inches is forest litter

- test began at 2:30 p.m.

- $6^{n}$ head was used for test

- no leakage around outer ring 
Graph of Infiltration Data (Site 3-1988)

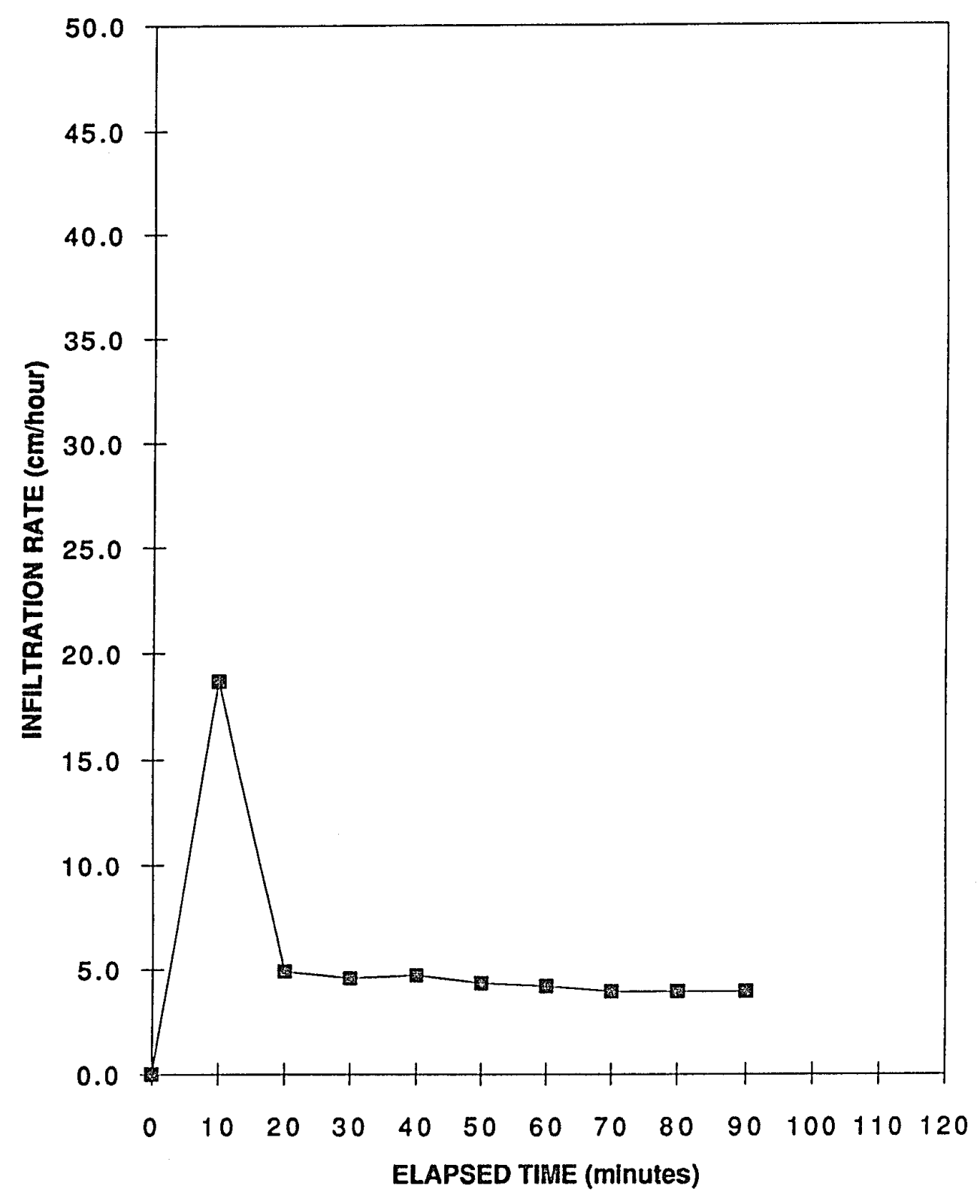


Dimensions of Inner ring

Radius (cm)

Area (square $\mathrm{cm}$ )

Multiplier (1/area)

Infiltration Rate $(\mathrm{cm} / \mathrm{hr})$
$=5.4$

$=91.61$

$=0.01092$

$=$ Infiltration (ml/10 minutes) * Multiplier * $60 \mathrm{~min} / \mathrm{hr}$

\begin{tabular}{ccc} 
Time & Infiltration & \\
(Minutes) & Volume per & Infiltration \\
Time (ml) & Rate $(\mathrm{cm} / \mathrm{hr})$ \\
\hline
\end{tabular}

Notes Associated with Site 4-1988

- 7/26/88

- same location as 3-1987

- taken in forest area near stream

-upper 2 to 3 inches is forest litter

- test began at 4:30 p.m.

- 6" head was used for test

- very rocky soil 
Graph of Infiltration Data (Site 4-1988)

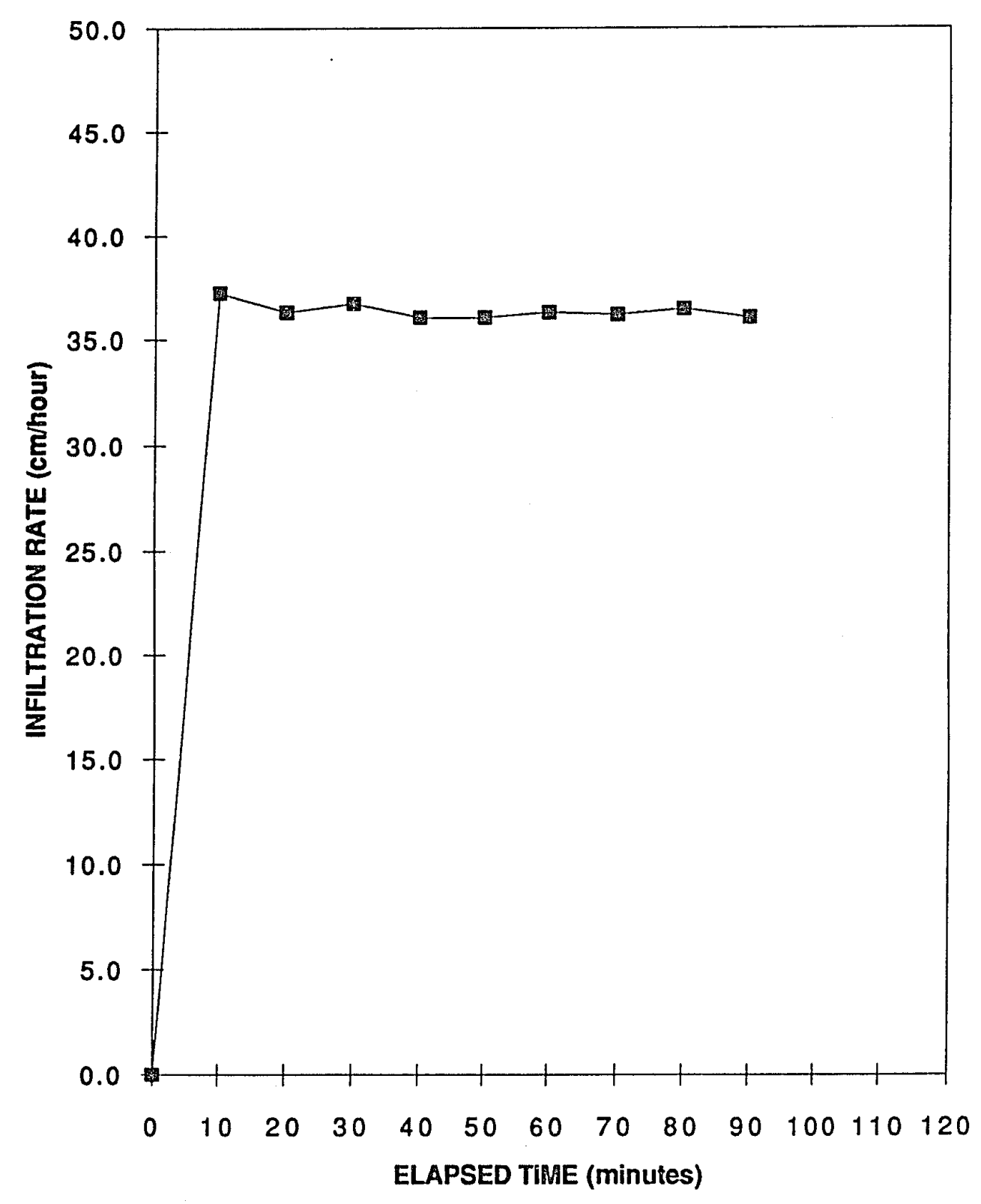


Infiltration Data (Site 5-1988)

Dimensions of Inner ring

Radius (cm)

Area (square $\mathrm{cm}$ )

Multiplier (1/area)

Infiltration Rate $(\mathrm{cm} / \mathrm{hr})$
$=5.4$

$=91.61$

$=0.01092$

$=$ Infiltration (ml/10 minutes) * Multiplier * $60 \mathrm{~min} / \mathrm{hr}$

\footnotetext{
Infiltration

Time Volume per Infiltration

(Minutes) Time (ml) Rate $(\mathrm{cm} / \mathrm{hr})$
}

$\begin{array}{lll}0 & 0 & 0.00\end{array}$

$10 \quad 406 \quad 26.59$

$20 \quad 220 \quad 14.41$

$\begin{array}{lll}30 & 215 & 14.08\end{array}$

$\begin{array}{lll}40 & 218 & 14.28\end{array}$

$\begin{array}{lll}50 & 221 & 14.47\end{array}$

$\begin{array}{lll}60 & 210 & 13.75\end{array}$

$\begin{array}{lll}70 & 230 & 15.06\end{array}$

$80 \quad 210 \quad 13.75$

$90 \quad 230 \quad 15.06$

Notes Associated with Site 5-1988

- $8 / 2 / 88$

- same location as 4-1987

- sunny, cool

- approximately 80 degrees fahrenheit

- test began at 10:30 a.m.

- $6^{\prime \prime}$ head was used for test (test 4-1987 used a $3^{\prime \prime}$ head)

- slope surface is approximately 2 to 5 degrees 
Graph of Infiltration Data (Site 5-1988)

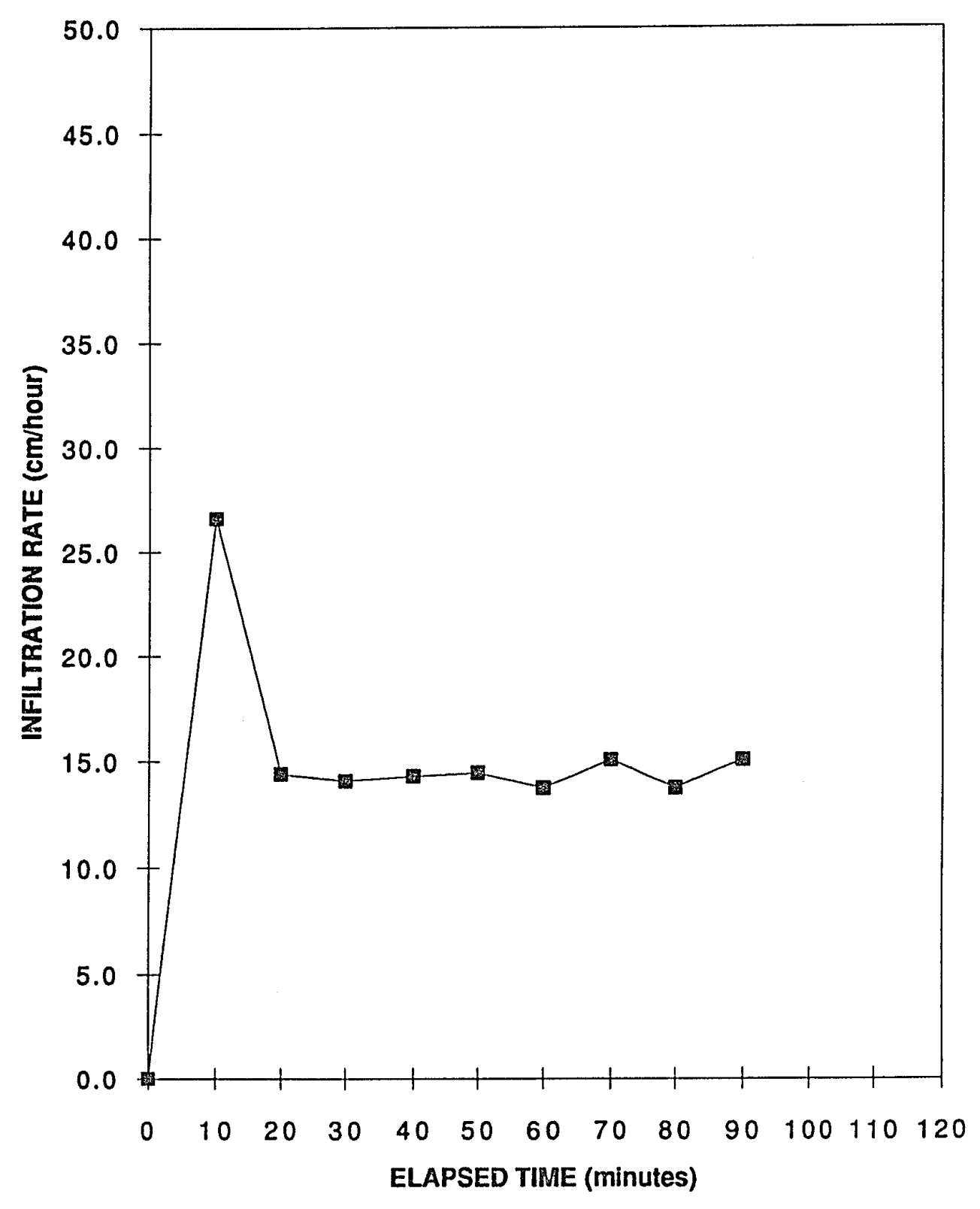


Infiltration Data (Site 6-1988)

Dimensions of Inner ring

Radius (cm)

Area (square $\mathrm{cm}$ )

Multiplier (1/area)

Infiltration Rate $(\mathrm{cm} / \mathrm{hr})$
$=5.4$

$=91.61$

$=0.01092$

$=$ Infiltration $(\mathrm{ml} / 10$ minutes $) *$ Multiplier * $60 \mathrm{~min} / \mathrm{hr}$

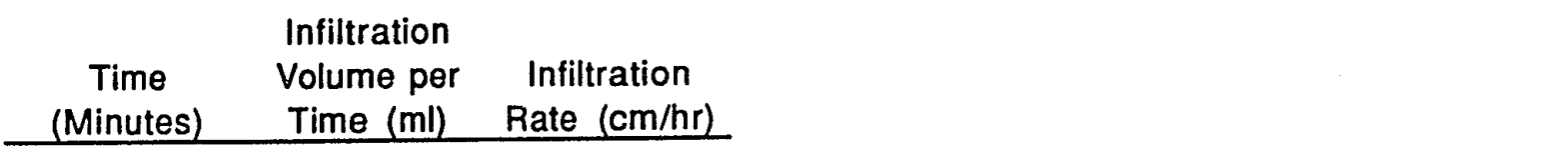

$\begin{array}{rrr}0 & 0 & 0.00 \\ 10 & 302 & 19.78 \\ 20 & 160 & 10.48 \\ 30 & 140 & 9.17 \\ 40 & 120 & 7.86 \\ 50 & 120 & 7.86 \\ 60 & 120 & 7.86 \\ 70 & 121 & 7.92 \\ 80 & 122 & 7.99 \\ 90 & 120 & 7.86\end{array}$

Notes Associated with Site 6-1988

- $8 / 2 / 88$

- sunny, cool, breeze blowing

- old road site

- appears to be unused (no tire tracks)

- rusty old cables attached to trees (old loging road ?)

- no vegetation growing on tire track sides

- test is on tire surface

- very rocky, hard to drive rings

- outer ring driven in approximately 4"

- test began a 1:30 p.m.

- 6" head was used for test 
Graph of Infiltration Data (Site 6-1988)

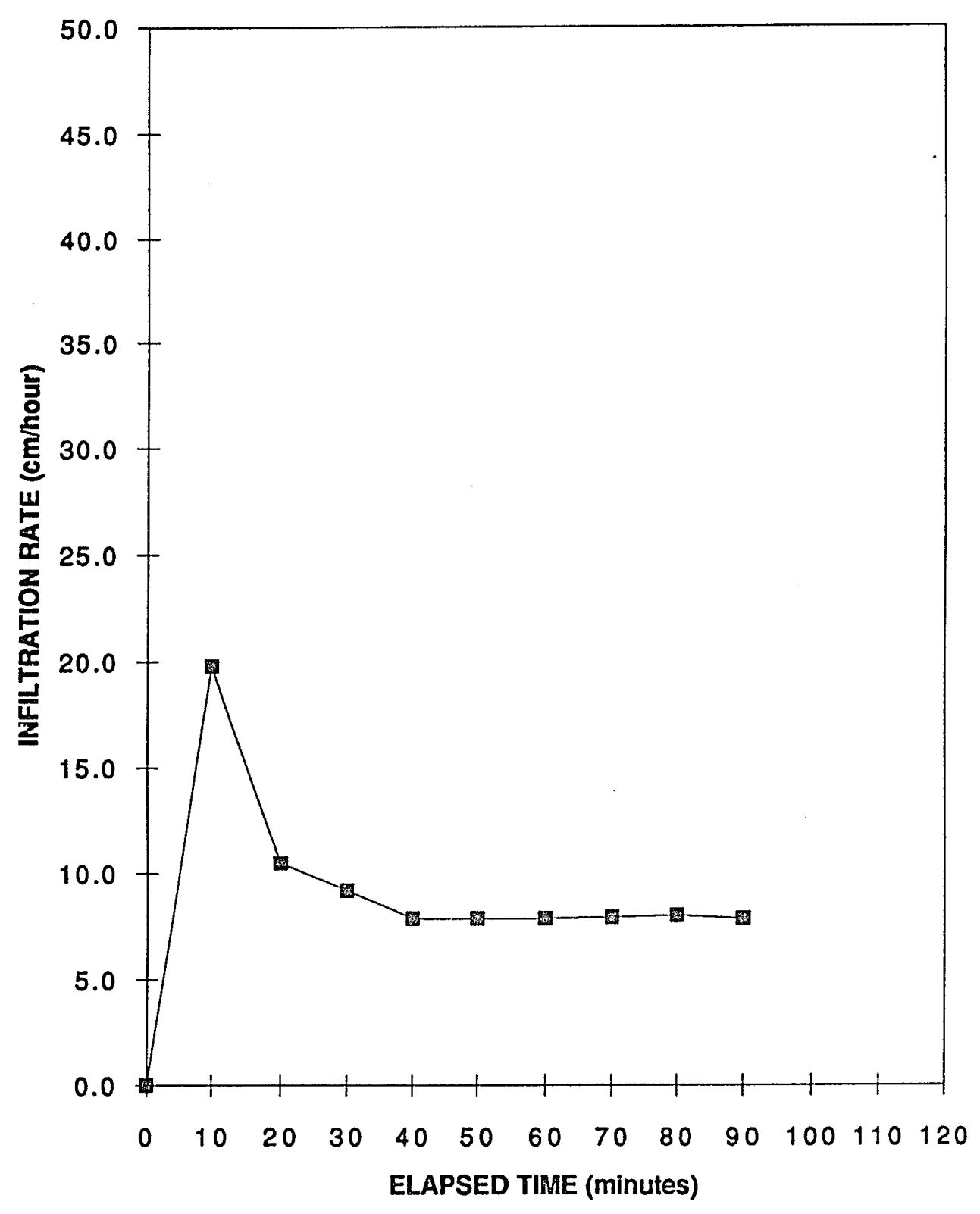


Infiltration Data (Site 7-1988)

Dimensions of Inner ring

Radius (cm)

Area (square $\mathrm{cm}$ )

Multiplier (1/area)

Infiltration Rate $(\mathrm{cm} / \mathrm{hr})$
$=5.4$

$=91.61$

$=0.01092$

$=$ Infiltration (ml/10 minutes) * Multiplier * $60 \mathrm{~min} / \mathrm{hr}$

\begin{tabular}{ccc} 
Time & $\begin{array}{c}\text { Infiltration } \\
\text { Volume per }\end{array}$ & $\begin{array}{c}\text { Infiltration } \\
\text { (Minutes) }\end{array}$ \\
\hline
\end{tabular}

Notes Associated with Site 7-1988

- $8 / 2 / 88$

- 4' from road site 6-1988 in trees

- appears to be untouched forest

- near stream

- pine litter in upper $2^{n}$ of soil

- rings drove in very easy

- test began a 3:30 p.m.

- $6^{n}$ head was used for test

- problem with pine needles floating

- dificult to keep heads constant (infiltration rates high)

- inconsistency in readings is due to high infiltration rate 
Graph of Infiltration Data (Site 7-1988)

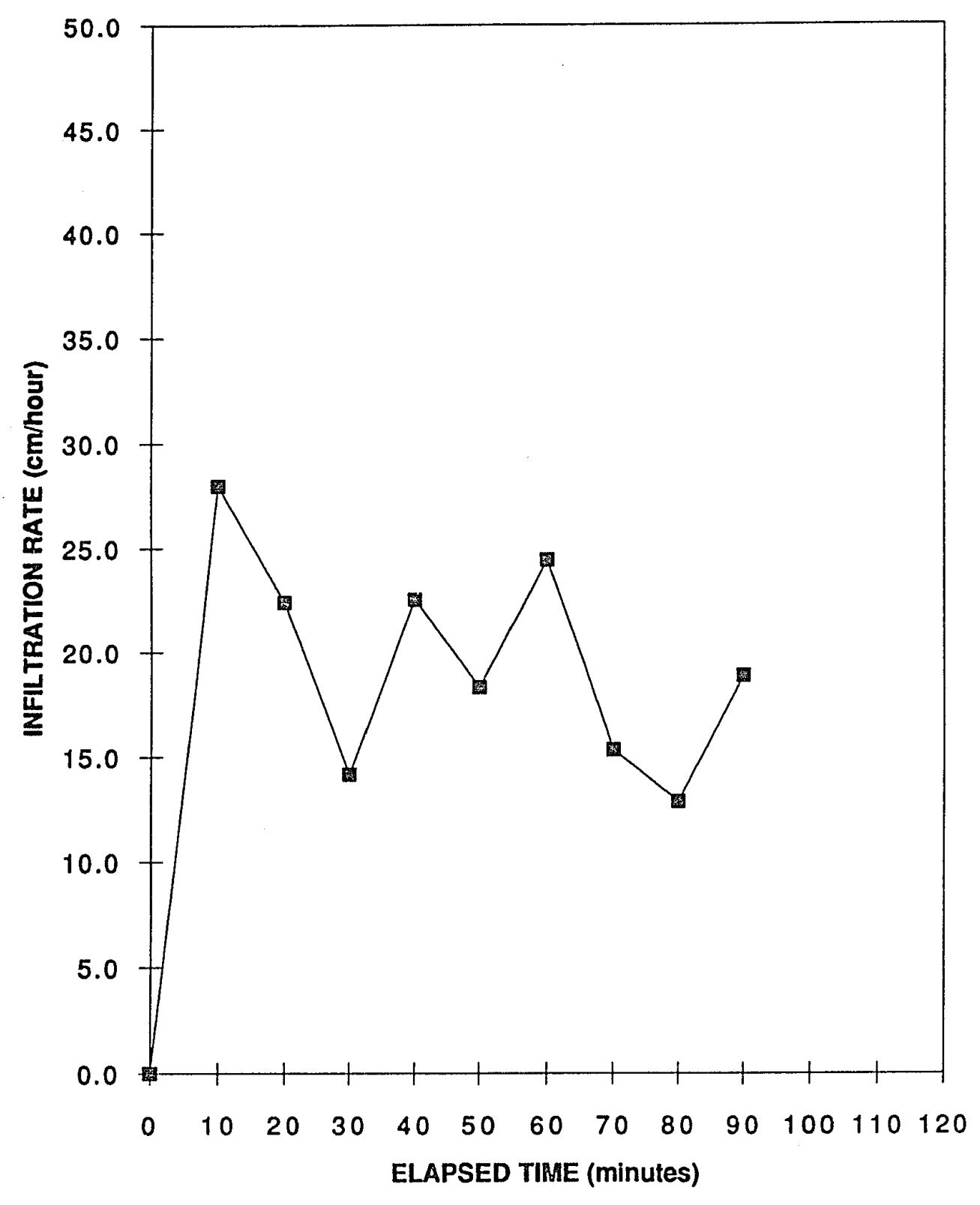


Dimensions of Inner ring

Radius (cm)

Area (square $\mathrm{cm}$ )

Multiplier (1/area)

Infiltration Rate $(\mathrm{cm} / \mathrm{hr})$
$=5.4$

$=91.61$

$=0.01092$

= Infiltration (m//10 minutes) * Multiplier * $60 \mathrm{~min} / \mathrm{hr}$

\begin{tabular}{ccc} 
& Infiltration & \\
Time & Volume per & Infiltration \\
(Minutes) & Time $(\mathrm{ml})$ & Rate $(\mathrm{cm} / \mathrm{hr})$ \\
\hline
\end{tabular}

Notes Associated with Site 8-1988

- $8 / 3 / 88$

- road

- very rocky

- gully through road

- lots of erosion visible

- road has a 20 percent slope

- test was on flat spot

- outer ring driven only $4^{\prime \prime}$

- 6" head was used for test

- very little vegetation on road 
Graph of Infiltration Data (Site 8-1988)

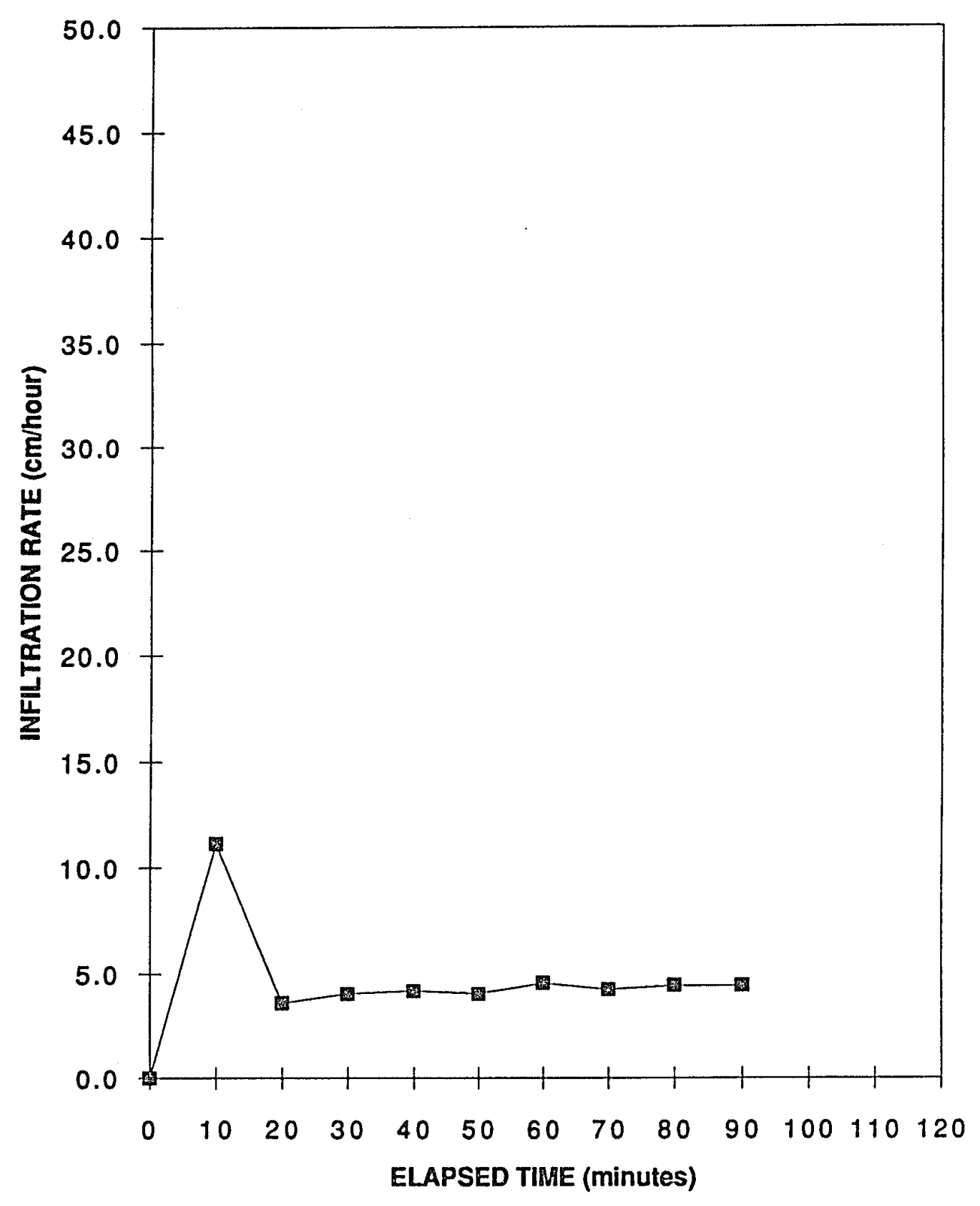


Infiltration Data (Site 9-1988)

Dimensions of Inner ring

Radius (cm)

Area (square $\mathrm{cm}$ )

Multiplier (1/area)

Infiltration Rate $(\mathrm{cm} / \mathrm{hr})$
$=5.4$

$=91.61$

$=0.01092$

$=$ Infiltration (ml/10 minutes) * Multiplier * $60 \mathrm{~min} / \mathrm{hr}$

\begin{tabular}{|c|c|c|}
\hline $\begin{array}{c}\text { Time } \\
\text { (Minutes) }\end{array}$ & $\begin{array}{l}\text { Infiltration } \\
\text { Volume per } \\
\text { Time (ml) } \\
\end{array}$ & $\begin{array}{c}\text { Infiltration } \\
\text { Rate }(\mathrm{cm} / \mathrm{hr})\end{array}$ \\
\hline 0 & 0 & 0.00 \\
\hline 10 & 414 & 27.12 \\
\hline 20 & 310 & 20.30 \\
\hline 30 & 308 & 20.17 \\
\hline 40 & 300 & 19.65 \\
\hline 50 & 296 & 19.39 \\
\hline 60 & 294 & 19.26 \\
\hline 70 & 286 & 18.73 \\
\hline 80 & 290 & 18.99 \\
\hline 90 & 288 & 18.86 \\
\hline
\end{tabular}

Notes Associated with Site 9-1988

- $8 / 3 / 88$

- road, up 100 yards from fork with road near site 8-1988

- appears to have been abandoned earlier than road at site 8-1988

- trees are growing in center of road (maximum height is 20')

- tire sided are fairly barren with lots of rocks and cobbles

- fairly easy to drive rings

- erosion does not appear to be a problem

- road has a slope of approximately 15 degrees

- flat zone where test was conducted

- soil was fairly dry and powdery

- $6^{n}$ head was used for test 
Graph of Infiltration Data (Site 9-1988)

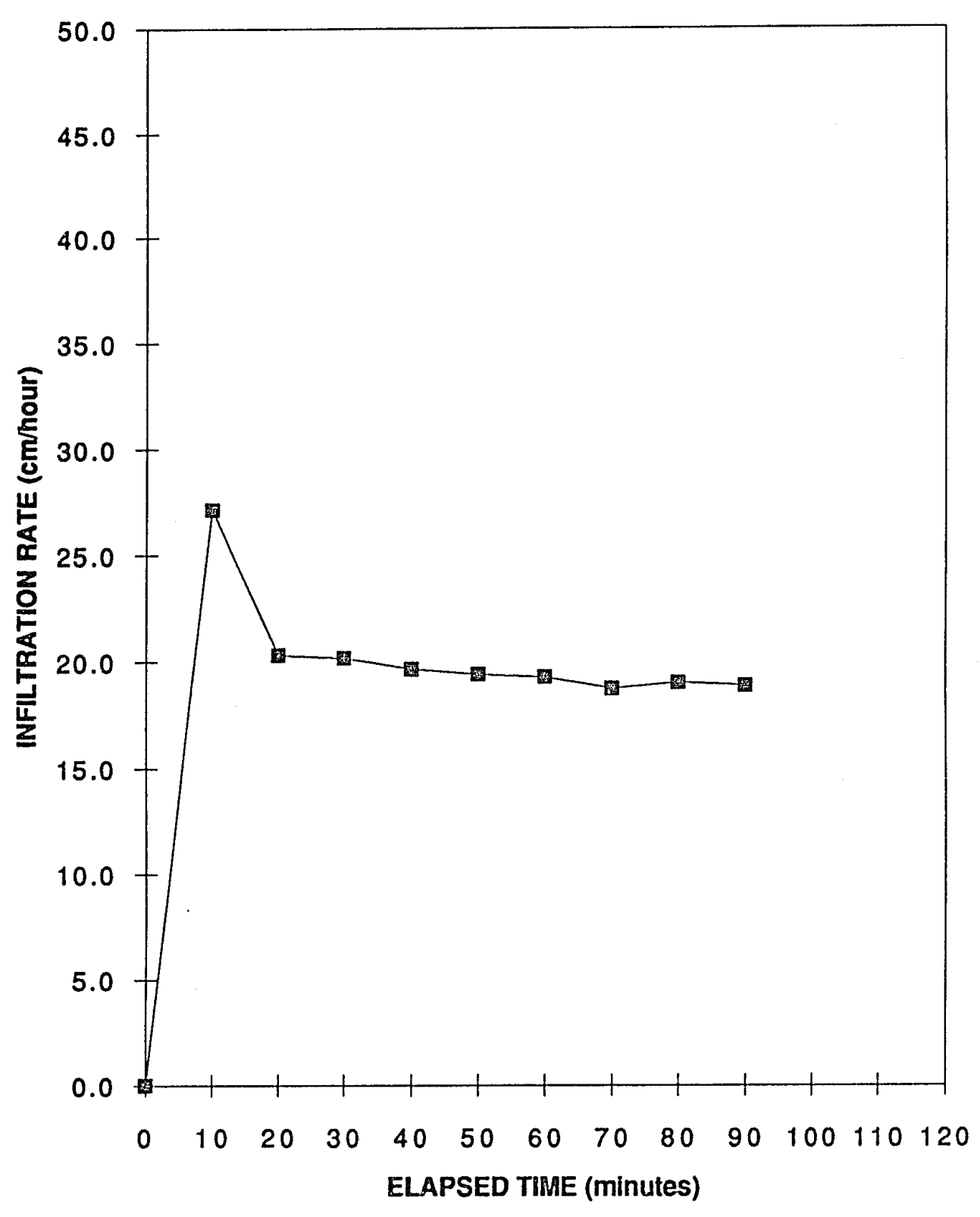


Infiltration Data (Site 10-1988)

Dimensions of Inner ring

Radius (cin)

Area (square $\mathrm{cm}$ )

Multiplier (1/area)

Infiltration Rate $(\mathrm{cm} / \mathrm{hr})$
$=5.4$

$=91.61$

$=0.01092$

$=$ Infiltration (ml/10 minutes $)$ * Multiplier * $60 \mathrm{~min} / \mathrm{hr}$

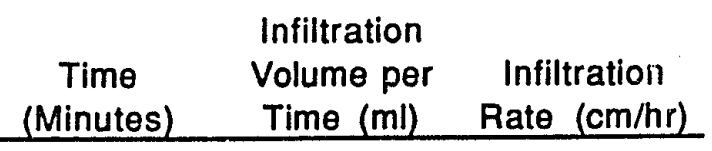

$\begin{array}{lll}90 & 92 & 6.03\end{array}$

Notes Associated with Site 10-1988

- $8 / 3 / 88$

- test began at 3:00 p.m.

- road in logged area

- abundant branches and twigs

- road has little vegetation

- fairly flat zone

- upper $2^{n}$ is loose forest material

- erosion does not appear to be a problem

- 6" head was used for test 
Graph of Infiltration Data (Site 10-1988)

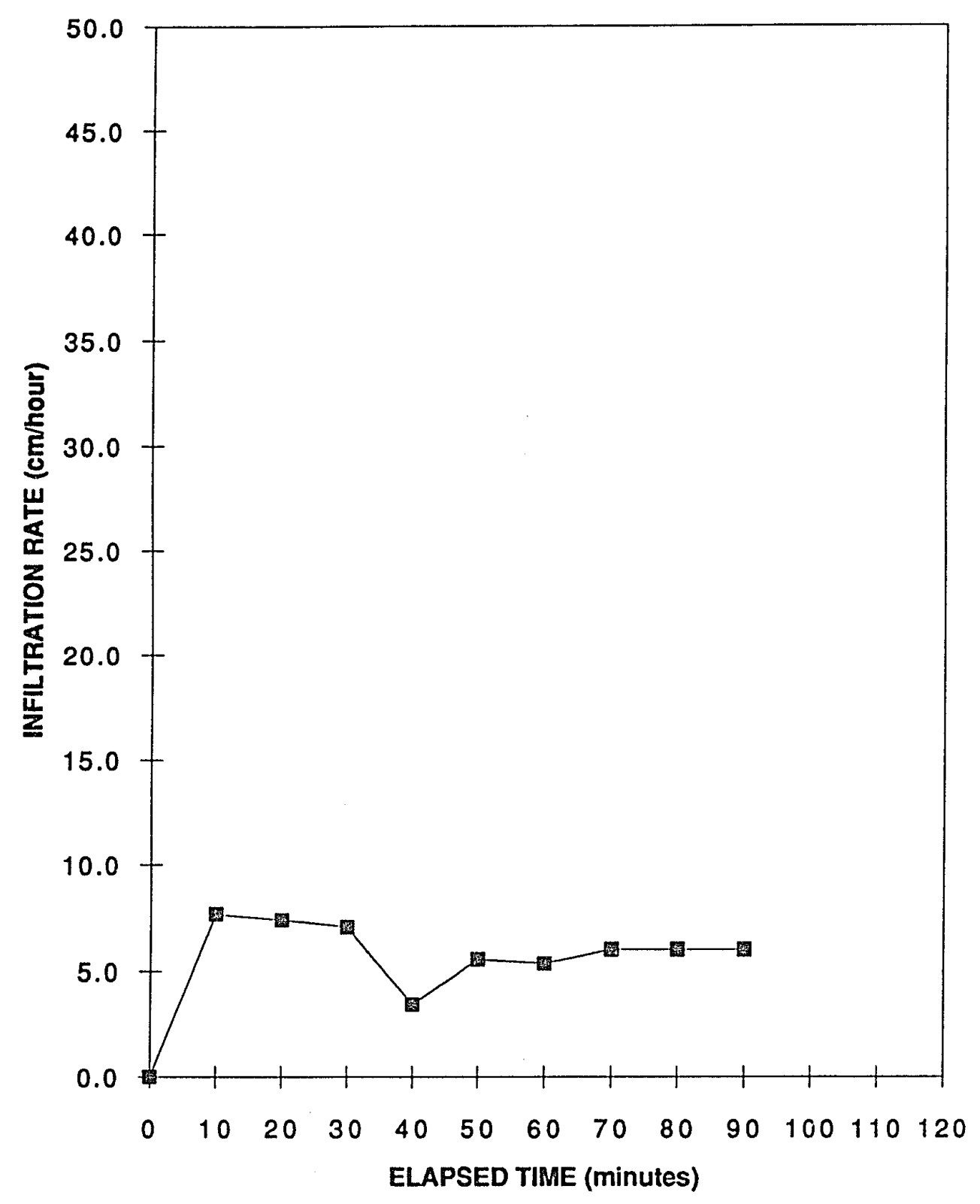


Infiltration Data (Site 11-1988)

Dimensions of Inner ring

Radius (cm)

Area (square $\mathrm{cm}$ )

Multiplier (1/area)

Infiltration Rate $(\mathrm{cm} / \mathrm{hr})$
$=5.4$

$=91.61$

$=0.01092$

$=$ Infiltration (ml/10 minutes) * Multiplier * $60 \mathrm{~min} / \mathrm{hr}$

\begin{tabular}{ccc} 
Infiltration & \\
Time & Volume per & Infiltration \\
(Minutes) & Time (ml) & Rate $(\mathrm{cm} / \mathrm{hr})$ \\
\hline
\end{tabular}

$\begin{array}{rrc}0 & 0 & 0.00 \\ 10 & 500 & 32.75 \\ 20 & 594 & 38.90 \\ 30 & 608 & 39.82 \\ 40 & 690 & 45.19 \\ 50 & 676 & 44.28 \\ 60 & 675 & 44.21 \\ 70 & 676 & 44.28\end{array}$

Notes Associated with Site 11-1988

- 8/3/88

- cloudy and cool

- test began at 4:45 p.m.

- forest area approximately $20^{\prime}$ from road of site 10-1988

- $2^{n}$ of forest litter on ground

- rings drove easily

- downed trees abundant

- road intrance 0.4 miles from major fork towards ridge

- road intrance 0.85 miles from asphalt road

- 6" head was used for test

- ran out of water after 70 minutes 
Graph of Infiltration Data (Site 11-1988)

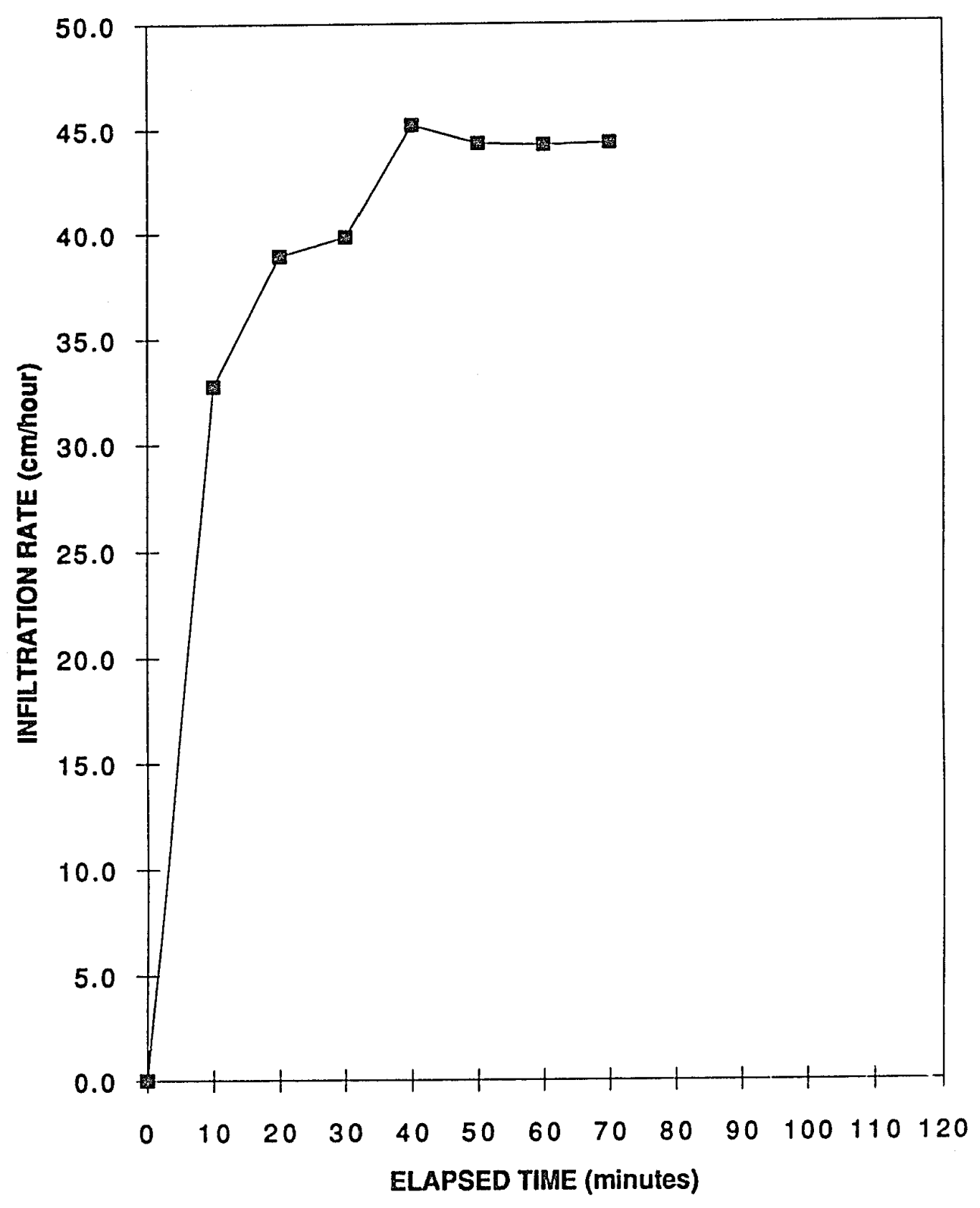


Infiltration Data (Site 12-1988)

Dimensions of Inner ring

Radius (cm)

Area (square $\mathrm{cm}$ )

Multiplier (1/area)

Infiltration Rate $(\mathrm{cm} / \mathrm{hr})$
$=5.4$

$=91.61$

$=0.01092$

$=$ Infiltration (ml/10 minutes) * Multiplier * $60 \mathrm{~min} / \mathrm{hr}$

\begin{tabular}{ccc}
$\begin{array}{c}\text { Time } \\
\text { (Minutes) }\end{array}$ & $\begin{array}{c}\text { Infiltration } \\
\text { Volume per } \\
\text { Time (ml) }\end{array}$ & $\begin{array}{c}\text { Infiltration } \\
\text { Rate (cm/hr) }\end{array}$ \\
\hline 0 & 0 & 0.00 \\
10 & 218 & 14.28 \\
20 & 125 & 8.19 \\
30 & 100 & 6.55 \\
40 & 99 & 6.48 \\
50 & 100 & 6.55 \\
60 & 106 & 6.94 \\
70 & 104 & 6.81 \\
80 & 100 & 6.55 \\
90 & 100 & 6.55
\end{tabular}

Notes Associated with Site 12-1988

- $8 / 4 / 88$

- test began at 12:00 p.m.

- old road (appears unused for many years

- trees growing in middle of road, approximately $4^{\prime}$ tall

- very difficult to drive rings

- road cut shows large boulders and rocks

- erosion on road surface is slight

- both upper and lower road cuts show erosion

- road appears to have been highly used

- slope of road is approximately 10 degrees

- $6^{n}$ head was used for test 


\section{Graph of Infiltration Data (Site 12-1988)}

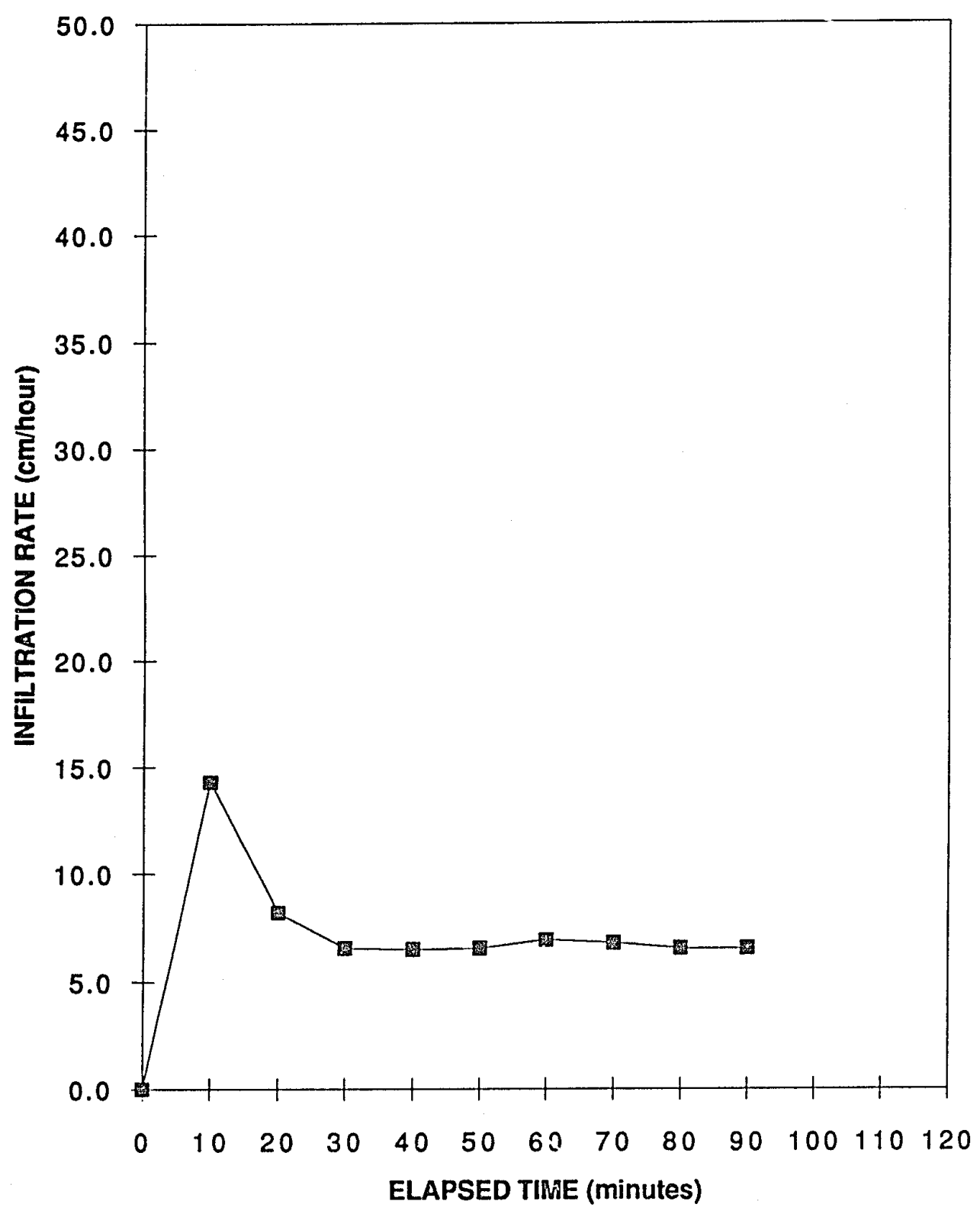


Infiltration Data (Site 13-1988)

Dimensions of Inner ring

Radius (cm)

Area (square $\mathrm{cm}$ )

Multiplier (1/area)

Infiltration Rate $(\mathrm{cm} / \mathrm{hr})$
$=5.4$

$=91.61$

$=0.01092$

$=$ Infiltration (ml/10 minutes) * Multiplier * $60 \mathrm{~min} / \mathrm{hr}$

Notes Associated with Site 13-1988

- $8 / 4 / 88$

- 100' upslope of 12-1988 in forest

- abundant forest debri

- logged slope

- rusty cables attached to trees

- not virgin, but can be compared with road down slope

- approximately 30 degree slope

- very permeable

- no evidence of channeling around site

- forest litter is upper $4^{n}$

- few visible rocks around test site

- $1500 \mathrm{ml}$ of water infiltrated in 5 minutes

- infiltration rate was to high to conduct test 
Infiltration Data (Site 14-1988)

Dimensions of Inner ring

Radius (cm)

Area (square $\mathrm{cm}$ )

Multiplier (1/area)

Infiltration Rate $(\mathrm{cm} / \mathrm{hr})$
$=5.4$

$=91.61$

$=0.01092$

$=$ Infiltration (ml/10 minutes) * Multiplier * $60 \mathrm{~min} / \mathrm{hr}$

\footnotetext{
Infiltration

Time Volume per Infiltration

(Minutes) Time (ml) Rate (cm/hrr)
}

$\begin{array}{lll}0 & 0 & 0.00\end{array}$

$\begin{array}{lll}10 & 228 & 14.93\end{array}$

$\begin{array}{lll}20 & 156 & 10.22\end{array}$

$\begin{array}{lll}30 & 152 & 9.96\end{array}$

$40 \quad 152 \quad 9.96$

$\begin{array}{lll}50 & 154 & 10.09\end{array}$

$\begin{array}{lll}60 & 150 & 9.82\end{array}$

$\begin{array}{lll}70 & 156 & 10.22\end{array}$

$\begin{array}{lll}80 & 152 & 9.96\end{array}$

Notes Associated with Site 14-1988

- $8 / 4 / 88$

- cool and cloudy, started to rain

- old road

- 0.55 miles from fork up stream

- 1.75 miles from main road downstream

- road is off of asphalt road

- road is blocked by railroad ties and mound of dirt

- appears to have been recently blocked (1-2 years)

- only vegetation is grass (mostly in the middle of the road)

- very difficult to drive rings

- small rocks are visible

- center of road is approximately 4 to 5 inches higher than sides

- $6^{n}$ head was used for test 
Graph of Infiltration Data (Site 14-1988)

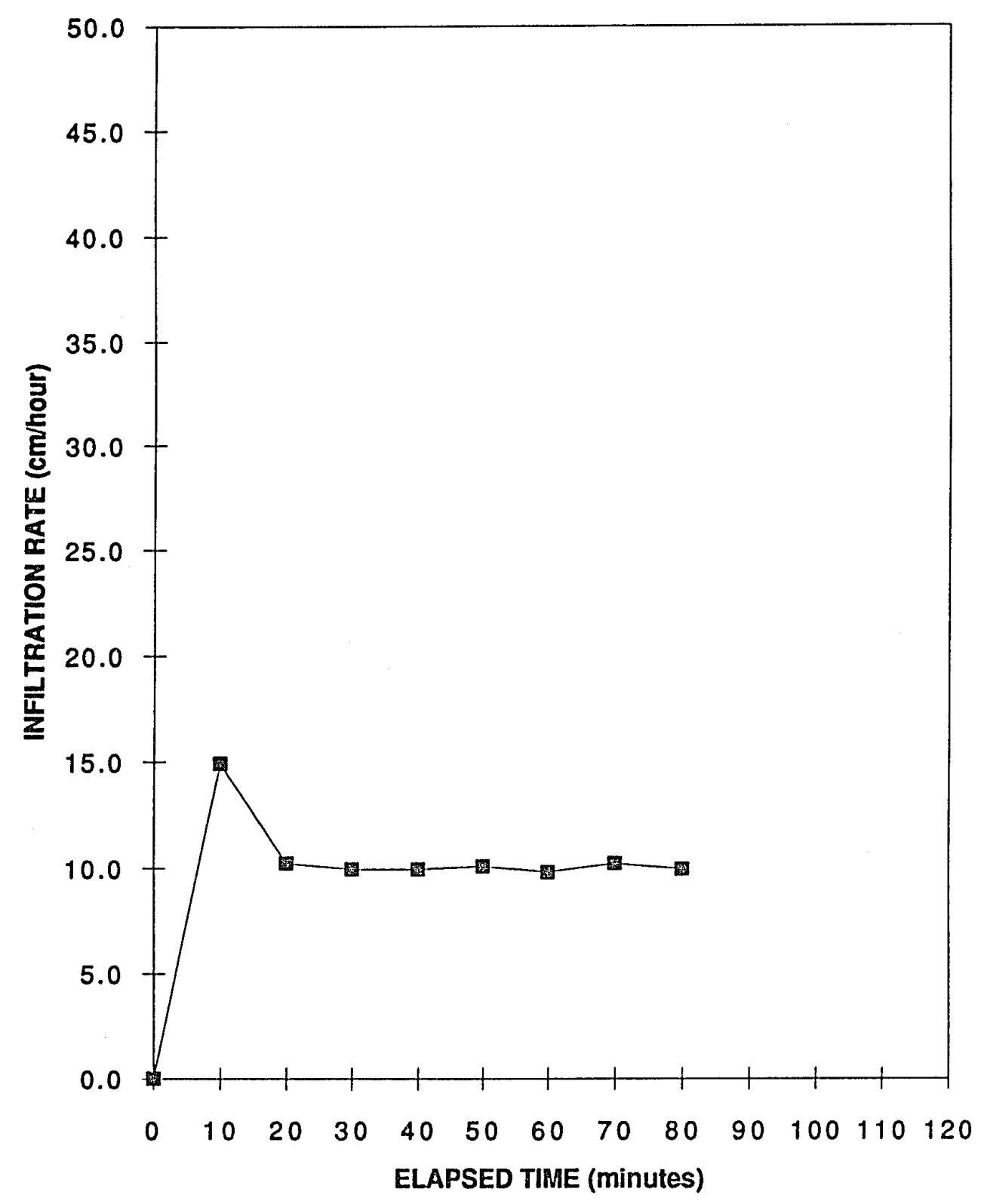




\section{PLEASE NOTE:}

Oversize maps and charts are filmed in sections in the following manner:

\section{LEFT TO RIGHT, TOP TO BOTTOM, WITH SMALL OVERLAPS}

The following map or chart has been refilmed in its entirety at the end of this dissertation

(not available on microfiche). A xerographic reproduction has been provided for paper copies and is inserted into the inside of the back cover.

Black and white photographic prints (17" $\times 23 ")$ are available for an additional charge.

\section{University Microfilms International}



(D.

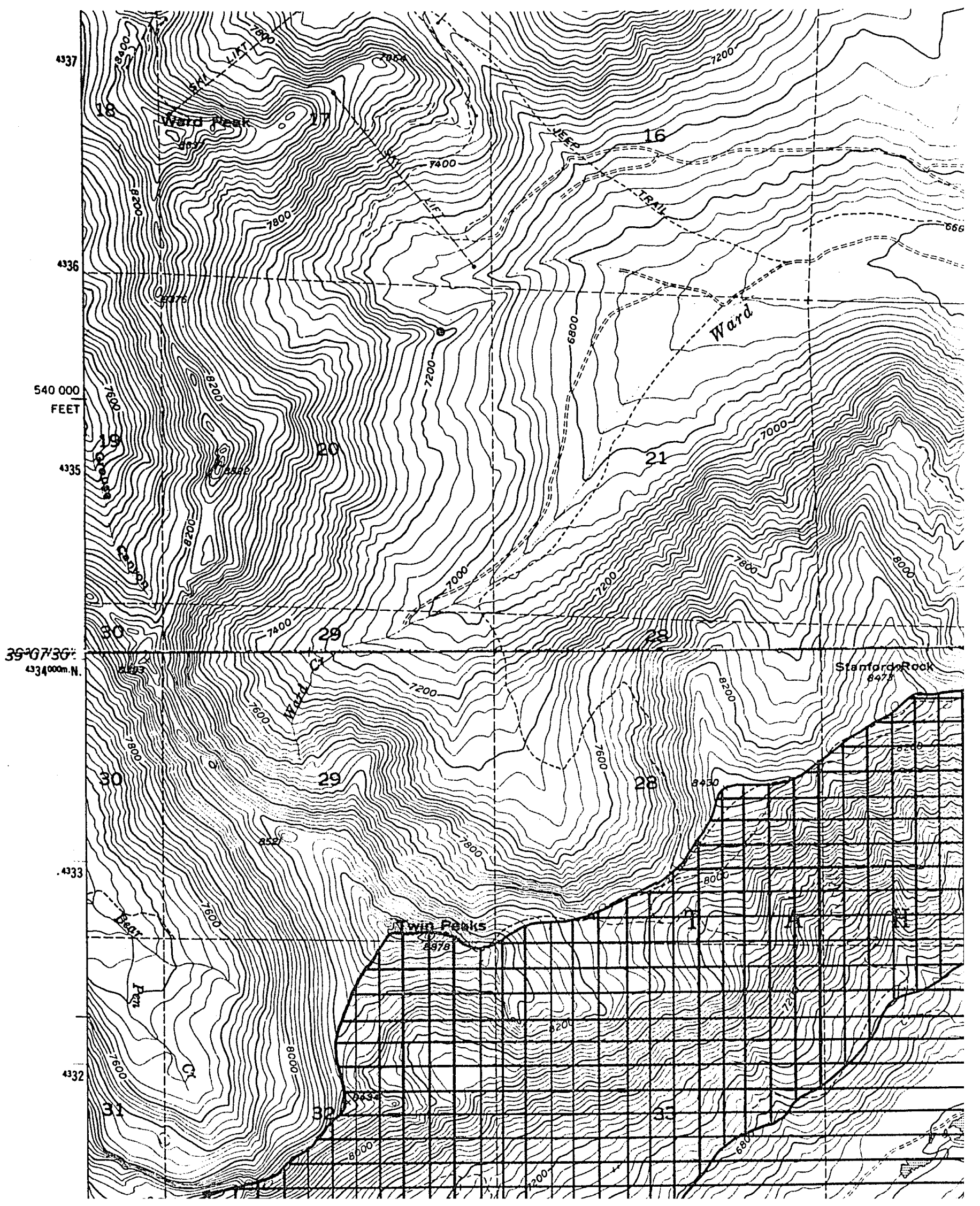




\section{PLATE \\ Simplified Geologic Map \\ (D.S. Harwood, U.S. Geological Survey)}

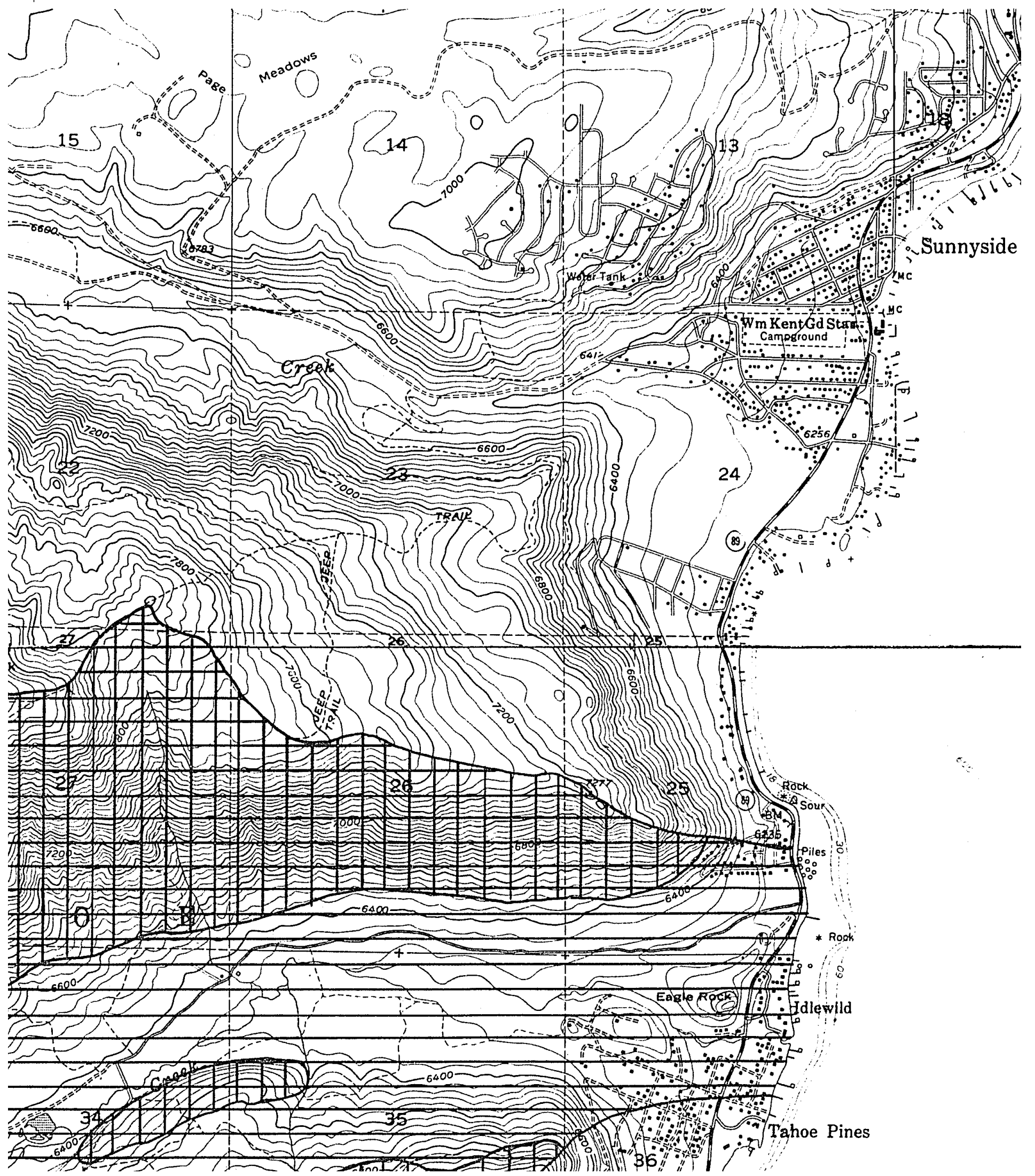




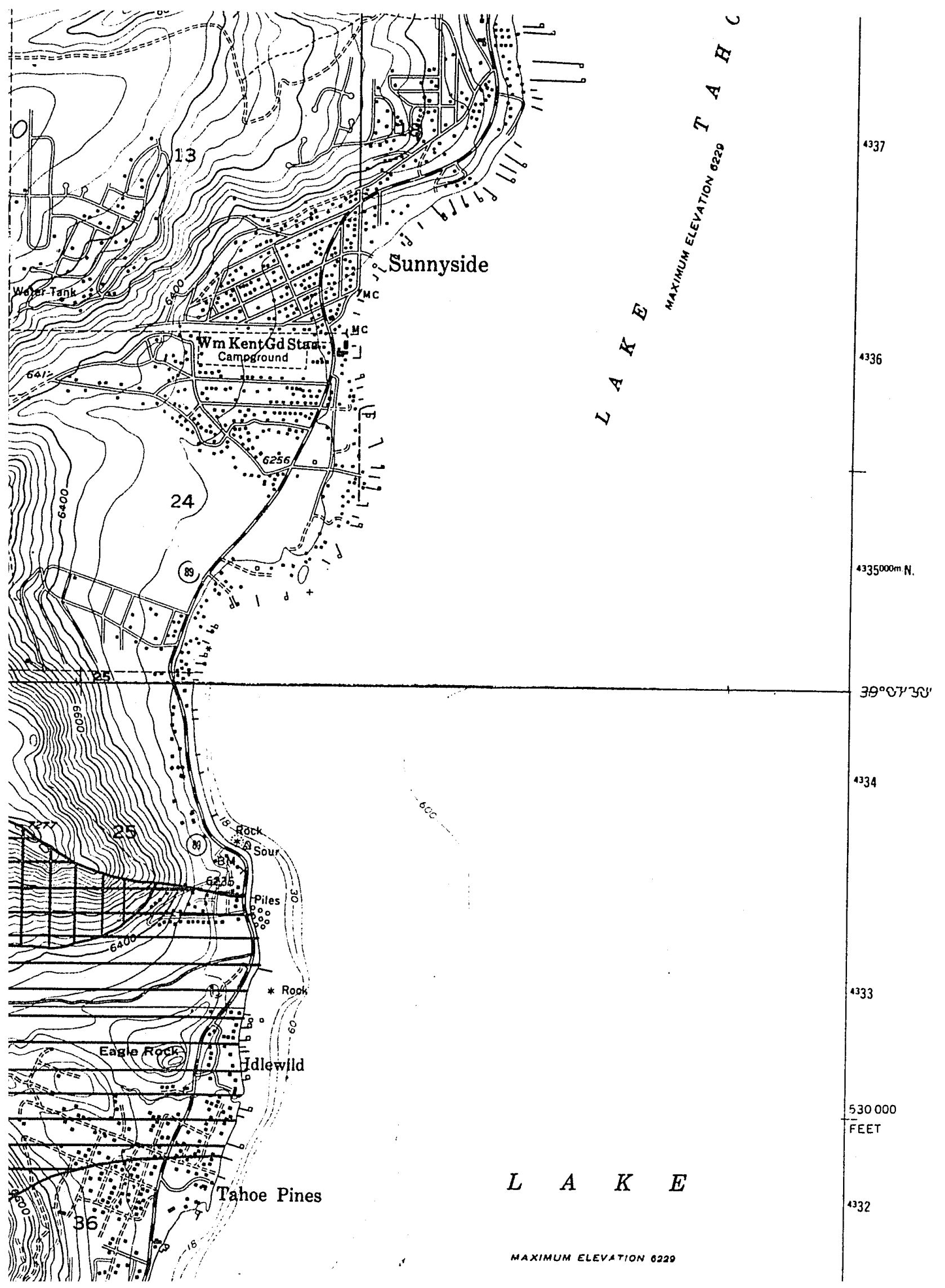


T.15 N.

은

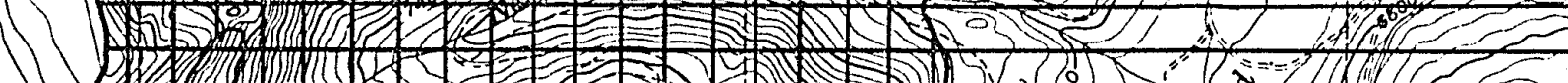

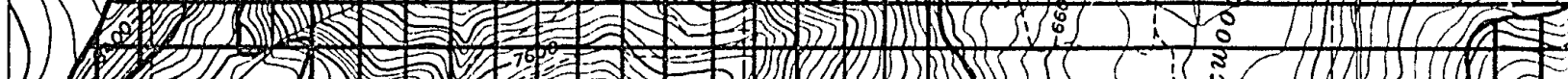

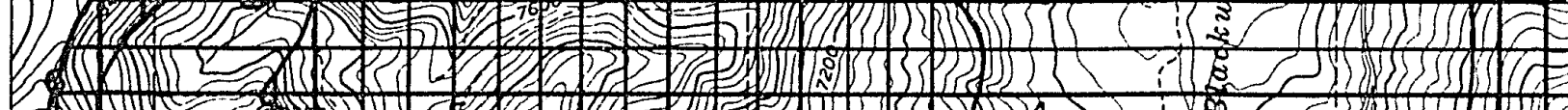

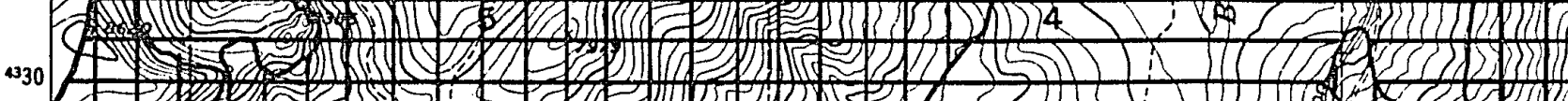

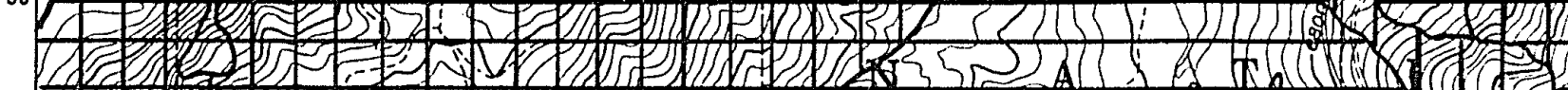

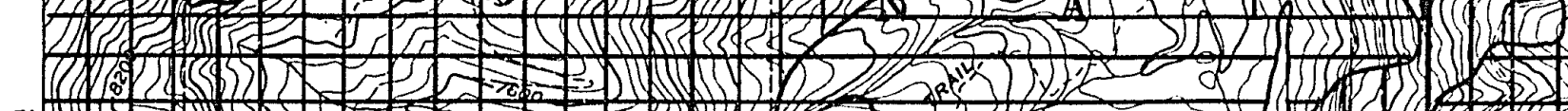

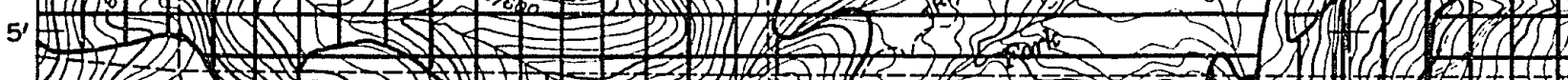
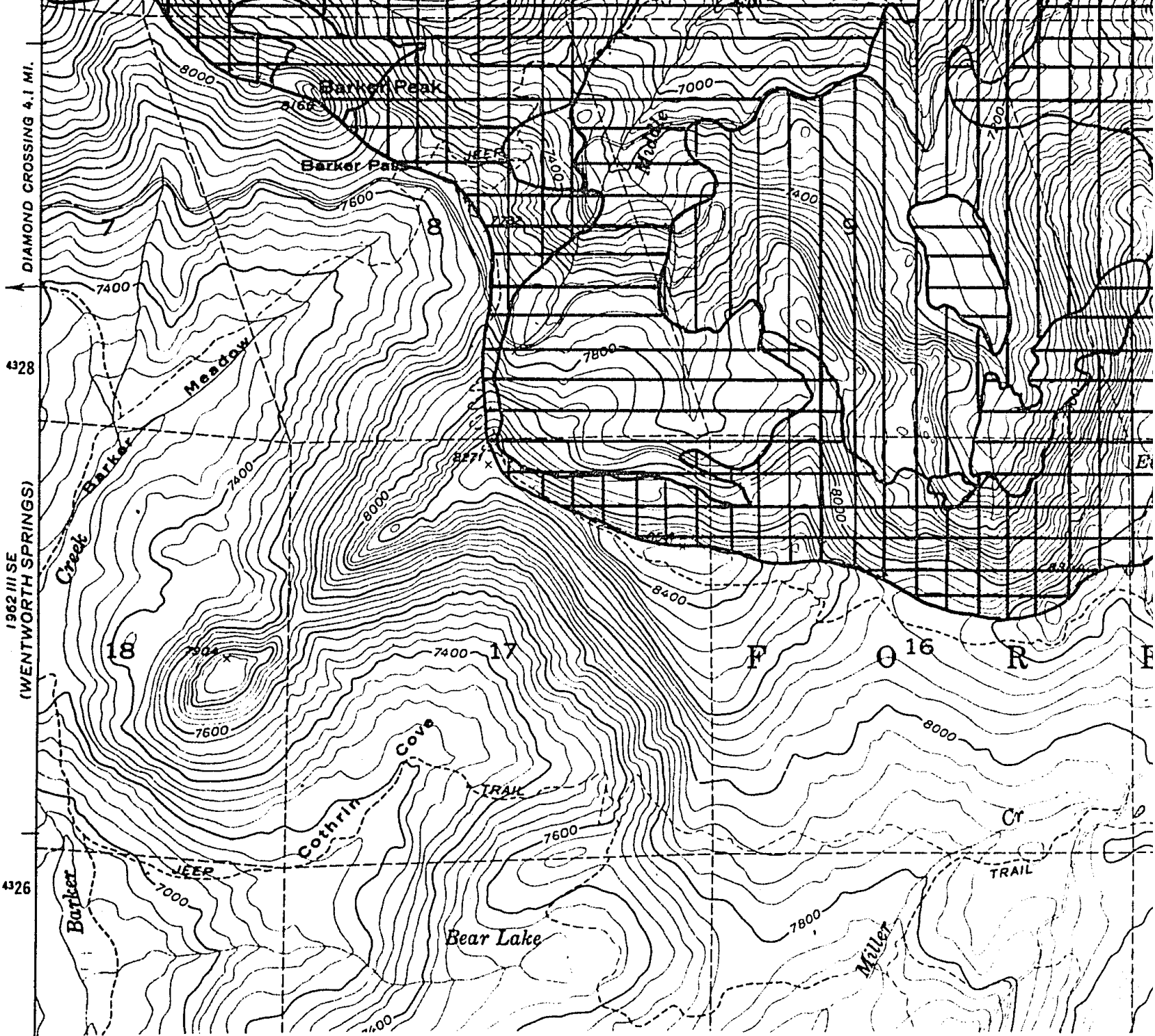

Base from U.S. Geological Survey 1:24,000 Homewood, 1955

(photorevised 1969, photoinspected 1973, photoinspected 1978);

Wentworth Springs, 1953 (photorevised 1973) 


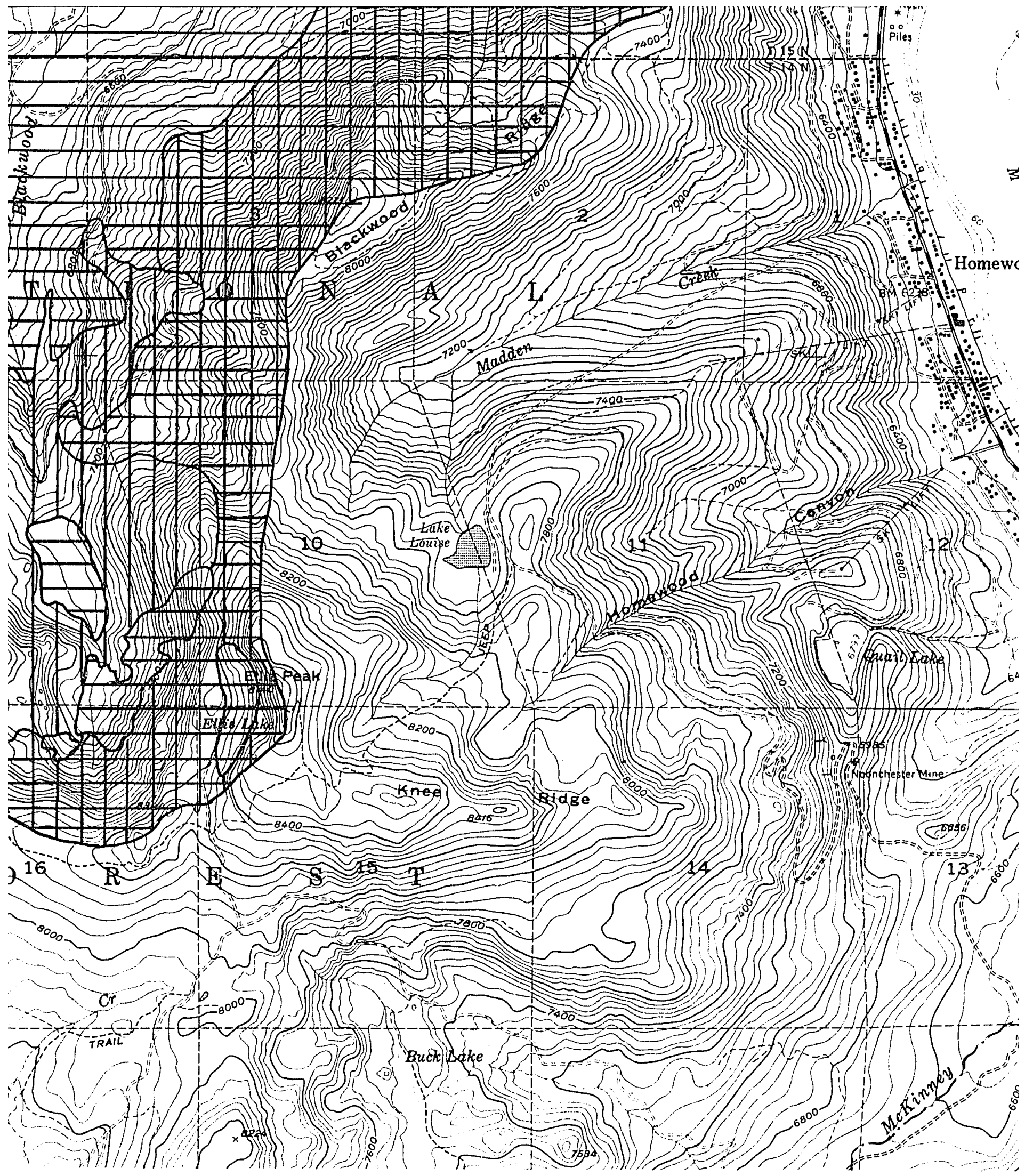

SCALE $1: 24,000$

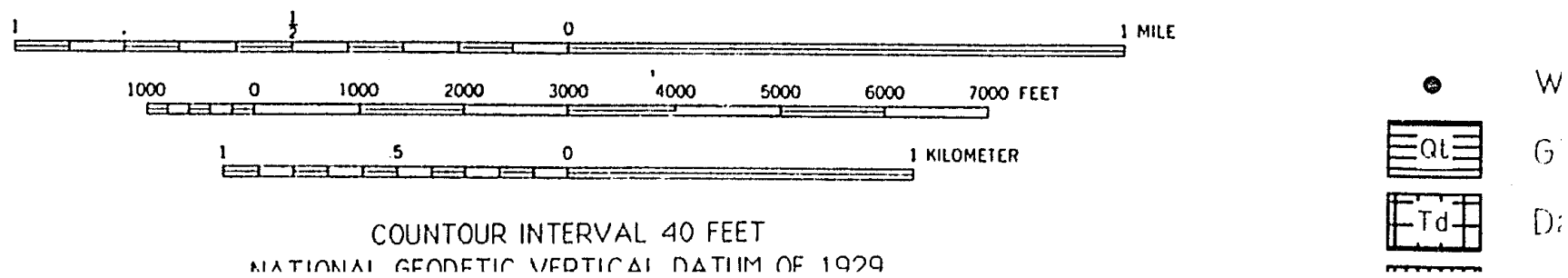




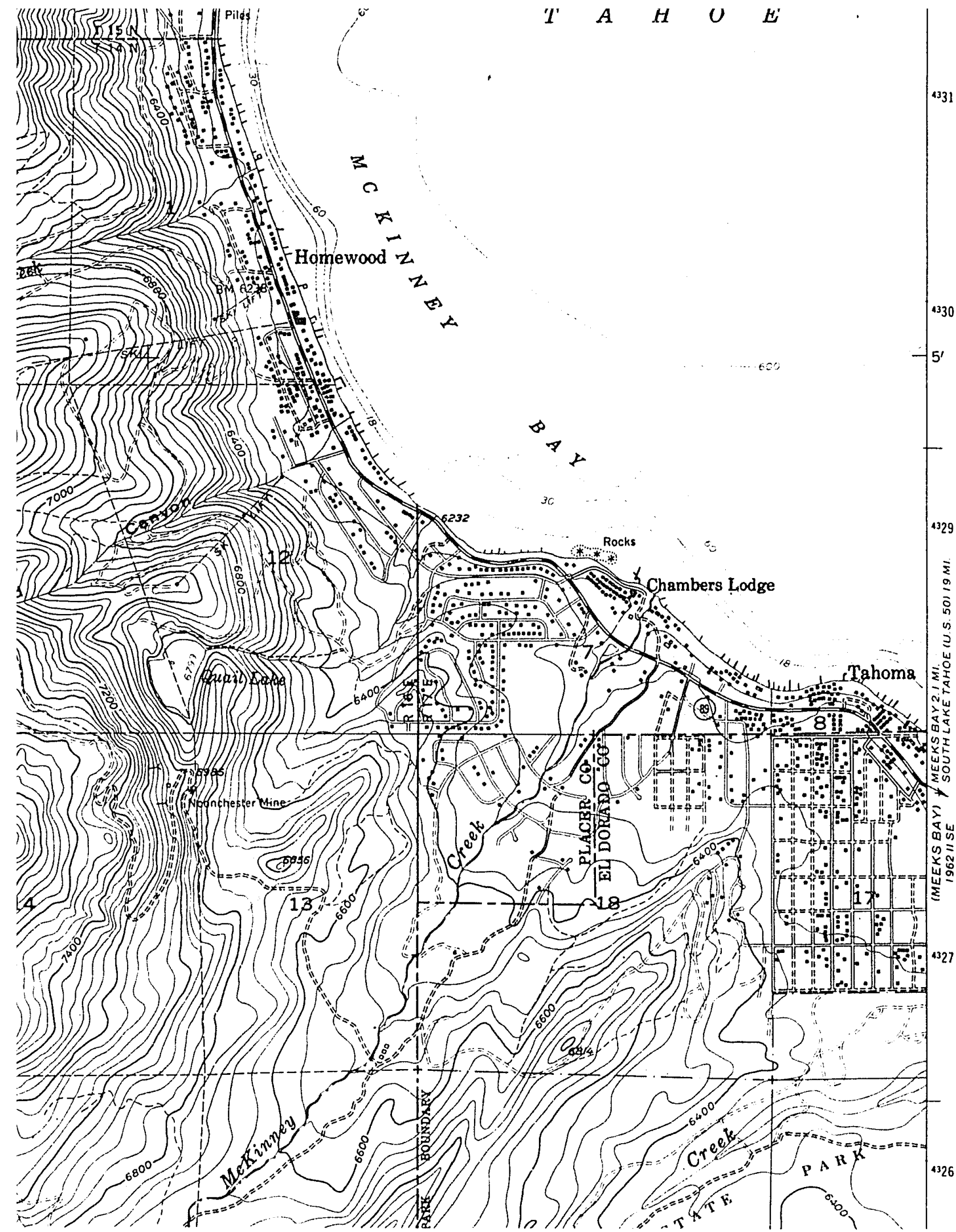

LEGEND

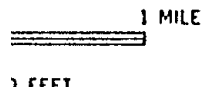

$: R$
- Ward Bench Cllmatological Monitoring Station

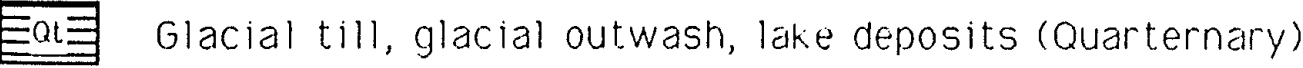

ETd Dacitic blocks, pumice, lahars, andacite flows (Tertiary)

.IJmTh Metasediments, metamor phic rocks (Jurassic) 


\section{PLEASE NOTE:}

Oversize maps and charts are filmed in sections in the following manner:

\section{LEFT TO RIGHT, TOP TO BOTTOM, WITH SMALL OVERLAPS}

The following map or chart has been refilmed in its entirety at the end of this dissertation (not available on microfiche). A xerographic reproduction has been provided for paper copies and is inserted into the inside of the back cover.

Black and white photographic prints $\left(17^{\prime \prime} \times 23^{\prime \prime}\right)$ are available for an additional charge.

\section{University Microfilms International}




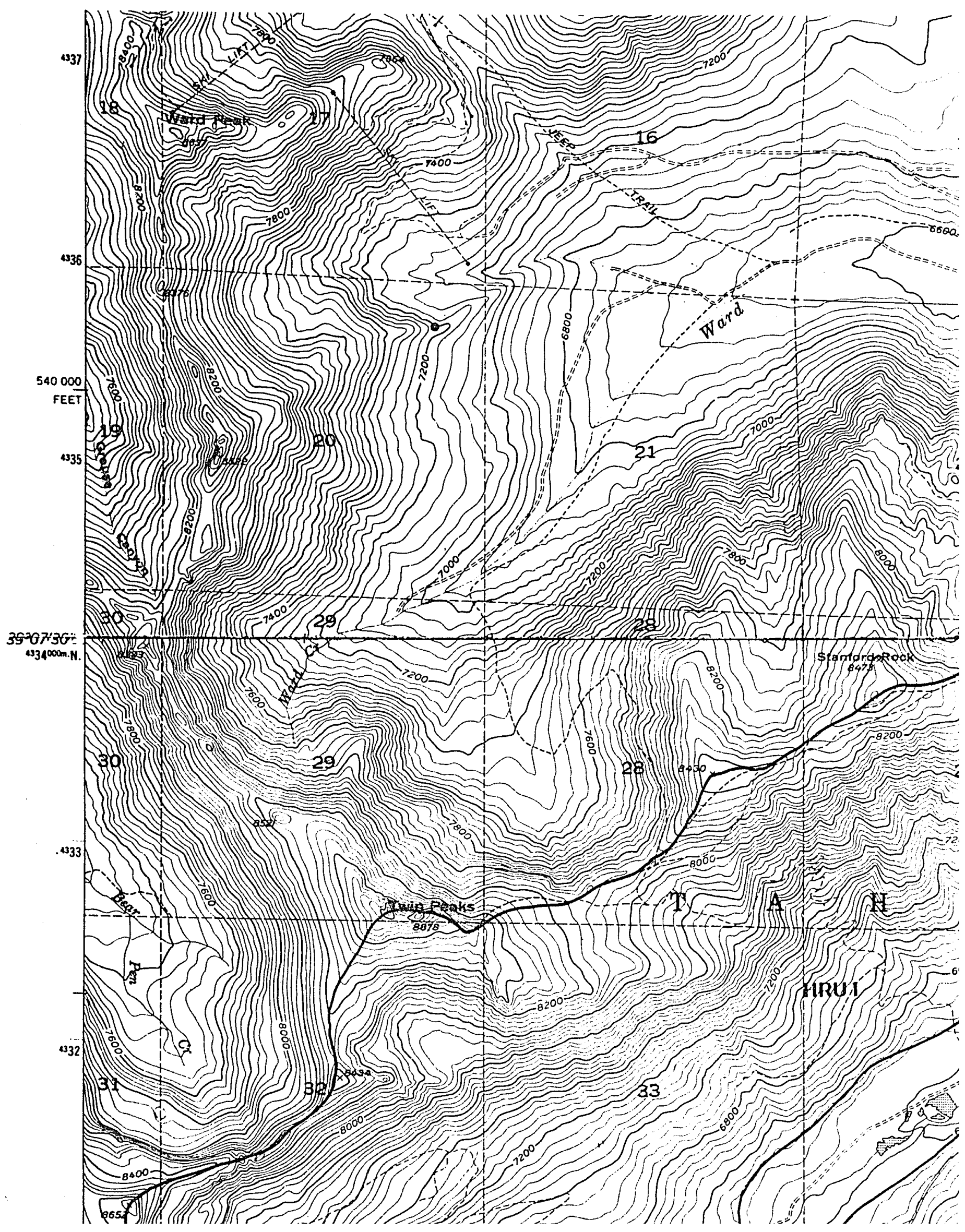




\section{H.ATE 2}

\section{Hydrologi: Response Units (HRUs)}



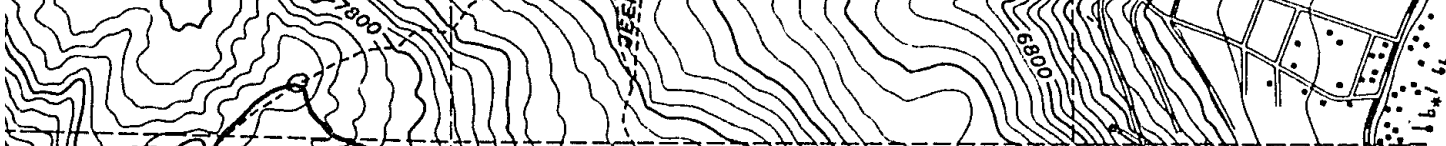

situr 2 -

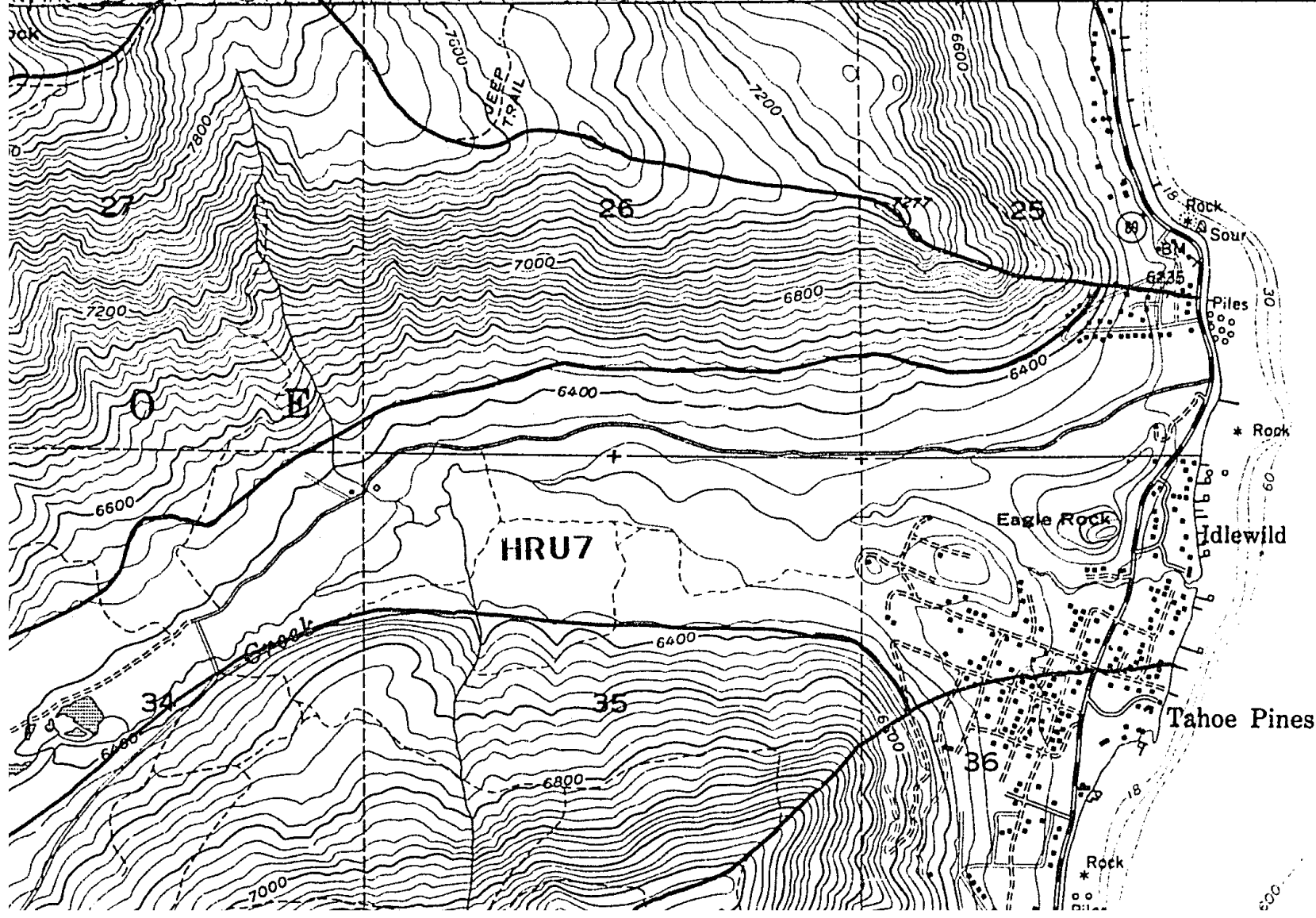




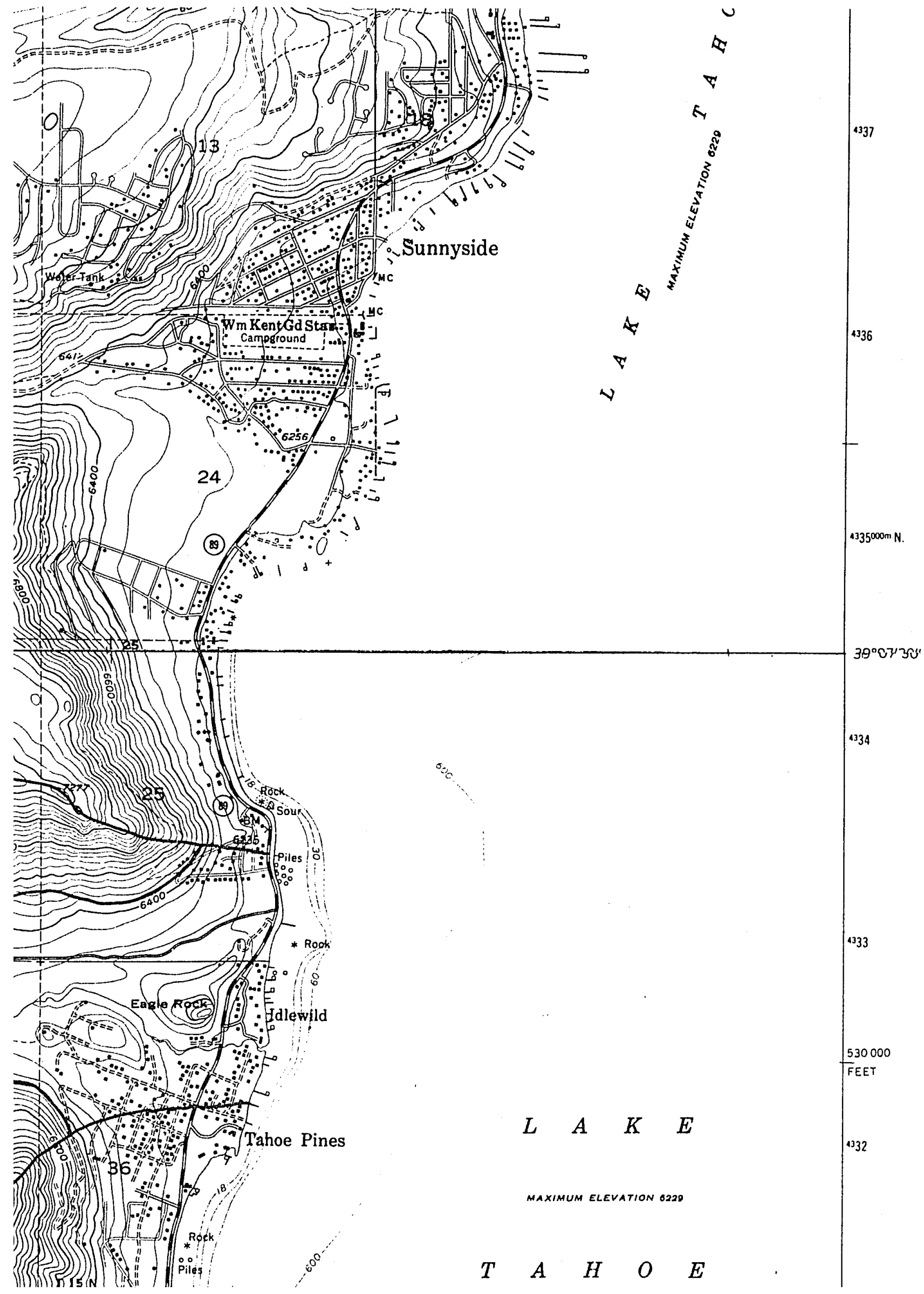




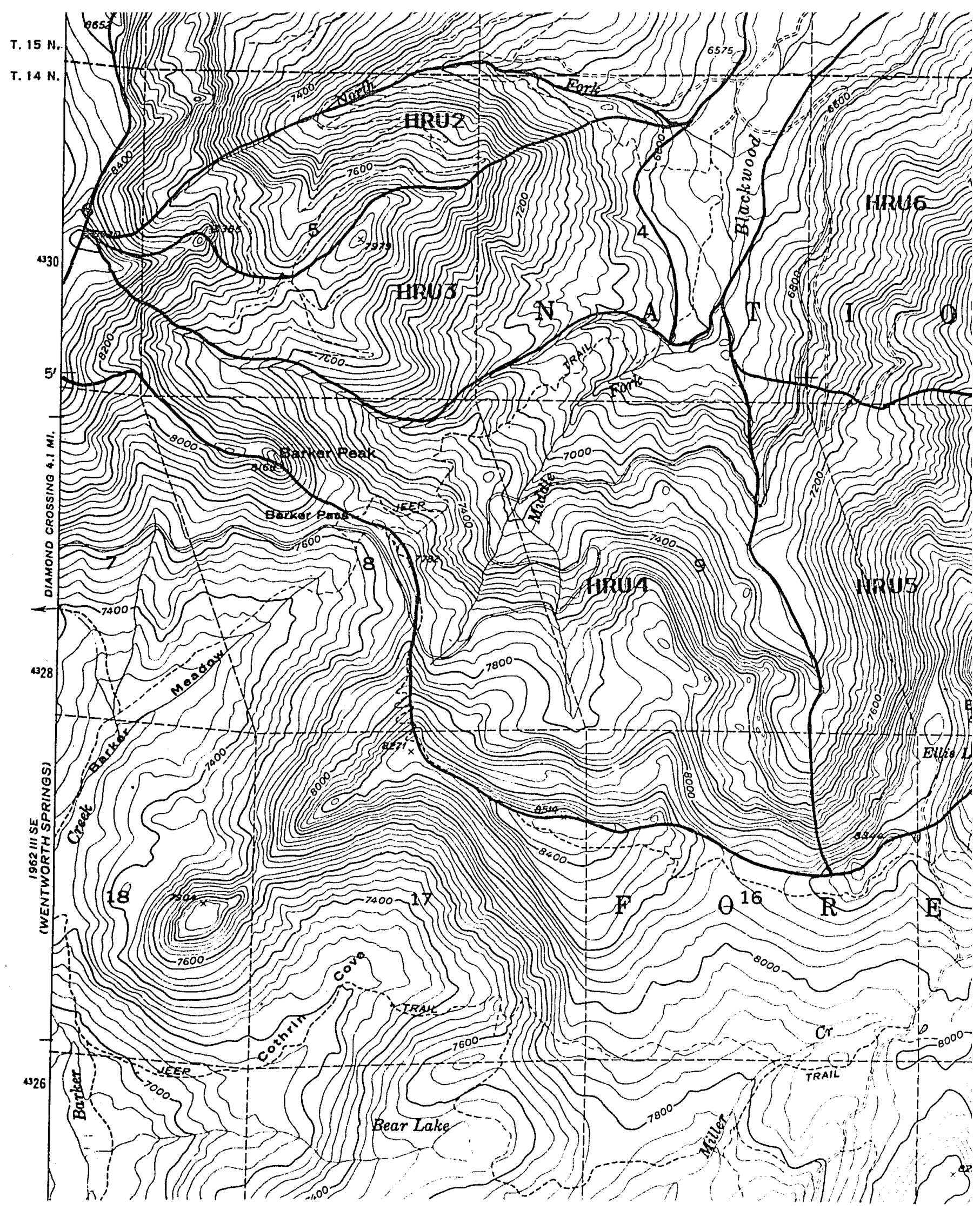

Base from U.S. Geological Survey 1:24,000 Homerood, 1955

(photorevised 1969, photoinspected 1973, photoinspected 1978);

Wentworth Springs, 1953 (photorevised 1973)

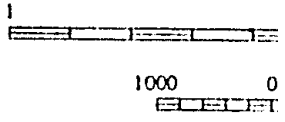






SCALE $1: 24,000$

LEGEND

I KILOMETER

- Ward Bench Climatol HRU Hydrologic Response 


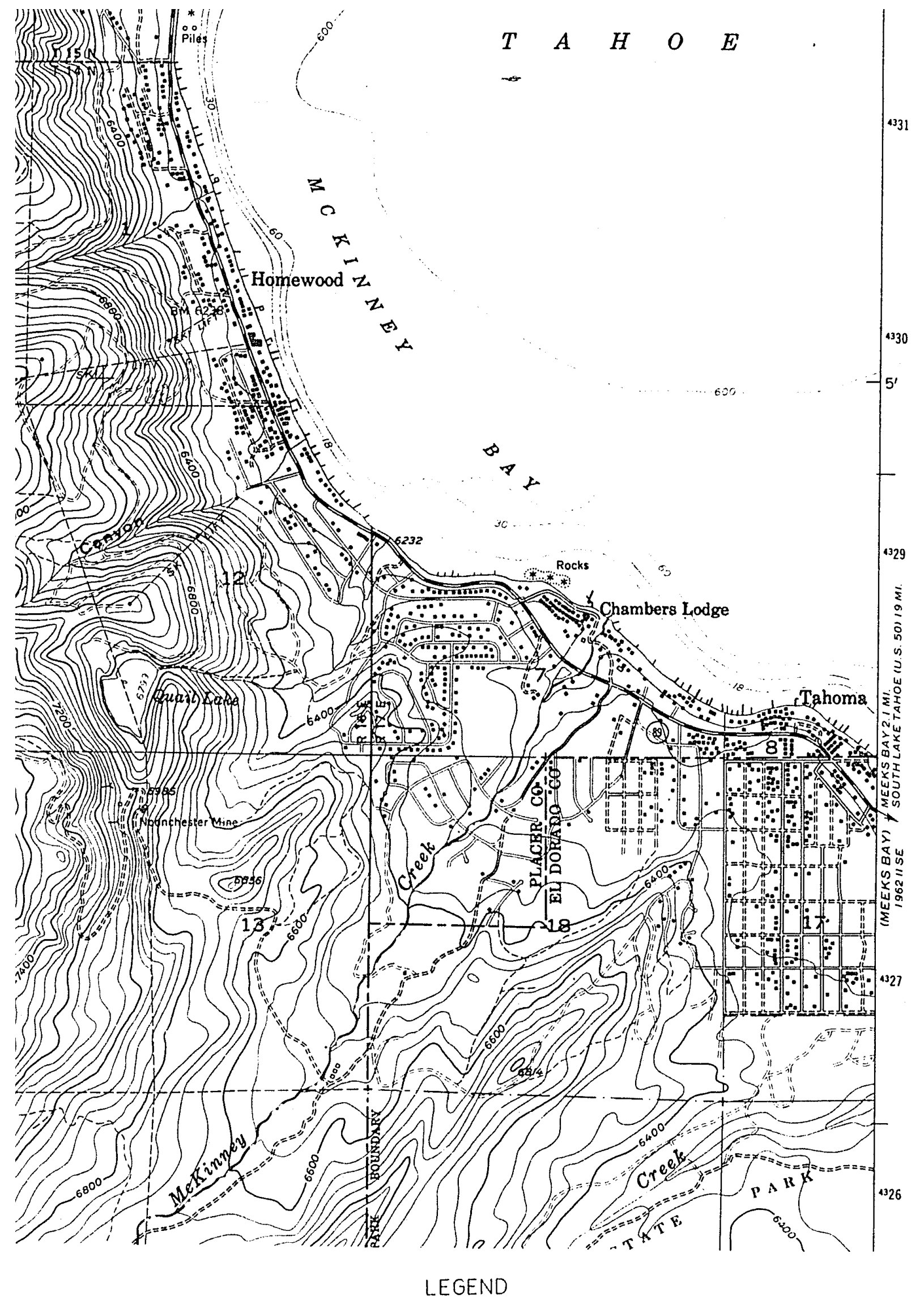

$\underbrace{\text { IMILE }}$

- Ward Bench Climatological Monitoring Station

HRU1 Hydrologic Response Unit 


\section{PLEASE NOTE:}

Oversize maps and charts are filmed in sections in the following manner:

\section{LEFT TO RIGHT, TOP TO BOTTOM, WITH SMALL OVERLAPS}

The following map or chart has been refilmed in its entirety at the end of this dissertation (not available on microfiche). A xerographic reproduction has been provided for paper copies and is inserted into the inside of the back cover.

Black and white photographic prints (17" $\left.\times 23^{\prime \prime}\right)$ are available for an additional charge. 


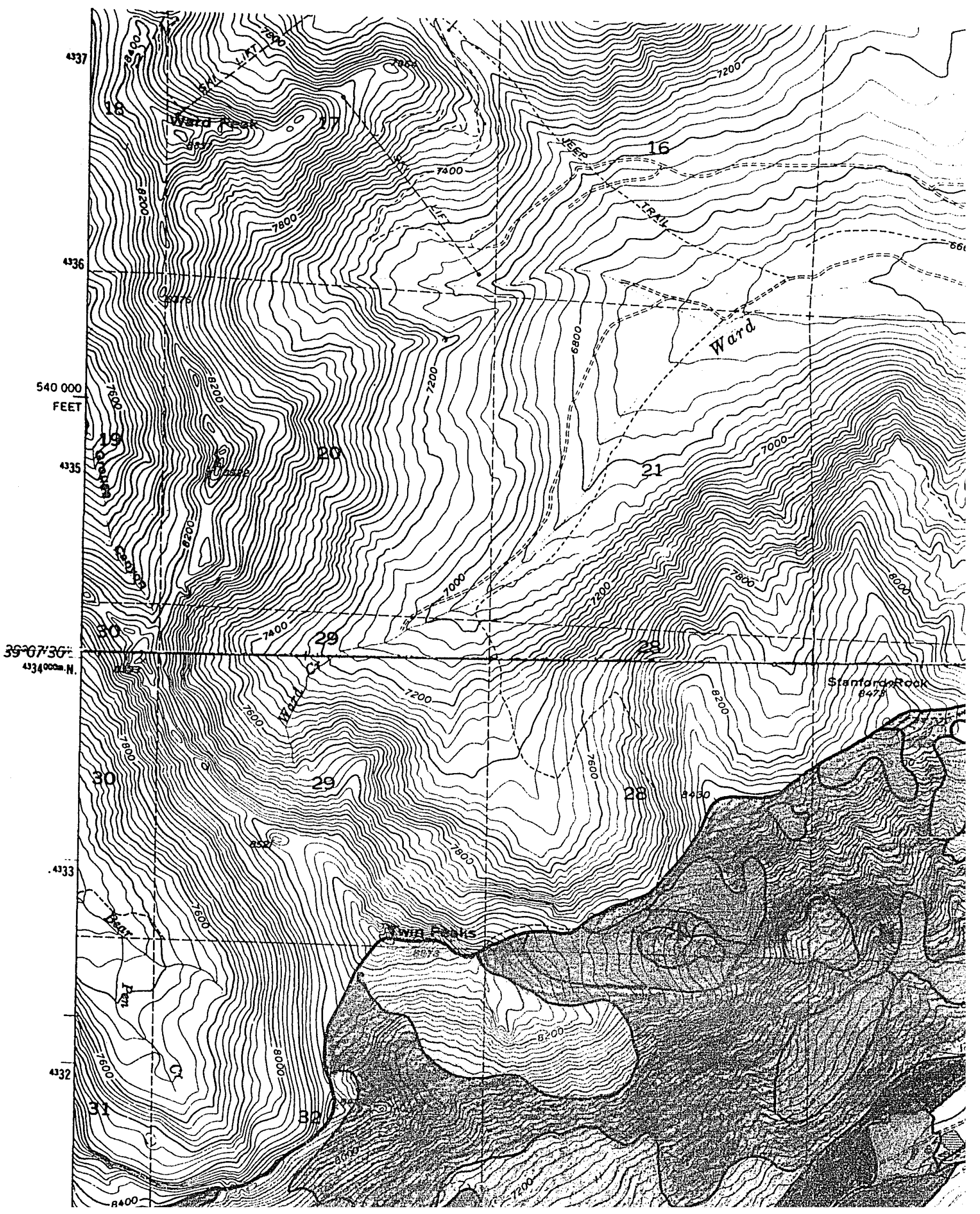




\section{PLATE 3 Soil Survey}






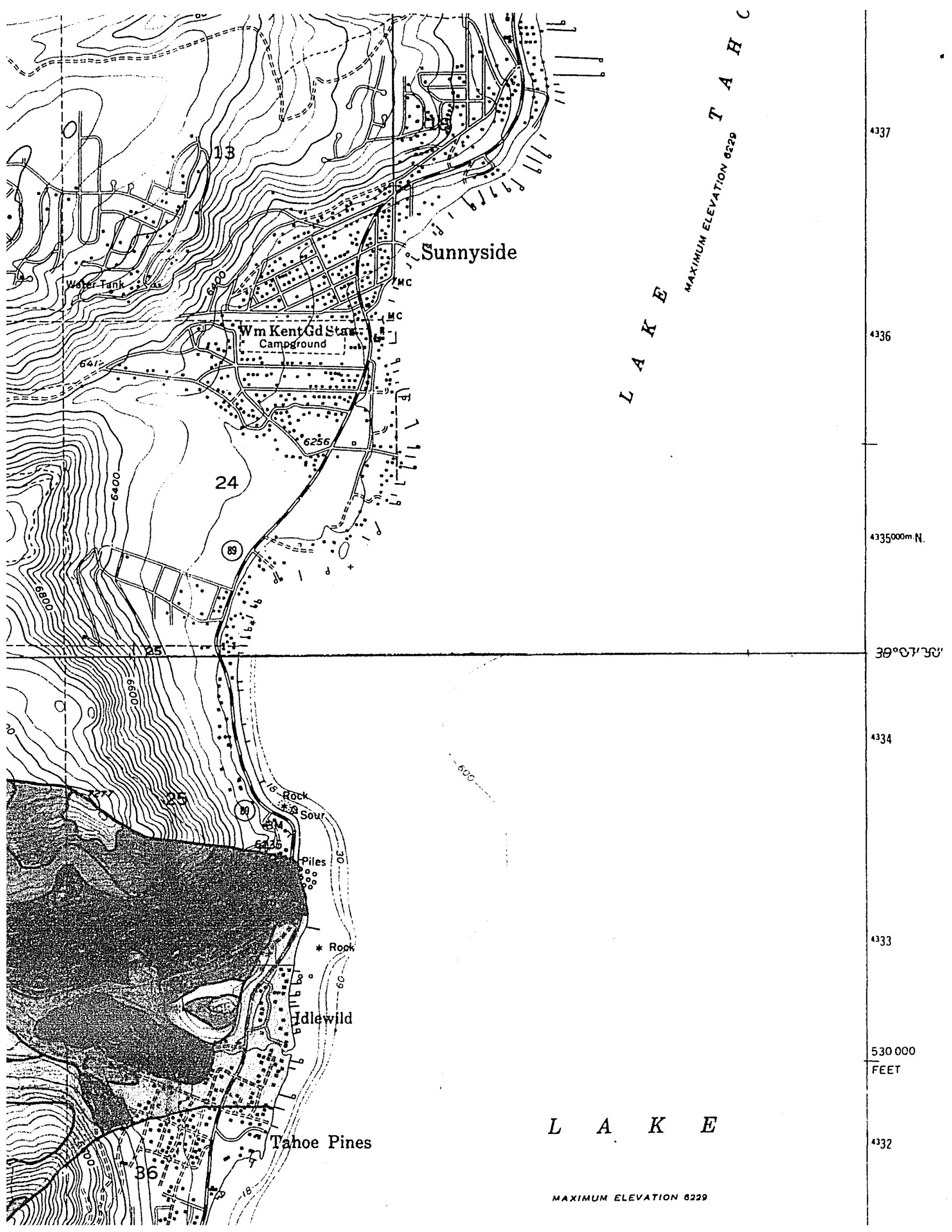




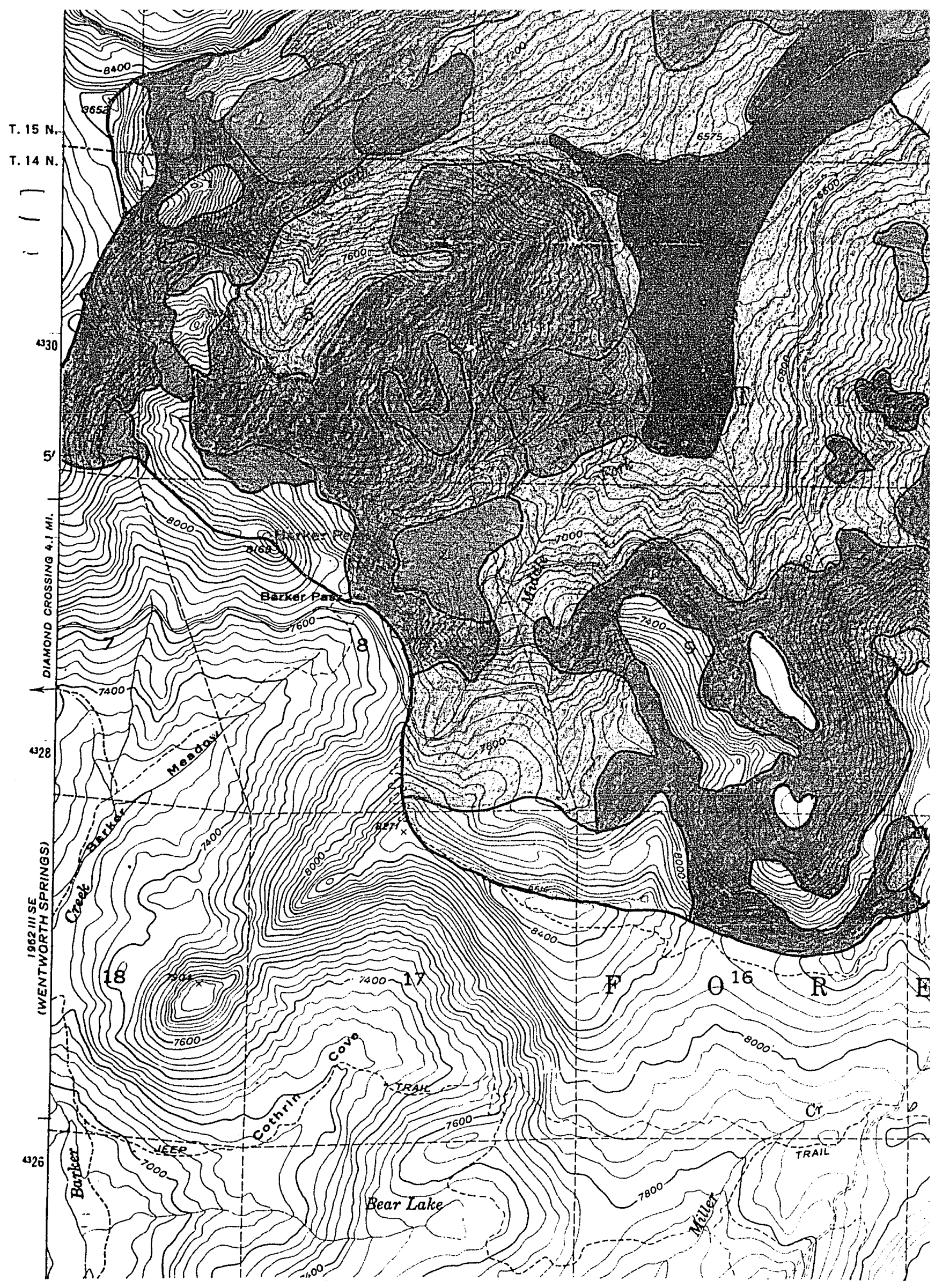

Base from U.S. Geological Survey 1:24,000 Homewood, 1955

(photorevised 1969, photoinspected 1973, photoinspected 1978);

Wentworth Springs, 1953 (photorevised 1973) 

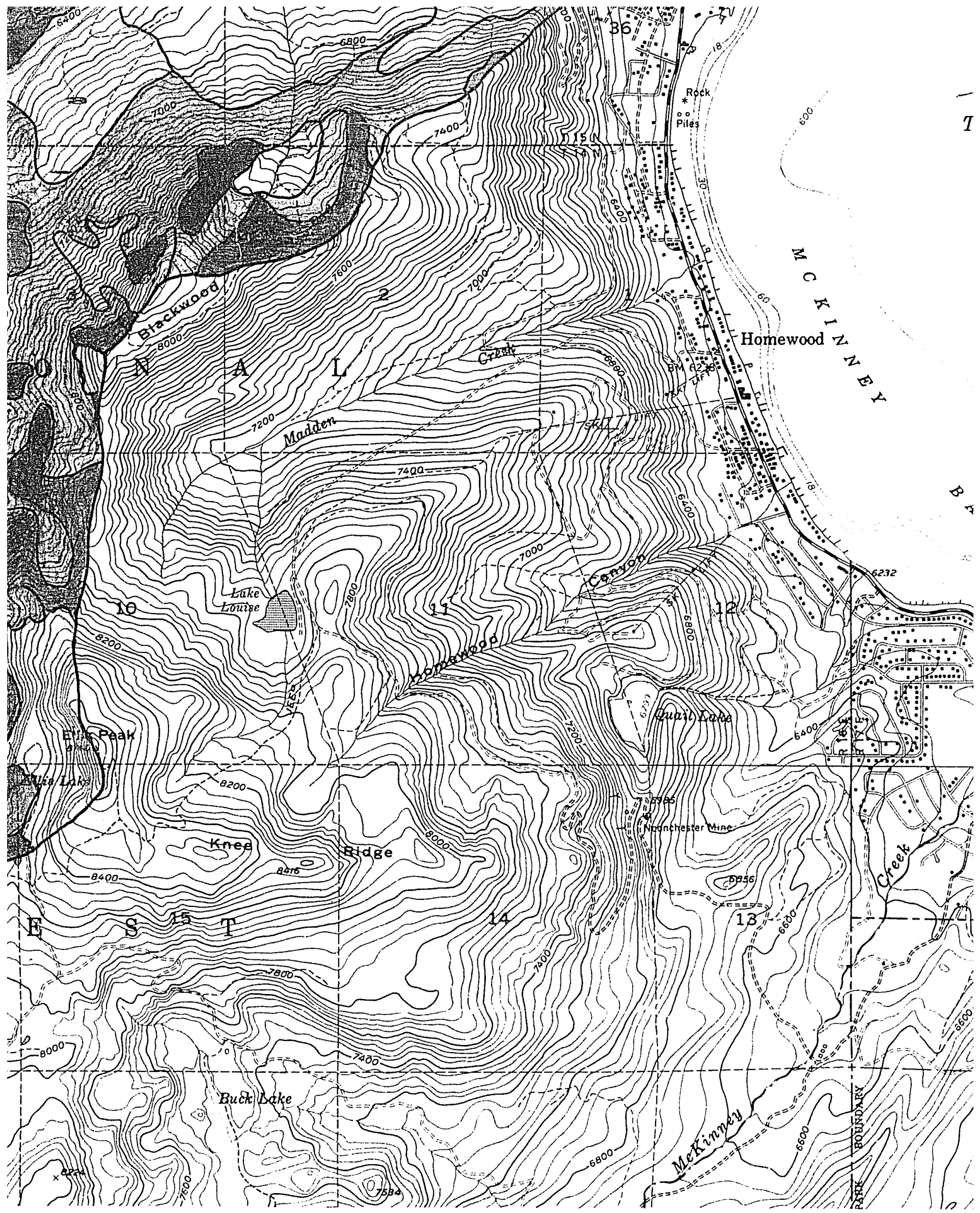

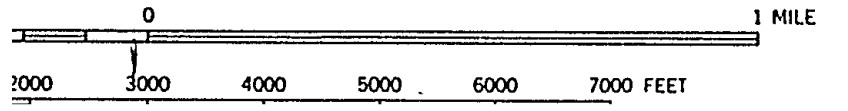

- Ward Bench Climatological Monitoring Station 


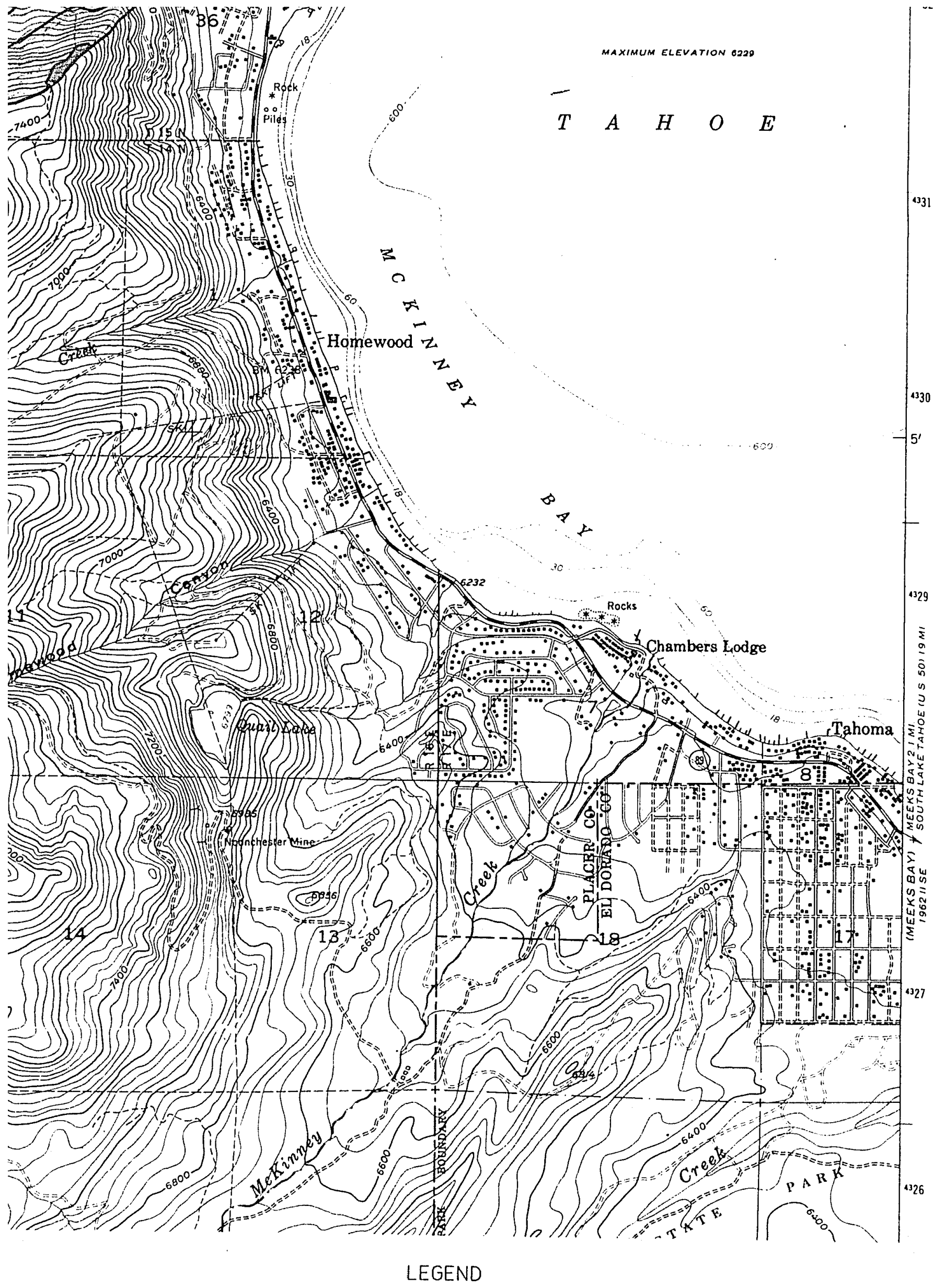

- Ward Bench Climatological Monitoring Station Gravelly Alluvial Land $(G r)$

2 Talloc - Gravelly Cuarse Sandy Loem (TCB) Talloc - Gravelly Coarse Sandy Loem (TCC) 


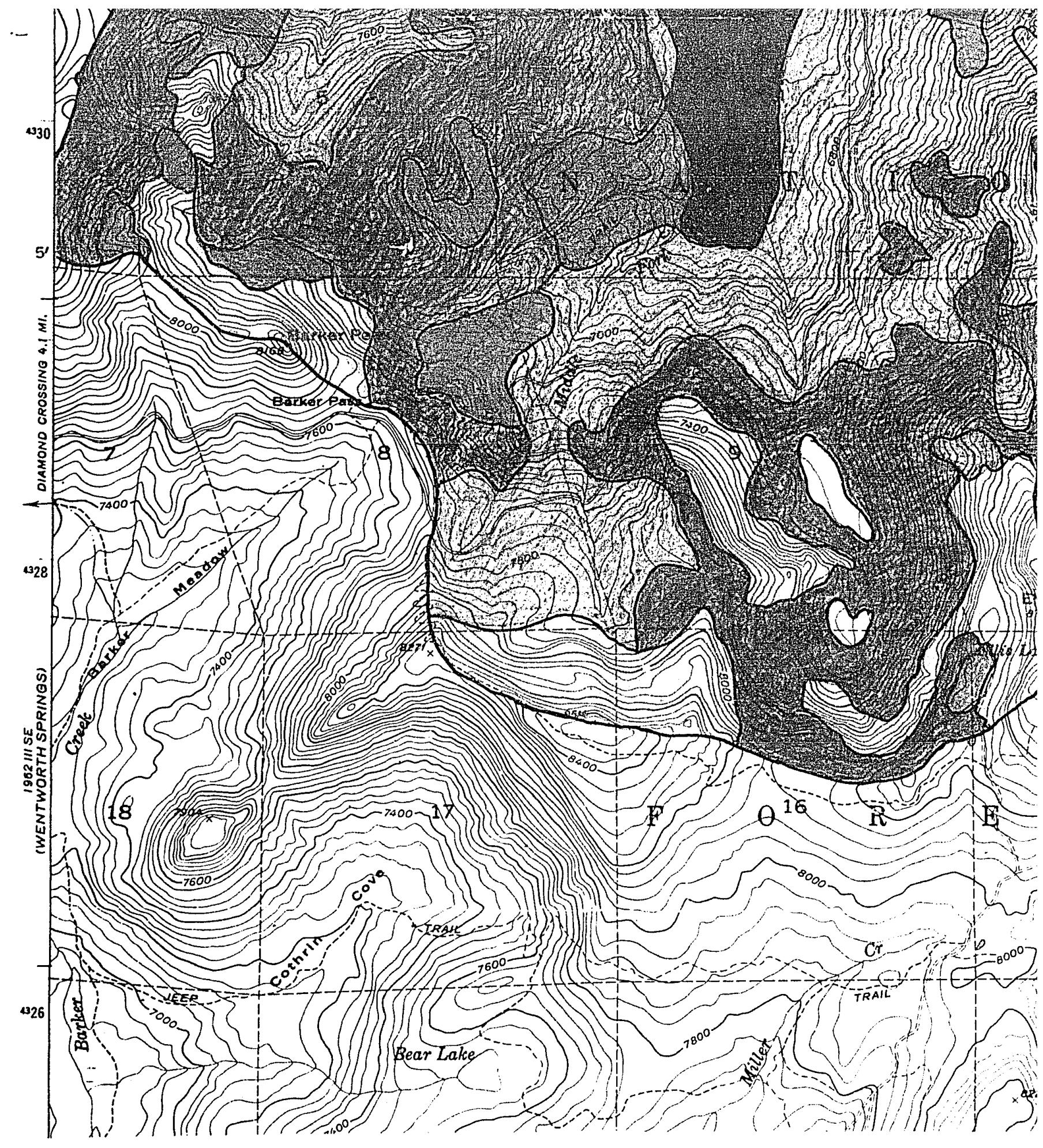

Base from U.S. Geological Survey 1:24,000 Homewood, 1955

(photorevised 1969, photoinspected 1973, photoinspected 1978);

Wentworth Springs, 1953 (photorevised 1973)

Soil Characteristics from J. H. Rogers, Soil Conservation Service, Soil Survey of the Tahoe Basin Area, California and Nevada, 1974

SCALE 1

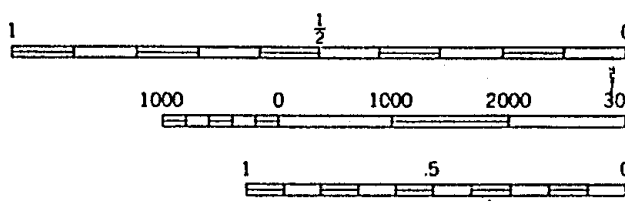

COUNTOUR INTE NATIONAL GEODETIC VEF 


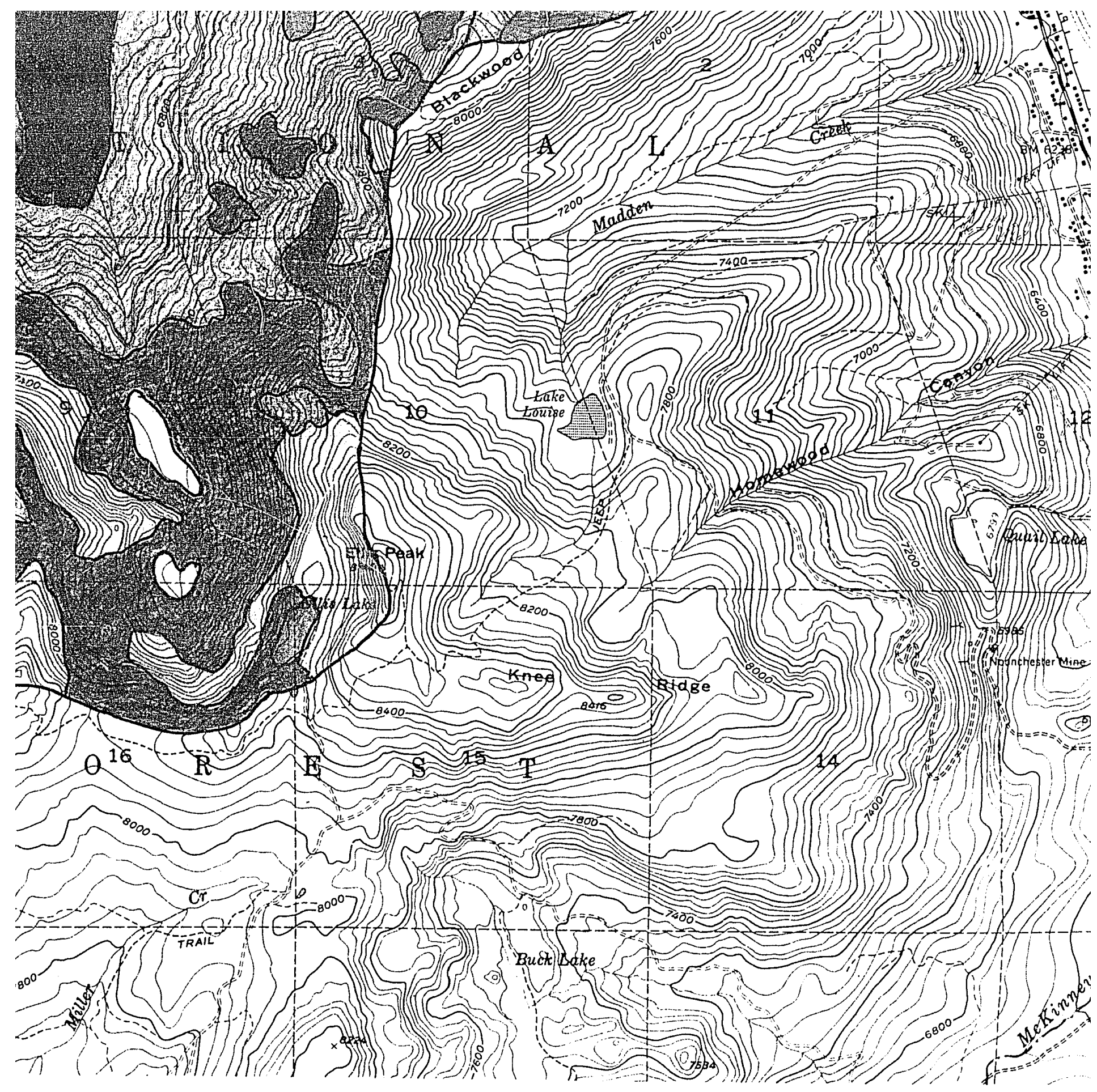

SCALE $1: 24,000$

I MILE

COUNTOUR INTERVAL 40 FEET

NATIONAL GEODETIC VERTICAL DATUM OF 1929
- Ward Bench Climatological Mi

Gravelly Alluvial Land (Gr)

Marsh (Mh)

Meiss - Cobbly Loam (MXE)

Meiss - Cobbly Loam (MXF)

Pits and Dumps $(P X)$

Rock Land ( $R a$ )

Rock Outcrop and Rubble Land

Strong Colluvial Land ( $\mathrm{Sm}$ ) 


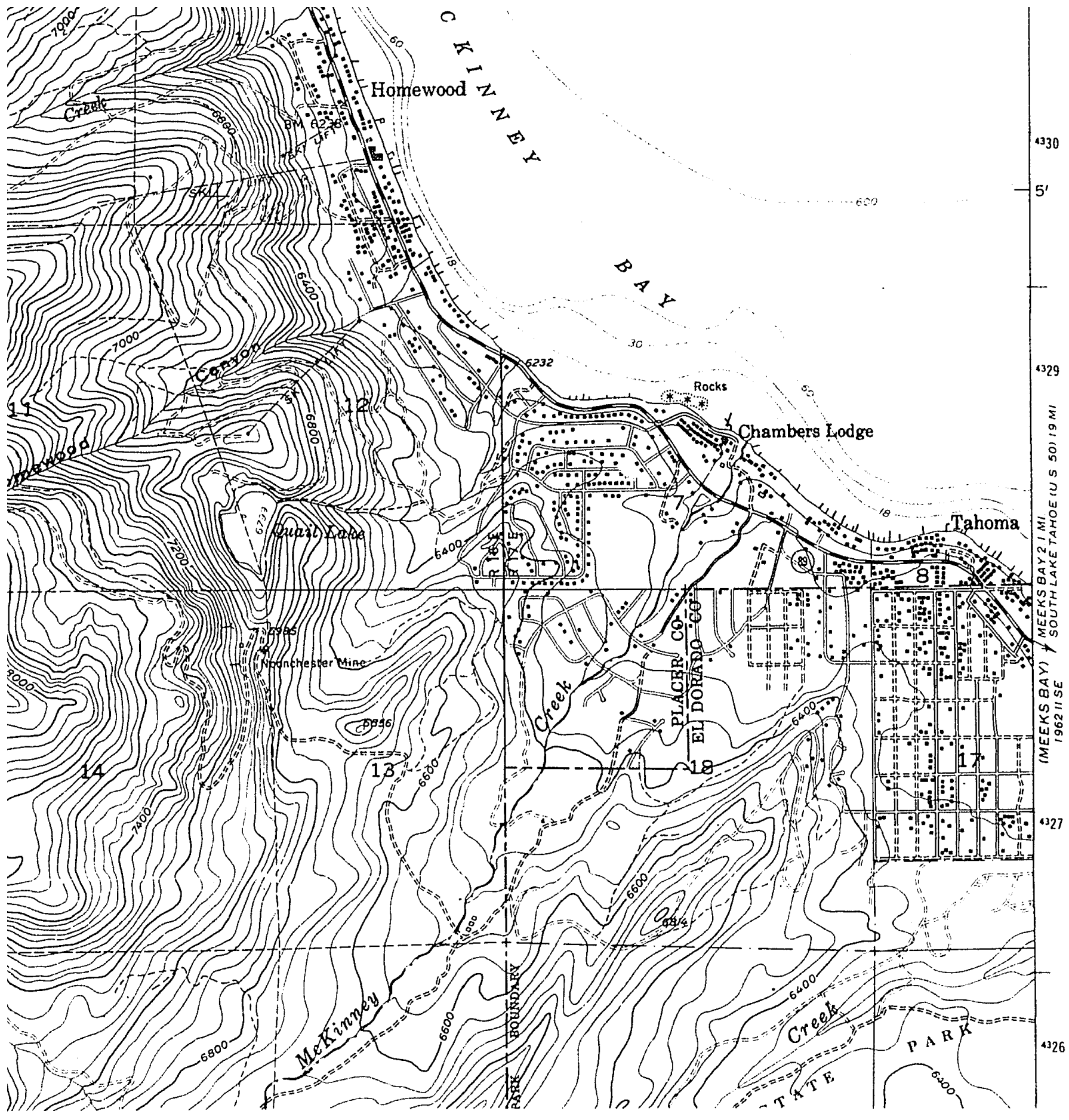

\section{LEGEND}

- Ward Bench Climatological Monitoring Station Gravelly Alluvial Land ( $G r$ )

Marsh (Mh)

Meiss - Cobbly Loam (MXE)

Meiss - Cobbly Loam (MXF)

$P$ its and Dumps $(P x)$

Rock Land ( $R a$ )

Rock Outcrop and Rubble Land ( $R x$ )

Strong Colluvial Land ( Sm)
Talloc - Gravelly Coarse Sandy Loem (TCB)

Talloc - Gravelly Coarse Sandy Loem (TCC)

Talloc - Strong Coarse Sandy Loem (TdD)

Talloc - Very Strong Coarse Sandy Loem ( TeE)

Talloc - Very Strong Coarse Sandy Loem ( TeG)

Talloc - Very Strong Coarse Sandy Loem (TKC)

Waca - Cobbly Coarse Sandy Loem (WaE)

Wacà - Cobbly Coarse Sandy Loem (WaF)

Waca - Rock Outcrop Complex (WCF) 